Universidad de Lima

Facultad de Ciencias Empresariales y Económicas

Carrera de Administración

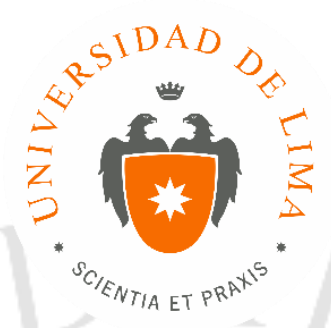

\title{
EJECUCIÓN DEL PROYECTO \\ INMOBILIARIO MULTIFAMILIAR TORRE BARRÓN EN LA URBANIZACIÓN DE SANTA BEATRIZ DEL DISTRITO DE CERCADO DE LIMA, PROVINCIA Y DEPARTAMENTO DE LIMA
}

Trabajo profesional teóricamente fundamentado (Proyecto profesional) para optar el

Título Profesional de Licenciado en Administración

Jorge Francisco La Torre Tarrillo

Código 19940446

Asesor

Gustavo Ruy Jiménez Mendoza

Lima - Perú

Noviembre del 2017 


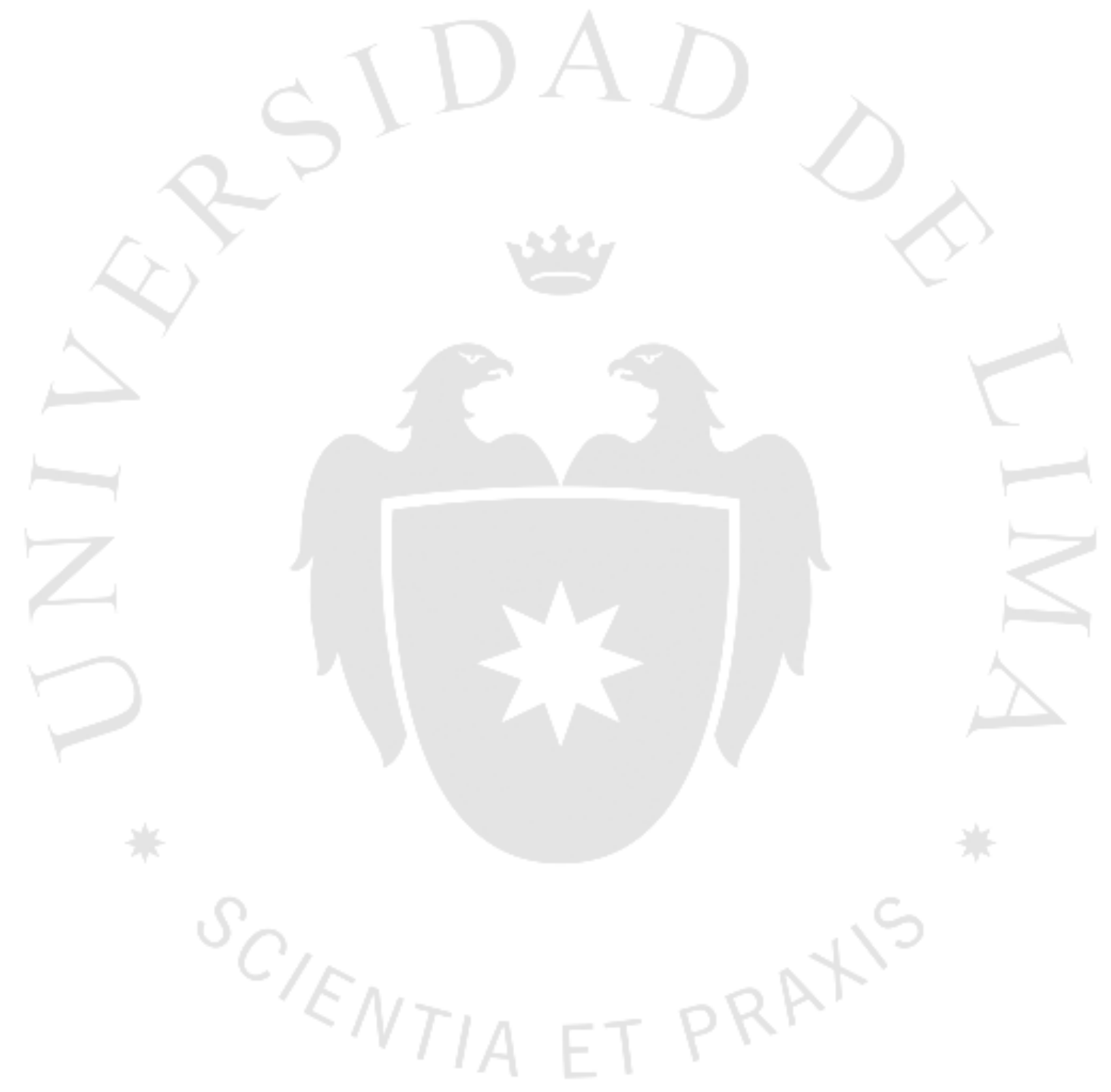




\section{DEDICATORIA}

Este trabajo está dedicado a todas aquellas personas emprendedoras que buscan una guía para la ejecución de su primer proyecto inmobiliario. 


\section{AGRADECIMIENTOS}

Agradezco a Dios, a mi esposa Kathie, a mis hijos Valeria y Mateo, a mi madre Lucy, a mi hermano Nicanor y a todas aquellas personas que siempre me apoyaron, alentaron y confiaron en mí. 


\section{EJECUCIÓN DEL PROYECTO}

INMOBILIARIO MULTIFAMILIAR TORRE BARRÓN EN LA URBANIZACIÓN DE SANTA BEATRIZ DEL DISTRITO DE CERCADO DE LIMA, PROVINCIA Y DEPARTAMENTO DE LIMA 


\section{TABLA DE CONTENIDO}

INTRODUCCIÓN..............................................................

CAPÍTULO I: DEFINICIÓN DEL NEGOCIO.......................................3

1.1. Oferta, segmento y ventajas competitivas................................

1.2. La visión y la misión del negocio..........................................4

1.2.1. Visión.................................................................. 4

1.2.2. Misión...................................................................4

1.3. Sustento de la elección del negocio....................................4

CAPÍTULO II: ESTUDIO DE MERCADO.........................................6

2.1. Definición de los clientes potenciales...................................6

2.2. Evaluación de las encuestas............................................

2.3. La demanda actual y la demanda proyectada.............................. 9

2.4. Análisis del entorno general y específico..............................9

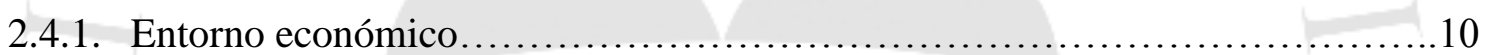

2.4.2. Entorno demográfico y social....................................... 10

2.4.3. Entorno político y jurídico........................................ 13

2.4.4. Sector construcción................................................. 14

2.4.5. Mercado de las edificaciones urbanas..................................... 16

2.4.6. Proveedores potenciales ............................................. 17

2.5. Análisis de la competencia............................................ 18

CAPÍTULO III: PLAN ORGANIZACIONAL...................................21

3.1. Matriz FODA de la empresa.......................................... 21

3.1.1. Fortalezas........................................................ 21

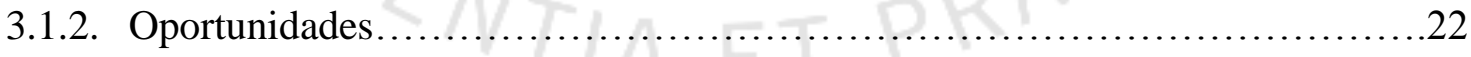

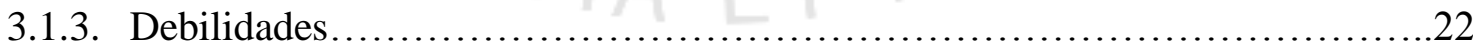

3.1.4. Amenazas.......................................................... 22

3.2. La visión y la misión de la empresa.....................................22

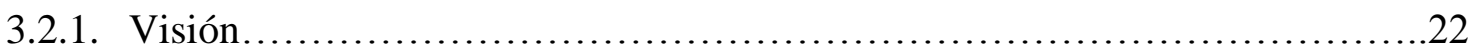

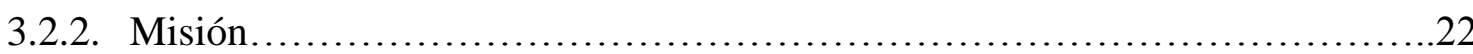

3.3. Políticas generales de la empresa...................................23

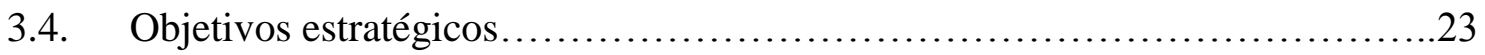


3.5. Estrategias a nivel corporativo y de negocio...............................24

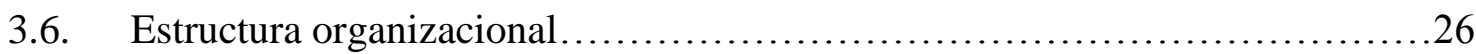

3.7. Funciones y actividades de las áreas principales..........................26

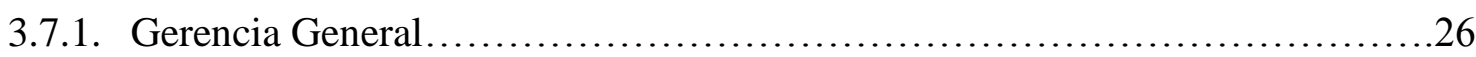

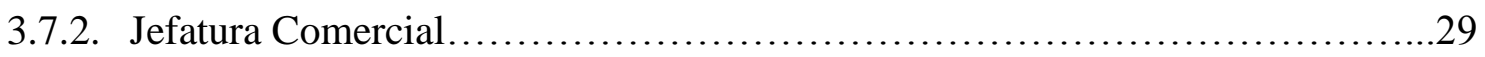

3.7.3. Jefatura de Operaciones............................................29

3.7.4. Jefatura de Administración................................................. 30

3.8. Personal requerido, nivel de formación y perfil.............................30

3.8.1. Gerente General.................................................. 31

3.8.2. Jefe Comercial......................................................... 31

3.8.3. Jefe de Operaciones................................................... 31

3.8.4. Jefe de Administración.............................................. 32

3.8.5. Asistente administrativo................................................ 32

3.8.6. Encargado de seguridad ................................................. 32

3.9. Sistema informático y sus alcances.......................................

3.10. Cadena de valor de la empresa y sus interrelaciones de valor.................33

3.10.1. Actividades primarias.............................................. 34

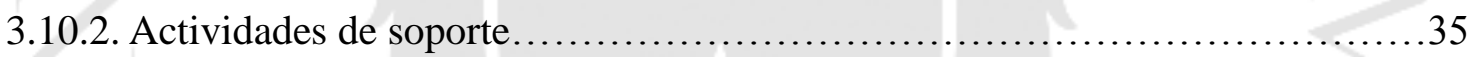

CAPÍTULO IV: PLAN DE MARKETING Y VENTAS.............................36

4.1. Qué necesidades satisface el producto y cómo las satisface....................36

4.2. Objetivos de marketing.............................................. 37

4.3. Estrategia del producto................................................. 37

4.4. Estrategia de precios............................................. 42

4.5. Estrategia de publicidad ............................................44

4.6. Estrategia de promoción............................................46

4.7. Estrategia de ingreso al mercado...................................46

4.8. Determinación de la participación del mercado..............................46

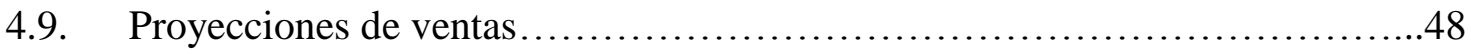

4.10. Estrategias de ventas....................................................49

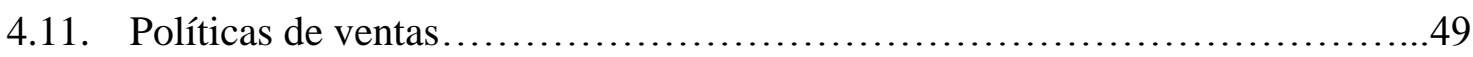

CAPÍTULO V: ESTUDIO TÉCNICO...........................................50

5.1. Localización del proyecto...........................................50

5.1.1. Macro localización del proyecto.....................................50

5.1.2. Micro localización del proyecto......................................52 
5.2 Diseño del proyecto................................................. 55

5.3 Desarrollo del proyecto........................................... 57

5.3.1. El proceso de construcción..........................................57

5.3.2. Selección de la tecnología............................................64

5.3.3. Estrategia logística................................................67

CAPÍTULO VI: PLANEAMIENTO Y PRESUPUESTOS...........................69

6.1. Cronograma general de implementación..................................69

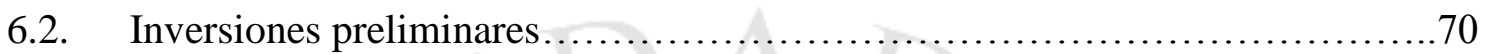

6.3. Planeamiento comercial............................................. 70

6.4. Planeamiento operativo.......................................... 71

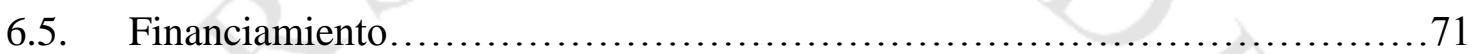

CAPÍTULO VII: ESTADOS FINANCIEROS....................................72

7.1. Estado de resultados.................................................. 72

7.2. Estado de situación financiera........................................ 73

7.3. Flujo de caja......................................................... 74

CAPÍTULO VIII: EVALUACIÓN DE FACTIBILIDAD DEL PROYECTO.......75

8.1. Determinación del costo de inversión de los accionistas......................75

8.2. Determinación de las variables estimadas para el proyecto..................76

8.3. Flujo económico del proyecto estimado..................................77

8.4. Evaluación económica del proyecto estimado (VAN y TIR Económicos).......77

8.5. Flujo financiero del proyecto estimado....................................77

8.6. Evaluación financiera del proyecto estimado (VAN y TIR Financieros).........78

8.7. Análisis del punto de equilibrio.......................................... 78

8.8. Simulación bajo un escenario optimista.................................. 78

8.9. Simulación bajo un escenario conservador................................ 80

CONCLUSIONES.............................................................82

REFERENCIAS................................................................86

BIBLIOGRAFÍA....................................................................90

ANEXOS......................................................................... 


\section{ÍNDICE DE TABLAS}

Tabla 2.1. Indicadores del sector construcción 2003 - 2007........................14

Tabla 4.1. Relación de departamentos y estacionamientos del edificio Torre Barrón...40

Tabla 4.2. Características de la competencia y del edificio Torre Barrón..............42

Tabla 4.3. Precios de departamentos y estacionamientos del edificio Torre Barrón.....43

Tabla 4.4. Proyección de ventas del edificio Torre Barrón...........................48

Tabla 5.1. Tabla de enfrentamiento macro localización............................51

Tabla 5.2. Tabla de calificación..............................................51

Tabla 5.3. Ranking de factores macro localización............................52

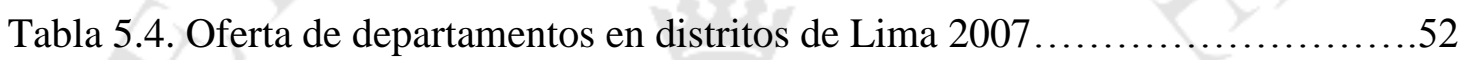

Tabla 5.5. Tabla de enfrentamiento micro localización..............................53

Tabla 5.6. Ranking de factores micro localización.................................54

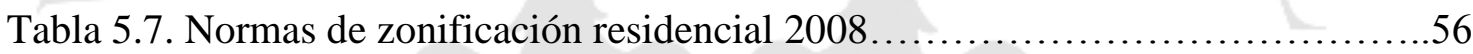

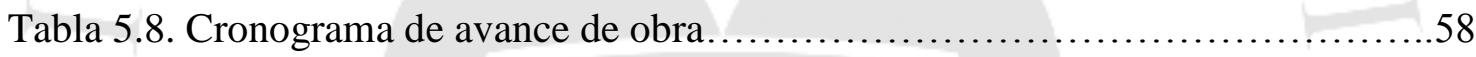

Tabla 6.1. Cronograma general de implementación resumido Mar - Dic 2008........69

Tabla 7.1. Estado de Resultados del 01Marzo al 31 Diciembre 2008.................. 72

Tabla 7.2. Estado de Situación Financiera al 31 de Diciembre de 2008.................73

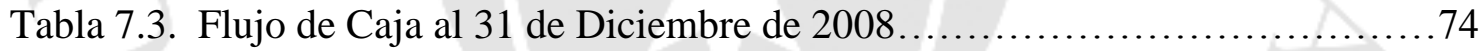

Tabla 8.1. Flujo económico del proyecto estimado.................................77

Tabla 8.2. Flujo financiero del proyecto estimado................................ 77

Tabla 8.3. Flujo económico del proyecto en punto de equilibrio......................78

Tabla 8.4. Flujo económico del proyecto bajo un escenario optimista..................79

Tabla 8.5. Flujo financiero del proyecto bajo un escenario optimista.................79

Tabla 8.6. Flujo económico del proyecto bajo un escenario conservador...............80

Tabla 8.7. Flujo financiero del proyecto bajo un escenario conservador...............81 


\section{ÍNDICE DE FIGURAS}

Figura 2.1. Tenencia de la vivienda en Santa Beatriz 2007......................... 12

Figura 2.2. Población segmentada por edades en Santa Beatriz 2007..................12

Figura 2.3. Colocación de créditos hipotecarios para vivienda 2005 - 2008............ 15

Figura 2.4. Participación de mercado en la colocación de préstamos hipotecarios

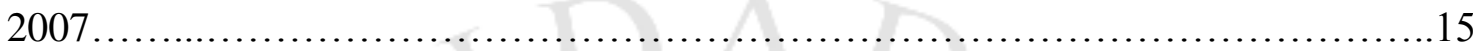

Figura 2.5. Oferta total de viviendas (julio 2007) ............................... 16

Figura 2.6. Proyectos inmobiliarios ubicados en Santa Beatriz 2008..................19

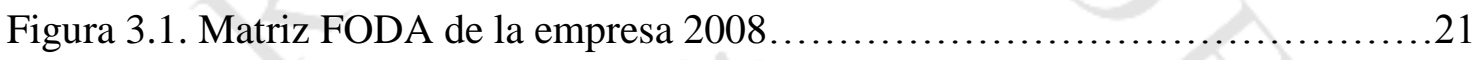

Figura 3.2. Diagrama de las 5 fuerzas de Michael Porter 2008.....................25

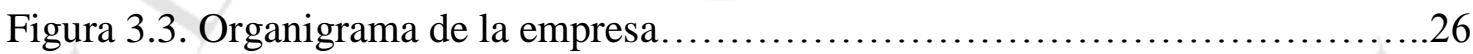

Figura 3.4. Cadena de valor de la empresa...................................... 34

Figura 4.1. Pirámide de Abraham Maslow............................................. 36

Figura 4.2. Niveles del producto........................................... 37

Figura 4.3. Imagen del edificio multifamiliar "Torre Barrón" ........................ 38

Figura 4.4. Ubicación del edificio multifamiliar "Torre Barrón"......................39

Figura 4.5. Diseño arquitectónico de los departamentos del edificio “Torre Barrón”...41

Figura 4.6. Cuenta de Facebook del edificio "Torre Barrón".......................45

Figura 4.7. Participación del mercado en el año cero..............................47

Figura 4.8. Participación del mercado proyectada al año $5 \ldots \ldots \ldots \ldots \ldots \ldots \ldots \ldots \ldots . \ldots . \ldots \ldots$

Figura 5.1. Plano de la Urbanización de Santa Beatriz - Cercado de Lima.............54

Figura 5.2. Imagen del predio adquirido.................................. 55

Figura 5.3. Instalación de muros de ladrillos Placa P-10 "LACASA"................59

Figura 5.4. Imagen final del edificio "Torre Barrón" ............................60

Figura 5.5. Instalación de vigas prefabricadas y bovedillas "FIRTH" ...............64

Figura 5.6. Vaciado de concreto en techos aligerados...........................65

Figura 5.7. Camión mezclador de concreto y bomba telescópica "FIRTH”.............66

Figura 5.8. Encofrado de placas estructurales.................................66

Figura 5.9. Proceso de eliminación de desmonte.............................68 


\section{ÍNDICE DE ANEXOS}

Anexo 1: Edad de las personas encuestadas.................................. 92

Anexo 2: Género de las personas encuestadas.................................93

Anexo 3: Estado civil de los encuestados......................................94

Anexo 4: Dependientes de los encuestados....................................95

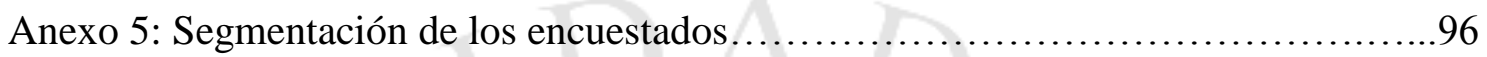

Anexo 6: Tipo de trabajo de los encuestados................................... 97

Anexo 7: Nivel de ingresos de los encuestados................................. 98

Anexo 8: Recordación de constructoras.......................................... 99

Anexo 9: Nivel de cumplimiento de expectativas.............................. 100

Anexo 10: Ventajas de los actuales proyectos................................. 101

Anexo 11: Desventajas de los proyectos....................................... 102

Anexo 12: Apreciación de información ofrecida................................... 103

Anexo 13: Información necesaria para la toma de decisiones.......................104

Anexo 14: Cantidad de departamentos que debería tener un edificio...................105

Anexo 15: Cantidad de pisos que debería tener un edificio......................... 106

Anexo 16: Frontis ideal de un departamento..................................... 107

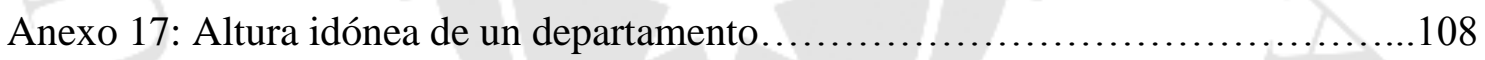

Anexo 18: Ambientes que deberían tener vista hacia la calle.........................109

Anexo 19: Cantidad mínima de muebles en ambiente de sala.......................110

Anexo 20: Cantidad mínima de personas en ambiente de comedor....................111

Anexo 21: Ubicación del ambiente de lavandería................................. 112

Anexo 22: Cantidad apropiada de dormitorios..................................113

Anexo 23: Tamaño de camas en los dormitorios.............................. 114

Anexo 24: Cantidad de baños necesarios.........................................115

Anexo 25: Demanda insatisfecha de hogares en Lima Metropolitana y el Callao

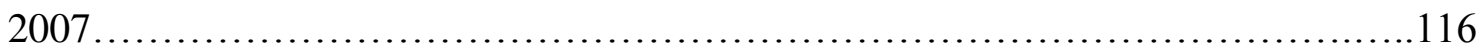

Anexo 26: Demanda insatisfecha de departamentos en Lima Metropolitana y el Callao

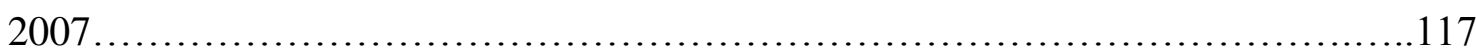

Anexo 27: Indicadores económicos 2000 - 2007.............................118

Anexo 28: Crecimiento de los grupos de edad (1995 - 2010)......................119 
Anexo 29: Población total estimada por sexo y tasa de crecimiento, 2003 - 2010 (miles)

Anexo 30: Créditos hipotecarios para vivienda (miles de NS/.) 2005-2008 .121

Anexo 31: Demanda insatisfecha según precio de la vivienda (julio 2007)...........122

Anexo 32: Oferta total de vivienda según precios de venta (julio 2007)..............123

Anexo 33: Oferta total de viviendas vendidas según precios de venta (julio 2007)...124

Anexo 34: Oferta total de departamentos según precios de venta (julio 2007) 125

Anexo 35: Oferta total de departamentos según sector urbano y precio (julio 2007)...126 Anexo 36: Oferta total de departamentos según distrito y grupo (julio 2007).

Anexo 37: Precios promedio anuales de los materiales de construcción, 2003 2007.

Anexo 38: Variación porcentual anual de los precios de los materiales de construcción, $2003-2007$ 130

Anexo 39: Comparativo entre preferencias de los clientes y características reales del edificio

Anexo 40: Imágenes del volante díptico del proyecto. 133

Anexo 41: Distribución de volantes dípticos. 134

Anexo 42: Entidades próximas al proyecto.................................... 135

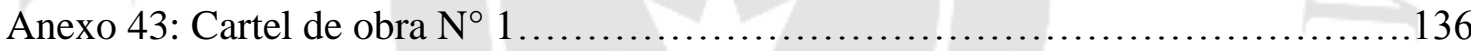

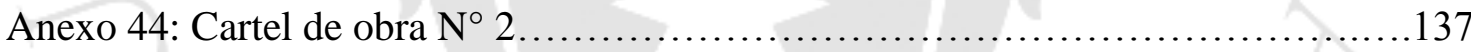

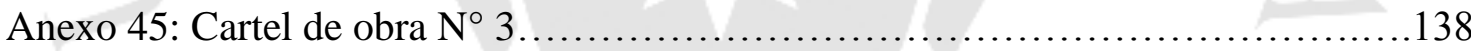

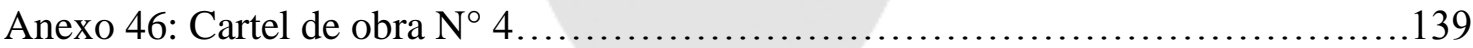

Anexo 47: Participación del mercado proyectada del año cero al año 5...............140

Anexo 48: Relación de los acabados instalados en los departamentos................141

Anexo 49: Vista frontal del edificio "Torre Barrón"............................... 143

Anexo 50: Plano de planta del primer piso.................................... 144

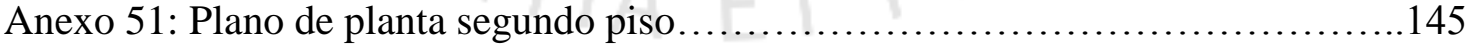

Anexo 52: Plano de planta típica 3er al 6to piso................................. 146

Anexo 53: Plano de planta sétimo piso........................................ 147

Anexo 54: Licencia de Obra para Edificación Nueva...............................148

Anexo 55: Relación de Unidades Inmobiliarias, Numeración Municipal y

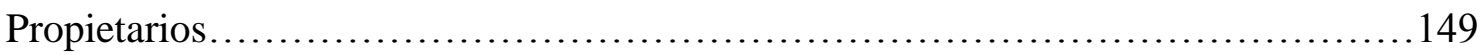

Anexo 56: Cronograma General de Implementación Detallado......................150

Anexo 57: Presupuesto de Ventas Netas......................................... 152 
Anexo 58: Presupuesto de Cobranza por Ventas.................................153

Anexo 59: Presupuesto de Gastos de Marketing................................... 154

Anexo 60: Presupuesto de Desembolso de Gastos de Marketing....................155

Anexo 61: Presupuesto de Gastos de Administración y Ventas......................156

Anexo 62: Presupuesto de Desembolso de Gastos de Administración y Ventas........157

Anexo 63: Presupuesto de Gastos Bancarios...................................158

Anexo 64: Presupuesto de Desembolso de Gastos Bancarios........................159

Anexo 65: Presupuesto de Gastos por Adquisición de Terreno...................... 160

Anexo 66: Presupuesto de Desembolso de Gastos por Adquisición de Terreno........161

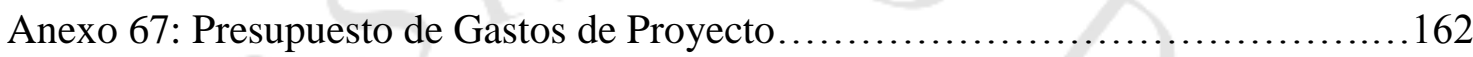

Anexo 68: Presupuesto de Desembolso de Gastos de Proyecto.......................163

Anexo 69: Presupuesto de Gastos de Construcción................................ 164

Anexo 70: Presupuesto de Desembolso de Gastos de Construcción...................165

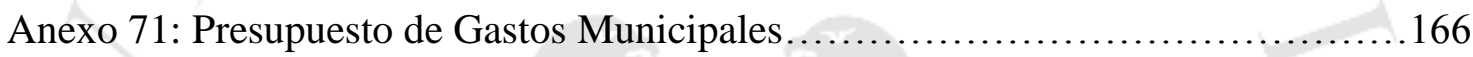

Anexo 72: Presupuesto de Desembolso de Gastos Municipales.......................167

Anexo 73: Presupuesto de Gastos de Titulación...................................168

Anexo 74: Presupuesto de Desembolso de Gastos de Titulación......................169

Anexo 75: Presupuesto de Gastos Imprevistos................................ 170

Anexo 76: Presupuesto de Desembolso de Gastos Imprevistos.....................171

Anexo 77: Presupuesto de Gastos Financieros................................... 172

Anexo 78: Presupuesto de Pago de Deuda...................................... 173

Anexo 79: Estado de Resultados Mensual del 1 de marzo al 31 de diciembre de

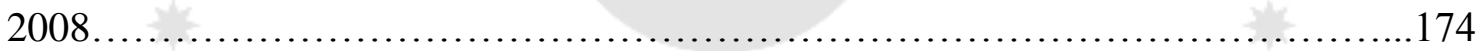

Anexo 80: Flujo de Caja Mensual al 31 de diciembre de 2008...................... 175

Anexo 81: Evolución de la Demanda Efectiva de Hogares y Precio Promedio de los

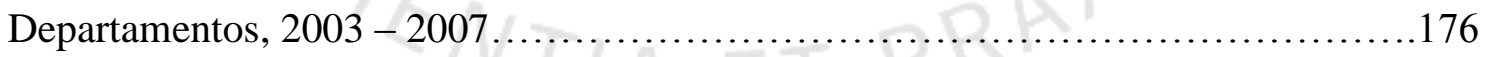

Anexo 82: Evolución del Precio de los Terrenos, de los Materiales, de la UIT, de la RMV y de los PRESC, $2003-2007$. 


\section{INTRODUCCIÓN}

El presente trabajo ha sido elaborado con la finalidad de servir de guía a aquellos emprendedores que decidan incursionar en el negocio de la construcción y desarrollar un primer proyecto inmobiliario. El trabajo está dividido en ocho capítulos, totalmente diferenciados y concatenados entre sí, y toma en cuenta las principales herramientas administrativas para poder planificar, organizar, dirigir y controlar el proyecto.

En el primer y segundo capítulos, explicamos la razón de ser del negocio, describimos nuestra oferta, el segmento al que nos dirigimos y nuestras principales ventajas competitivas. Así mismo, definimos a nuestros potenciales clientes, presentamos una evaluación de las encuestas realizadas y determinamos la demanda actual y la demanda proyectada. Complementamos la información, realizando un análisis situacional del entorno general y del entorno específico.

En el tercer capítulo, presentamos la organización de la empresa, empleando la matriz FODA para tener claro los aspectos positivos y negativos, tanto de origen interno como externo y poder determinar nuestra visión, misión, políticas generales, objetivos estratégicos y las estrategias para conseguirlos, a nivel corporativo y a nivel de negocio. Así mismo, planteamos la estructura organizacional, las funciones y actividades de las áreas principales, el personal requerido y el sistema informático a utilizar. Finalmente, definimos la cadena de valor de la empresa y sus interrelaciones de valor.

En el cuarto capítulo, nos enfocamos en nuestro proyecto inmobiliario, el Edificio Multifamiliar Torre Barrón, estableciendo las necesidades que satisface de nuestros clientes, determinando los objetivos de marketing y desarrollando las diferentes estrategias para lograrlos (estrategias del producto, de precios, de publicidad, de promoción y de ingreso al mercado). Así mismo, establecemos la participación del mercado, la proyección de ventas, las estrategias y las políticas de ventas

En el quinto capítulo, determinamos la localización óptima y el diseño del proyecto inmobiliario. Revelamos el proceso constructivo, desde la adquisición del inmueble sobre el que se ejecutó la obra hasta la inscripción de la Declaratoria de Fábrica de Obra Nueva, el Reglamento Interno del edificio, la Independización y Numeración de los inmuebles, en la Superintendencia Nacional de los Registros Públicos. Así mismo, desarrollamos la estrategia logística del proyecto. 
En el sexto capítulo, presentamos el proyecto en términos de presupuestos, es decir, desarrollamos el cronograma general de implementación del proyecto y las inversiones realizadas necesarias para su ejecución. Así mismo, presentamos las principales partidas que componen el planeamiento comercial y el planeamiento operativo y la estructura de financiamiento determinada para el proyecto.

En el séptimo y octavo capítulos, realizamos un análisis de los principales estados financieros de la empresa (Estado de Resultados, Estado de Situación Financiera y Flujo de Caja), evaluamos la factibilidad del proyecto, determinando los flujos económico y financiero, planteados en un horizonte de tiempo de cinco años. Así mismo, realizamos un análisis del punto de equilibrio y presentamos un análisis de sensibilidad del proyecto en dos posibles escenarios, optimista y conservador.

Finalmente, enunciamos las principales conclusiones del proyecto y presentamos los anexos que ayudarán a profundizar, conocer y entender la información brindada en los diferentes capítulos. 


\section{CAPÍTULO I: DEFINICIÓN DEL NEGOCIO}

En el presente capítulo definiremos nuestro negocio, explicando la razón de ser del negocio y nuestra oferta, describiendo el segmento al que nos dirigimos y detallando nuestras principales ventajas competitivas. Así mismo, enunciaremos la visión y misión de nuestra empresa. Finalmente, presentaremos el sustento de la elección de nuestro negocio.

\subsection{Oferta, segmento y ventajas competitivas}

Constructora Las Torres Sociedad Anónima Cerrada es una empresa que constituimos con el objeto de dedicarnos a efectuar actividades relacionadas con operaciones de tipo inmobiliario como son la compraventa de inmuebles, la construcción, la modificación, el arrendamiento y la administración de los mismos, así como todos los actos relacionados con las actividades inmobiliarias. La empresa la conformamos tres socios, Julia Mercedes La Torre Dávila, Nicanor Antonio La Torre Tarrillo y Jorge Francisco La Torre Tarrillo, el 14 de febrero de 2008 y la inscribimos ante la Superintendencia Nacional de los Registros Públicos (SUNARP), en el Registro de Personas Jurídicas de Lima obteniendo la Partida Electrónica No 12135204 y ante la Superintendencia Nacional de Administración Tributaria (SUNAT) obteniendo el Registro Único de Contribuyentes $\mathrm{N}^{\mathrm{o}} 20518771877$.

Constructora Las Torres S.A.C. inició sus operaciones con el planeamiento y ejecución de un proyecto inmobiliario en la Urbanización de Santa Beatriz del Distrito de Cercado de Lima, Provincia y Departamento de Lima. El proyecto consistió en la construcción de un edificio multifamiliar, cuyas características buscaban satisfacer las necesidades y preferencias del segmento de mercado seleccionado.

El segmento de mercado al cual nos dirigimos estaba conformado por familias constituidas en general por cuatro o más personas (padre, madre e hijos); cuyos ingresos eran percibidos por los padres, algunos dependientes, otros empresarios; con hijos en edad escolar y universitaria; en todos los casos, aspiracionales, provenientes de las zonas marginales de Lima y cuyas demandas de vivienda eran la amplitud de los espacios o ambientes, el diseño funcional y moderno, la adecuada ventilación e iluminación natural, la reducida cantidad de viviendas, la privacidad, tranquilidad y 
seguridad conseguida por la calidad de la estructura y de los acabados, la céntrica ubicación del inmueble, entre otras.

Entre las principales ventajas competitivas podemos mencionar, la misma ejecución del proyecto con características no tomadas en cuenta por otras constructoras que nos permitieron diferenciarnos con facilidad de otros proyectos presentes, la escasa oferta inmobiliaria en la urbanización, su ubicación estratégica, la atención y asesoría personalizada ofrecida hacia los clientes, la sinergia conseguida con las entidades financieras, nuestro equipo multidisciplinario de profesionales, entre otras.

\subsection{La visión y la misión del negocio}

\subsubsection{Visión}

"Buscamos ser reconocidos como una de las principales constructoras del país, que desarrolla proyectos inmobiliarios que satisfacen las necesidades de sus clientes, generando empleos que aseguran el bienestar y el compromiso de sus colaboradores, formando alianzas estratégicas con sus proveedores e incrementando la riqueza de sus accionistas."

\subsubsection{Misión}

"Estamos orientados a ofrecer una mejor calidad de vida a las familias, brindándoles un mejor lugar donde vivir, desarrollando proyectos inmobiliarios acorde a sus necesidades, requerimientos y preferencias."

\subsection{Sustento de la elección del negocio}

Para decidir en qué sector incursionar y rentabilizar nuestra inversión, evaluamos diferentes variables. A nivel macro podríamos afirmar que los factores económicos, demográficos, sociales, políticos y jurídicos, representaron una oportunidad en su conjunto ya que los principales indicadores mostraban una situación favorable para emprender un negocio. Para el año 2007, el PBI Total y el PBI Per Cápita venían incrementándose en $9 \%$ respecto al año anterior, el tipo cambiario mostraba cierta estabilidad (S/. 3.13) y la inflación se conservaba controlada (1.8\%). A nivel 
demográfico, el incremento poblacional mostraba una tendencia creciente de $1.4 \%$ anual. Así mismo, el grupo o segmento al cual iba dirigido el negocio, se había incrementado anualmente desde el año 2000, ya que de acuerdo al Instituto Nacional de Estadística e Informática (INEI) el segmento poblacional de 20 a 59 años crecería de $48.18 \%$ a $51.93 \%$ entre el año 2000 y 2010. Por otro lado, la estabilidad política y jurídica amparada por el gobierno de momento, complementaba la evaluación de los diferentes factores.

A un nivel específico, podríamos afirmar que los favorables indicadores del sector construcción representaban una oportunidad para invertir en dicho rubro. El PBI - Construcción se incrementó en el 2007 en 16.5\%, las importaciones de los materiales de construcción aumentaron en $72 \%$, la producción de cemento en $16 \%$, la producción de barras de construcción en $24.7 \%$, las colocaciones bancarias en el sector en $28.8 \%$ y los préstamos hipotecarios para vivienda en $15.9 \%$. Es importante mencionar que este comportamiento o tendencia en el sector construcción se venía manifestando desde el año 2003, lo cual representaba una situación optimista para la incursión en dicho sector.

Nuestra decisión fue definitiva al evaluar los estudios del mercado inmobiliario realizados por la Cámara Peruana de la Construcción (CAPECO). La demanda insatisfecha de hogares en Lima Metropolitana y el Callao, representaba una excelente oportunidad de negocio. En el año 2007 la demanda efectiva de hogares superaba en veintiuna veces a la oferta inmediata de viviendas, por lo que la demanda insatisfecha representaba un $95 \%$ de la demanda total efectiva. Por su parte, la demanda insatisfecha de departamentos mostraba un comportamiento similar. Dicho análisis se complementó con los estudios económicos del BBVA Banco Continental que determinaron que la concentración o participación de mercado de las empresas constructoras en Lima Metropolitana y Callao era baja a fines del año 2007, ya que ninguna de las más de 400 empresas dedicadas a la construcción de proyectos inmobiliarios de viviendas representaba más del 10\% de las ventas. Así mismo, se determinó que las empresas promotoras y constructoras obtuvieron rentabilidades sobre sus patrimonios de más del $20 \%$ durante los años 2006 y 2007. Dicha situación fue atractiva para nosotros, como inversionistas, tanto por la alta rentabilidad obtenida como por la posibilidad de ingresar al mercado inmobiliario y conseguir incrementar con facilidad nuestra participación. 


\section{CAPÍTULO II: ESTUDIO DE MERCADO}

En el presente capítulo definiremos a nuestros potenciales clientes, presentaremos una evaluación de las encuestas realizadas, definiremos la demanda actual y proyectaremos la demanda esperada. Así mismo, realizaremos un análisis del entorno general (económico, demográfico, social, político y jurídico) y del entorno específico (sector construcción, mercado inmobiliario y proveedores potenciales). Finalmente, presentaremos un análisis de la competencia.

\subsection{Definición de los clientes potenciales}

Para poder determinar el segmento de mercado al cual nos íbamos a dirigir, realizamos un estudio de mercado basado en encuestas, que nos permitieron establecer sus principales características y necesidades. Las encuestas se realizaron a 100 personas en la Urbanización de Santa Beatriz, del Distrito de Cercado de Lima, Provincia y Departamento de Lima, en marzo del año 2008. Las personas que fueron entrevistadas pertenecían a un rango de edad entre los 30 y 50 años aproximadamente, 52\% del género femenino y $48 \%$ del masculino, casados y/o convivientes en su mayoría, con hijos en edad escolar y universitaria. Ver anexos 1, 2, 3 y 4.

Al analizar los resultados pudimos comprobar que los clientes potenciales podían ser clasificados en tres conjuntos o categorías, los que residían en Santa Beatriz (20\%), los que trabajaban en la urbanización (35\%) y los que tenían a sus hijos estudiando en ella (45\%). Respecto al grupo de encuestados que residían en la urbanización, el $85 \%$ eran trabajadores dependientes y $15 \%$ independientes. De los trabajadores dependientes, solo el $18 \%$ tenía un nivel de ingresos superior a los $\mathrm{S} /$. 4,000.00, mientras que de los independientes, el 33\%. Del grupo de los encuestados que trabajaban en la urbanización, el $86 \%$ eran trabajadores dependientes y $14 \%$ independientes. De los trabajadores dependientes, solo el $17 \%$ tenía un nivel de ingresos superior a los S/. 4,000.00, mientras que de los independientes, el 40\%. En relación a los que tenían a sus hijos estudiando en Santa Beatriz, el $87 \%$ eran trabajadores dependientes y $13 \%$ independientes. De los trabajadores dependientes, solo el 10\% tenía un nivel de ingresos superior a los S/. 4,000.00, mientras que de los independientes, el 50\%. En resumen podemos concluir que el $86 \%$ de los encuestados 
eran trabajadores dependientes de los cuales solo el $14 \%$ tenían ingresos superiores a los S/. 4,000.00; por otro lado el $14 \%$ de los encuestados eran trabajadores independientes, de los cuales el 43\% mantenían ingresos por encima de los S/. 4,000.00. Finalmente, podemos afirmar que solo el $18 \%$ del total encuestados obtenían ingresos superiores a los S/. 4,000,00. Ver anexos 5, 6 y 7.

\subsection{Evaluación de las encuestas}

Las encuestas desarrolladas buscaron determinar la oferta inmobiliaria en la zona de ejecución del proyecto y establecer lo que las personas buscaban como vivienda ideal, es decir, qué características debían tener las viviendas para que cumplieran con sus expectativas y preferencias.

De acuerdo a las encuestas realizadas podemos afirmar que son solo dos las constructoras que consideraron como oportunidad de negocio, desarrollar algún proyecto inmobiliario multifamiliar en la Urbanización de Santa Beatriz, el Grupo Constructor Rocazul, conocido por un $60 \%$ de los encuestados y el Grupo Inmobiliario Imagina, recordado por un $35 \%$. Ver anexo 8.

Pese al reconocimiento y experiencia de dichas empresas, el 55\% de los encuestados afirmó que los departamentos que se ofrecían por la zona no cumplían con sus expectativas, siendo las principales razones, el reducido tamaño de las viviendas (100\%), la excesiva cantidad de departamentos (95\%), la poca cantidad de estacionamientos (90\%), la falta de ascensor (20\%), entre otras. Así mismo, un 20\% afirmó que las viviendas ofrecidas en la zona si cumplían con sus perspectivas, por ofrecer modernidad (100\%), financiamiento (85\%), la atención brindada (40\%), adecuada asesoría (25\%), entre otras razones. El 25\% restante manifestó que las constructoras de la zona cumplían sus expectativas moderadamente. Respecto a la información brindada en los proyectos, a un $85 \%$ le pareció insuficiente, mientras que un $10 \%$ la calificó como precisa y un $5 \%$ como excesiva. En ese sentido, se preguntó qué información les gustaría recibir para tomar una adecuada decisión, respondiendo que sería importante conocer el tamaño de la vivienda (100\%), los precios (100\%), los descuentos (100\%), la descripción de los ambientes (95\%), la descripción de los acabados (90\%), la descripción de la estructura (90\%) y el financiamiento (85\%). Ver anexos $9,10,11,12$ y 13 . 
Por otro lado, respecto al segundo grupo de preguntas, podemos afirmar que el $87 \%$ de los encuestados preferirían proyectos con 15 departamentos como máximo y que el $81 \%$ considera que un edificio debería tener como máximo 07 pisos. Ver anexos 14 y 15.

En relación al diseño de las viviendas, las personas afirmaron que un departamento debería tener más de 05 metros de frontis (50\%), con una altura entre 02 y 03 metros (75\%), vista hacia la calle (98\%), que la sala y/o el comedor deberían ser los ambientes con vista hacia la calle $(90 \%)$, que en la sala deberían entrar más de 02 muebles $(83 \%)$, que en el comedor deberían poder sentarse a la mesa 06 personas (68\%), que los ambientes de cocina y lavandería no deberían estar en una misma zona (82\%), que en la cocina se deberían contemplar muebles reposteros (98\%), que la lavandería debería estar ubicada internamente pero con buena ventilación (77\%), que el departamento debería contar con cuarto y baño de servicio (92\%), 03 dormitorios (75\%), en los cuales deberían entrar camas de 02 o más plazas (88\%) y 02 baños ( $80 \%)$, que tengan buena iluminación natural y suficiente ventilación (100\%) y que no es necesario que tenga una terraza o balcón (55\%). Ver anexos 16, 17, 18, 19, 20, 21, 22, 23 y 24.

Por otro lado, respecto a los acabados, podemos afirmar que las personas preferirían ventanas de aluminio (46\%) y acero (44\%), pisos laminados en sala y comedor $(88 \%)$ y en los dormitorios $(90 \%)$, pisos cerámicos en la cocina (97\%), lavandería (100\%) y baños $(100 \%)$, grifería y sanitarios de la marca "Trebol” (85\%), que los dormitorios deberían contar con closets (100\%), que tanto los baños (100\%), la cocina $(82 \%)$ y la lavandería $(65 \%)$ deberían contar con agua fría y caliente, que preferirían elegir el color de pintura de su departamento (95\%).

A un nivel específico, podemos afirmar que los encuestados preferían contar con puntos de cable en los ambientes de sala y/o comedor (85\%) y dormitorios (100\%), puntos de Internet en sala y/o comedor (23\%) y dormitorios (100\%) y puntos de telefonía fija en sala y/o comedor (89\%), dormitorios (100\%) y cocina (56\%). Así mismo consideraban necesario contar con más de 02 tomacorrientes en los dormitorios (80\%), en la sala (85\%), en el comedor (85\%) y en la cocina (90\%), mientras que en los baños $(75 \%)$ y en la lavandería $(57 \%)$ consideraban que era suficiente contar solo con 02 tomacorrientes. Respecto a los servicios básicos, preferían contar con medidores independientes tanto de agua como de energía eléctrica e intercomunicador (100\%). 
Finalmente, en relación a los ambientes comunes, podemos afirmar que en su mayoría prefirieron una ascensor con capacidad para 06 o más personas (80\%), que el piso del estacionamiento debía ser de cemento pulido (86\%), que las puertas de ingreso a los estacionamientos debían ser de fierro y madera (38\%), que la puerta de ingreso peatonal debía ser de madera (56\%), que no era importante contar con un departamento “piloto" (77\%), que no era conveniente contar con áreas verdes (66\%), que no era adecuado contar con sala de juegos (88\%), que no era necesario tener una sala de eventos $(90 \%)$ y que no consideraban importante tener una piscina $(98 \%)$.

\subsection{La demanda actual y la demanda proyectada}

Basados en los estudios del mercado inmobiliario realizados por la Cámara Peruana de la Construcción (CAPECO), determinamos que la demanda insatisfecha de hogares en Lima Metropolitana y el Callao, representaba una gran oportunidad de negocio, ya que desde el año 2004 la demanda efectiva de hogares estaba muy por encima de la oferta inmediata de viviendas.

En el año 2007 la demanda efectiva de hogares $(296,921)$ era veintiún veces la oferta inmediata de viviendas $(13,902)$, por lo que la demanda insatisfecha $(283,019)$ representaba un $95.32 \%$ de la demanda efectiva. De acuerdo al análisis de los cuatro últimos años pudimos afirmar que la demanda insatisfecha de hogares se incrementaría en $9 \%$ anualmente. Ver anexo 25.

Por su lado, la demanda efectiva de departamentos (291,304) mostraba el mismo comportamiento que el de los hogares, ya que era veintiún veces la oferta inmediata de viviendas $(13,639)$, por lo que la demanda insatisfecha de departamentos $(277,665)$ representaba un $95.32 \%$ de la demanda efectiva. De acuerdo al análisis de los cuatro últimos años pudimos determinar que la demanda insatisfecha de departamentos se incrementaría en $16 \%$ anualmente. Ver anexo 26.

\subsection{Análisis del entorno general y específico}

En este sub capítulo presentamos un análisis del entorno económico, demográfico, social, político y jurídico. Así mismo, exponemos una evaluación específica del sector construcción, del mercado de las edificaciones urbanas y de los potenciales proveedores. 


\subsubsection{Entorno económico}

De acuerdo al análisis del entorno económico realizado desde el 2000 hasta el 2007, podríamos afirmar que la situación del país era favorable para los diferentes sectores, ya que la economía presentaba indicadores, que venían creciendo de manera sostenida en los últimos años. Tanto el PBI total como el PBI Per Cápita venían incrementándose a razón de 5\% anual en promedio, desde los últimos cinco años. El tipo de cambio presentaba una tendencia decreciente desde el 2002, básicamente por la devaluación del dólar norteamericano a nivel mundial, por el incremento de las exportaciones de minerales, de las remesas del exterior, de la afluencia de turistas, entre otros factores. Por otro lado, la inflación promedio presentó variaciones diferentes siendo la más alta, la mostrada en el 2004 que fue de 3.66\%. En cuanto a las tasas de interés interbancarias en moneda nacional y extranjera, tuvieron un ligero incremento en los últimos cuatro años. Ver anexo 27.

\subsubsection{Entorno demográfico y social}

El crecimiento poblacional tuvo la misma tendencia que el PBI, es decir, presentó un comportamiento incremental, cuya tasa promedio fue de $1.40 \%$ anual.

Respecto a los segmentos poblacionales por edad podríamos agruparlos en cuatro grandes conjuntos: de 0 a 19 años, de 20 a 39 años, de 40 a 59 años y de 60 años en adelante. El primer grupo se fue reduciendo en $5.63 \%$ anual en promedio mientras que los otros tres por el contrario se fueron incrementando en estos últimos diez años, en $1.59 \%, 8.29 \%$ y $8.86 \%$ respectivamente, siendo esta la tendencia a largo plazo. Es importante mencionar que desde 1995 el grupo más grande, ha sido el de 0 a 19 años y el grupo más pequeño el de 60 a más años. Las proyecciones al 2010 confirmaron este comportamiento. Ver anexo 28.

En cuanto a la población segmentada por sexo, se podría afirmar que en el año 2006 predominantemente fue masculina (14,254 habitantes), representando un $50.28 \%$ y en el caso del sexo femenino (14,095 habitantes) representando un $49.72 \%$, cifras que se pueden visualizar en el anexo 29.

Siendo más específicos y basándonos en el Censo Nacional de Población y Vivienda del año 2007, podemos afirmar que la Urbanización de Santa Beatriz estaba conformada por 4,019 viviendas, distribuidas en 63 manzanas y con una población de 
11,999 habitantes. Respecto a los tipos de vivienda encontrados, podemos mencionar que el $51 \%$ eran departamentos en edificios $(2,055)$, el $34 \%$ casas independientes (1367), el 12\% viviendas en quintas (461) y el 3\% restante estaba conformado por viviendas en casa de vecindad, hoteles, hostales, etc. En relación al material de construcción predominante en las viviendas censadas, se puede afirmar que el $79 \%$ estaban edificadas con ladrillos o bloques de cemento en las paredes y el $15 \%$ con adobe o tapia. Así mismo, podemos indicar que en el 35\% de las viviendas se encontró losetas y terrazos en los pisos, en el $33 \%$ parquet o madera pulida y en el $22 \%$ cemento. Respecto a los servicios básicos podemos señalar que en el $84 \%$ de las viviendas el abastecimiento de agua se daba a través de la red pública dentro de la vivienda, mientras que en el $15 \%$ fuera de ella. Otro dato importante a mencionar es que el $98 \%$ de las viviendas contaban con servicio de agua potable todos los días. Por otro lado, en el $86 \%$ de las viviendas, la red pública de desagüe estaba dentro de la vivienda, mientras que en el $14 \%$ estaba fuera. Finalmente podemos mencionar que todas las viviendas de la urbanización contaban con servicio de alumbrado eléctrico. En relación a la cantidad de habitaciones, podemos mencionar que el $31 \%$ de las viviendas tenían entre 1 y 2 habitaciones, el $46 \%$ entre 3 y 4 habitaciones mientras que el $23 \%$ tenían más de 4 . Respecto a la tenencia de la vivienda, podemos indicar que el $41 \%$ de las viviendas censadas eran propias y estaban totalmente pagadas, el $40 \%$ eran alquiladas, el $13 \%$ eran propias pero se venían pagando a plazos, mientras que el $6 \%$ restante estaban cedidas por el centro de trabajo, era una institución, etc., según se muestra en la figura 2.1.

Respecto a la vivencia en la urbanización, el 34\% no vivía en Santa Beatriz hace 5 años, mientras que el $66 \%$ sí. Por otro lado, el 97\% hablaba Castellano, el 2\% Quechua y el 1\% Aymará, Asháninka, otra lengua nativa, idioma extranjero y/o es sordomudo. El $96 \%$ sabía leer y escribir. El 33\% asistía a algún colegio, instituto o universidad. En relación al último nivel de estudios que aprobaron, se puede afirmar que el 3\% no tenía nivel, el 2\% poseía educación inicial, el 12\% tenía nivel Primaria, el 29\% Secundaria, el 6\% Superior No Universitaria incompleta, el 13\% Superior No Universitaria completa, el 12\% Superior Universitaria incompleta y el 23\% Superior Universitaria completa. Respecto a la población segmentada por género, se puede determinar que el 54\% estaba conformado por mujeres y el $46 \%$ por hombres. Finalmente, en relación a la población segmentada por grupos de edad, podemos 
determinar que el grupo mayoritario era el de 20 a 39 años (33.8\%), seguido de los grupos de 0 a 19 años $(24.8 \%)$ y de 40 a 50 años (24.8\%), tal como se muestra en la figura 2.2.

Figura 2.1

Tenencia de la vivienda en Santa Beatriz 2007

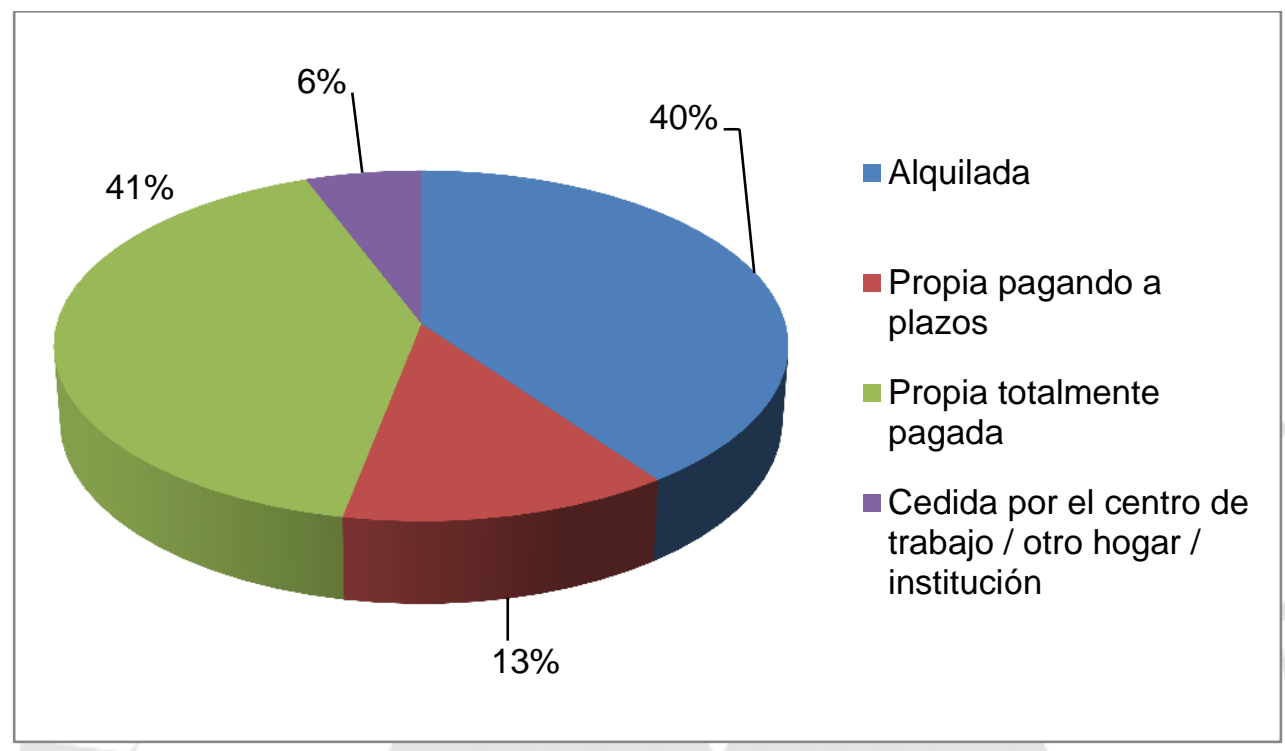

Fuente: INSTITUTO NACIONAL DE ESTADÍSTICA E INFORMÁTICA (INEI)

Censos Nacionales 2007: XI de Población y VI de Vivienda.

Base de datos a nivel de manzanas. Elaboración: Propia.

Figura 2.2

Población segmentada por edades en Santa Beatriz 2007

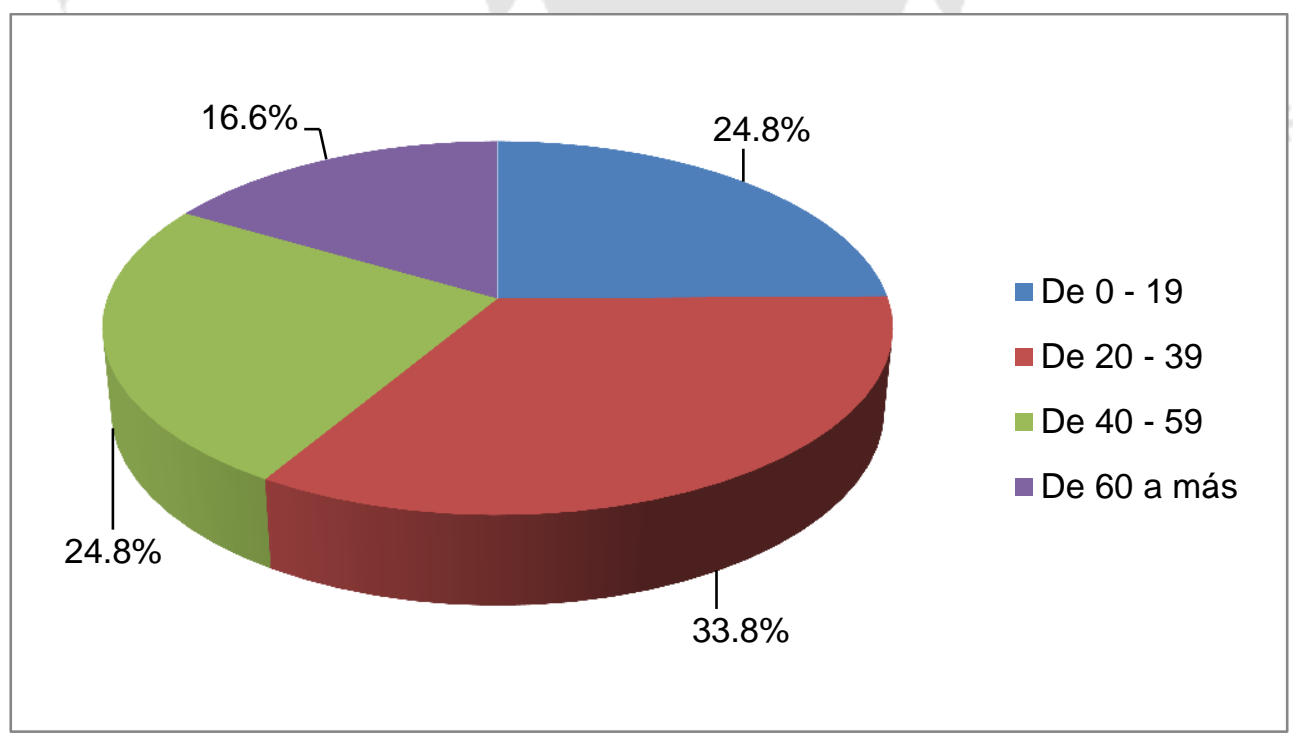

Fuente: INSTITUTO NACIONAL DE ESTADÍSTICA E INFORMÁTICA (INEI)

Censos Nacionales 2007: XI de Población y VI de Vivienda.

Base de datos a nivel de manzanas. Elaboración: Propia. 


\subsubsection{Entorno político y jurídico}

En el año 2006 Alan Gabriel Ludwig García Pérez, fue elegido por segunda vez como Presidente del Perú. Este segundo gobierno democrático, se caracterizó por el inicio de grandes proyectos económicos, la reestructuración de las relaciones diplomáticas y la continuidad de la estabilidad política y jurídica del estado. Durante los tres primeros años de gobierno, pasaron por la cartera del Ministerio de Vivienda, Construcción y Saneamiento, los ministros Hernán Garrido Lecca (2006-2007) y Enrique Cornejo Ramírez (2007-2008); como Presidentes del Congreso de la República, Mercedes Cabanillas Bustamante (2006-2007) y Luis Gonzales Posada Eyzaguirre (2007-2008); como Presidente de la Corte Suprema, Walter Vásquez Bejarano (2005-2007) y Francisco Távara Córdova (2007-2009); y como Alcalde de la Municipalidad Metropolitana de Lima a Luis Castañeda Lossio (2003-2010).

Para la ejecución del proyecto empresarial que llevamos a cabo nos basamos en diferentes reglamentos, decretos supremos y leyes tales como:

- Resolución No 079-2005-SUNARP/SN “Texto Único Ordenado del Reglamento General de los Registros Públicos".

Decreto Supremo No 005-2007-EF “Texto Único de Procedimientos Administrativos de la Superintendencia Nacional de Administración Tributaria".

Decreto Supremo No 011-2006-VIVIENDA "Reglamento Nacional de Edificaciones".

- Decreto Supremo No 024-2008-VIVIENDA "Reglamento de Licencias de Habilitación Urbana y Licencias de Edificación".

- Decreto Supremo No 055-1999-EF “Ley de Impuesto general a las Ventas e Impuesto Selectivo al Consumo".

- Decreto Supremo No 064-2001-EF “Modificación al D.S. No 29-1994-EF en lo referido a la aplicación del IGV en la primera venta de inmuebles realizada por el constructor".

- Ordenanza No 1334 “Texto Único de Procedimientos Administrativos de la Municipalidad Metropolitana de Lima”.

- Ley N 27157 "Ley de Regularización de Edificaciones, del Procedimiento para la Declaratoria de Fábrica y del Régimen de Unidades Inmobiliarias de Propiedad Exclusiva y de Propiedad Común". 


\subsubsection{Sector construcción}

De acuerdo a nuestra investigación, determinamos que los principales indicadores estratégicos de la construcción empezaron a tener una tendencia creciente a partir del año 2005. Durante el año 2007 el PBI de la Construcción se incrementó en 16.5\% respecto al año anterior; la importación de materiales de construcción aumentó en $71.8 \%$; la producción de cemento varió en $16.0 \%$ y los despachos locales de cemento en $15.1 \%$; la producción de hierro y acero se incrementó en $13.1 \%$, mientras que la producción de barras de construcción en 24.7\%; las colocaciones bancarias en el sector aumentaron en $28.84 \%$, tal como se muestra en la tabla 2.1 .

Tabla 2.1

Indicadores del sector construcción 2003 - 2007

\begin{tabular}{|c|c|c|c|c|c|}
\hline Indicadores & 2003 & 2004 & 2005 & 2006 & 2007 \\
\hline PBI Construcción (variación real \%) & 4,2 & 4,7 & 8,4 & 14,8 & 16,5 \\
\hline VAB Construcción (var \%) & 4,8 & 4,7 & 8,7 & 14,7 & 16,0 \\
\hline \multicolumn{6}{|l|}{ Materiales de Construcción (mill. US\$) } \\
\hline Importaciones (mill. US\$) & 197,4 & 189,0 & 301,6 & 533,1 & 915,9 \\
\hline Variación Porcentual (\%) & $-27,1$ & $-4,3$ & 59,6 & 76,8 & 71,8 \\
\hline Precios (var \%) & 0,8 & 12,5 & 6,5 & 3,4 & 7,5 \\
\hline \multicolumn{6}{|l|}{ Otros indicadores (var\%) } \\
\hline Producción de Cemento (var \%) & 2,3 & 9,3 & 11,0 & 13,6 & 16,0 \\
\hline Despachos Locales Cemento (miles TM) & $3.780,0$ & $3.995,0$ & $4.394,0$ & $5.081,0$ & $5.850,0$ \\
\hline Despachos Locales Cemento (var \%) & 3,1 & 5,7 & 10,0 & 15,6 & 15,1 \\
\hline Producción de Hierro y Acero (var \%) & 6,7 & 4,8 & 7,7 & 12,7 & 13,1 \\
\hline Producción barras de construcción (miles TM) & 367,4 & 386,1 & 406,6 & 429,8 & 536,1 \\
\hline Producción barras de construcción (var \%) & 9,9 & 5,1 & 5,3 & 5,7 & 24,7 \\
\hline \multicolumn{6}{|l|}{ Colocaciones Bancarias en el Sector } \\
\hline Millones US\$ & 226,9 & 199,1 & 231,9 & 247,6 & 319,0 \\
\hline$\%$ del Total & 2.9 & 2.5 & 2.6 & 2.3 & 2.5 \\
\hline
\end{tabular}

Fuente: PERU EJECUTIVO Proyecciones Económicas 2006-2011 y 2007-2012 MAXIMIXE CASER (Club de Análisis de Riesgos Estratégicos). Datos Históricos: INEI, BCRP, SBS, ASOCEM, Sider Perú, Aceros Arequipa. Proyecciones: MAXIMIXE.

Elaboración: Propia.

Así mismo, podemos afirmar que los préstamos hipotecarios para vivienda otorgados por el sistema financiero se incrementaron en $15.9 \%$ durante el año 2007, tendencia que se mantuvo creciente desde el año 2006. Por la colocación de créditos hipotecarios registrados al mes de junio del año 2008, pudimos afirmar que se mantendría esta tendencia, según se muestra en la figura 2.3 y en el anexo 30. 
Figura 2.3

Colocación de créditos hipotecarios para vivienda 2005 - 2008

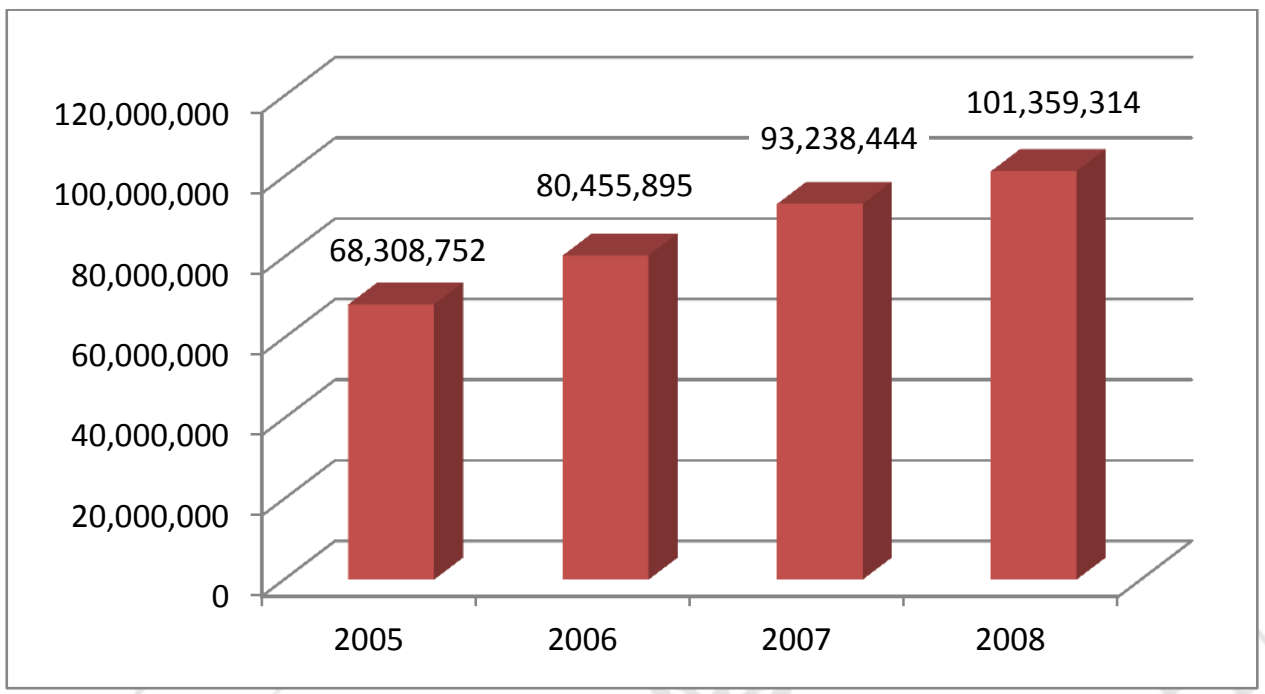

Nota: La información consignada en el año 2008 es proyectada.

Fuente: Superintendencia de Banca, Seguros y AFP - Boletín Estadístico de Banca Múltiple - Alcance y Participación de Mercado: Ranking de Créditos Directos por Tipo Elaboración: Propia.

Cabe mencionar que las entidades financieras que otorgaron la mayor cantidad de créditos hipotecarios durante el año 2007, fueron el Banco de Crédito del Perú (S/. 36.300.981) con una participación del 39\%, seguido por el Banco BBVA Continental (S/. 27.526.097) con un 30\% y por el Scotiabank (S/. 11.641.020) con un 12\%. Durante el primer semestre del año 2008 estos mismos bancos fueron los que otorgaron más créditos hipotecarios para vivienda, con una proyección anual del 8\%. Ver figura 2.4.

Figura 2.4

Participación de mercado en la colocación de préstamos hipotecarios 2007

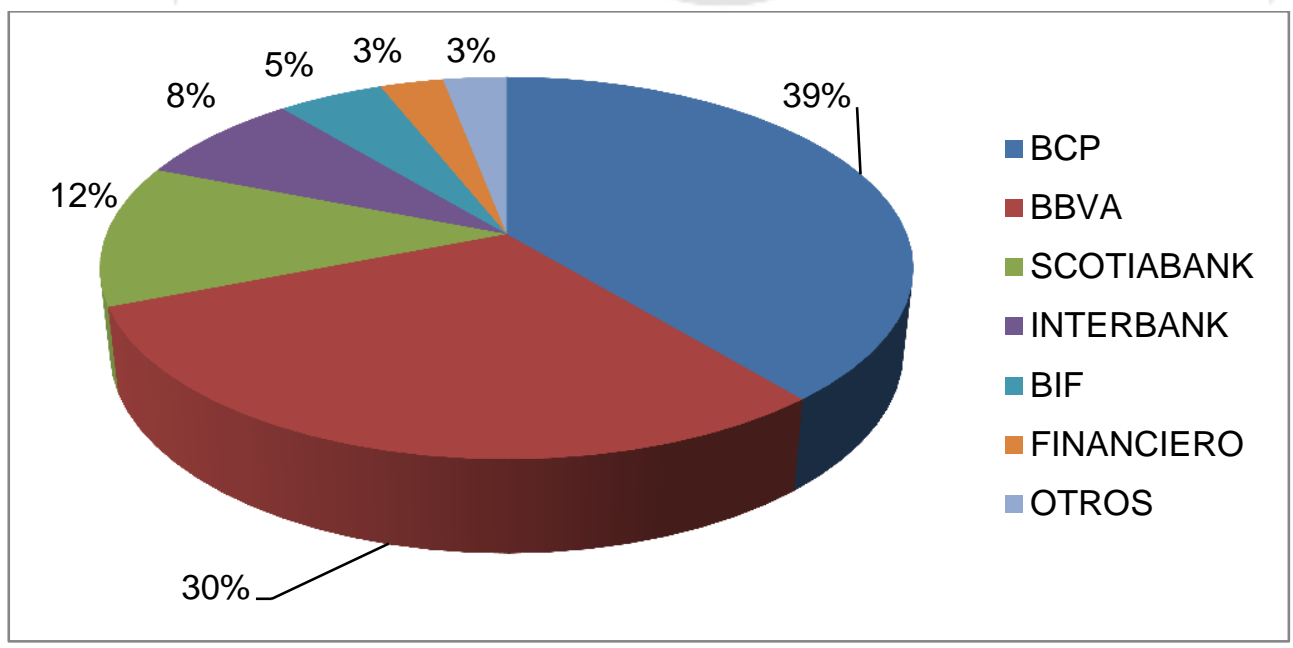

Fuente: Superintendencia de Banca, Seguros y AFP - Boletín Estadístico de Banca Múltiple - Alcance y Participación de Mercado: Ranking de Créditos Directos por Tipo Elaboración: Propia. 


\subsubsection{Mercado de las edificaciones urbanas}

De acuerdo a la información obtenida de la Cámara Peruana de la Construcción (CAPECO) podemos afirmar que durante el primer semestre del año 2007, la demanda efectiva de hogares en Lima Metropolitana y el Callao, estaba muy por encima de la oferta inmediata de vivienda, generando una demanda insatisfecha de 283,019 hogares, es decir, un $95 \%$ de la demanda total efectiva. La demanda efectiva de hogares ascendía a 296,921 mientras que la oferta inmediata de viviendas llegaba a 13,902. Cabe mencionar que la mayor demanda insatisfecha se concentraba en las viviendas cuyo precio oscilaban entre los US\$4,000 y US\$25,000 (81.45\%). Ver anexo 31.

Así mismo, podemos afirmar que durante el primer semestre del año 2007, la oferta de viviendas estaba conformada por 14,140 departamentos que representaban el $98 \%$ de la oferta total y por 268 casas que representaban el 2\%. Durante el mismo periodo, la oferta total de viviendas vendidas estaba conformada por 10,043 departamentos que representaban el $95 \%$ del total y por 528 casas que representaban el $5 \%$. Ver anexos 32 y 33.

Respecto a la oferta total de departamentos en Lima Metropolitana y el Callao, podemos afirmar que el $96 \%$ (13,639 unidades) estaba conformado por la oferta inmediata, mientras que el 4\% (501 unidades) estaba representado por la oferta futura, tal como se aprecia en la figura 2.5 y en el anexo 34.

Figura 2.5

Oferta total de viviendas (julio 2007)

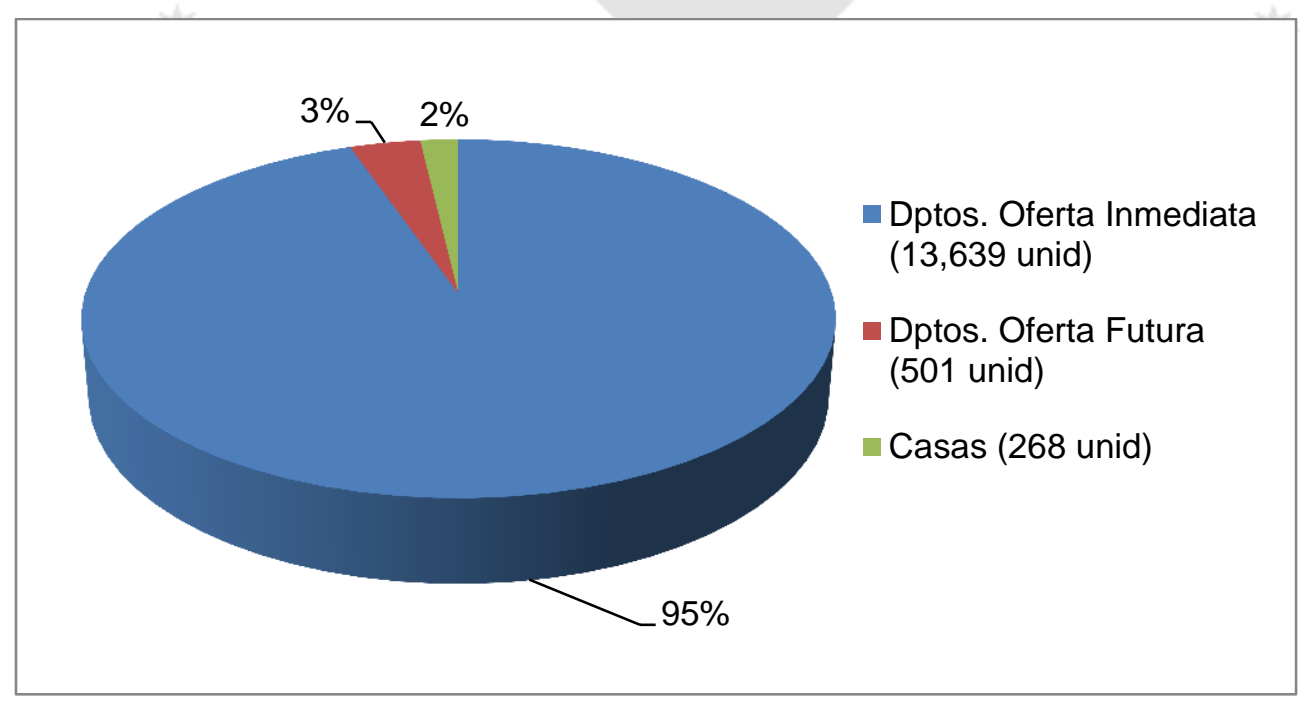

Fuente: XII Estudio Año 2007 El Mercado de Edificaciones Urbanas en Lima Metropolitana y el Callao - Cámara Peruana de la Construcción (CAPECO) Elaboración: Propia. 
Por otro lado, el precio promedio de los departamentos en Lima Metropolitana y el Callao ascendía a Cincuenta y Tres Mil Seiscientos Veintinueve y 00/100 Dólares Americanos (US\$ 53,629.00), siendo el área promedio de 92,6 metros cuadrados y de Quinientos Veintinueve y 00/100 Dólares Americanos (US\$ 529.00) el precio por metro cuadrado. Ver anexo 35.

Una vez analizada la demanda efectiva de hogares y la oferta inmediata de viviendas, determinamos que la demanda insatisfecha de hogares representaba una gran oportunidad de negocio, sin embargo, debíamos analizar con mayor detenimiento la oferta de departamentos en Lima Metropolitana, específicamente en el distrito de Cercado de Lima ( lugar donde desarrollaríamos nuestro proyecto inmobiliario), la cual estaba conformada por 39 departamentos en el grupo A con áreas de $81 \mathrm{~m} 2$ en promedio, 165 departamentos en el grupo B con áreas de $67 \mathrm{~m} 2$ y 30 departamentos en el grupo C con áreas de 79 m2. Ver anexo 36.

\subsubsection{Proveedores potenciales}

Para fines de nuestro proyecto agrupamos a los proveedores en diez categorías:

- Proveedores de metálicos, en los que consideramos a quienes nos podían suministrar acero corrugado, alambre y clavos, como Aceros Arequipa o distribuidores como Tradisa;

- Proveedores de concreto u hormigón, como Firth, Unicon o Supermix;

- Proveedores de agregados y aglomerantes, en los que consideramos a los que nos podían proveer cemento, yeso, cal, piedra chancada, arena gruesa y arena fina, como Cementos Lima, Cemento Pacasmayo y canteras cercanas;

- Proveedores de ladrillos, como Compañía Minera Luren o Ladrillo Pirámide;

- Proveedores de encofrados, como Ulma, Efco o Peri;

- Proveedores de materiales varios, entre los que podemos mencionar maderas, cables eléctricos, tubería, herramientas, entre otros. Para ello consideramos empresas como Remasa El Pino, Indeco, Pavco, etc.;

- Proveedores de materiales de acabados, entre los que podemos indicar cerámicos, aparatos sanitarios, puertas, ventanas, pintura, entre otros. Consideramos a empresas como Celima, Trebol, Decorlux, Pinturas Aurora;

- Proveedores de ascensores, como JV Ascensores, Otis o Schindler; 
- Proveedores de servicios financieros, como el Banco Financiero, Banco BCP, BBVA Banco Continental, etc.;

- Proveedores de servicios básicos (agua, energía eléctrica, telefonía fija, internet, etc.), como Sedapal, Luz del Sur y Movistar.

Para complementar el análisis de nuestros potenciales proveedores fue importante observar permanentemente la variación de los precios de los principales materiales. Para ello recurrimos al estudio mensual que el Instituto Nacional de Estadística e Informática (INEI) realiza a los precios de los materiales de construcción, desde el año 2003 hasta el año 2007. De dicho estudio pudimos determinar que a partir del año 2005 los precios de la mayoría de los materiales se incrementaron hasta en $40 \%$ en algunos de los casos. El precio promedio de los ladrillos llegó a incrementarse en $41 \%$ para el año 2007, el precio de la mayólica en 6\%, el precio del hormigón o concreto en $10 \%$, el precio de los fierros corrugados en $3.5 \%$ y el precio promedio de la madera en $7 \%$. Ver anexos 37 y 38 .

\subsection{Análisis de la competencia}

Basados en el Servicio de Estudios Económicos del BBVA Banco Continental denominado "Situación Inmobiliaria Perú de Agosto de 2008, confirmamos que la concentración o participación de mercado de las empresas constructoras en Lima Metropolitana y Callao era baja a fines del año 2007, ya que ninguna de las más de 400 empresas dedicadas a la construcción de proyectos inmobiliarios de viviendas representaba más del $10 \%$ de las ventas. Así mismo, se determinó que las empresas promotoras y constructoras obtuvieron rentabilidades sobre sus patrimonios de más del $20 \%$ durante los años 2006 y 2007. Dicha situación volvió al sector construcción atractivo para los inversionistas, tanto por la alta rentabilidad obtenida como por la posibilidad de ingresar al mercado inmobiliario y conseguir incrementar con facilidad su participación ya que la demanda excedía a la oferta ampliamente.

En ese sentido, la Urbanización de Santa Beatriz no fue la excepción. Después de realizar un trabajo de campo en dicha urbanización, a fines de marzo del 2008, pudimos encontrar veinte edificios multifamiliares, dieciocho de ellos construidos y habitados, con una antigüedad no mayor a cinco años y dos aún en proceso de construcción. Cabe mencionar que dicho trabajo de campo se realizó basado en la observación y en entrevistas a propietarios de los diferentes inmuebles. 
El $60 \%$ de los edificios multifamiliares encontrados en Santa Beatriz, fueron desarrollados por la empresa Constructora Roca Azul, el 20\% por la empresa Constructora Imagina y el $20 \%$ restante, por empresas constructoras de menor tamaño. Por normativa distrital, basada en la zonificación y en los parámetros urbanísticos y edificatorios, encontramos edificios con un máximo de ocho pisos, con treinta departamentos en promedio, con un estacionamiento por cada dos departamentos. Los edificios con menos de seis pisos, carecían de ascensor y las áreas de los departamentos eran de sesenta metros cuadrados en promedio. En la figura 2.6, mostramos la relación y ubicación de los edificios multifamiliares próximos a nuestro proyecto, diferenciándolos en dos categorías, edificios terminados y edificios en construcción.

Figura 2.6

Proyectos inmobiliarios ubicados en Santa Beatriz 2008

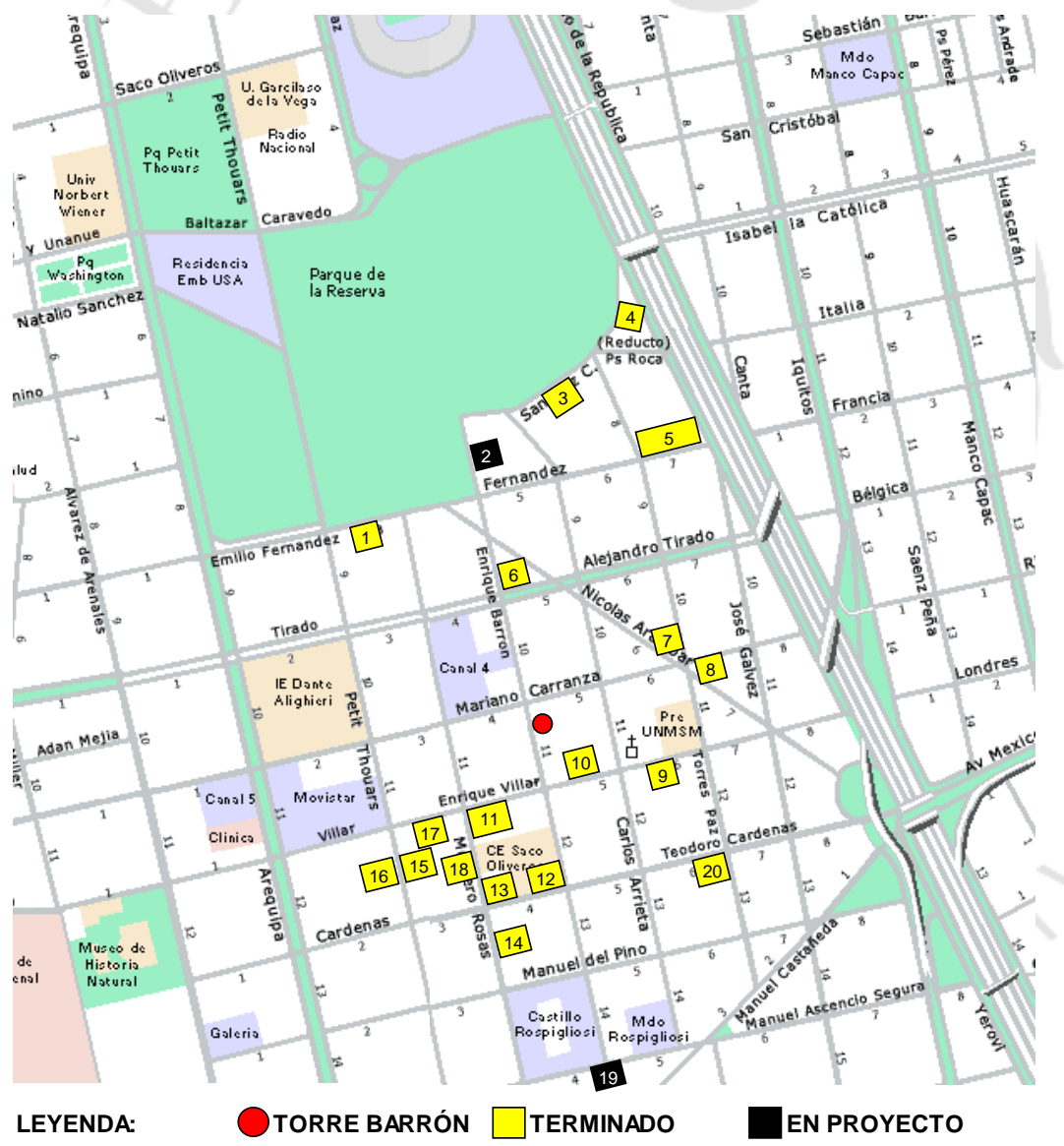

\footnotetext{
1. Edificio de 7 pisos con 31 dptos.

11. Residencial de 5 pisos con 34 dptos.

2. Proyecto de 8 pisos con 32 dptos Lima Kensetsu 12. Edificio Regina $V$ de 8 pisos con 32 dptos.

3. Resid. Parq. de la Reserva de 5 pisos con 60 dptos 13. Edificio Regina III de 7 pisos con 34 dptos.

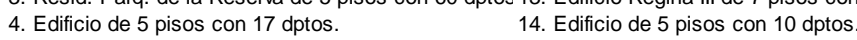

5. Residencial dos bloques de 8 pisos con 80 dptos. 15. Edificio de 8 pisos con 26 dptos.

6. Edificio Regina II de 7 pisos con 28 dptos. 16. Edificio de 5 pisos con 20 dptos.

7. Edificio Regina I de 7 pisos con 28 dptos. 17. Residencial de 4 pisos con 24 dptos.

8. Edificio Villa Leticia de 7 pisos con 28 dptos. 18. Edificio de 5 pisos con 10 dptos.

9. Edificio Resid. Natalia de 8 pisos con 24 dptos. 19. Proyecto de 7 pisos con 18 dptos Yufra Construct

10. Edificio de 8 pisos con 20 dptos. 20. Edificio Regina IV de 8 pisos con 37 dptos.
}

Elaboración: Propia 
Respecto a los dos proyectos que se encontraban en proceso de construcción pudimos determinar que el proyecto de la empresa Lima Kensetsu se ubicaba en el Jirón Enrique Barrón y desarrollarían un edificio de 8 pisos, con 32 departamentos cuyas áreas oscilarían entre los 73 y 95 metros cuadrados, conformados por 3 dormitorios, sala y comedor, 2 baños, cuarto y baño de servicio y dos ascensores, con precios que fluctuarían entre los 51 y 68 mil dólares americanos. Por su parte el proyecto de la empresa Yufra Constructores se ubicaba en el Jirón Manuel Segura y desarrollarían un edificio de 7 pisos, con 18 departamentos cuyas áreas oscilarían entre los 60 y 94 metros cuadrados, conformados por 2 y 3 dormitorios, sala y comedor, 2 baños y ascensor, con precios que fluctuarían entre los 41 y 59 mil dólares americanos. 


\section{CAPÍTULO III: PLAN ORGANIZACIONAL}

El presente capítulo aborda una de las principales actividades de la Administración, la organización de la empresa. Empezamos el capítulo desarrollando la matriz de las fortalezas, oportunidades, debilidades y amenazas de nuestra empresa. A continuación desarrollamos y declaramos nuestra visión, misión, políticas generales, objetivos estratégicos y las estrategias para conseguirlos, tanto a nivel corporativo como a nivel de negocio. Luego presentamos y explicamos la estructura organizacional, las funciones y actividades de las áreas principales, el personal requerido (describiendo su nivel de formación y perfil) y el sistema informático a utilizar. Finalmente, definimos la cadena de valor de la empresa y sus interrelaciones de valor.

\subsection{Matriz FODA de la empresa 2008}

A continuación presentamos nuestra matriz FODA elaborada a inicios del 2008, conformada por 4 Fortaleza, 4 Oportunidades, 4 Debilidades y 4 Amenazas.

Figura 3.1

Matriz FODA de la empresa 2008
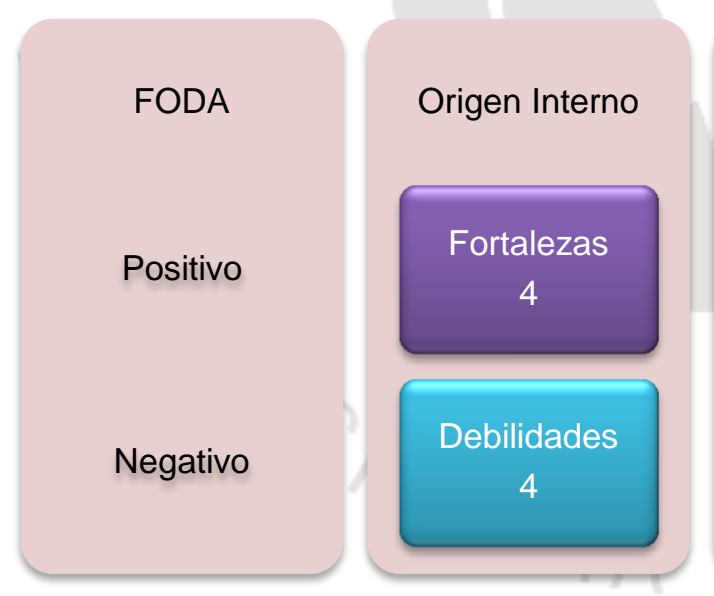

\section{Origen Externo}

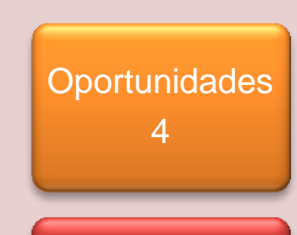

Amenazas

4

Elaboración: Propia

\subsubsection{Fortalezas}

- Estructura organizativa horizontal y reducida.

- Equipo de trabajo profesional multidisciplinario.

- Alianzas estratégicas con proveedores.

- Oferta inmobiliaria diferenciada. 


\subsubsection{Oportunidades}

- Alta demanda insatisfecha de los departamentos.

- Identificación de un nicho de mercado.

- Crecimiento demográfico de la ciudad de Lima.

- Alta rentabilidad del negocio inmobiliario.

\subsubsection{Debilidades}

- Escasa experiencia en el negocio.

- Limitado respaldo financiero.

- Cero historiales crediticios.

- Desarrollo del primer proyecto inmobiliario.

\subsubsection{Amenazas}

- Posible ingreso de competidores.

- Potencial incremento de los precios de los materiales.

- Virtual aumento de las tasas crediticias.

- Probable crecimiento del precio de los terrenos.

\subsection{La visión y la misión de la empresa}

\subsubsection{Visión}

"Buscamos ser reconocidos como una de las principales constructoras del país, que desarrolla proyectos inmobiliarios que satisfacen las necesidades de sus clientes, generando empleos que aseguran el bienestar y el compromiso de sus colaboradores, formando alianzas estratégicas con sus proveedores e incrementando la riqueza de sus accionistas."

\subsubsection{Misión}

Respecto a nuestra misión, la definimos tomando en cuenta cuatro interrogantes, qué hacemos, por qué lo hacemos, para qué lo hacemos y cómo lo hacemos. Ante la primera pregunta, qué hacemos, desarrollamos proyectos inmobiliarios; respecto a la segunda, 
por qué lo hacemos, porque queremos que las familias tengan un mejor lugar para vivir; en relación a la tercera, para qué lo hacemos, para que las familias mejoren su calidad de vida; finalmente, cómo lo hacemos, basándonos en sus necesidades, requerimientos y preferencias de viviendas. Una vez respondidas las preguntas, pudimos definir nuestra misión: "Estamos orientados a ofrecer una mejor calidad de vida a las familias, brindándoles un mejor lugar donde vivir, desarrollando proyectos inmobiliarios acorde a sus necesidades, requerimientos y preferencias."

\subsection{Políticas generales de la empresa}

Constructora La Torres se comprometió desde su constitución a ser reconocida como una empresa cuyas actividades se basarían en principios y valores empresariales acordes al dinamismo actual de los negocios. De esta manera aseguraríamos alcanzar nuestra visión empresarial ya que la práctica de estos principios y valores en nuestras actividades se daría a todo nivel y con todos los "stakeholders" o grupos de interés para nuestra empresa, es decir, conseguiríamos beneficiar a nuestros clientes, a nuestros colaboradores, a nuestros proveedores, a nuestros accionistas y en general a la comunidad. Nuestros principios y valores empresariales son:

- Tratar a los demás como nos gustaría ser tratados.

- Cumplir lo prometido y/o acordado.

Establecer vínculos de confianza y honestidad.

- Ser apasionados por lo que hacemos.

- Ser ordenados y disciplinados.

- Respetar las leyes, normas y reglamentos.

- Mejorar nuestros procesos continuamente.

\subsection{Objetivos estratégicos}

Para poder establecer nuestros objetivos estratégicos de largo plazo, nos apoyamos en el Servicio de Estudios Económicos del BBVA Banco Continental denominado "Situación Inmobiliaria Perú de Agosto de 2008. En dicho estudio determinaron que la concentración o participación de mercado de las empresas constructoras era baja a fines del año 2007, ya que ninguna de las 400 empresas dedicadas a la construcción de proyectos inmobiliarios de viviendas representaba más del $10 \%$ de las ventas. Así 
mismo, se estableció que las empresas promotoras y constructoras obtuvieron rentabilidades sobre sus patrimonios de más del 20\% durante los años 2006 y 2007.

Tomando como referencia dicha información, decidimos establecer cuatro objetivos estratégicos de largo plazo:

- Obtener una participación de mercado del $10 \%$ en un periodo de cinco años.

- Conseguir una rentabilidad sobre nuestro patrimonio (ROE) de $20 \%$ y una rentabilidad sobre nuestro aporte de $25 \%$, durante el primer año.

- Incrementar nuestra rentabilidad en 5\% anualmente durante los siguientes cinco años, desarrollando un proyecto inmobiliario de viviendas anualmente.

- Estructurar el financiamiento de los proyectos con un $20 \%$ de aporte propio y un $10 \%$ de financiamiento bancario como máximo, y un $70 \%$ como mínimo de aporte de los clientes (cuotas iniciales y créditos hipotecarios).

\subsection{Estrategias a nivel corporativo y de negocio}

Para poder establecer o formular nuestras estrategias a nivel corporativo y de negocio, realizamos un análisis de la competencia empleando el modelo de las cinco fuerzas de Michael Porter. Respecto a la rivalidad entre las empresa competidoras pudimos afirmar que era alta por la gran cantidad de empresas constructoras e inmobiliarias presentes en la industria (más de 400 a fines del 2007) y por ser una industria muy atractiva por su alta rentabilidad (20\%). Por otro lado, pese a la gran cantidad de potenciales clientes o consumidores, el poder de negociación de los mismos no era alto, ya que la oferta inmobiliaria era muy inferior a la demanda. De acuerdo a CAPECO, a fines del año 2007 la demanda efectiva de hogares ascendía a 296,921 mientras que la oferta inmediata de viviendas llegaba a 13,902. En relación al poder de negociación de los proveedores, pudimos determinar que era alto, porque a pesar que entre ellos existe una gran competencia, conforman un mercado muy consolidado ofreciendo servicios, productos y precios muy similares entre ellos. Son pocas las empresas que fabrican y comercializan los principales materiales de construcción, tales como el cemento (Cementos Lima, Cementos Pacasmayo, Cementos Yura, Cementos Sol), el acero (Corporación Aceros Arequipa y Empresa Siderúrgica del Perú) y el hormigón (Unicon, Supermix, Mixercon, Firth). Respecto a la entrada potencial de nuevos competidores, ésta era muy factible por las razones comentadas anteriormente, es decir, al analizar el 
sector se determinó que era muy atractivo para los inversionistas, por dos razones fundamentales, la alta rentabilidad y la alta demanda insatisfecha de viviendas. Finalmente, en cuanto al desarrollo potencial de productos sustitutos, pudimos afirmar que era escaso ya que éstos podían ser representados por las casas y de acuerdo al estudio del mercado inmobiliario de CAPECO, las casas representaban menos del $2 \%$ del total de la oferta de viviendas en Lima Metropolitana (para el primer semestre del año 2007 se ofertaban 268 casas, que sumaban 49.087 metros cuadrados; por su lado se vendían 14.149 departamentos, que conformaban 1.309.139 metros cuadrados).

Figura 3.2

Diagrama de las 5 fuerzas de Michael Porter 2008

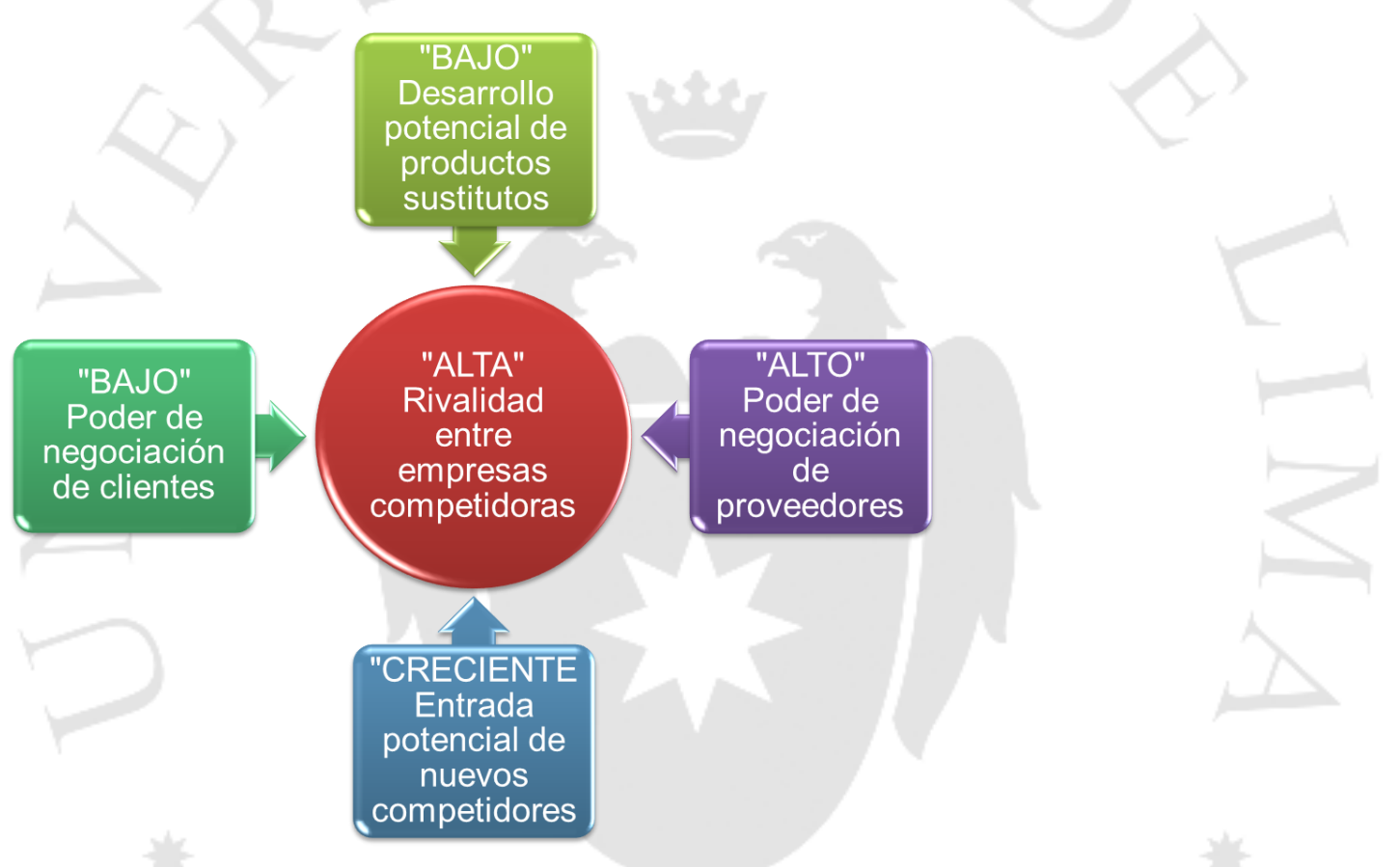

Elaboración: Propia.

En conclusión, pudimos aseverar que la intensidad de la competencia entre las empresas de la industria era alta, básicamente por tres de las cinco fuerzas que Michael Porter considera en su modelo: la alta rivalidad entre las empresas competidoras, el alto poder de negociación de los proveedores y la creciente entrada de nuevos competidores. Basados en este análisis, nuestra empresa determinó seguir a nivel corporativo y de negocio, dos claras estrategias, una estrategia intensiva de penetración en el mercado y una estrategia genérica de diferenciación, enfocada en un segmento del mercado. Ambas estrategias se complementaron y se justificaron al encontrar la oportunidad de cubrir parte de la gran demanda insatisfecha con una oferta diferenciada y poder obtener una conveniente participación del mercado constructivo e inmobiliario. 


\subsection{Estructura organizacional}

La estructura organizacional fue planteada de manera horizontal y reducida, con la finalidad de agilizar el proceso de toma de decisiones y reducir significativamente los costos laborales. La organización estaba conformada por una Gerencia General, una Jefatura Comercial, una Jefatura de Operaciones y una Jefatura Administrativa.

Figura 3.3

Organigrama de la empresa

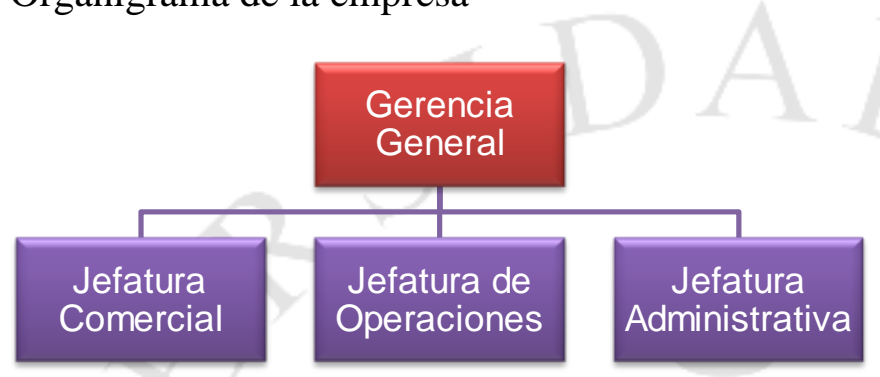

Elaboración: Propia.

\subsection{Funciones $\mathbf{y}$ actividades de las áreas principales}

Como se indicó en el organigrama, se planteó una estructura horizontal y reducida, conformada por una Gerencia General y tres jefaturas, que a continuación describiremos.

\subsubsection{Gerencia General}

Tal como lo indica la minuta de constitución de la empresa, la Gerencia General se encargaría de administrar la sociedad constituida, ejecutando todas las disposiciones adoptadas por la Junta General de Accionistas y todo acto y/o contrato correspondiente al objeto de la sociedad. En ese sentido, la Gerencia General tiene cinco diferentes facultades, administrativas, laborales, contractuales, bancarias y facultades de representación.

Dentro de las principales facultades administrativas podemos mencionar:

- Ejecutar los acuerdos de la Junta General de Accionistas;

- Suscribir los estados financieros; todo tipo de documentos, minutas y escrituras públicas, incluidas las de Constituciones de Sociedades, así como cualquier otro documento; 
- Ordenar la realización de auditorías a nivel nacional y regional, balances o la ejecución de cualquier otra medida de control contable, administrativa, destinada a conocer la situación de la empresa;

- Otorgar recibos, facturas o cancelaciones; solicitar, adquirir, transferir, dar y tomar en arrendamiento a nombre de la sociedad, registro de patentes, marcas, nombres comerciales y/o concesiones y celebrar cualquier tipo de contrato referente a la propiedad industrial o intelectual;

- Representar a la sociedad ante las personas jurídicas en las que sea socia, asociada o accionista; entre otras.

Respecto a las principales facultades laborales podemos señalar:

- Celebrar contratos de trabajo bajo cualquier modalidad sea a tiempo determinado o indeterminado;

- Nombrar a los trabajadores de la empresa funcionarios a nivel nacional o internacional; amonestar, suspender y separar a los trabajadores; aceptar la renuncia de trabajadores; otorgar permisos sin límite de tiempo a los trabajadores; promover, trasladar o re categorizar a los trabajadores; otorgar gratificaciones y otro tipo de incentivo a los trabajadores;

- Emplear, contratar, suspender o despedir a los funcionarios, empleados y demás trabajadores de la sociedad, determinando sus obligaciones, horario de labores, vacaciones y en general, el régimen de trabajo, fijando sus remuneraciones y acordando sus gratificaciones.

En relación a las principales facultades contractuales podemos señalar:

- Negociar, celebrar, suscribir, modificar, rescindir, resolver y dar por concluidos los contratos de trabajo a plazo determinado e indeterminado; contratos preparatorias o contratos de compraventa definitiva o con reserva de propiedad; permuta, comodato o donación de bienes muebles o inmuebles, contratos de mutuo con o sin garantía hipotecaria o de cualquier otra índole; arrendamiento de bienes muebles e inmuebles; arrendamiento financiero y "lease back"; “joint venture"; "know how”; "factoring”; maquila; asociación en participación, comisión y gestión de negocios;

- Participar en constitución de sociedades, asociaciones o personas jurídicas de cualquier tipo; prestación de servicios en general, lo que incluye la locación 
de servicios, el contrato de obra, el mandato y el depósito; contrato de fianza simple y fianza solidaria; seguros; comisión mercantil, concesión privada y pública, construcción, publicidad, transportes, distribución; entre otras.

En relación a las facultades bancarias, podríamos mencionar:

- Abrir y cerrar todo tipo de cuentas y depósitos, sea en moneda nacional o extranjera, en cualquier entidad del sistema financiero nacional $o$ internacional; solicitar y acordar créditos en cuenta corriente u otra modalidad, avance o sobregiro y crédito documentario;

- Girar, endosar, aceptar, avalar y dar en garantía, letras, letras hipotecarias, pagarés, vales y en general cualquier documentación crediticia;

- Descontar, protestar y cobrar letras, letras hipotecarias, pagarés, vales y en general cualquier documentación crediticia;

- Girar, endosar, protestar, cobrar y dar en garantía cheques y cualquier otra orden de pago, pudiendo girar cheques en sobregiro;

- Solicitar la emisión de cartas de crédito o cartas fianza, avales u otros documentos de crédito, realizar pagos en garantía;

- Contratar pólizas de seguros y endosarlas; otorgar fianzas y prestar aval.

Finalmente, en relación a las facultades de representación, podemos mencionar:

- Representar a la sociedad ante todo tipo de instituciones públicas o privadas, autoridades administrativas y funcionarios judiciales, políticas, civiles, municipales, administrativas constitucionales, tributarios, de aduana, policiales y militares, con las facultades de presentar toda clase de recursos y reclamaciones y desistirse de ellos, ya sea en el Perú o el extranjero;

- Presentar toda clase de declaraciones, denuncias, renunciar derechos, cobrar o consignar dinero o en su caso, bienes;

- Solicitar permisos, patentes y las inscripciones de registros que sean necesarios en organismos públicos de cualquier clase;

- Participar en las licitaciones y/o concursos, ya sean públicos o privados, así como en los demás procesos de selección y/o contratación con empresas y entidades del estado peruano o de otro país;

- Representar a la sociedad ante las distintas autoridades, instancias del poder judicial, así como los procesos que se tramiten ante autoridad administrativa, 
laboral, civil, penal, la jurisdicción arbitral, policial y/o militar, bien sea como demandante o demandada, asumir la representación de la sociedad con las facultades suficientes para practicar los actos a que se refiere el código procesal civil y la ley general de arbitraje;

- Asumir la representación de la sociedad especialmente en procedimientos laborales ante el Ministerio de Trabajo y los Juzgados y Salas Especializadas de Trabajo en todas las divisiones e instancias; entre otras.

\subsubsection{Jefatura Comercial}

Esta jefatura fue considerada como primordial dentro de la organización ya que sería responsable de generar los ingresos económicos para la empresa, sin embargo, se encontraría al mismo nivel que las otras dos jefaturas. Dentro de sus principales funciones y responsabilidades podemos mencionar:

Diseñar la estrategia comercial que permitiría lograr alcanzar los objetivos del área, así como desarrollar el plan de marketing y ventas.

- Buscar, orientar y asesorar adecuadamente a los potenciales clientes, buscando su fidelización y recomendación. Evaluar a los potenciales clientes, estudiar sus necesidades y ofrecerles diferentes soluciones o alternativas a sus requerimientos, preferencias y/o necesidades.

Plantear y definir las estrategias de producto, precios, publicidad y promoción.

\subsubsection{Jefatura de Operaciones}

Esta jefatura cumpliría una función relevante para la empresa ya que velaría por la correcta ejecución de los proyectos a ser desarrollados. Dentro de sus principales funciones y responsabilidades podemos señalar:

- Desarrollar el presupuesto de compras y/o adquisiciones.

- Controlar permanentemente la calidad, cantidad y costos de los principales materiales de construcción.

- Buscar, negociar y contratar a los contratistas y sub contratistas de los diferentes proyectos a desarrollar. Supervisar, evaluar y controlar a los contratistas y subcontratistas, asegurando que cumplan lo acordado. 
- Analizar permanentemente la industria de la construcción, el mercado inmobiliario, la competencia y los precios de los materiales de construcción.

\subsubsection{Jefatura de Administración}

Esta jefatura representaría el área de soporte o apoyo a las demás jefaturas. Dentro de sus principales funciones y responsabilidades podemos indicar:

- Buscar, seleccionar, evaluar, contratar, capacitar, motivar y controlar al personal. Manejar la planilla/laboral, estableciendo las remuneraciones, gratificaciones y bonificaciones, así como los horarios de trabajo, vacaciones y obligaciones de los trabajadores.

- Velar por las buenas condiciones laborales, de seguridad y medio ambientales. Implementar y estandarizar las normas de seguridad, salud e higiene ocupacional y medio ambiente en los diferentes proyectos, capacitando permanentemente a los trabajadores.

- Llevar la contabilidad interna de la empresa, controlando y manteniendo actualizada la información de los estados financieros.

- Programar y realizar oportunamente los pagos de las diferentes obligaciones, a los trabajadores, proveedores, contratistas y al Estado. Realizar las diferentes gestiones ante las autoridades laborales, municipales y registrales. Manejar, actualizar y difundir los reglamentos administrativos, laborales, municipales, registrales, de edificación, de seguridad industrial, medio ambientales, entre otros.

- Gestionar el abastecimiento, buscando sinergias y alianzas estratégicas con los principales proveedores, negociando condiciones crediticias favorables para la empresa. Manejar el inventario de existencias de la empresa y de los proyectos, controlando los ingresos y las salidas de los materiales y gestionando el manejo de los residuos.

\subsection{Personal requerido, nivel de formación y perfil}

Para conducir la Gerencia General y las tres jefaturas que conformaban la organización, decidimos contratar un Gerente General, un Jefe Comercial, un Jefe de Operaciones y un Jefe de Administración. Así mismo, decidimos contar con un Asistente 
Administrativo y un Encargado de Seguridad, que integrarían el equipo administrativo. En los siguientes párrafos describiremos los puestos requeridos, detallando el perfil, el nivel de formación y las competencias necesarias para cada uno de ellos.

\subsubsection{Gerente General}

El Gerente General debía ser un profesional en Administración de Empresas, Ingeniería Industrial, Contabilidad o alguna carrera similar; con 5 años de experiencia en Gerencias, Jefaturas o cargos similares; con conocimientos de planeamiento estratégico, diseño de planes de negocio, finanzas y contabilidad, derecho laboral y recursos humanos, marketing y ventas; con las siguientes competencias: capacidad de resolución de problemas, capacidad de organización del trabajo, responsabilidad en el trabajo, capacidad de trabajar en equipo, actitud enfocada en el logro de objetivos; relación interpersonal, liderazgo, control, decisión, autonomía e integridad; con conocimientos de herramientas de Office a nivel avanzado.

\subsubsection{Jefe Comercial}

El Jefe Comercial debía ser un profesional en Administración de Empresas, Ingeniería Industrial, Economía o alguna carrera similar; con 5 años de experiencia en el área Comercial como mínimo y por lo menos 3 años de experiencia en venta de intangibles; con conocimientos en planeamiento estratégico, diseño de planes de negocio, administración, finanzas, marketing y publicidad; con las siguientes competencias: capacidad de resolución de problemas, capacidad de organización del trabajo, responsabilidad en el trabajo, capacidad de trabajar en equipo, actitud enfocada en el logro de objetivos, relación interpersonal, tolerancia al estrés, atención al cliente, decisión e integridad; con conocimientos de herramientas de Office a nivel avanzado.

\subsubsection{Jefe de Operaciones}

El Jefe de Operaciones debía ser un profesional en Ingeniería Civil con colegiatura vigente; con 5 años de experiencia en el sector de construcción; con experiencia demostrada en edificación de proyectos inmobiliarios, condominios, centros comerciales, etc.; con conocimientos en costos y presupuestos y en sistemas de gestión integrados; con experiencia en gestión de compras y gestión de almacén; con 
experiencia en supervisión y control de contratistas; con experiencia en gestión de seguridad, salud e higiene ocupacional y medio ambiente; con las siguientes competencias: capacidad de resolución de problemas, capacidad de organización del trabajo, responsabilidad en el trabajo, capacidad de trabajar en equipo, capacidad de iniciativa, creatividad, decisión e integridad ; con conocimientos de herramientas de Office, MS Proyect y software de diseño de estructuras a nivel avanzado.

\subsubsection{Jefe de Administración}

El Jefe de Administración debía ser un profesional en Administración de Empresas, Ingeniería Industrial, Contabilidad o alguna carrera similar; con 5 años de experiencia en el área de Administración como mínimo y por lo menos 3 años en posiciones similares en empresas de construcción, inmobiliarias, de infraestructura, consorcios o empresas contratistas; con conocimientos de Contabilidad y de Sistemas de Control; con experiencia en gestión de compras y gestión de almacén; con experiencia en gestión de recursos humanos; con experiencia en gestión de seguridad, salud e higiene ocupacional y medio ambiente; con las siguientes competencias: capacidad de resolución de problemas, capacidad de organización del trabajo, responsabilidad en el trabajo, capacidad de trabajar en equipo, relación interpersonal, liderazgo e integridad; con conocimientos de herramientas de Office a nivel avanzado.

\subsubsection{Asistente administrativo}

El Asistente Administrativo debía ser un técnico en Administración de Empresas, Contabilidad o alguna carrera similar; con 3 años de experiencia en el área de Administración como mínimo; con conocimientos de Contabilidad; con experiencia en gestión de compras y gestión de almacén; con experiencia en gestión de recursos humanos; con las siguientes competencias: responsabilidad en el trabajo, capacidad de trabajar en equipo, relación interpersonal e integridad; con conocimientos de herramientas de Office a nivel intermedio.

\subsubsection{Encargado de seguridad}

El encargado de Seguridad debía ser un profesional o técnico en Ingeniería de Seguridad, Higiene Industrial y Prevención de Riesgos Ocupacionales; con 3 años de 
experiencia como mínimo en el área de seguridad industrial, higiene ocupacional y medio ambiente en empresas de construcción, inmobiliarias y/o almacenes; con conocimiento de leyes, reglamentos, estatutos, políticas, normas y procedimientos relativos al área de seguridad industrial, protección ambiental e higiene ocupacional; con conocimientos de métodos de prevención y registros de accidentes, inspecciones, etc.; con las siguientes competencias: capacidad de resolución de problemas, responsabilidad en el trabajo, capacidad de trabajar en equipo, relación interpersonal e integridad; con conocimientos de herramientas de Office a nivel intermedio.

\subsection{Sistema informático y sus alcances}

Respecto al sistema informático que decidimos implementar, consideramos necesario la utilización de ordenadores portátiles que operarían bajo el sistema operativo Microsoft Windows, contando con las principales herramientas de Microsoft Office (Word, Excel, Power Point, etc.) y software de diseño de estructuras como Autocad, entre otros. Así mismo, se contaría con una impresora multifuncional (que imprima, escanee y fotocopie) para documentos hasta de tamaño A4 (210 x $297 \mathrm{~mm})$ y una impresora profesional para planos hasta de tamaño A1 (594 x $841 \mathrm{~mm}$ ), ambas con acceso inalámbrico para que todos los usuarios puedan acceder. El servicio de Internet sería proporcionado por algún operador local, como Movistar o Claro, requiriendo una velocidad mínima de $10 \mathrm{Mbps}$.

\subsection{Cadena de valor de la empresa y sus interrelaciones de valor}

Como se mencionó en párrafos anteriores, la empresa se dividía en una Gerencia General y tres jefaturas, cada una de las cuales se encargaría de realizar actividades primarias o de soporte.

La Gerencia General y la Jefatura de Administración se encargarían de las actividades de soporte, es decir, de la infraestructura de la empresa, de la gestión de recursos humanos, del desarrollo tecnológico y del abastecimiento. Por su lado, la Jefatura de Operaciones, se encargaría de las actividades primarias conformadas por la logística interna, las operaciones y la logística externa. En cuanto a la Jefatura Comercial, se encargaría de las actividades primarias restantes, es decir, del marketing y ventas, y de los servicios de postventa. Ver figura 3.4. 
Figura 3.4

Cadena de valor de la empresa

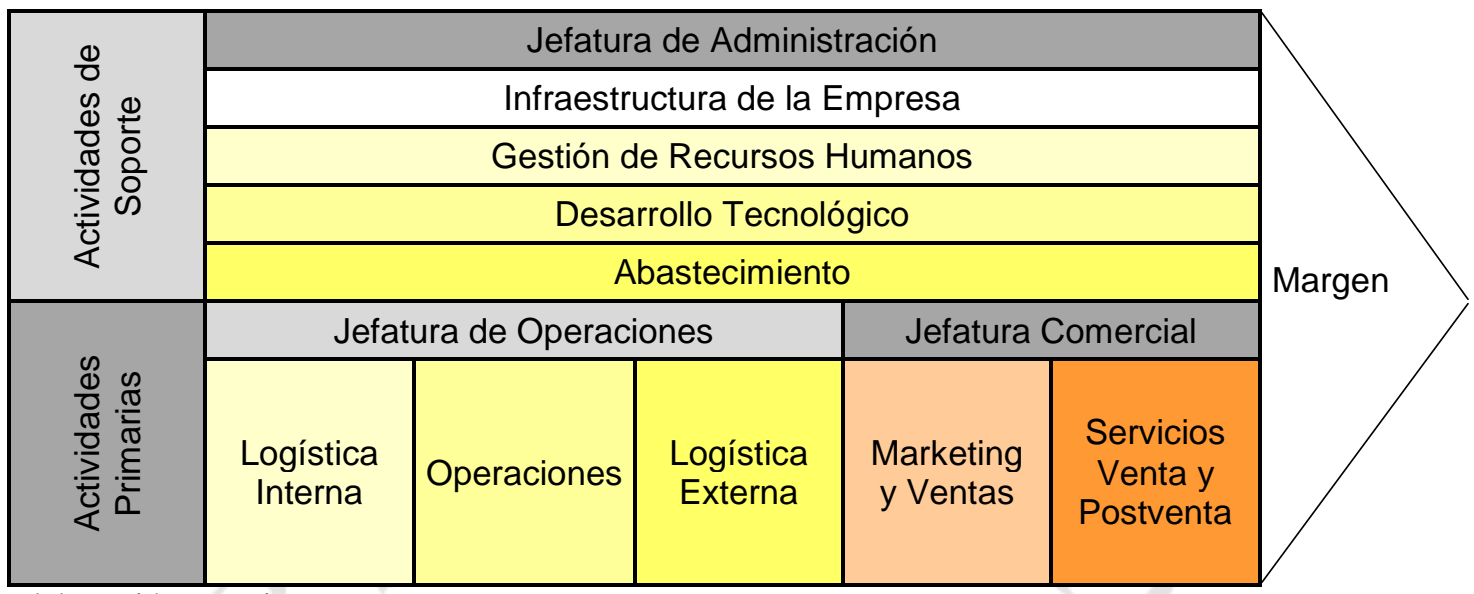

Elaboración: Propia

\subsubsection{Actividades primarias}

Respecto a las actividades primarias, éstas serían ejecutadas por la Jefatura Comercial y la Jefatura de Operaciones:

- Marketing y Ventas: diseñar la estrategia comercial que permitiría lograr alcanzar los objetivos del área, así como desarrollar el plan de marketing y ventas; plantear y definir las estrategias de producto, precios, publicidad y promoción.

- Servicio de Venta y Postventa: buscar, orientar y asesorar adecuadamente a los potenciales clientes, buscando su fidelización y recomendación; evaluar a los potenciales clientes, estudiar sus necesidades y ofrecerles diferentes soluciones o alternativas a sus requerimientos, preferencias y/o necesidades.

- Logística Interna: desarrollar el presupuesto de compras y/o adquisiciones; buscar, negociar y contratar a los contratistas y sub contratistas de los diferentes proyectos a desarrollar.

- Operaciones: controlar permanentemente la calidad, cantidad y costos de los principales materiales de construcción; analizar permanentemente la industria de la construcción, el mercado inmobiliario, la competencia y los precios de los materiales de construcción.

- Logística Externa: supervisar, evaluar y controlar a los contratistas y subcontratistas, asegurando que cumplan lo acordado. 


\subsubsection{Actividades de soporte}

Las actividades de soporte tal como lo hemos manifestado, las desarrollarían la Jefatura de Administración, ordenándolas de la siguiente manera:

- Infraestructura de la Empresa: llevar la contabilidad interna de la empresa, controlando y manteniendo actualizada la información de los estados financieros; programar y realizar oportunamente los pagos de las diferentes obligaciones, a los trabajadores, proveedores, contratistas y al Estado; manejar, actualizar y difundir los reglamentos administrativos, laborales, municipales, registrales, de edificación, de seguridad industrial, medio ambientales, entre otros; realizar las diferentes gestiones ante las autoridades laborales, municipales y registrales.

- Gestión de Recursos Humanos: buscar, seleccionar, evaluar, contratar, capacitar, motivar y controlar al personal; manejar la planilla laboral, estableciendo las remuneraciones, gratificaciones y bonificaciones, así como los horarios de trabajo, vacaciones y obligaciones de los trabajadores; velar por las buenas condiciones laborales, de seguridad y medio ambientales; implementar y estandarizar las normas de seguridad, salud e higiene ocupacional y medio ambiente en los diferentes proyectos, capacitando permanentemente a los trabajadores.

- Desarrollo Tecnológico: implementar los sistemas informáticos en la organización.

- Abastecimiento: gestionar el abastecimiento, buscando sinergias y alianzas estratégicas con los principales proveedores, negociando condiciones crediticias favorables para la empresa; manejar el inventario de existencias de la empresa y de los proyectos, controlando los ingresos y las salidas de los materiales y gestionando el manejo de los residuos. 


\section{CAPÍTULO IV: PLAN DE MARKETING Y VENTAS}

En el presente capítulo nos enfocamos en nuestro producto, es decir, en el proyecto inmobiliario multifamiliar Torre Barrón. Establecemos qué necesidades satisface nuestro producto y cómo lo hace. Determinamos los objetivos de marketing y desarrollamos las diferentes estrategias para lograrlos (estrategias del producto, de precios, de publicidad, de promoción y de ingreso al mercado). Así mismo, determinamos la participación del mercado, la proyección de ventas, las estrategias y las políticas de ventas para alcanzarlas.

\subsection{Qué necesidades satisface el producto y cómo las satisface}

Tomando como referencia la teoría psicológica de la pirámide o jerarquía de las necesidades humanas que propuso Abraham Maslow, identificamos que las necesidades que satisfacía nuestro producto eran la necesidad de seguridad de recursos (como una casa o departamento) y la necesidad de protección (como una vivienda). En el entorno socio cultural en el que desarrollamos nuestros productos entendemos que estas necesidades se transformaron en deseos particulares, que pretendimos satisfacer, estudiando las características de mayor valor para los potenciales clientes. Es por ello que las encuestas desarrolladas determinarían las características que debían tener las viviendas que construiríamos para que satisficieran sus deseos, expectativas y preferencias.

\section{Figura 4.1}

Pirámide de Abraham Maslow

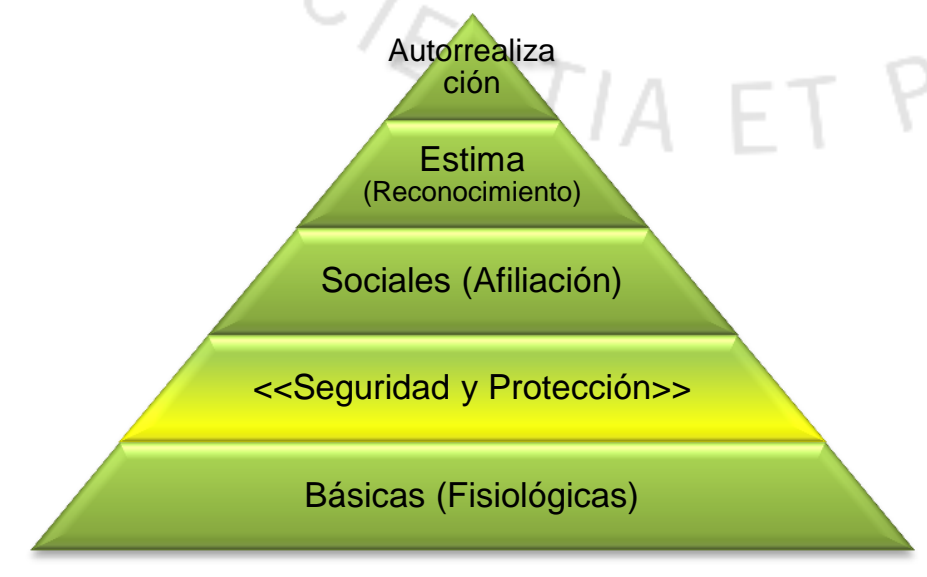

Elaboración: Propia. 


\subsection{Objetivos de marketing}

Los objetivos de marketing debían estar alineados con los objetivos de la empresa, obtener una participación de mercado del $10 \%$ en un periodo de cinco años, conseguir una rentabilidad sobre el patrimonio de $20 \%$ y sobre el aporte de $25 \%$, durante el primer año e incrementarla en 5\% anualmente durante los siguientes cinco años, desarrollar un proyecto inmobiliario de viviendas anualmente y cumplir con la estructura de financiamiento planteada. Estos objetivos empresariales definirían los objetivos de marketing planteados por la Jefatura Comercial: vender como mínimo el 50\% de los departamentos en la etapa de pre venta, es decir, antes del inicio de la ejecución del proyecto y el $100 \%$ antes de su término, con lo que evitaríamos recurrir al financiamiento bancario y el proyecto se desarrollaría en un $80 \%$ con aporte de terceros (clientes) a cero costo y en $20 \%$ con nuestro aporte de capital.

\subsection{Estrategia del producto}

Nuestro producto fue analizado en tres niveles, como producto fundamental, como producto real y como producto aumentado.

\section{Figura 4.2}

Niveles del producto

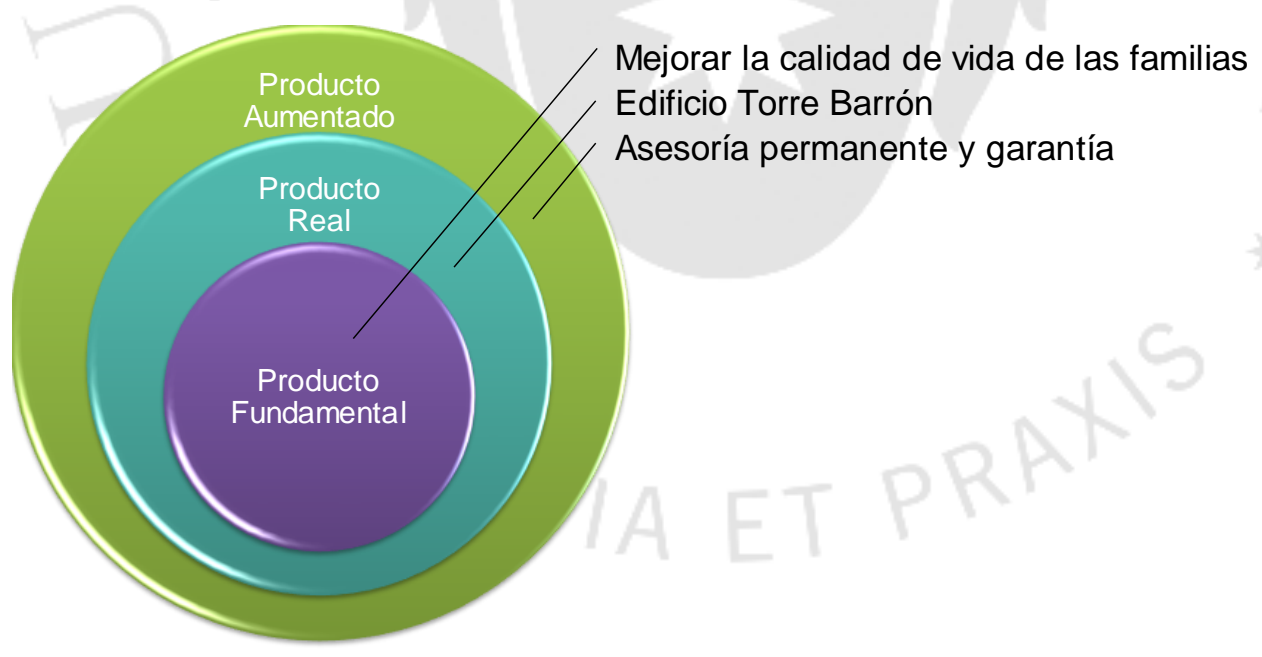

Elaboración: Propia.

Como producto fundamental establecimos que nuestra empresa ofrecería una "mejor calidad de vida a las familias", brindándoles un mejor lugar donde vivir, desarrollando proyectos inmobiliarios acorde a sus necesidades, requerimientos y preferencias, tal como lo estipulaba nuestra misión. 
Como producto real, desarrollamos un proyecto inmobiliario que consistió en la construcción, promoción y venta de un edificio multifamiliar denominado "Torre Barrón”, compuesto por un bloque, con una altura de siete pisos, con un total de doce departamentos, distribuidos a razón de dos departamentos por piso, a partir del segundo nivel, con áreas que oscilaban entre los 90 y $127 \mathrm{~m} 2$ y doce estacionamientos en el primer nivel, tal como se muestra en la figura 4.3.

\section{Figura 4.3}

Imagen del edificio multifamiliar "Torre Barrón"

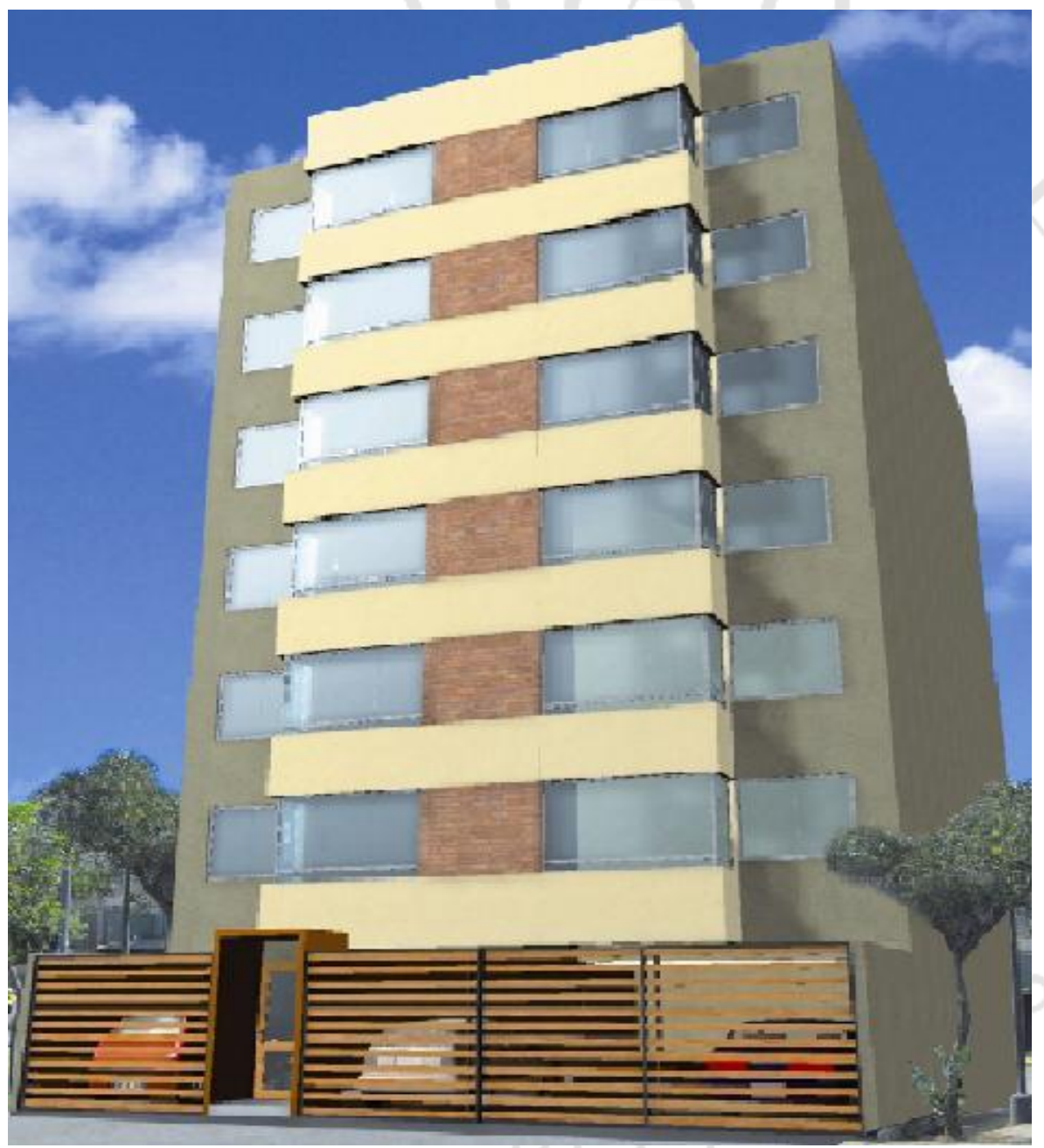

Elaboración: Propia.

El inmueble se edificó sobre un terreno de $330 \mathrm{~m} 2$, de propiedad de nuestra empresa, ubicado en el Jr. Comandante Enrique Barrón № 1113, Urbanización de Santa Beatriz, del Distrito de Cercado de Lima, Provincia y Departamento de Lima. En la zona urbana donde se ubicaba existían los servicios de agua potable, desagüe, electricidad, entre otros, por lo que se esperaba contar con una factibilidad positiva de los servicios correspondientes. Ver figura 4.4. 
Figura 4.4

Ubicación del edificio multifamiliar "Torre Barrón"

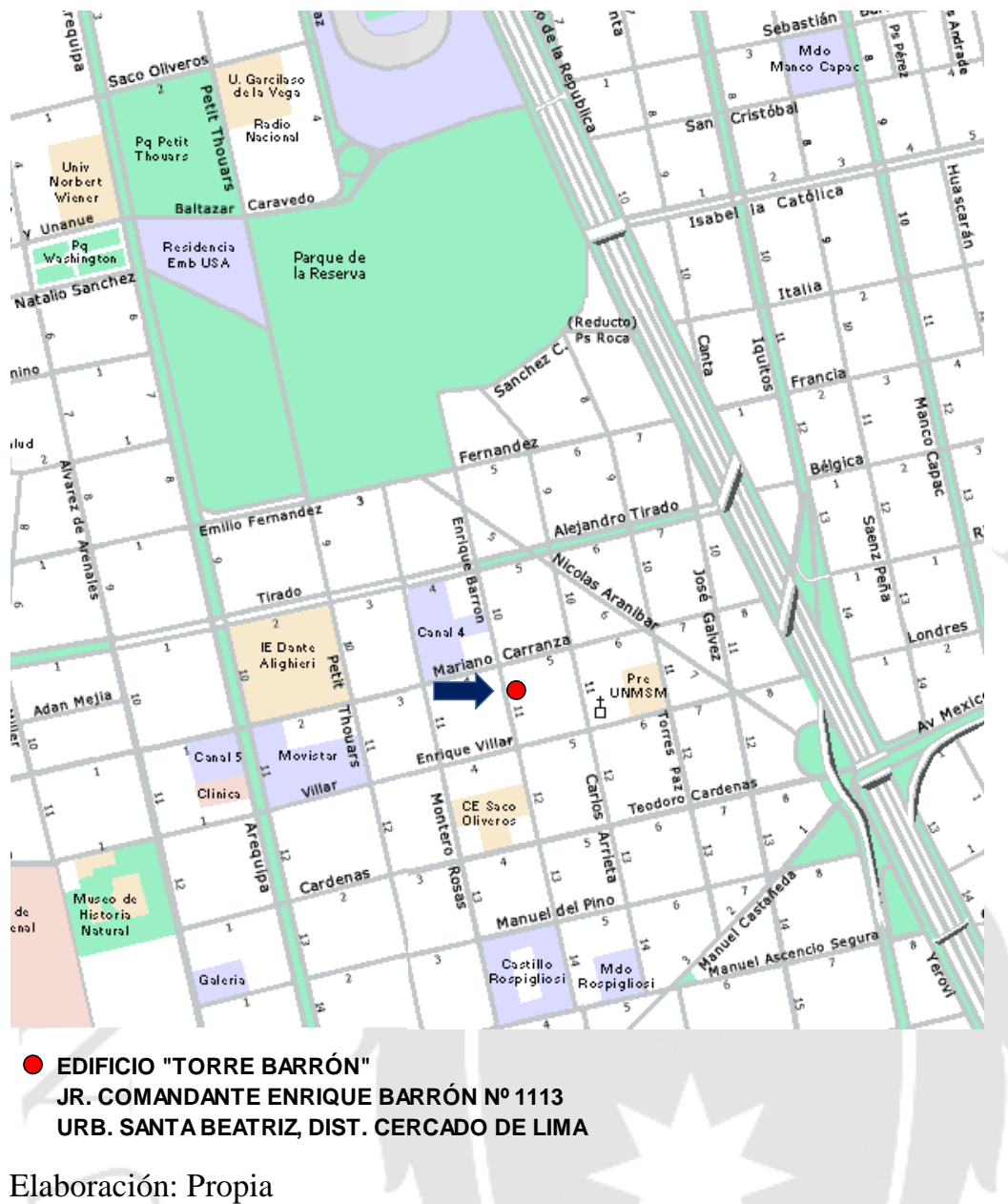

En concordancia a la zonificación y al Certificado de Parámetros Urbanísticos y Edificatorios $\mathrm{N}^{\circ}$ 41-2006 otorgado por la Municipalidad Metropolitana de Lima, debimos considerar y ajustarnos al tipo de zonificación que era Residencial de Alta Densidad (RDA), al porcentaje mínimo de área libre del 40\%, a la altura máxima de edificación que era de siete (7) pisos y al índice de espacios de estacionamientos que era de 1 unidad por cada vivienda. Los departamentos estaban compuestos de salacomedor, 3 dormitorios, 2 baños completos, uno interno al dormitorio principal y cocina-lavandería. Todos los departamentos fueron del tipo flat, contaban con baño de servicio y seis de los doce departamentos consideran además con cuarto de servicio. Tenían un diseño funcional que optimizaba el área que ocupaban, con ambientes iluminados y ventilados, con salas - comedor que se abrían al retiro frontal y dormitorio principal que abría hacia el retiro posterior y zonas de servicios nucleados, con lo cual se optimizaban también las instalaciones, tal como se describe en la tabla 4.1 y se muestra en la figura 4.5. 


\section{Tabla 4.1}

Relación de departamentos y estacionamientos del edificio "Torre Barrón”

\begin{tabular}{|c|c|c|}
\hline Unidad Inmobiliaria & Área (m2) & Características diferenciadoras \\
\hline Departamento 201 & 126.53 & Baño y cuarto de servicio, patio y terraza \\
\hline Departamento 202 & 122.44 & Baño de servicio, patio y terraza \\
\hline Departamento 301 & 98.00 & Baño y cuarto de servicio \\
\hline Departamento 302 & 92.20 & Baño de servicio \\
\hline Departamento 401 & 98.00 & Baño y cuarto de servicio \\
\hline Departamento 402 & 92.20 & Baño de servicio \\
\hline Departamento 501 & 98.00 & Baño y cuarto de servicio \\
\hline Departamento 502 & 92.20 & Baño de servicio \\
\hline Departamento 601 & 98.00 & Baño y cuarto de servicio \\
\hline Departamento 602 & 92.20 & Baño de servicio \\
\hline Departamento 701 & 94.00 & Baño y cuarto de servicio \\
\hline Departamento 702 & 90.20 & Baño de servicio \\
\hline Estacionamiento $1 \mathrm{~A}$ & 12.00 & Semitechado \\
\hline Estacionamiento $1 \mathrm{~B}$ & 15.17 & Techado con espacio para depósito \\
\hline Estacionamiento $2 \mathrm{~A}$ & 12.00 & Semitechado \\
\hline Estacionamiento 2B & 14.60 & Techado con espacio para depósito \\
\hline Estacionamiento 3 & 12.00 & Semitechado \\
\hline Estacionamiento 4 & 12.45 & Techado \\
\hline Estacionamiento 5 & 12.46 & Techado \\
\hline Estacionamiento 6 & 16.48 & Techado con espacio para depósito \\
\hline Estacionamiento 7 & 16.49 & Semitechado con espacio para depósito \\
\hline Estacionamiento 8 & 12.31 & Semitechado \\
\hline Estacionamiento 9 & 12.31 & Semitechado \\
\hline Estacionamiento 10 & 16.49 & Semitechado con espacio para depósito \\
\hline
\end{tabular}

Elaboración: Propia.

Considerando que el proyecto se encontraba en una región de alto riesgo sísmico, fue necesario que el sistema constructivo sea seguro y antisísmico, por lo que se eligió el sistema de encofrados con tableros de triplay fenólico en combinación con algunos pórticos, mientras que la tabiquería estaría compuesta por bloques del tipo P-10 del sistema "LACASA". Las redes tanto de agua como desagüe fueron empotradas, sin embargo se previó ductos para alojar las tuberías que recorrían en forma vertical, así como para alojar los medidores de agua para cada departamento. Los alimentadores de electricidad hacia los departamentos se condujeron a través de ductos diseñados especialmente para estos, así como los correspondientes a teléfonos exteriores, comunicadores y TV cable. Cada departamento contó con un medidor de energía 
eléctrica, ubicado en un banco de medidores al exterior del edificio. La edificación consideró un ascensor con cabina estándar para 6 personas de origen importado, una escalera de emergencia y un sistema contra incendios.

Figura 4.5

Diseño arquitectónico de los departamentos del edificio “Torre Barrón”

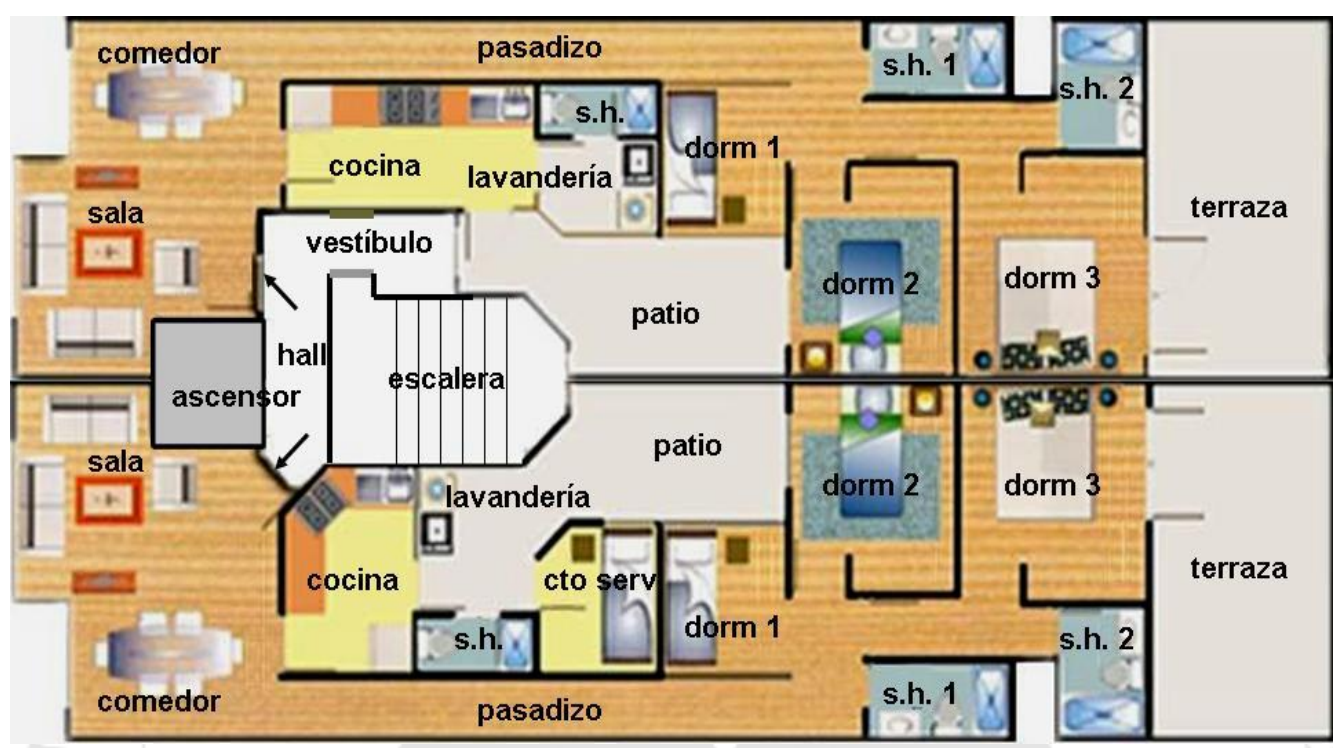

Elaboración: Propia.

Finalmente, como producto aumentado establecimos dos características complementarias y diferenciadoras, el servicio de asesoría permanente a los clientes y la garantía por el inmueble adquirido. El servicio de asesoría permanente a los clientes consistía en: asesorar comercialmente al cliente, ofreciéndole una vivienda que se ajustara a sus necesidades, preferencias y capacidad de adquisición y apalancamiento; asesorar legalmente al cliente, elaborando y revisando conjuntamente el contrato de compra venta; y asesorar financieramente al cliente, para la obtención de un crédito hipotecario con las diferentes entidades bancarias. Respecto a la garantía por el inmueble adquirido, nos encargamos de comunicarlo y difundirlo a nuestros clientes, para generar una mayor confianza en nuestra propuesta. Para ello nos basamos en el Artículo $\mathrm{N}^{\circ} 54$ del Reglamento Nacional de Edificaciones que estipula lo siguiente: "...el constructor y el profesional responsable de la obra responderán frente al cliente, en el caso de que sean objeto de controversia o desacuerdo por daños materiales ocasionados en el producto de la edificación dentro de los cinco años", plazo que de acuerdo al reglamento fue contado desde la fecha de recepción o finalización de obra por la Municipalidad Metropolitana de Lima. Cabe mencionar que el diseño de nuestro proyecto se basó en las encuestas desarrolladas con la finalidad de lograr satisfacer las 
necesidades y preferencias de nuestros clientes. En el Anexo 39 presentamos un comparativo entre las preferencias de los clientes y las características reales del edificio Torre Barrón.

\subsection{Estrategia de precios}

Los precios de los departamentos del proyecto inmobiliario Edificio Torre Barrón se determinaron considerando tanto factores externos como internos. Respecto a los factores externos, tuvimos que analizar el mercado, la demanda y la competencia. De acuerdo a Philip Kotler y Gary Armstrong, el tipo de mercado en el que participábamos era bajo la competencia de monopolio, ya que el mercado inmobiliario estaba compuesto de muchos compradores (demanda insatisfecha de 283,019 hogares en Lima Metropolitana) y muchos vendedores (más de 400 constructoras e inmobiliarias) que comerciaban con una gama de precios. En este tipo de mercados se desarrollan ofertas diferenciadas para diferentes segmentos de clientes o consumidores. De acuerdo a nuestra estrategia genérica de diferenciación, enfocada en un segmento del mercado, el Edificio Torre Barrón representaba un producto diferente a lo ofrecido hasta ese momento en la Urbanización de Santa Beatriz. Mientras que las áreas de nuestros departamentos eran mayores, los precios por metro cuadrado eran inferiores, lo cual concordaba con nuestra estrategia de determinación de precio de penetración de mercado, para atraer un mayor número de compradores y lograr una participación de mercado mayor.

Tabla 4.2

Características de la competencia y del edificio "Torre Barrón"

\begin{tabular}{|lrrr||}
\hline Características / Proyectos & $\begin{array}{r}\text { Lima } \\
\text { Kensetsu }\end{array}$ & $\begin{array}{r}\text { Yufra } \\
\text { Constructores }\end{array}$ & $\begin{array}{r}\text { Edificio } \\
\text { Torre Barrón }\end{array}$ \\
\hline Cantidad de pisos & 8 & 7 & 7 \\
Cantidad de departamentos & 32 & 18 & 12 \\
Área mínima de departamento & $73 \mathrm{~m} 2$ & $60 \mathrm{~m} 2$ & $90.20 \mathrm{~m} 2$ \\
Área máxima de departamento & $95 \mathrm{~m} 2$ & $94 \mathrm{~m} 2$ & $126.53 \mathrm{~m} 2$ \\
Precio mínimo de departamento & $\$ 51,000.00$ & $\$ 42,000.00$ & $\$ 62,333.33$ \\
Precio máximo de departamento & $\$ 68,000.00$ & $\$ 59,000.00$ & $\$ 74,333.33$ \\
Precio mínimo por m2 & $\$ 698.63$ & $\$ 627.66$ & $\$ 587.48$ \\
Precio máximo por m2 & $\$ 715.79$ & $\$ 700.00$ & $\$ 691.06$ \\
\hline
\end{tabular}

Elaboración: Propia. 
Basados en esta información establecimos un precio promedio de USD 691.00 por metro cuadrado, lo que representaba un valor inferior al precio de la competencia. Respecto a nuestra estrategia de ajuste de precios, otorgamos un descuento máximo del $5 \%$ sobre el precio base de los departamentos, en la etapa de pre venta y/o si la compra se realizaba al contado. En la Tabla 4.3 presentamos los precios de los departamentos y estacionamientos (en Nuevos Soles y en Dólares Americanos).

Tabla 4.3

Precios de departamentos y estacionamientos del edificio "Torre Barrón"

\begin{tabular}{|c|c|c|c|}
\hline Unidad Inmobiliaria & Área (m2) & Precio en NS/. & Precio en USD \\
\hline Departamento 201 & 126.53 & $223,000.00$ & $74,333.33$ \\
\hline Departamento 202 & 122.44 & $212,000.00$ & $70,666.67$ \\
\hline Departamento 301 & 98.00 & $203,000.00$ & $67,666.67$ \\
\hline Departamento 302 & 92.20 & $191,000.00$ & $63,666.67$ \\
\hline Departamento 401 & 98.00 & $203,000.00$ & $67,666.67$ \\
\hline Departamento 402 & 92.20 & $191,000.00$ & $63,666.67$ \\
\hline Departamento 501 & 98.00 & $203,000.00$ & $67,666.67$ \\
\hline Departamento 502 & 92.20 & $191,000.00$ & $63,666.67$ \\
\hline Departamento 601 & 98.00 & $203,000.00$ & $67,666.67$ \\
\hline Departamento 602 & 92.20 & $191,000.00$ & $63,666.67$ \\
\hline Departamento 701 & 94.00 & $195,000.00$ & $65,000.00$ \\
\hline Departamento 702 & 90.20 & $187,000.00$ & $62,333.33$ \\
\hline Estacionamiento $1 \mathrm{~A}$ & 12.00 & $10,000.00$ & $3,333.33$ \\
\hline Estacionamiento 1B & 15.17 & $15,000.00$ & $5,000.00$ \\
\hline Estacionamiento 2A & 12.00 & $10,000.00$ & $3,333.33$ \\
\hline Estacionamiento 2B & 14.60 & $15,000.00$ & $5,000.00$ \\
\hline Estacionamiento 3 & 12.00 & $10,000.00$ & $3,333.33$ \\
\hline Estacionamiento 4 & 12.45 & $10,000.00$ & $3,333.33$ \\
\hline Estacionamiento 5 & 12.46 & $10,000.00$ & $3,333.33$ \\
\hline Estacionamiento 6 & 16.48 & $15,000.00$ & $5,000.00$ \\
\hline Estacionamiento 7 & 16.49 & $15,000.00$ & $5,000.00$ \\
\hline Estacionamiento 8 & 12.31 & $10,000.00$ & $3,333.33$ \\
\hline Estacionamiento 9 & 12.31 & $10,000.00$ & $3,333.33$ \\
\hline Estacionamiento 10 & 16.49 & $15,000.00$ & $5,000.00$ \\
\hline
\end{tabular}

Elaboración: Propia. 


\subsection{Estrategia de publicidad}

Nuestra estrategia de publicidad buscaba conseguir dos objetivos primordiales, informar y persuadir a nuestro público objetivo en dos etapas del proyecto. Inicialmente decidimos informar a nuestro mercado sobre las principales características del proyecto inmobiliario, tales como el nombre, su ubicación, la información de contacto, una descripción detallada del mismo, el diseño de los departamentos y los requisitos para la obtención de un crédito hipotecario. Buscábamos diferenciarnos de la competencia resaltando los aspectos más importantes, como la imagen futura del edificio, el diseño funcional de los departamentos, la poca cantidad de viviendas y las áreas de los departamentos que respecto a la oferta de la zona, eran mayores.

Para poder informar adecuadamente a los clientes, empleamos diferentes medios de comunicación, tales como la distribución de volantes dípticos, la instalación de carteles de obra, publicaciones en los principales diarios impresos, envío de correos electrónicos, creación de una cuenta de Facebook, entre otros.

Respecto a los volantes dípticos, se imprimieron 10,000 unidades, que contenían información escrita y gráfica del proyecto, tal como se muestra en el anexo 40. Dicho material gráfico se distribuyó en las diferentes empresas, colegios, institutos, academias, entidades financieras y vecinos en general, próximos al proyecto inmobiliario, ubicados en los distritos de Cercado de Lima (Santa Beatriz), Jesús María y Lince, tal como se señala en los anexos 41 y 42.

Así mismo, se exhibieron diferentes carteles de obra en el frontis del proyecto, cuyo objetivo era que las personas interesadas puedan ubicarlo con facilidad, acercarse e informarse del mismo, tal como se presenta en los anexos 43 y 44. Con la instalación de los dos últimos carteles, buscábamos conseguir nuestro siguiente objetivo, es decir, persuadir al cliente de que debía adquirir nuestros departamentos. Transmitiendo un mensaje de escases o pérdida de oportunidad, logramos que la decisión de compra de los potenciales clientes se acelere y se concrete. Ver anexos 45 y 46.

Adicionalmente, se realizaron publicaciones en el diario de mayor circulación y tiraje a nacional durante seis meses consecutivos, Diario El Comercio, los días domingo, en su suplemento de Clasificados. Una ventaja adicional de publicar el anuncio del proyecto en dicho diario, fue la posibilidad de hacerlo virtualmente en su página web, con lo cual llegaríamos a una mayor cantidad de clientes. 
Otra manera de publicitar el proyecto fue a través de un contrato de "Opción de Venta" que celebramos con la empresa Casas \& Bienes Perú S.A.C., con R.U.C N ${ }^{\circ}$ 20492011763, mediante el cual autorizábamos a publicitar el proyecto y realizar la venta en corretaje de los departamentos y estacionamientos aún disponibles, reconociendo una comisión del tres por ciento (3\%) calculado sobre el precio de venta de los inmuebles, por las gestiones realizadas.

De manera complementaria, empleamos una herramienta de gran utilidad, el “mailing masivo", es decir, el envió folletería virtual a través de los correos electrónicos obtenidos de diversas bases de datos. Durante la etapa de preventa llegamos a enviar correos electrónicos a más de 10 mil destinatarios.

Finalmente recurrimos a las redes sociales para publicitar el proyecto, creando una cuenta de "Facebook" denominada Torre Barrón, tal como se muestra en la figura 4.6. A través de esta cuenta mantuvimos continuo contacto con nuestros clientes, resolviendo cualquier duda o consulta y publicando permanentemente fotos del avance de la obra.

Figura 4.6

Cuenta de Facebook del edificio "Torre Barrón"

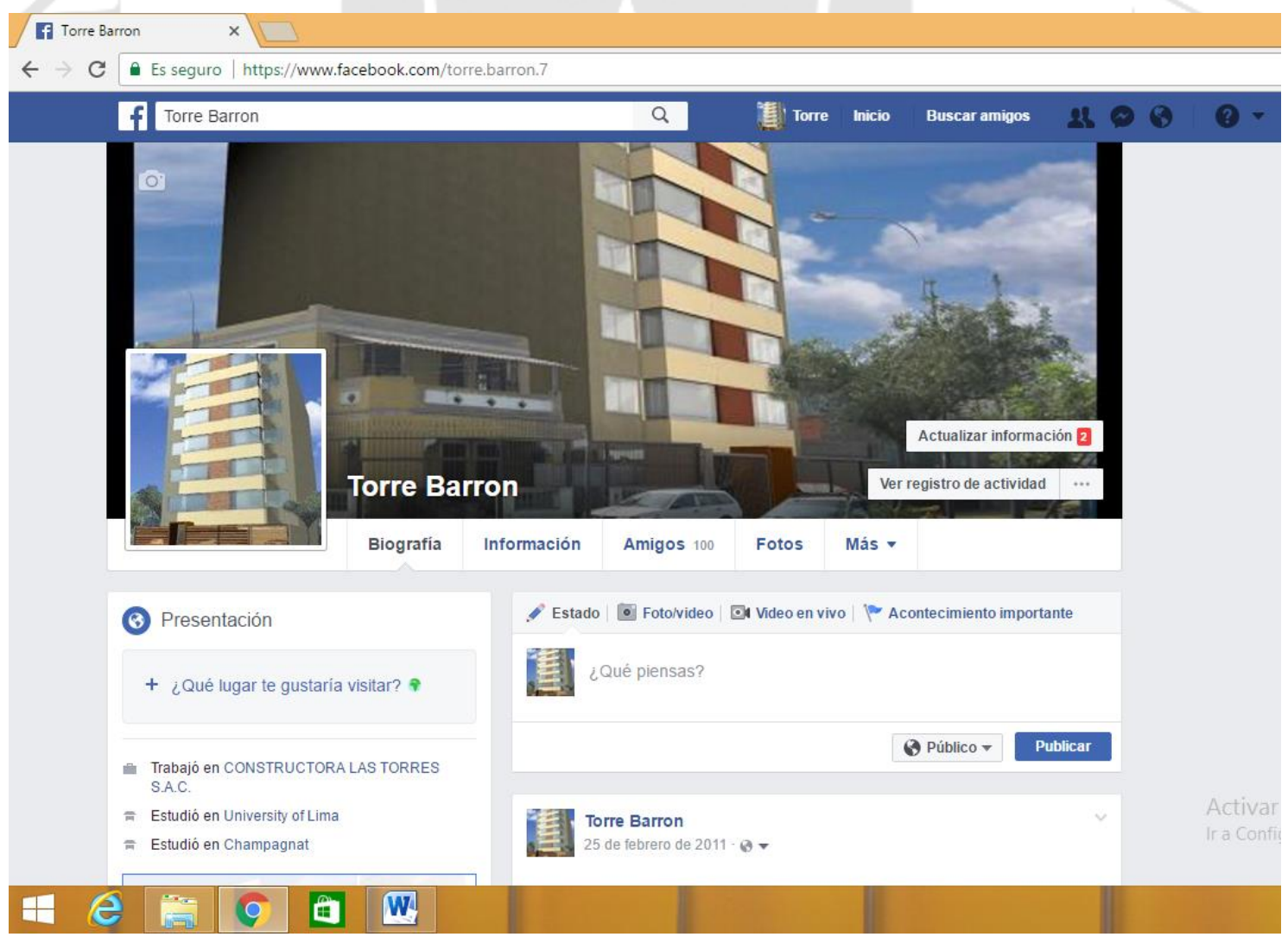

Elaboración: Propia. 


\subsection{Estrategia de promoción}

Como se mencionó anteriormente, uno de los objetivos de nuestra publicidad fue el de persuadir al cliente para adquirir los departamentos acelerando su decisión de compra. Este objetivo se pudo conseguir implementando una estrategia de promoción a corto plazo en diferentes momentos o etapas de la ejecución del proyecto. Durante la etapa de pre venta, es decir, antes del inicio de la construcción del edificio, ofrecimos un descuento de hasta el $5 \%$ por la compra futura del inmueble. Durante la etapa de ejecución de la obra planteamos un descuento de hasta 5\% por la compra de los departamentos si ésta era al contado, es decir, sin la gestión de un crédito hipotecario.

Otros incentivos durante este periodo, fueron los de permitir que los clientes pudieran elegir el color de pintura de las paredes del departamento adquirido, el color de la tina de baño, el modelo y color de los sanitarios a instalar en el baño de la habitación principal, el modelo de los cerámicos a instalar en la cocina y baños, el tipo de piso a instalar en el departamento, etc.

\subsection{Estrategia de ingreso al mercado}

Nuestra estrategia intensiva de penetración en el mercado se complementó con nuestras estrategias de producto, precios, publicidad y promoción ya que ofrecimos un producto totalmente diferenciado (áreas superiores a los 90 metros cuadrados, diseños funcionales, poca cantidad de departamentos, todos los inmuebles con vista a la calle, reposteros en las cocinas, closets en los dormitorios, un estacionamiento por cada departamento, medidores de agua y luz independientes, ascensor y escalera de emergencia, sistema contra incendios, instalaciones de gas, adecuada iluminación y ventilación naturales); establecimos un precio por metro cuadrado inferior al de nuestra competencia en $3.58 \%$; publicitamos el proyecto por diferentes medios de manera agresiva y permanente; promocionamos el proyecto ofreciendo descuentos competitivos en diferentes etapas de la ejecución del proyecto.

\subsection{Determinación de la participación del mercado}

De acuerdo al estudio de mercado realizado en Santa Beatriz, determinamos que la participación del mercado inmobiliario estaba dividida entre cinco empresas constructoras, Constructora Roca Azul con un 60\% (12 edificios multifamiliares 
construidos), Constructora Imagina con un 20\% (4 edificios construidos), Lima Kensetsu con un 5\% (1 edificio en proyecto), Yufra Constructores con un 5\% (1 edificio en proyecto) y otros con $10 \%$ (2 edificios construidos). Ver figura 4.7.

Figura 4.7

Participación del mercado en el año cero

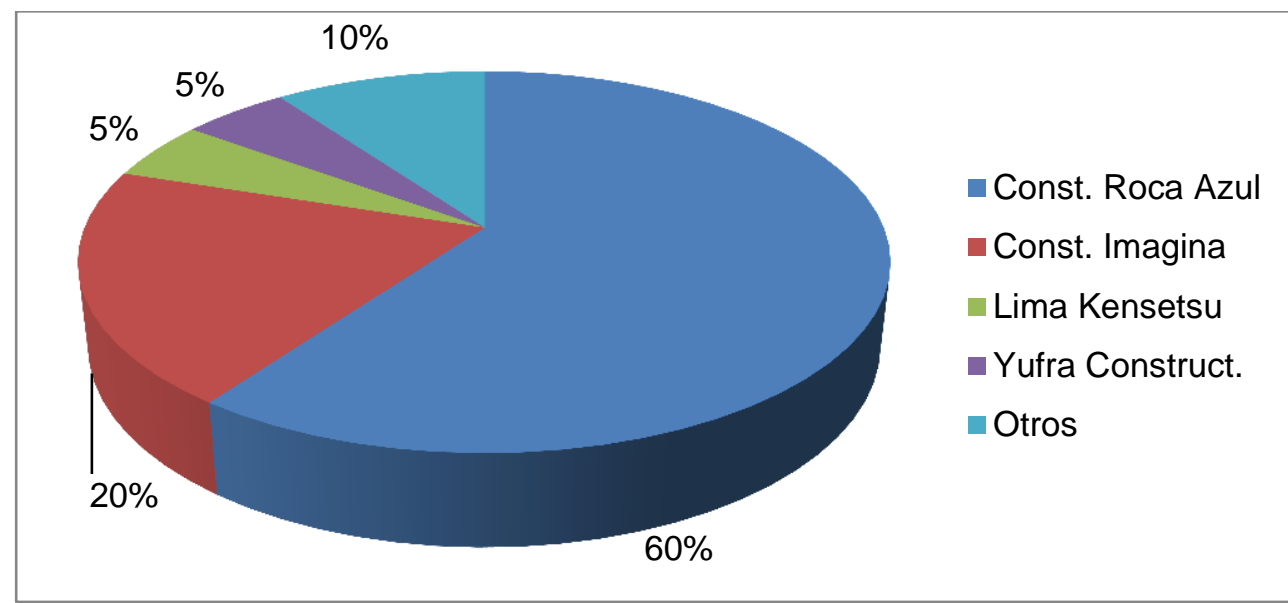

Elaboración: Propia.

Para determinar nuestra participación proyectada a cinco años, asumimos que desarrollaríamos un proyecto inmobiliario cada año, alcanzando una participación del $10 \%$ a partir del cuarto año. Otros supuestos para determinar dicha participación fueron que la Constructora Imagina desarrollaría también un proyecto inmobiliario cada año y que con el ingreso de nuevos competidores, agrupados en el conjunto "Otros" ejecutarían de dos a más proyectos por año progresivamente, alcanzando a construir hasta seis edificios multifamiliares en el año 5. Ver figura 4.8 y anexo 14.

Figura 4.8

Participación del mercado proyectada al año 5

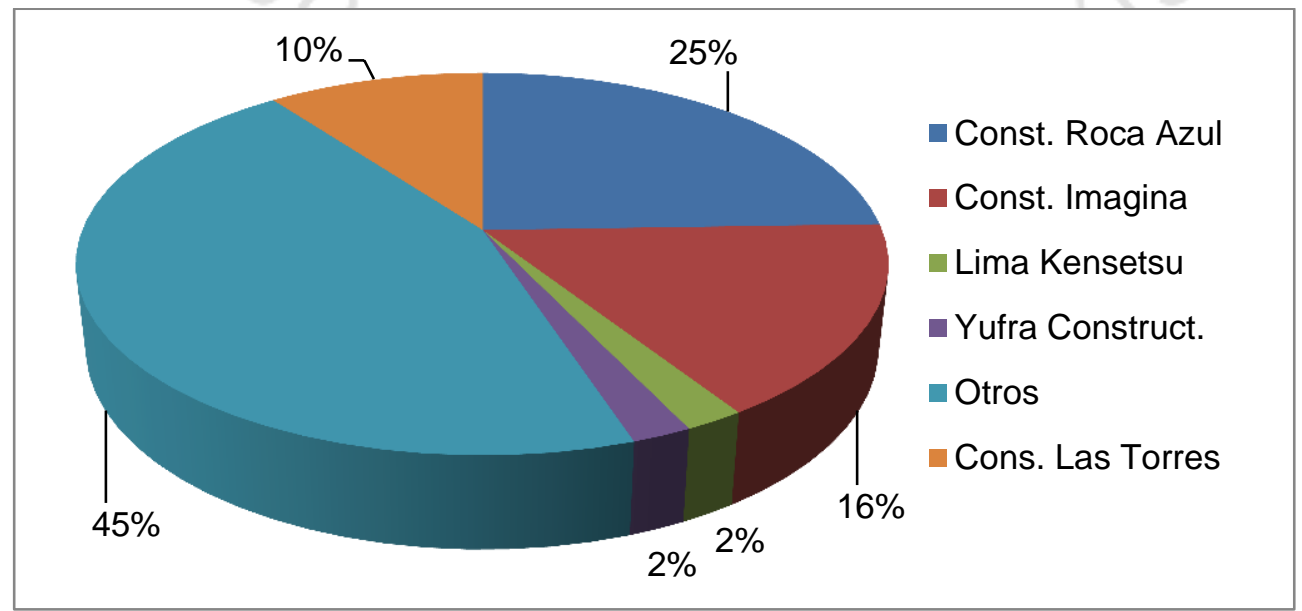

Elaboración: Propia. 


\subsection{Proyecciones de ventas}

Nuestra proyección de ventas para el proyecto inmobiliario Torre Barrón consideraba vender todas las unidades inmobiliarias (12 departamentos y 12 estacionamientos) en un plazo máximo de seis meses. El 50\% de las unidades se venderían durante el periodo de preventa, es decir, durante los tres primeros meses, antes del inicio de la ejecución de la obra. El saldo se vendería durante la construcción del proyecto, es decir, los últimos tres meses.

Tabla 4.4

Proyección de ventas del edificio "Torre Barrón"

\begin{tabular}{|c|c|c|c|c|c|c|c|}
\hline Unidad Inmobiliaria & Mes 1 & Mes 2 & Mes 3 & Mes 4 & Mes 5 & Mes 6 & Total S/. \\
\hline Departamento 201 & 223,000 & - & - & - & - & - & 223,000 \\
\hline Departamento 202 & 212,000 & - & - & - & - & - & 212,000 \\
\hline Departamento 301 & - & 203,000 & - & - & - & - & 203,000 \\
\hline Departamento 302 & - & 191,000 & - & - & - & - & 191,000 \\
\hline Departamento 401 & - & - & 203,000 & - & - & - & 203,000 \\
\hline Departamento 402 & - & - & 191,000 & - & - & - & 191,000 \\
\hline Departamento 501 & - & - & - & 203,000 & - & - & 203,000 \\
\hline Departamento 502 & - & - & - & 191,000 & - & - & 191,000 \\
\hline Departamento 601 & - & - & - & - & 203,000 & - & 203,000 \\
\hline Departamento 602 & - & - & - & - & 191,000 & - & 191,000 \\
\hline Departamento 701 & - & - & - & - & - & 195,000 & 195,000 \\
\hline Departamento 702 & - & - & - & - & - & 187,000 & 187,000 \\
\hline Estacionamiento $1 \mathrm{~A}$ & 10,000 & - & - & - & - & - & 10,000 \\
\hline Estacionamiento 1B & 15,000 & - & - & - & - & - & 15,000 \\
\hline Estacionamiento $2 \mathrm{~A}$ & - & 10,000 & - & - & - & - & 10,000 \\
\hline Estacionamiento 2B & - & 15,000 & - & - & - & - & 15,000 \\
\hline Estacionamiento 3 & - & - & 10,000 & - & - & - & 10,000 \\
\hline Estacionamiento 4 & - & - & 10,000 & - & - & - & 10,000 \\
\hline Estacionamiento 5 & - & - & - & 10,000 & - & - & 10,000 \\
\hline Estacionamiento 6 & - & - & - & 15,000 & - & - & 15,000 \\
\hline Estacionamiento 7 & - & - & - & - & 15,000 & - & 15,000 \\
\hline Estacionamiento 8 & - & - & - & - & 10,000 & - & 10,000 \\
\hline Estacionamiento 9 & - & - & - & - & - & 10,000 & 10,000 \\
\hline Estacionamiento 10 & - & - & - & - & - & 15,000 & 15,000 \\
\hline Total S/. & 460,000 & 419,000 & 414,000 & 419,000 & 419,000 & 407,000 & $2,538,000$ \\
\hline
\end{tabular}

Elaboración: Propia. 


\subsection{Estrategias de ventas}

Respecto a nuestra estrategia de venta podemos afirmar que mantuvimos una fuerza de ventas interna y una fuerza de ventas externa. Nuestra fuerza de ventas interna estuvo dirigida por el Jefe Comercial, quien desde la caseta de ventas ubicada dentro de la obra atendía personalmente a los clientes para asesorarlos comercial, legal y financieramente. La asesoría comercial consistía en ofrecerle al cliente una vivienda que se ajustara a sus necesidades, preferencias y capacidad de adquisición y apalancamiento. La asesoría legal por su parte, consistía en elaborar y revisar el contrato de compra venta junto con el cliente. Finalmente, la asesoría financiera consistía en analizar la capacidad de endeudamiento del cliente y ayudarlo a obtener un crédito hipotecario con una tasa adecuada o preferencial. No obstante, el Jefe Comercial también realizaba visitas a los potenciales clientes fuera de obra, es decir, en sus centros de trabajo, en sus domicilios, entre otros lugares. En relación a nuestra fuerza de ventas externa, se manejó indirectamente ya que estuvo conformada por los ejecutivos de cuentas de la empresa Casas \& Bienes Perú S.A.C., con quien celebramos un contrato de "Opción de Venta", mediante el cual autorizamos a realizar la venta en corretaje de los inmuebles, reconociendo una comisión por la gestión realizada.

\subsection{Políticas de ventas}

El proceso de la venta se iniciaba cuando el cliente después de haber sido asesorado, tomaba la decisión de adquirir alguno de los inmuebles. El primer paso consistía en la separación de la unidad inmobiliaria, para lo cual el cliente firmaba un documento de separación y pagaba Un Mil Quinientos y 00/100 Nuevos Soles (S/. 1.500,00). Dicho acuerdo tenía dos semanas de plazo para que el cliente pueda abonar la cuota inicial. La venta del inmueble se cerraba o concluía con el pago parcial o total del valor del inmueble y la firma del contrato de compraventa de bien futuro. El pago parcial consistía en el pago de una cuota inicial mínima equivalente al $20 \%$ del valor del inmueble. La diferencia sería cancelada a través de un crédito hipotecario obtenido en cualquier entidad bancaria. Por otro lado, el pago total se realizaba cuando el cliente adquiría el inmueble bajo la modalidad de compra al contado. En este caso, el Jefe Comercial tenía la potestad de otorgarle al cliente un descuento de hasta el 5\% sobre el valor del inmueble. Es importante mencionar que todo pago se realizó a través de transferencias bancarias o depósitos en nuestra cuenta corriente. 


\section{CAPÍTULO V: ESTUDIO TÉCNICO}

En el presente capítulo determinamos la localización óptima y el diseño de nuestro proyecto inmobiliario. Seguidamente explicamos el proceso constructivo, desde la adquisición del inmueble sobre el que se ejecutó la obra, hasta la instalación de los acabados. Finalmente, desarrollamos la estrategia logística del proyecto.

\subsection{Localización del proyecto}

Con el objetivo de determinar la localización óptima del proyecto, desarrollamos dos estudios técnicos. El primero a nivel de macro localización para acordar el departamento, región o ciudad del país donde nos estableceríamos. El segundo estudio técnico lo desarrollamos a nivel de micro localización para convenir la ubicación exacta del proyecto en el departamento, región o ciudad escogido. En ambos casos empleamos herramientas de análisis tales como tablas de enfrentamiento y ranking de factores.

\subsubsection{Macro localización del proyecto}

El objetivo del estudio de macro localización fue determinar la ciudad o departamento idóneo para ubicar y desarrollar el proyecto. Para ello tomamos en cuenta tres posibles lugares del país basándonos en el incremento de proyectos inmobiliarios. Las ciudades analizadas fueron Lima, Arequipa y Chiclayo, considerando los siguientes factores:

- El incremento de proyectos inmobiliarios

- El incremento de créditos hipotecarios

- El poder adquisitivo de la población

- El incremento demográfico

- La disponibilidad de materiales

- La disponibilidad de mano de obra calificada

Consideramos que el incremento de proyectos inmobiliarios era el factor más importante, seguido del incremento de los créditos hipotecarios, ya que ambos nos indicaban la tendencia de las personas a adquirir departamentos en este tipo de proyectos. Así mismo, consideramos que tanto el poder adquisitivo como el incremento demográfico eran medianamente importantes. Finalmente, establecimos que la 
disponibilidad de los materiales y de mano de obra calificada eran los factores menos importantes ya que podríamos conseguirlos en Lima y trasladarlos de ser necesario. En el siguiente cuadro mostraremos la tabla de enfrentamiento de los factores analizados.

Tabla 5.1

Tabla de enfrentamiento macro localización

\begin{tabular}{|l|ccccccccc|}
\hline \multicolumn{1}{|c}{ Factor } & & $\mathrm{A}$ & $\mathrm{B}$ & $\mathrm{C}$ & $\mathrm{D}$ & $\mathrm{E}$ & $\mathrm{F}$ & Total & $\%$ \\
\hline Incremento de proyectos inmobiliarios & $\mathrm{A}$ & $\mathrm{X}$ & 1 & 1 & 1 & 1 & 1 & 5 & 0.28 \\
Incremento de créditos hipotecarios & $\mathrm{B}$ & 0 & $\mathrm{X}$ & 1 & 1 & 1 & 1 & 4 & 0.22 \\
Poder adquisitivo de la población & $\mathrm{C}$ & 0 & 0 & $\mathrm{X}$ & 1 & 1 & 1 & 3 & 0.17 \\
Incremento demográfico & $\mathrm{D}$ & 0 & 0 & 1 & $\mathrm{X}$ & 1 & 1 & 3 & 0.17 \\
Disponibilidad de materiales & $\mathrm{E}$ & 0 & 0 & 0 & 1 & $\mathrm{X}$ & 1 & 2 & 0.11 \\
Disponibilidad de mano obra calificada & $\mathrm{F}$ & 0 & 0 & 0 & 0 & 1 & $\mathrm{X}$ & 1 & 0.06 \\
\hline
\end{tabular}

Elaboración: Propia.

Respecto a la tabla de calificación consideramos apropiado establecer tres niveles de evaluación: bueno, con una valoración de 10 puntos; regular, con una valoración de 5 puntos; y malo, con una valoración de 1 punto.

Tabla 5.2

Tabla de calificación

\begin{tabular}{|cc|}
\hline Evaluación & Valoración \\
\hline Bueno & 10 \\
Regular & 5 \\
Malo & 1 \\
\hline
\end{tabular}

Elaboración: Propia.

Una vez establecidos los parámetros para el análisis, determinamos tres posibles ciudades para desarrollar el proyecto, Lima, Arequipa y Lambayeque. De acuerdo al segundo Boletín Estadístico del año 2007 emitido por el Ministerio de Vivienda, Construcción y Saneamiento y el Diagnóstico Urbano del año 2007 elaborado por la Municipalidad de Chiclayo, el incremento de proyectos inmobiliarios y créditos hipotecarios, tanto en Lima como en Lambayeque se aceleraron considerablemente, mientras que en Arequipa disminuyeron por diversos factores económicos. Respecto al poder adquisitivo de la población y al incremento demográfico, durante los últimos se mantuvo un comportamiento ascendente en las tres regiones analizadas. Respecto a la disponibilidad de materiales, en todas las regiones se podía acceder a los principales materiales empleados en construcción (cemento, acero, hormigón, maderas, encofrados, 
entre otros). Finalmente, en cuanto a la disponibilidad de mano de obra calificada, es en Lima donde se concentra la mayor cantidad de trabajadores de construcción $(47.9 \%$ de la PEA ocupada en el sector) especializados en albañilería, carpintería y fierrería. Una vez realizado el ranking de factores, llegamos a la conclusión de que la localización óptima o más apropiada para ejecutar el proyecto, era la ciudad de Lima, teniendo como segunda opción la región de Lambayeque.

\section{Tabla 5.3}

Ranking de factores macro localización

\begin{tabular}{|c|c|c|c|c|c|c|c|}
\hline \multirow{2}{*}{ Factor } & \multirow{2}{*}{$\%$} & \multicolumn{2}{|c|}{ Lima } & \multicolumn{2}{|c|}{ Arequipa } & \multicolumn{2}{|c|}{ Lambayeque } \\
\hline & & Calif & Punt & Calif & Punt & Calif & Punt \\
\hline Incremento de proyectos inmobiliarios & 0.28 & 10 & 2.80 & 5 & 1.40 & 10 & 2.80 \\
\hline Incremento de créditos hipotecarios & 0.22 & 10 & 2.20 & 5 & 1.10 & 10 & 2.20 \\
\hline Poder adquisitivo de la población & 0.17 & 10 & 1.70 & 10 & 1.70 & 10 & 1.70 \\
\hline Incremento demográfico & 0.17 & 10 & 1.70 & 10 & 1.70 & 10 & 1.70 \\
\hline Disponibilidad de materiales & 0.11 & 10 & 1.10 & 10 & 1.10 & 10 & 1.10 \\
\hline Disponibilidad de mano de obra calificada & 0.06 & 10 & 0.60 & 5 & 0.30 & 5 & 0.30 \\
\hline Puntuación total & & & 10.10 & & 7.30 & & 9.80 \\
\hline
\end{tabular}

Elaboración: Propia.

\subsubsection{Micro localización del proyecto}

El objetivo del estudio de micro localización era determinar el distrito apropiado para ubicar y desarrollar el proyecto en la ciudad de Lima. Para ello tomamos en cuenta tres posibles lugares basándonos en el incremento de proyectos inmobiliarios y el costo de los terrenos. De acuerdo al estudio del mercado inmobiliario realizado por CAPECO en el 2007, los distritos de Jesús María y San Miguel fueron los que mostraron una mayor oferta de departamentos.

Tabla 5.4.

Oferta de departamentos en distritos de Lima 2007

\begin{tabular}{|lrrc||}
\hline \multicolumn{1}{|c}{ Distritos } & \multicolumn{1}{c}{ Unidades } & \multicolumn{1}{c|}{ M2 } & Área Prom. \\
\hline Jesús María & 1.183 & 100.519 & $85 \mathrm{~m} 2$ \\
\hline Lince & 283 & 23.492 & $83 \mathrm{~m} 2$ \\
Magdalena del Mar & 952 & 84.074 & $88 \mathrm{~m} 2$ \\
Pueblo Libre & 427 & 36.751 & $86 \mathrm{~m} 2$ \\
San Miguel & 1.067 & 89.287 & $84 \mathrm{~m} 2$ \\
\hline
\end{tabular}

Elaboración: Propia. 
En ese sentido, analizamos los distritos de Jesús María, San Miguel y Santa Beatriz (Cercado de Lima), considerando los siguientes factores:

- El precio de los terrenos por metro cuadrado

- El precio de los departamentos por metro cuadrado

- El incremento de proyectos inmobiliarios

- El incremento de créditos hipotecarios

- Acceso a los servicios básicos

Consideramos que el precio de los terrenos por metro cuadrado era el factor más importante por representar una alta inversión y una variable importante en el análisis de rentabilidad del proyecto. Otro factor importante fue el precio de los departamentos por metro cuadrado, ya que se tomaría en cuanta para definir nuestros precios. Estimamos que también eran importantes el incremento de proyectos inmobiliarios y créditos hipotecarios, ya que ambos nos indicaban la tendencia de las personas a adquirir departamentos en este tipo de proyectos. Menos importante que los anteriores pero fue necesario considerar el acceso a los servicios básicos de energía eléctrica, de agua potable, de red de alcantarillado, de telefonía e Internet, de gas natural, entre otros. En el siguiente cuadro mostraremos la tabla de enfrentamiento de los factores analizados.

Tabla 5.5

Tabla de enfrentamiento micro localización

\begin{tabular}{|lcccccccc|}
\hline \multicolumn{1}{|c}{ Factor } & & $\mathrm{A}$ & $\mathrm{B}$ & $\mathrm{C}$ & $\mathrm{D}$ & $\mathrm{E}$ & Total & $\%$ \\
\hline Precio de los terrenos por M2 & $\mathrm{A}$ & $\mathrm{X}$ & 1 & 1 & 1 & 1 & 4 & 0.31 \\
Precio de los departamentos por M2 & $\mathrm{B}$ & 1 & $\mathrm{X}$ & 1 & 1 & 1 & 4 & 0.31 \\
Incremento de proyectos inmobiliarios & $\mathrm{C}$ & 0 & 0 & $\mathrm{X}$ & 1 & 1 & 2 & 0.15 \\
Incremento de créditos hipotecarios & $\mathrm{D}$ & 0 & 0 & 1 & $\mathrm{X}$ & 1 & 2 & 0.15 \\
Acceso a servicios básicos & $\mathrm{E}$ & 0 & 0 & 0 & 1 & $\mathrm{X}$ & 1 & 0.08 \\
\hline
\end{tabular}

Elaboración: Propia.

Respecto a la tabla de calificación utilizamos la misma que se menciona en la Tabla 5.2. Una vez establecidos los parámetros para el análisis, determinamos tres posibles distritos para desarrollar el proyecto, San Miguel, Jesús María y Santa Beatriz (Cercado de Lima). De acuerdo al estudio de mercado que realizamos en los diferentes distritos de Lima, determinamos que el precio promedio de los terrenos por metro cuadrado era más competitivo en la Urbanización Santa Beatriz (USD 318.00), que en los distritos de San Miguel (USD 366.00) y Jesús María (USD 511.00). Por otro lado, 
de acuerdo a la Oficina General de Estadística e Informática (OGEI) del Ministerio de Vivienda, Construcción y Saneamiento, determinamos que el precio de los departamentos por metro cuadrado era superior en Jesús María (USD 495.00) y San Miguel (USD 466.00), en comparación con Santa Beatriz (USD 386.00). Así mismo, determinamos que tanto los proyectos como los créditos hipotecarios se incrementaron en los tres distritos, pero en menor proporción en San Miguel. Finalmente, pudimos concluir que en los tres distritos era factible acceder a los servicios básicos.

Tabla 5.6

Ranking de factores micro localización

\begin{tabular}{|c|c|c|c|c|c|c|c|}
\hline \multirow{2}{*}{ Factor } & \multirow{2}{*}{$\%$} & \multicolumn{2}{|c|}{ Santa Beatriz } & \multicolumn{2}{|c|}{ San Miguel } & \multicolumn{2}{|c|}{ Jesús María } \\
\hline & & Calif & Punt & Calif & Punt & Calif & Punt \\
\hline Precio de los terrenos por M2 & 0.31 & 10 & 3.10 & 10 & 3.10 & 5 & 1.55 \\
\hline Precio de los departamentos por M2 & 0.31 & 10 & 3.10 & 5 & 1.55 & 5 & 1.55 \\
\hline Incremento de proyectos inmobiliarios & 0.15 & 10 & 1.50 & 5 & 0.75 & 10 & 1.50 \\
\hline Incremento de créditos hipotecarios & 0.15 & 10 & 1.50 & 5 & 0.75 & 10 & 1.50 \\
\hline Acceso a servicios básicos & 0.08 & 10 & 0.80 & 10 & 0.80 & 10 & 0.80 \\
\hline Puntuación total & & & 10.00 & & 6.95 & & 6.90 \\
\hline
\end{tabular}

Elaboración: Propia.

Una vez realizado el ranking de factores, llegamos a la conclusión de que la localización óptima o más apropiada para ejecutar el proyecto, era la Urbanización de Santa Beatriz en el distrito de Cercado de Lima.

Figura 5.1

Plano de la Urbanización de Santa Beatriz - Cercado de Lima

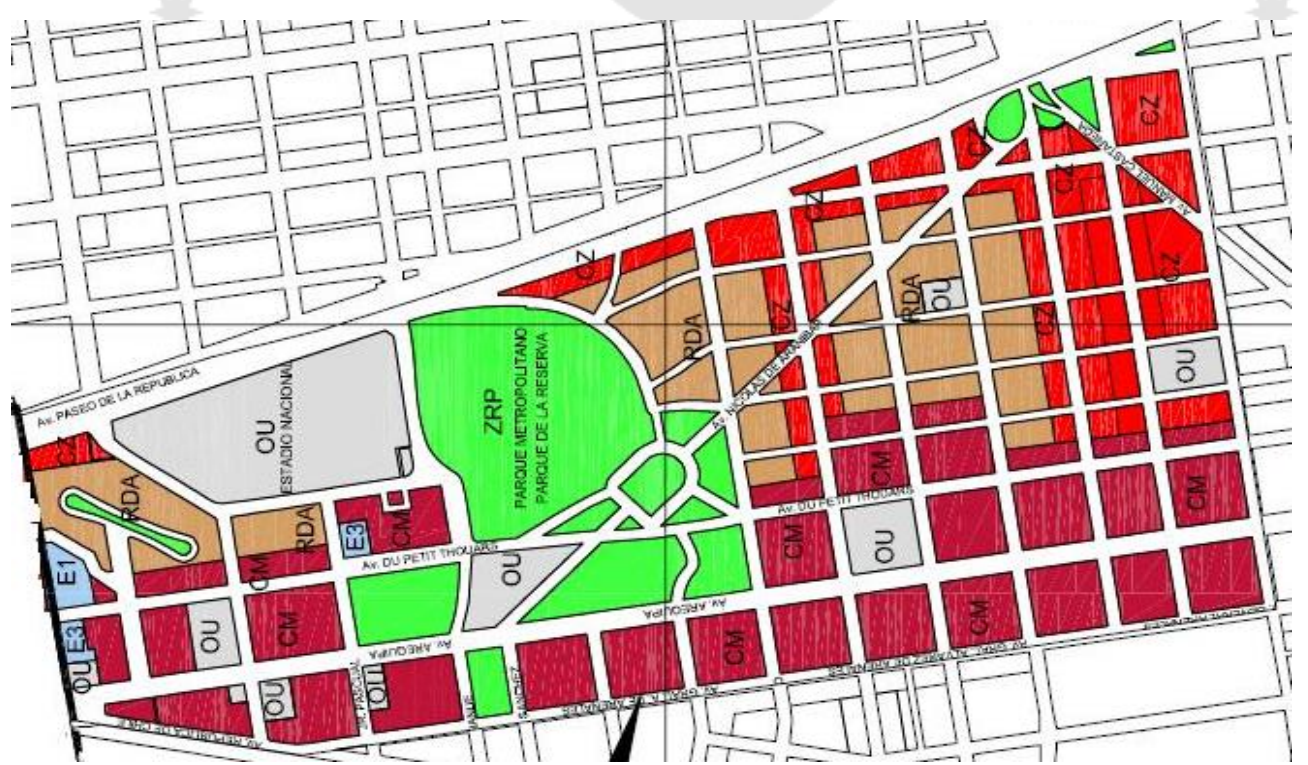

Elaboración: Propia. 


\subsection{Diseño del proyecto}

Definida Santa Beatriz como la localización óptima, encontramos en ella diferentes inmuebles con áreas que superaban los 300 metros cuadrados, apropiados para desarrollar el proyecto. Dentro de las diferentes alternativas optamos por adquirir el inmueble ubicado en el Jirón Comandante Enrique Barrón $N^{\circ} 1113$, cuyas dimensiones eran de 12 metros de frontis y 27.5 metros de fondo con lo cual se pudo diseñar el proyecto en un área total de 330 metros cuadrados. Ver figura 5.2.

Figura 5.2

Imagen del predio adquirido

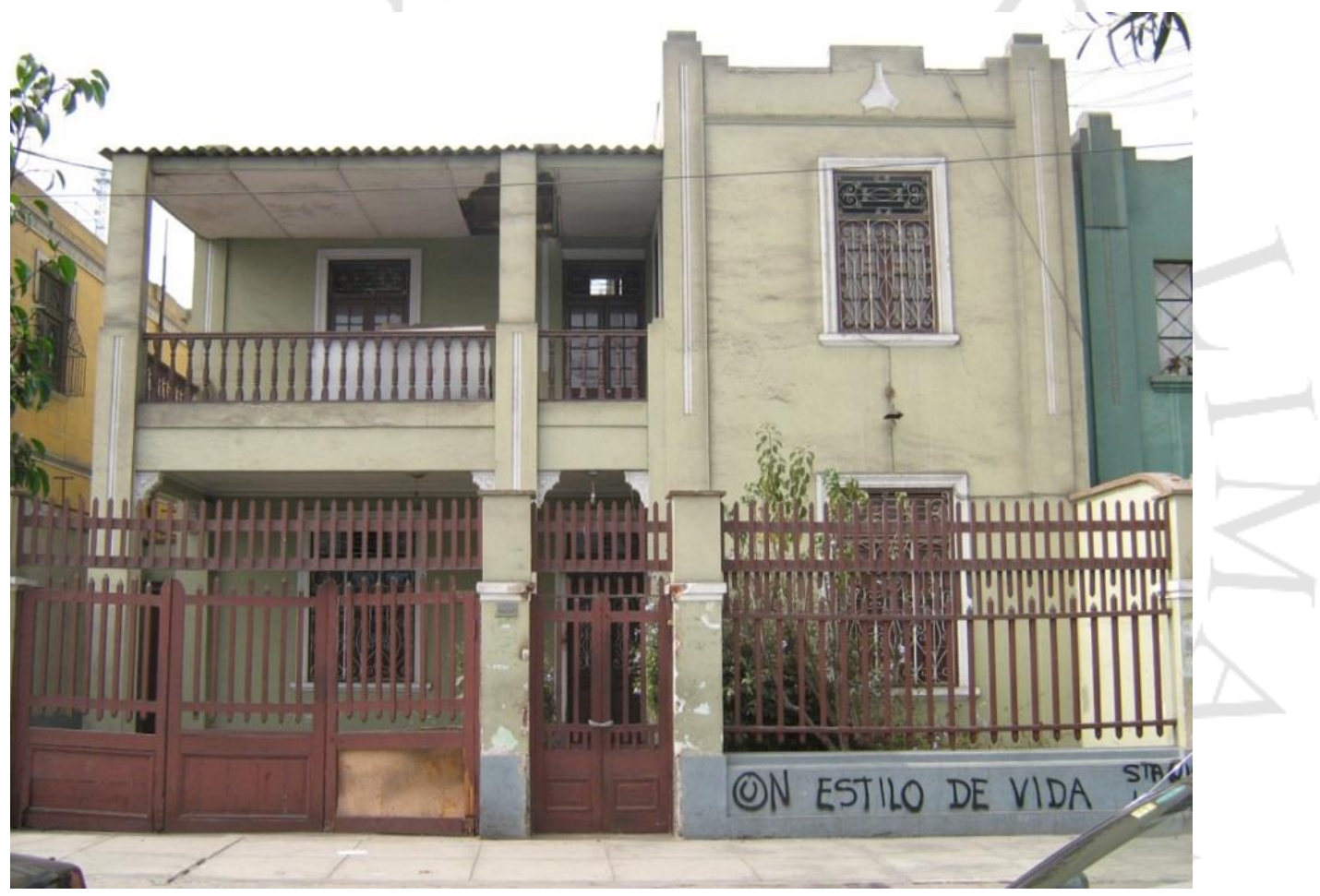

Nota: Predio inscrito en la Partida Electrónica No 07009113 del Registro de la Propiedad Inmueble de la Zona Registral No IX - Sede Lima. Elaboración: Propia.

Para adquirir el predio y poder diseñar el edifico multifamiliar nos basamos en el área del mismo y en los documentos legales que se indican a continuación:

- Copia literal completa del inmueble, conformada por la Ficha Registral, la Partida Electrónica y el Certificado Registral Inmobiliario (CRI).

- Copia del documento que acredita adquisición de la propiedad del inmueble, pudiendo ser el Testimonio de Compra Venta, el Testimonio de Permuta, el Testimonio de Dación en Pago.

- Copia de recibos de servicios básicos del inmueble cancelados, entre ellos los cuatro últimos recibos de agua y los cuatro últimos recibos de luz. 
- Copia de autovaluo de los cuatro últimos ejercicios (2005 -2008), es decir, la Hoja Resumen (HR), el Predio Urbano (PU), la Declaración Jurada (DJ), los comprobantes de pago del impuesto predial y de arbitrios, a la fecha y la Constancia de No Adeudo del contribuyente.

- El Certificado de Parámetros Urbanísticos y Edificatorios N N $^{\circ}$ 1-2006 otorgado por la Municipalidad Metropolitana de Lima, que de acuerdo a dicho documento, diseñamos el proyecto adecuándonos al tipo de zonificación que era Residencial de Alta Densidad (RDA), al porcentaje mínimo de área libre que era del 40\%, a la altura máxima de edificación que era de siete (7) pisos y al índice de espacios de estacionamientos que era de 1 unidad por cada vivienda o departamento. Ver tabla 5.7.

Tabla 5.7

Normas de zonificación residencial 2008

\begin{tabular}{|ccccccc|}
\hline Zona & Usos Permitidos & $\begin{array}{c}\text { Lote } \\
\text { Mínimo } \\
(\mathrm{m} 2)\end{array}$ & $\begin{array}{c}\text { Frente } \\
\text { Mínimo } \\
(\mathrm{ml})\end{array}$ & $\begin{array}{c}\text { Altura de } \\
\text { Edificación } \\
\text { Máxima (pisos) }\end{array}$ & $\begin{array}{c}\text { Área } \\
\text { Libre } \\
\text { Mínima }\end{array}$ & $\begin{array}{c}\text { Estaciona } \\
\text { miento }\end{array}$ \\
\hline $\begin{array}{c}\text { Residencial } \\
\text { de Densidad } \\
\text { Media }\end{array}$ & Unifamiliar & 120 & 6 & 3 & $30 \%$ & $1 \mathrm{c} / \mathrm{dpto}$. \\
RDM & Multifamiliar & 150 & 8 & 5 & $40 \%$ & $1 \mathrm{c} / 2 \mathrm{dpt}$ \\
$\begin{array}{c}\text { Residencial } \\
\text { de Densidad }\end{array}$ & Mivienda - Taller & 180 & 8 & 7 & $40 \%$ & $1 \mathrm{c} / 2 \mathrm{dpt}$ \\
$\begin{array}{c}\text { Alta } \\
\text { RDA }\end{array}$ & Multifamiliar & 300 & 10 & 7 & $35 \%$ & $1 \mathrm{c} / \mathrm{dpto}$. \\
\hline Conjunto Residencial & 1600 & & 700 & $50 \%$ & $1 \mathrm{c} / \mathrm{dpto}$. \\
\hline
\end{tabular}

Fuente: Instituto Metropolitano de Planificación - Cuadros Normativos de Zonificación Residencial, Área de Tratamiento II. Recuperado de http://www.imp.gob.pe/index.php/reajuste-integral-del-plano-dezonificacion-de-lima-metropolitana

Elaboración: Propia.

Tomando como referencia esta información, se procedió a diseñar el proyecto Torre Barrón, que estaría compuesto por un bloque, con una altura de siete pisos, con un total de doce departamentos, distribuidos a razón de dos departamentos por piso, a partir del segundo nivel, con áreas que oscilaban entre los 90 y $127 \mathrm{~m} 2$ y doce estacionamientos en el primer nivel. Los departamentos, que fueron del tipo "flat", estaban compuestos de sala-comedor, 3 dormitorios, 2 baños completos, uno interno al dormitorio principal y cocina-lavandería, baño de servicio y seis de los doce departamentos consideraban además con cuarto de servicio. Tenían un diseño funcional 
que optimizaba el área que ocupaban, con ambientes totalmente iluminados y ventilados, con salas - comedor que se abrían al retiro frontal y dormitorio principal que abría hacia el retiro posterior y zonas de servicios nucleados. El sistema constructivo debía ser seguro y antisísmico, por lo que se eligió el sistema de encofrados con tableros de triplay fenólico en combinación con algunos pórticos, mientras que la tabiquería estaría compuesta por bloques del tipo P-10 del sistema "LACASA". Las redes tanto de agua como desagüe fueron empotradas, sin embargo se previó ductos para alojar las tuberías que recorrían en forma vertical, así como para alojar los medidores de agua para cada departamento. Los alimentadores de electricidad hacia los departamentos se condujeron a través de ductos diseñados especialmente para estos, así como los correspondientes a teléfonos exteriores, comunicadores y TV cable. Cada departamento contó con un medidor de energía eléctrica, ubicado en un banco de medidores al exterior del edificio. La edificación consideró un ascensor con cabina estándar para 6 personas, una escalera de emergencia y un sistema contra incendios. En el anexo 48 se muestra la relación de los acabados que se implementaron en los departamentos. En los anexos 49, 50, 51, 52 y 53 se aprecian los diseños o planos arquitectónicos de los departamentos y estacionamientos.

\subsection{Desarrollo del proyecto}

\subsubsection{El proceso de construcción}

Para la ejecución del proyecto decidimos contratar a la empresa ALM CONSTRUCTORES S.A.C., con R.U.C. N ${ }^{\circ}$ 20492153126, quienes se encargaron de construir íntegramente el edificio Torre Barrón. El proceso constructivo se desarrolló en etapas, siendo la demolición del predio la primera fase, seguido de la construcción del edificio, la implementación de los acabados y la instalación del ascensor. Para la primera etapa tramitamos ante la Municipalidad Metropolitana de Lima una licencia de demolición, obteniendo la Licencia de Demolición Total Nº 043-08-MML-GDU-SAUDE-LO, con fecha de expedición 16/06/2008 y expediente $\mathrm{N}^{\circ}$ 64447-08. Esta etapa consideraba, la demolición total del predio, el estudio de suelos y el movimiento de tierras. La demolición del inmueble tomó dos semanas, ya que por el tipo de construcción existente (muros de adobe y techos de madera machihembrada, revestidos con yeso), se ejecutó manualmente. El predio quedó completamente libre ya que se 
eliminó el cimiento existente y todo el desmonte generado, dejando solo operativos el medidor de energía eléctrica y el medidor de agua potable y desagüe.

Paralelamente se realizó el estudio de suelos, cuyo objeto fue evaluar las características físico-mecánicas del terreno para proponer, en base a los resultados obtenidos, alternativas y recomendaciones de cimentación que satisfagan las solicitaciones de las cargas actuantes. Para finalizar esta primera fase, se realizó el movimiento de tierras que consistió en las excavaciones necesarias para la construcción de los cimientos del edificio, tomando en cuenta las posibles interferencias a encontrar, tales como cables de telefonía, postes de energía eléctrica, tuberías de agua y desagüe y las edificaciones colindantes. Una vez identificadas dichas interferencias se coordinó con las diferentes entidades (Telefónica, Sedapal y Luz del Sur) para su reubicación definitiva.

Concluida la demolición, iniciamos el trámite de construcción del edificio ante la Municipalidad Metropolita de Lima, obteniendo la Licencia de Obra para Edificación Nueva N 083-2008.MML-GDU-SAU-DE-LO, con fecha de expedición 09/09/2008 y expediente $\mathrm{N}^{\circ}$ 77239-08, tal como se muestra en el anexo 54. Con esta gestión empezamos la segunda etapa del proceso constructivo, la construcción del edificio “Torre Barrón", que consideró seis partidas principales: las estructuras, la arquitectura, las instalaciones eléctricas, las instalaciones sanitarias, las instalaciones electro mecánicas y las instalaciones de gas, las cuales se desarrollarían en siete (7) meses, de acuerdo al cronograma de avance de obra que se muestra en la tabla 5.8.

\section{Tabla 5.8}

Cronograma de avance de obra

\begin{tabular}{|c|c|c|c|c|c|c|c|}
\hline Partidas & Mes 1 & Mes 2 & Mes 3 & Mes 4 & Mes 5 & Mes 6 & Mes 7 \\
\hline \multicolumn{8}{|l|}{ Estructuras (180 días) } \\
\hline \multicolumn{8}{|l|}{ Arquitectura (180 días) } \\
\hline \multicolumn{8}{|l|}{ Instalaciones Eléctricas (165 días) } \\
\hline \multicolumn{8}{|l|}{ Instalaciones Sanitarias (165 días) } \\
\hline \multicolumn{8}{|l|}{ Instalaciones de Gas (165 días) } \\
\hline Inst. Electro Mecánicas (90 días) & & & & & & & \\
\hline
\end{tabular}

Elaboración: Propia.

La partida de estructuras consideraba la construcción de los cimientos, zapatas, falsas zapatas, vigas de cimentación, columnas, vigas, techo aligerado, losas de 
concreto armado, placas de concreto armado, cisterna de agua, caseta de bombas, tanque elevado de agua, cuarto de máquinas para el ascensor y escaleras.

La partida de arquitectura comprendía la instalación de los muros y tabiques de ladrillos LACASA P-10, los tarrajeos y cielorrasos, los pisos (de cerámicos, laminados, de cemento pulido y de ladrillos pasteleros), contra pisos, zócalos y contra zócalos, las puertas de madera y de MDF, los muebles de cocina y los closets de las habitaciones, las puertas metálicas (cortafuegos, la puerta levadiza y las puertas del estacionamiento), las bisagras y cerraduras, las mamparas, ventanas y blocks de vidrio, la pintura de todos los ambientes y la instalación de los aparatos y accesorios sanitarios (inodoros, lavatorios, lavaderos, lavarropas, papeleras, jaboneras, toalleras y grifería en general).

Figura 5.3

Instalación de muros de ladrillos Placa P-10 "LACASA"

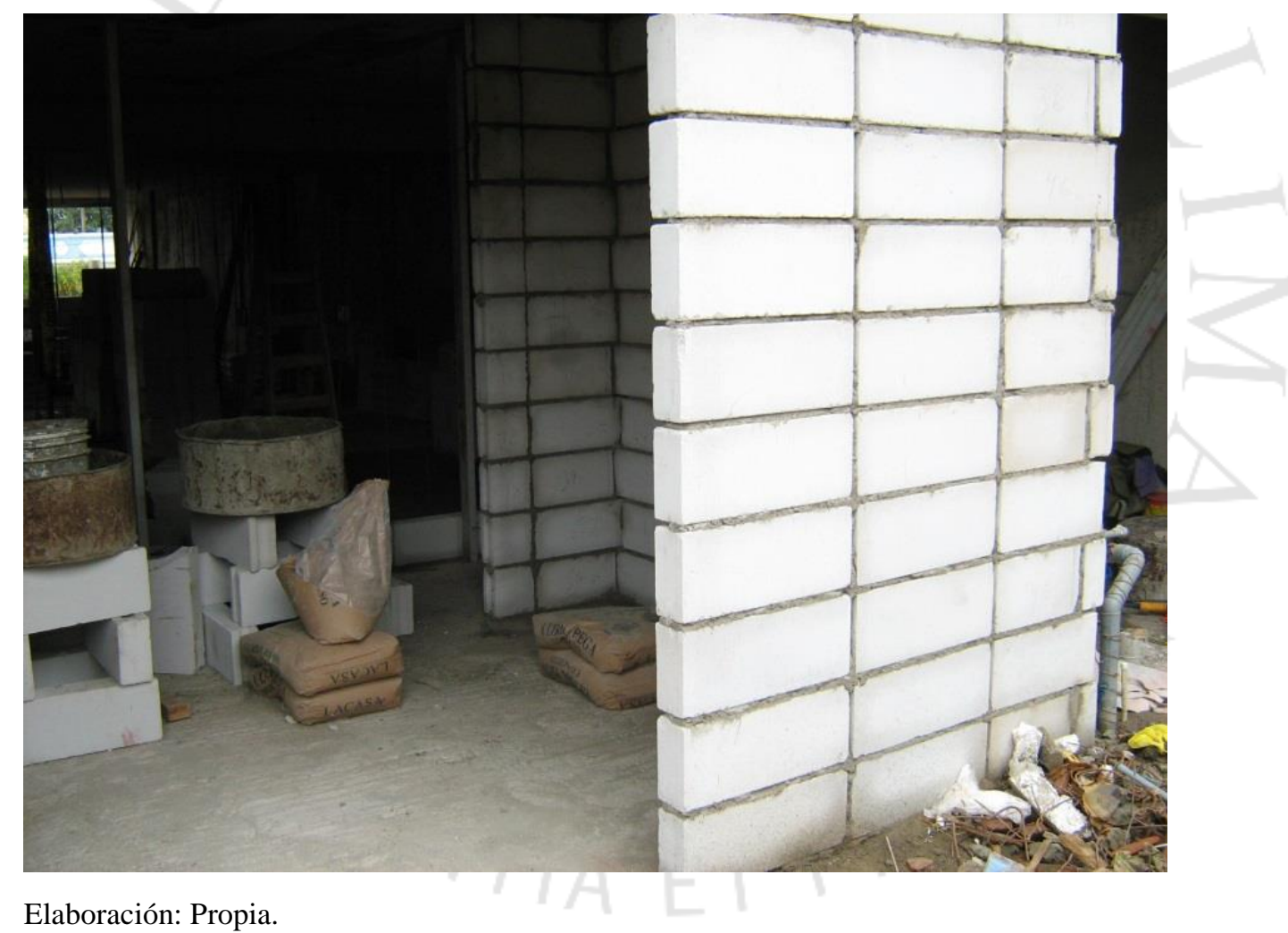

La partida de las instalaciones eléctricas contemplaba el alumbrado, los tomacorrientes e interruptores, las acometidas a los tableros eléctricos y los tableros (de servicios generales, de distribución para cada departamento y el tableros general de bombas contra incendios), las tuberías y conductores, las cajas de pase o derivación y de distribución, las salidas de fuerza (para intercomunicador, televisión cable, teléfono, sirenas, detectores de humo y de temperatura), el sistema de alarma contra incendios y 
las diferentes electrobombas. La partida de instalaciones sanitarias consideraba la implementación del sistema de agua fría y contra incendios, el sistema de agua caliente, los medidores de agua independientes y el sistema de desagüe (estos sistemas estaban conformados por tuberías, válvulas, sumideros, cajas de registros, accesorios varios, etc.). La partida de instalaciones de gas suponía la instalación de las tuberías de cobre y salidas para las cocinas de cada departamento. Finalmente, las instalaciones electro mecánicas consideraban la instalación del ascensor (de procedencia española y con capacidad para 6 personas) que fue adquirido mediante contrato de compra venta a la empresa J V ASCENSORES S.A., con R.U.C. No 20109914984.

Figura 5.4

Imagen final del edificio "Torre Barrón"

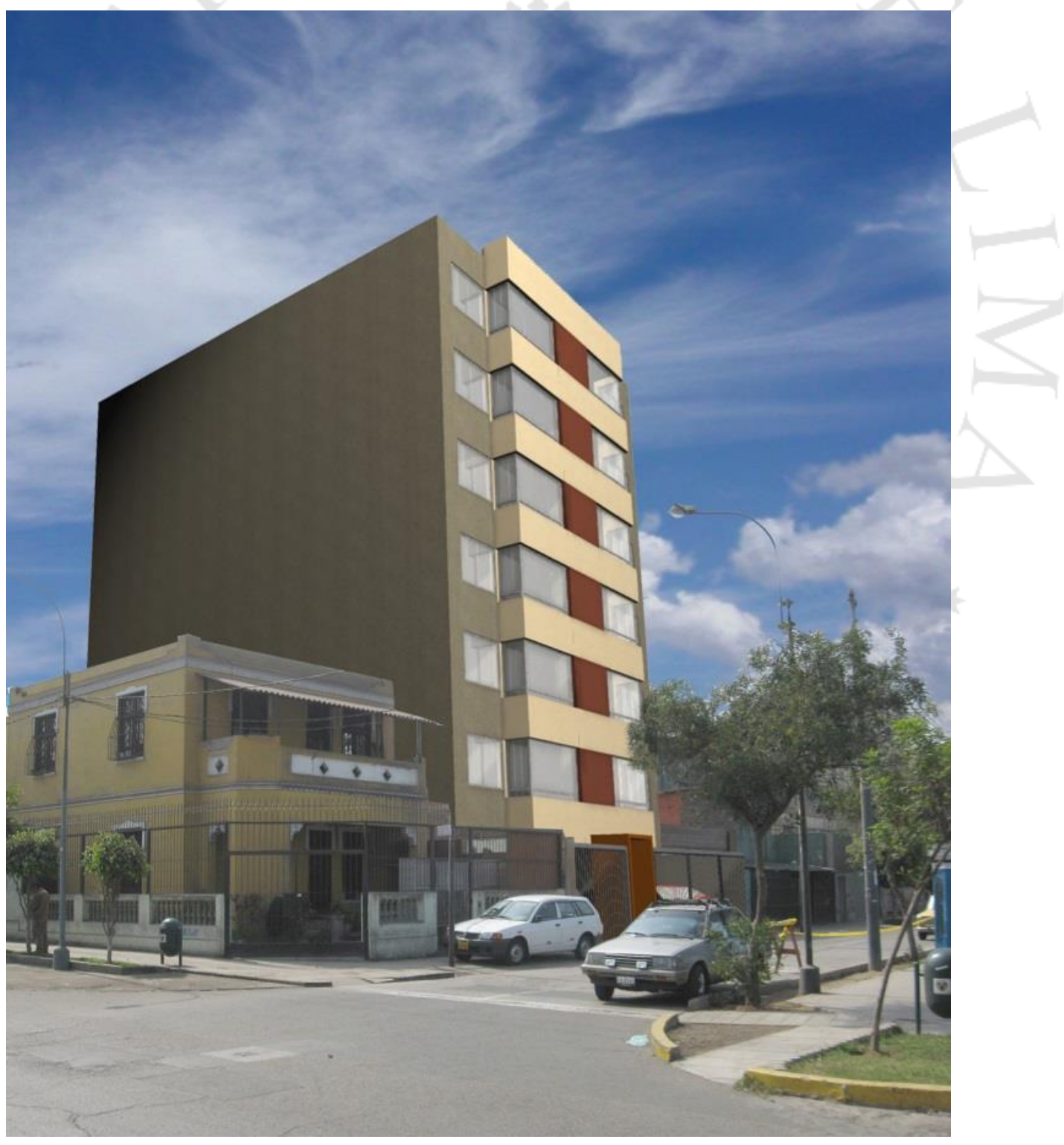

Elaboración: Propia. 
Un aspecto importante y fundamental para la ejecución y término del proyecto, son los trámites que se deben realizar en las diferentes entidades públicas y privadas involucradas, que para el caso de nuestro proyecto fueron la Municipalidad Metropolitana de Lima, la Superintendencia Nacional de los Registros Públicos (SUNARP), Servicio de Parques de Lima (SERPAR), Luz del Sur S.A.A., Sedapal S.A. y Telefónica del Perú S.A.A.

Una vez construido y terminado el edificio, solicitamos el Certificado de Pago de Aportes ante el Servicio de Parques de Lima (SERPAR). Obtenido dicho documento, gestionamos ante la Municipalidad Metropolitana de Lima los siguientes certificados:

- Certificado de Finalización de Obra y Zonificación

- Certificado de Numeración de las unidades inmobiliarias

- Declaratoria de Fábrica de Obra Nueva

Conseguidos estos documentos, solicitamos en la Superintendencia Nacional de los Registros Públicos (SUNARP), la inscripción de la Declaratoria de Fábrica de Obra Nueva, el Reglamento Interno del edificio, la Independización y Numeración de los inmuebles. Ver anexo 55.

Simultáneamente gestionamos en Luz del Sur S.A.A., la factibilidad del suministro y conexiones nuevas de energía eléctrica; en Sedapal S.A., la factibilidad del servicio y conexiones domiciliarias de agua potable y de desagüe; y en Telefónica del Perú S.A.A., la factibilidad del servicio de telecomunicaciones (telefonía, TV cable, Internet).

Un tema relevante y de obligatoriedad para la ejecución de la obra fue la elaboración, difusión e implementación del Plan de Seguridad y Salud Ocupacional, cuyo objeto fue establecer las directrices respecto a la seguridad y salud en el trabajo, prevención de riesgos y accidentes de trabajo, de enfermedades profesionales y de daños a terceros. La existencia e implementación de dicho plan tenía tres finalidades:

- Inculcar e instruir a todo el personal de la empresa y sus contratistas que laborarán en la ejecución de la obra, acerca de las políticas, normas y lineamientos que deberán observar respecto a la seguridad y salud en el trabajo y respecto de la prevención de riesgos y accidentes ocupacionales.

- Conseguir que la prevención de perdidas integrales afronte todos los riesgos profesionales y que desde una actitud proactiva, vigile y controle el conjunto 
de factores que puedan afectar a la seguridad y salud del trabajador, equipos, materiales de la empresa y de terceros, promoviendo todas aquellas acciones que puedan contribuir a la mejora de las condiciones de trabajo y en definitiva, a mejorar la calidad y productividad dentro de la obra.

- Regular todas las acciones preventivas encaminadas a la protección de la salud e integridad física de los trabajadores por medio de la mejora de las condiciones de trabajo.

El plan de seguridad consideraba la dotación de Elementos de Protección Personal (EPP's); la adecuación de ambientes necesarios para el personal como vestuarios y servicios higiénicos; el suministro y ubicación de equipos contra incendios; el registro actualizado de las lesiones, enfermedades, incidentes, accidentes, daños materiales, cuasi accidentes, incendios, etc.; la investigación y comunicación de los incidentes y/o accidentes que provoquen lesiones y/o enfermedades profesionales en el trabajo, al Ministerio de Trabajo y Promoción del Empleo. Así mismo, contemplaba la capacitación y entrenamiento del personal, mediante charlas de inducción (higiene, seguridad y medio ambiente), charlas técnicas específicas de acuerdo a operaciones, charlas de 5 minutos sobre trabajo diario (antes del inicio de las labores) y charlas de prevención de riesgos semanales. El plan también consideraba un programa de acciones disciplinarias, a través del cual se clasificaban las infracciones o faltas y se establecían las sanciones. Finalmente, establecía el tratamiento de las diferentes emergencias tales como, contingencia médica en caso de accidente, contingencia en caso de sismo y contingencia de paro cívico o tumulto.

Adicionalmente, elaboramos y proporcionamos a los propietarios un documento denominado "Manual del Propietario del Edificio Torre Barrón" con el propósito de servir de guía en el adecuado uso y mantenimiento de sus inmuebles, ofreciéndoles algunos consejos o recomendaciones útiles y prácticas. El manual estaba conformado por diez capítulos y contenía: la Memoria Descriptiva, en la que se describía la propuesta arquitectónica del Edificio Torre Barrón, indicando su ubicación, precisando el área del inmueble, mencionando la factibilidad de obtener los servicios básicos, las principales características del edificio y de los departamentos y los principales proveedores con los que se trabajó; las Normas de Convivencia, basadas en el respeto al derecho que todos tenemos a llevar una vida agradable y pacífica y tener nuestra propiedad en perfecto estado de conservación y orden; el Mantenimiento Preventivo, 
donde se mencionaban una serie de indicaciones sobre el adecuado uso y cuidado de los diferentes acabados con los que se implementaron los departamentos, tales como, pisos, muros de concreto y de ladrillos $\mathrm{P}-10$, pinturas y revestimientos, ventanas, puertas, cerraduras, griferías, lavaderos de cocina, closets y muebles de cocina; las Recomendaciones, Reparaciones y Modificaciones, en donde presentábamos las indicaciones de cómo se debería proceder ante la aparición de fisuras y humedad, de cómo utilizar las instalaciones eléctricas, de agua potable y de desagüe, sobre el cuidado de los aparatos sanitarios, de la instalación de cerraduras especiales y de seguridad y sobre la forma de proceder, en caso de que vaya a considerar una modificación en su vivienda; el Plan de Seguridad, Señalización y Evacuación, que presentaba un análisis de riesgo de la edificación, debiendo tomar en cuenta las sugerencias mencionadas para afrontar situaciones imponderables tales como un sismo y/o un incendio, complementándolo con las señalizaciones y rutas de evacuación empleadas para prevenir y orientar al usuario en la forma de cómo tendría que actuar frente a situaciones de riesgo; finalmente en Garantías y Servicio de Post Venta, mencionábamos sobre la garantía con la que cuentan las viviendas, de conformidad a la legislación vigente, y sobre el procedimiento para la presentación de observaciones posteriores a la entrega de la vivienda, respectivamente. A modo de anexos, adjuntamos los planos de la distribución de los departamentos y de los estacionamientos, los planos de señalización y evacuación, una relación con los principales teléfonos de emergencia, los certificados y cartas de garantía de nuestros principales contratistas y proveedores:

- ALM CONSTRUCTORES S.A.C., diseño y construcción del edificio;

- CERÁMICA LIMA S.A., suministro de cerámicos CELIMA;

- CÍA. MINERA LUREN S.A., suministro de ladrillos LACASA Placa P-10;

- CONTRASTE DE MEDIDORES E.I.R.L., suministro de medidores de agua;

- CORPORACIÓN CERÁMICA S.A., suministro de griferías y sanitarios TREBOL;

- CORPORACIÓN MARA S.A., suministro de pintura AURORA;

- DECORLUX S.A.C., suministro e instalación de pisos laminados;

- FIRTH INDUSTRIES PERÚ S.A., suministro de concreto premezclado;

- FISHER CORPORATION S.A.C., suministro de intercomunicadores COMMAX-DELTA y cerraduras PARKER LOCKS;

- INDUSTRIAL EPEM S.A., suministro de tomacorrientes e interruptores; 
- ITIC S.A., suministro de aditivos CHEMA para enchapar y fraguar cerámicos;

- J V ASCENSORES S.A., suministro e instalación de ascensor importado;

- TRADI S.A., suministro de barras de acero corrugado, clavos y alambres.

\subsubsection{Selección de la tecnología}

La selección de la tecnología estuvo relacionada al diseño y características propias del edificio. En su estructura empleamos concreto armado, es decir, concreto de diferentes resistencias reforzado con barras de acero corrugado dimensionado y de diferentes diámetros, para la edificación de zapatas, vigas de cimentación, columnas, vigas, techos aligerados, losas, cisterna, caseta de bombas, tanque elevado, cuarto de máquinas, escaleras y placas (muros estructurales), que eran encofrados con tableros de triplay fenólico de $18 \mathrm{~mm}$ x $1.22 \mathrm{~m}$ x $2.44 \mathrm{~m}$. El concreto premezclado fue suministrado y transportado por camiones mixer y bombeado hacia los pisos de mayor altura a través de bombas telescópicas de FIRTH. En los techos aligerados se emplearon además, viguetas prefabricadas pretensadas y bovedillas de arcilla también de FIRTH.

Figura 5.5

Instalación de vigas prefabricadas y bovedillas "FIRTH"

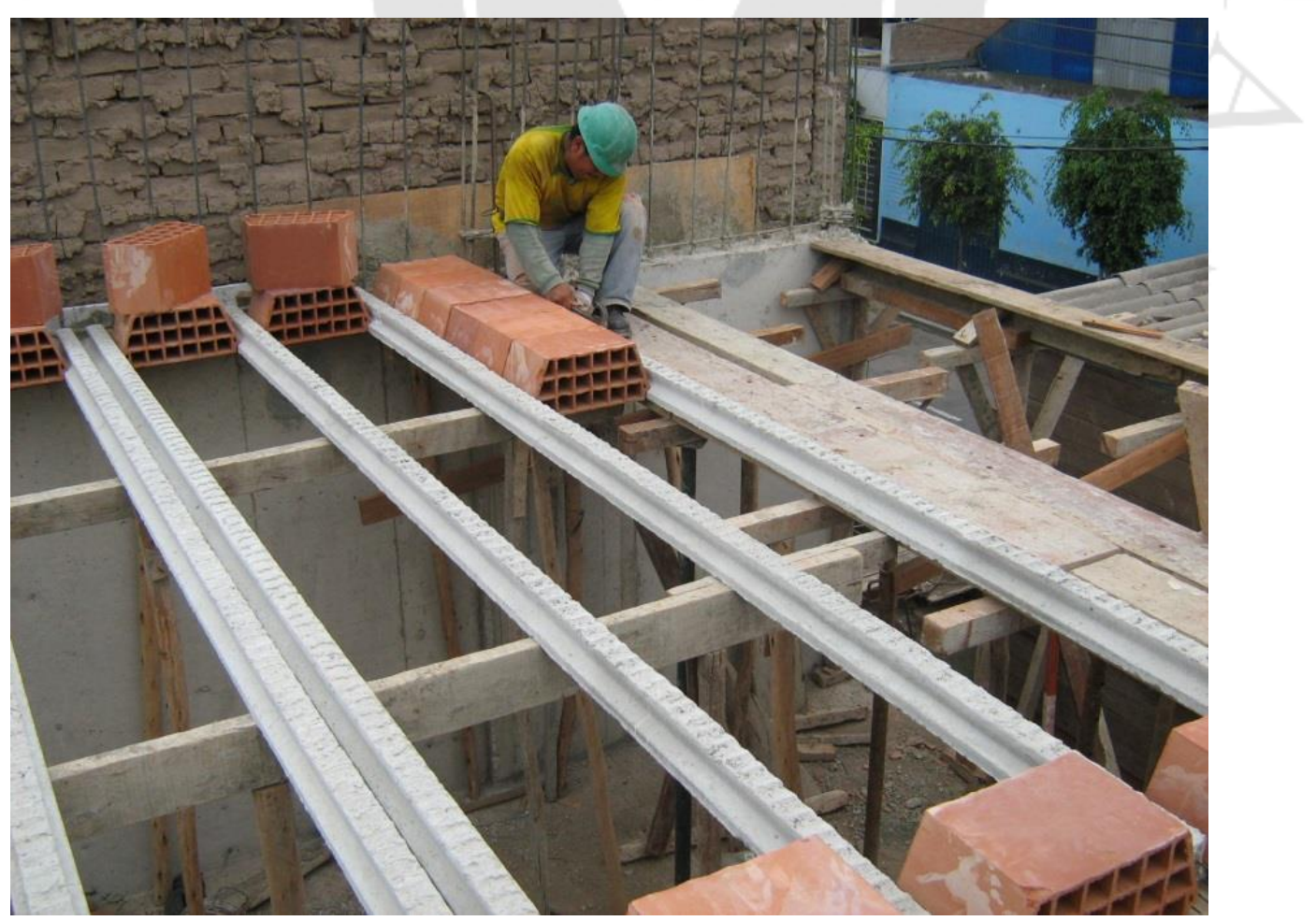

Elaboración: Propia. 
Así mismo, empleamos ladrillos sílico calcáreos LACASA Placa P-10 para los muros divisorios con un alto coeficiente termo acústico; cerámicos, parquet y pisos laminados de madera de alta resistencia al desgaste con base HDF (High Density Fibreboard) para los pisos; puertas principales de madera y puertas interiores de MDF (Medium Density Fibreboard); muebles de cocina y closets de las habitaciones de melamine; puertas metálicas cortafuego con cierrapuertas y barras anti pánico; pintura látex lavable en todos los ambientes. Utilizamos también, mamparas y ventanas de cristal primario y superficies de aluminio con el sistema NOVA; aparatos y accesorios sanitarios de alta calidad; electrobombas para el sistema contra incendios, para el consumo doméstico de agua potable y para el sumidero; un sistema de alarmas contra incendios, conformado por una central, una botonera de control y pulsadores; adicionalmente se consideró instalar detectores de humo, sensores de temperatura, extintores del tipo polvo químico seco (PQS) ABC de $4 \mathrm{~kg}$ (9 lbs) y gabinetes contra incendios ubicados en el hall de acceso a los departamentos y en el ingreso al edificio, con una manguera de agua de 30 metros de longitud; y un ascensor de última generación, de procedencia española, con capacidad para 6 personas (450 kgs) y con una velocidad de a 1.5 metros por segundo.

Figura 5.6

Vaciado de concreto en techos aligerados

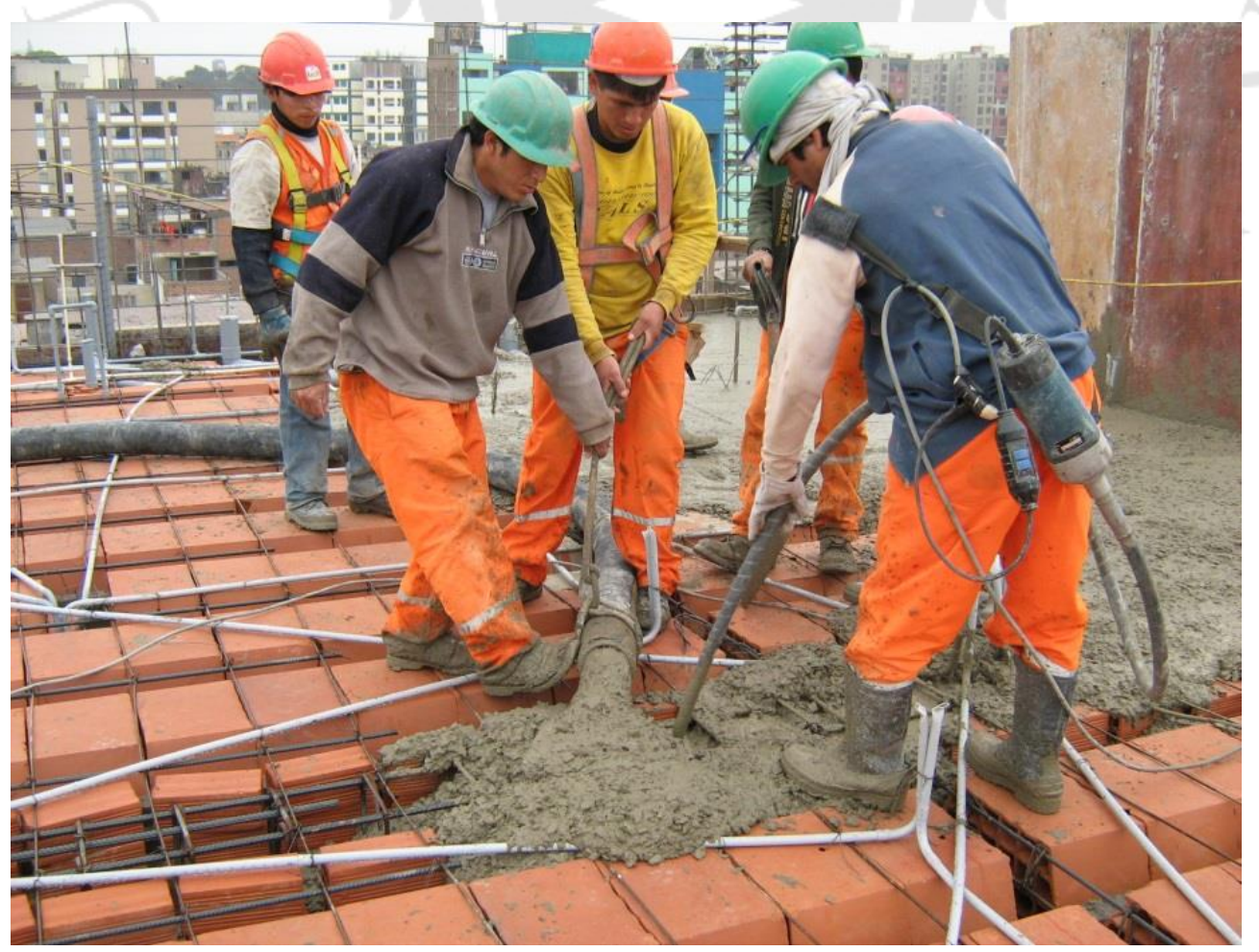

Elaboración: Propia. 
Figura 5.7

Camión mezclador de concreto y bomba telescópica "FIRTH"

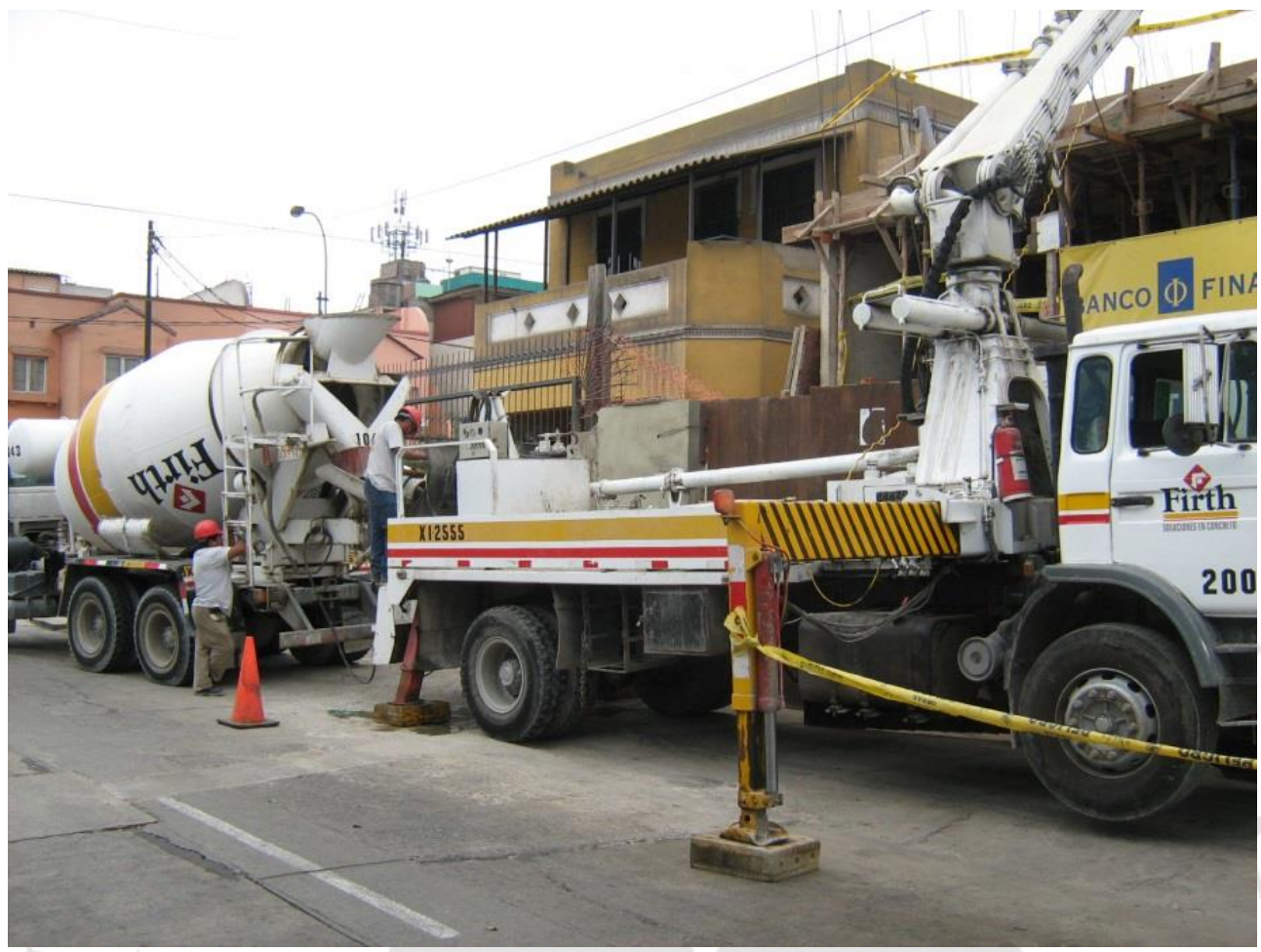

Elaboración: Propia.

Figura 5.8

Encofrado de placas estructurales

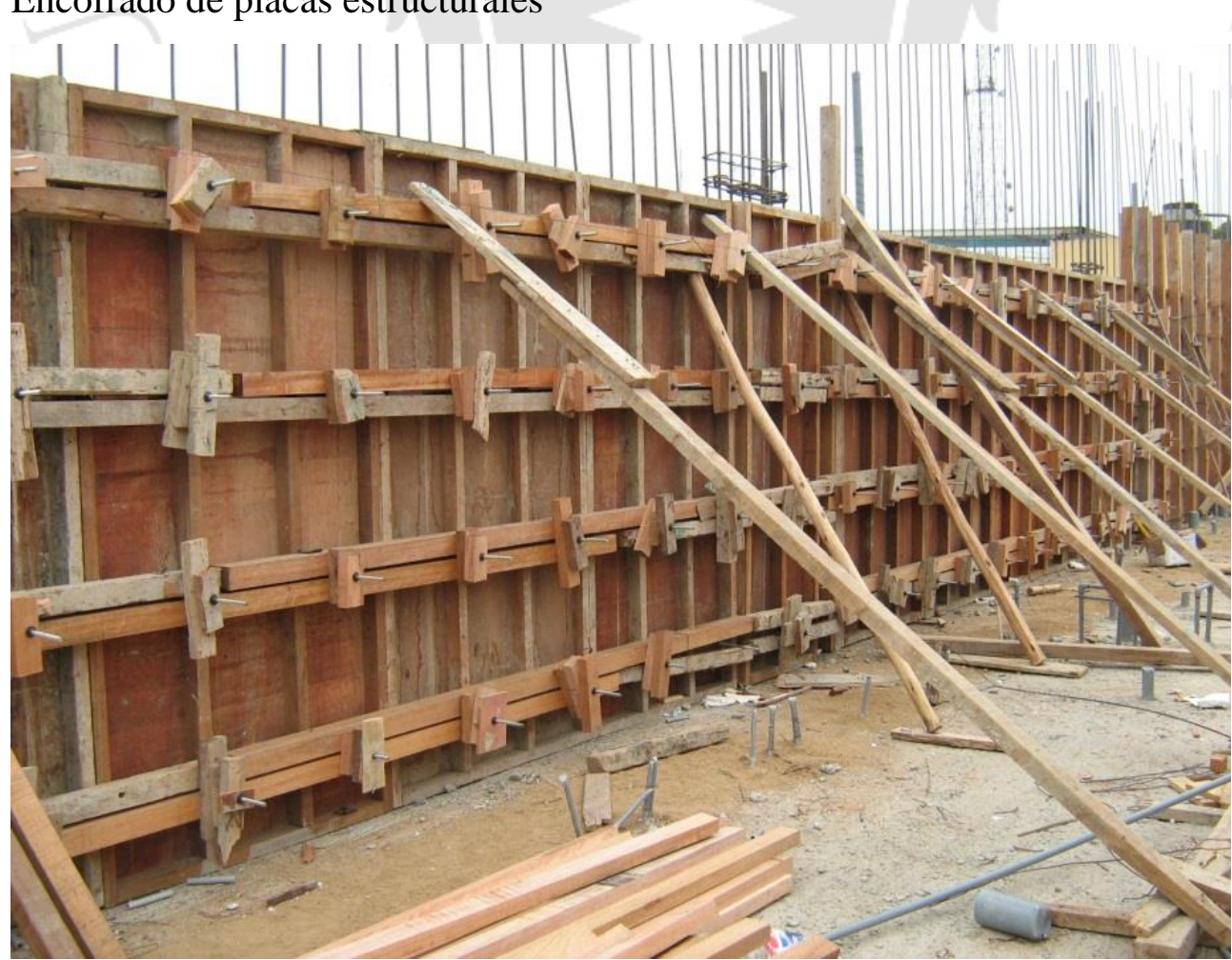

Elaboración: Propia. 


\subsubsection{Estrategia logística}

Nuestra estrategia logística se basó en tres políticas fundamentales, una política de abastecimiento, una política de inventarios y una política de manejo de residuos.

Respecto a nuestra política de abastecimiento, sería la Jefatura de Administración la responsable de manejarla o ejecutarla. Para ello determinamos dos tipos de compras, compras internas y compras estratégicas:

- Las compras internas correspondían a la adquisición de artículos y/o insumos (útiles de oficina, equipos de cómputo, insumos de cómputo, combustible, artículos de publicidad y promoción, impresión de documentos como facturas, boletas de venta y notas de crédito, artículos de limpieza, etc.) y servicios (mantenimiento de los equipos de cómputo, transporte para realizar diligencias, asesoría legal externa y asesoría contable externa) necesarios para poder administrar la empresa. Estas compras se pagaban al contado y se realizaban cada dos meses.

- Las compras estratégicas concernían a la adquisición de los materiales de construcción, acabados, elementos de protección personal, artículos de seguridad, herramientas, equipos menores y servicios necesarios para la construcción del Edificio Torre Barrón. Para realizar estas compras se gestionaron líneas de crédito de 15 y 30 días con los diferentes proveedores y se aplicó el sistema de abastecimiento "Justo a Tiempo" (JAT) para trasladar íntegramente el costo de almacenaje al proveedor. Las compras estratégicas se realizaban de acuerdo al presupuesto y cronograma de compras elaborado por la Jefatura de Operaciones, con quien se coordinaba permanentemente. Esta jefatura no solo era responsable de la elaboración del presupuesto de compras, se encargaba además de controlar la calidad, la cantidad y los costos de los materiales requeridos. Este proceso de control se desarrollaba revisando los materiales que ingresaban obra, comparándolos con la guía de remisión, la factura correspondiente y la orden de compra generada por la Jefatura de Administración.

Respecto a nuestra política de inventarios, también ejecutada por la Jefatura de Administración, establecimos dos tipos de inventarios, de insumos internos y de insumos estratégicos: 
- Para el inventario de los insumos internos, mantuvimos un stock para dos meses de duración.

- Para el inventario de los insumos estratégicos, aplicamos el sistema "Justo a Tiempo" (JAT), con lo cual todo material adquirido para la ejecución de la obra se utilizaba ni bien era entregado por el proveedor. La única excepción se dio en el almacenamiento de las herramientas, equipos menores, elementos de protección personal y artículos de seguridad, manteniendo un stock para dos meses de duración.

Finalmente, en relación a nuestra política de manejo de residuos, determinamos que serían acopiados temporalmente en zonas establecidas para ello, por un máximo de 30 días. Una vez cumplido el plazo, los residuos eran llevados a centros de eliminación autorizados denominados rellenos sanitarios. Entre los principales residuos generados podemos mencionar: bolsas de cemento, trozos de madera, trozos de alambres y cables, trozos de barras de acero corrugado, trozos de ladrillos y cerámicos, desmonte, etc.

Figura 5.9

Proceso de eliminación de desmonte

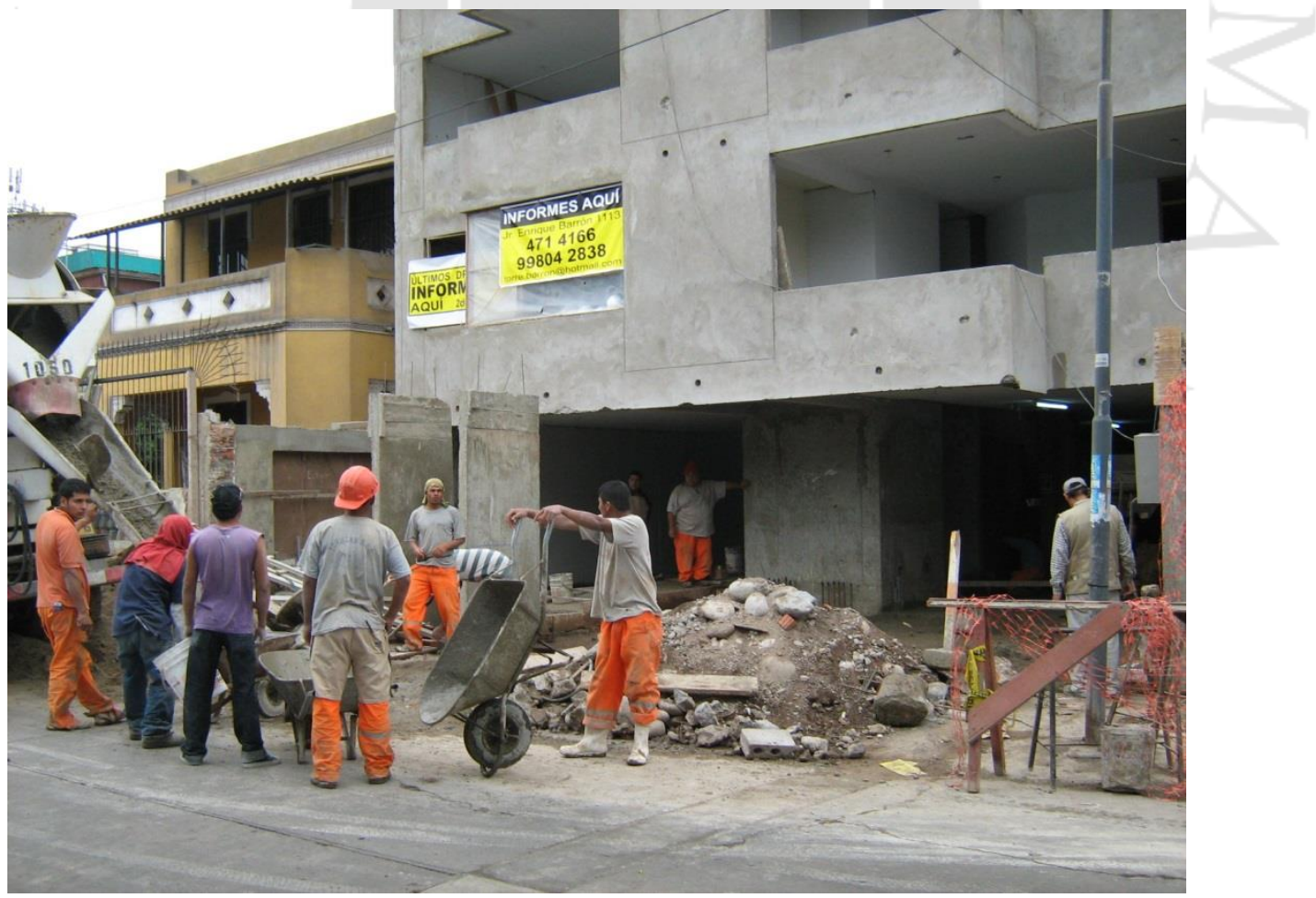

Elaboración: Propia. 


\section{CAPÍTULO VI: PLANEAMIENTO Y PRESUPUESTOS}

En el presente capítulo presentamos el proyecto en términos de presupuestos, es decir, desarrollamos el cronograma general de implementación del proyecto y las inversiones realizadas necesarias para su ejecución. Así mismo, presentamos las principales partidas que componen el planeamiento comercial y el planeamiento operativo. Finalmente, demostramos la estructura de financiamiento determinada para el proyecto.

\subsection{Cronograma general de implementación}

El proyecto inmobiliario multifamiliar "Torre Barrón” se desarrolló a lo largo de diez meses, desde la constitución de la empresa en marzo del 2008 y compra del inmueble donde se ejecutó la obra (abril del 2008) hasta su culminación con la declaratoria de fábrica de obra nueva, independización de las unidades inmobiliarias e inscripción del reglamento interno y junta de propietarios en la Superintendencia Nacional de los Registros Públicos (SUNARP) en diciembre del 2008.

En la siguiente tabla presentamos el cronograma general de implementación resumido en las principales partidas presupuestales. En el anexo 56 se muestra el cronograma detallado.

Tabla 6.1

Cronograma general de implementación resumido Marzo - Diciembre 2008

\begin{tabular}{|c|c|c|c|c|c|c|c|c|c|c|c|}
\hline Presupuestos & $\begin{array}{l}\text { Tipo } \\
\text { Gasto }\end{array}$ & $\begin{array}{c}\text { mar } \\
08\end{array}$ & $\begin{array}{c}\text { abr } \\
08\end{array}$ & $\begin{array}{c}\text { may } \\
08\end{array}$ & $\begin{array}{c}\text { jun } \\
08\end{array}$ & $\begin{array}{l}\text { jul } \\
08\end{array}$ & $\begin{array}{c}\text { ago } \\
08\end{array}$ & $\begin{array}{c}\text { sep } \\
08\end{array}$ & $\begin{array}{c}\text { oct } \\
08\end{array}$ & $\begin{array}{c}\text { nov } \\
08\end{array}$ & $\begin{array}{c}\text { dic } \\
08\end{array}$ \\
\hline P. de Ventas Netas & - & & & & & & & & & & \\
\hline P. de Gastos Marketing & Ind. & & & & & & & & & & \\
\hline P. de Gastos Admin. y Ventas & Ind. & & & & & & & & & & \\
\hline P. de Gastos Bancarios & Ind. & & & & B & & & & & & \\
\hline P. de Gastos Adq. del Terreno & Dir. & & & & & & & & & & \\
\hline P. de Gastos Proyecto & Ind. & & & & & & & & & & \\
\hline P. de Gastos Construcción & Dir. & & & & & & & & & & \\
\hline P. de Gastos Municipales & Ind. & & & & & & & & & & \\
\hline P. de Gastos Titulación & Ind. & & & & & & & & & & \\
\hline P. de Gastos Imprevistos & Ind. & & & & & & & & & & \\
\hline
\end{tabular}

Elaboración: Propia. 


\subsection{Inversiones preliminares}

Nuestras primeras inversiones se realizaron en tres partidas presupuestales fundamentales: inversión en gastos pre operativos, en capital de trabajo y en activos fijos.

La constitución de la empresa, conformada por la asesoría legal, la presentación de la minuta de constitución ante una notaría, la inscripción de la sociedad ante los Registros Públicos, la obtención del Registro Único del Contribuyente ante SUNAT, entre otros, representaron los gastos pre operativos, cuyo monto ascendió a S/. 4,000.00.

La inversión en capital de trabajo, conformada por el pago de remuneraciones, gastos de contabilidad, legalización de libros, compra de útiles de oficina, copias e impresiones, pago de servicios básicos, transporte, herramientas, equipos, combustible, gastos de representación, implementación de oficina de ventas, estudio de mercado e instalación del cartel de obra, ascendió a S/. 17,179.00.

Finalmente, la inversión en activos fijos, representada por la adquisición del terreno, el pago de alcabala, gastos notariales y registrales, ascendió a S/. 321,372.00.

\subsection{Planeamiento comercial}

La elaboración y control del planeamiento comercial fue responsabilidad del Jefe Comercial y estuvo conformado por los presupuestos de Ventas Netas y Cobranza; y por los presupuestos de gastos y desembolsos de Marketing, de Administración y Ventas y Bancarios, de acuerdo a la relación que se presenta a continuación:

- Presupuesto de Ventas Netas (ver anexo 57)

- Presupuesto de Cobranza por Ventas (ver anexo 58)

- Presupuesto de Gastos de Marketing (ver anexo 59)

- Presupuesto de Desembolso de Gastos de Marketing (ver anexo 60)

- Presupuesto de Gastos de Administración y Ventas (ver anexo 61)

- Presupuesto de Desembolso de Gastos de Administración y Ventas (ver anexo 62)

- Presupuesto de Gastos Bancarios (ver anexo 63)

- Presupuesto de Desembolso de Gastos Bancarios (ver anexo 64) 


\subsection{Planeamiento operativo}

En el caso del planeamiento operativo, su elaboración y control estuvieron a cargo del Jefe de Operaciones y fue conformado por los presupuestos de gastos y desembolsos que se mencionan a continuación:

- Presupuesto de Gastos por Adquisición de Terreno (ver anexo 65)

- Presupuesto de Desembolso de Gastos por Adquisición de Terreno (ver anexo 66)

- Presupuesto de Gastos del Proyecto (ver anexo 67)

- Presupuesto de Desembolso de Gastos del Proyecto (ver anexo 68)

- Presupuesto de Gastos de Construcción (ver anexo 69)

- Presupuesto de Desembolso de Gastos de Construcción (ver anexo 70)

- Presupuesto de Gastos Municipales (ver anexo 71)

- Presupuesto de Desembolso de Gastos Municipales (ver anexo 72)

- Presupuesto de Gastos de Titulación (ver anexo 73)

- Presupuesto de Desembolso de Gastos de Titulación (ver anexo 74)

- Presupuesto de Gastos Imprevistos (ver anexo 75)

- Presupuesto de Desembolso de Gastos Imprevistos (ver anexo 76)

\subsection{Financiamiento}

La búsqueda de financiamiento del proyecto estuvo a cargo del Jefe Administrativo y estuvo representada por dos presupuestos:

- Presupuesto de Gastos Financieros (ver anexo 77)

- Presupuesto de Pago de Deuda (ver anexo 78)

Respecto a la estructura de financiamiento del proyecto, estuvo conformada por cuatro componentes:

- Aporte o Capital Propio de S/. 548,000.00, que representó el 22.8\%;

- Financiamiento Bancario de S/. 220,000, que representó el 9.2\%;

- Desembolso de los Créditos Hipotecarios de S/. 1,128,509.00, que representaron el $46.9 \%$;

- Desembolso de las Cuotas Iniciales proporcionadas por los clientes de S/. $507,600.00$, que representaron el $21.1 \%$. 


\section{CAPÍTULO VII: ESTADOS FINANCIEROS}

En el presente capítulo realizamos un análisis de los estados financieros de la empresa: el Estado de Resultados (también llamado Estado de Ganancias y Pérdidas), el Estado de Situación Financiera (también conocido como Balance General) y el Flujo de Caja.

\subsection{Estado de Resultados}

De acuerdo a las partidas contables del Estado de Resultados que mostramos en la tabla 7.1, podemos determinar los siguientes ratios financieros:

- Margen Bruto (U.B. / V.N.): 17.88\%, es decir, por cada S/. 1.00 de ventas obtuvimos S/. 0.1788 de ganancia bruta;

- Margen Operativo (U.O. / V.N.): 8.91\%, es decir, por cada S/. 1.00 de ventas obtuvimos S/. 0.0891 de ganancia operativa;

- Margen antes de Impuestos (U.A.I. / V.N.): 8.21\%, es decir, por cada S/. 1.00 de ventas obtuvimos S/. 0.0821 de ganancia antes de impuestos;

- Margen Neto (U.N. / V.N.): 5.75\%, es decir, por cada S/. 1.00 de ventas obtuvimos S/. 0.0575 de ganancia neta.

Así mismo, podemos concluir que el Costo de Ventas representó el $87.1 \%$ del total de costos y gastos (S/. 2'196,497.00), los Gastos Operativos el 9.5\%, los Gastos Financieros el $0.7 \%$ y el Impuesto a la Renta el 2.6\%. Ver al detalle en el anexo 79.

Tabla 7.1

Estado de Resultados del 01Marzo al 31 Diciembre 2008

\begin{tabular}{|lcr|}
\hline Partidas Contables & Siglas & \multicolumn{1}{c|}{ Total en NS/. } \\
\hline Ventas Netas & V.N. & $2,330,388$ \\
(-) Costo de Ventas & C.V. & $-1,913,776$ \\
Utilidad Bruta & U.B. & 416,612 \\
(-) Gastos Operativos & G.O. & $-209,030$ \\
Utilidad Operativa & U.O. & 207,582 \\
(-) Gastos Financieros & G.F. & $-16,309$ \\
Utilidad antes de Impuestos & U.A.I. & 191,273 \\
(-) Impuesto a la Renta $(30 \%)$ & I.R. & $-57,382$ \\
\hline Utilidad Neta & U.N. & 133,891 \\
\hline
\end{tabular}

Elaboración: Propia. 


\section{2. $\quad$ Estado de Situación Financiera}

De acuerdo a las partidas contables del Estado de Situación Financiera que mostramos en la tabla 7.2, podemos determinar los siguientes ratios financieros:

- Liquidez (Activo Cte. / Pasivo Cte.): 35.55 lo que quiere decir que por cada S/. 1.00 de pasivo corriente, tuvimos S/. 35.55 de respaldo en el activo cte.;

- Capital de Trabajo (Activo Cte. - Pasivo Cte.): S/. 681,891.00 con lo cual, tuvimos una gran disponibilidad monetaria para llevar a cabo nuestras operaciones corrientes, luego de haber cubierto nuestras deudas de corto plazo;

- Rentabilidad Patrimonial o ROE (Utilidad Neta / Patrimonio): 19.64\%, es decir, por cada S/. 1.00 invertido obtuvimos una ganancia de S/. 0.1964, cumpliéndose de esta manera nuestro objetivo estratégico.

- Rentabilidad de los Activos o ROA (Utilidad Neta / Activo Total): 18.08\%, es decir, cada S/. 1.00 de activos generaron S/. 0.1808 de ganancia.

- Rentabilidad sobre el Aporte (Utilidad Neta / Aporte): 24.43\%, es decir, por cada S/. 1.00 aportado por los accionistas obtuvimos una ganancia de S/. 0.24

Tabla 7.2

Estado de Situación Financiera al 31 de Diciembre de 2008

\begin{tabular}{|c|c|}
\hline \multicolumn{2}{|l|}{ Activo } \\
\hline Caja y Bancos & 605,564 \\
\hline Valores Negociables & 0 \\
\hline Cuentas por cobrar a corto & 0 \\
\hline Inventario & 0 \\
\hline Otros Activos & 96,064 \\
\hline Total Activo Corriente & 701,628 \\
\hline Activo Tangible & 0 \\
\hline Depreciación Acumulada & 0 \\
\hline Activo Intangible & 0 \\
\hline Amortización Intangible & 0 \\
\hline Total Activo Fijo & 0 \\
\hline Total Activo & 701,628 \\
\hline
\end{tabular}

\section{Pasivo y Patrimonio}

Cuentas por pagar

Aportes por pagar

2,070

Retenciones por pagar

4,657

CTS por pagar

2,236

IGV por pagar

Impuestos por pagar

Intereses por pagar

Pte. Cte. de la DLP

Total Pasivo Corriente

19,737

Deuda a Largo Plazo

Capital Social

548,000

Reserva Legal

Resultados Acumulados

133,891

Total Patrimonio

681,891

Total Pasivo y Patrimonio 


\subsection{Flujo de Caja}

El análisis del Flujo de Caja nos permitió determinar que pese al déficit obtenido de la operación del proyecto, el aporte de los accionistas y el financiamiento bancario nos permitieron conseguir un saldo final positivo. Así mismo, pudimos concluir que los Costos Directos (Terreno y Construcción) representaron el 79.31\% del total de egresos, mientras que los Costos Indirectos (Marketing, Administración y Ventas, Bancarios, Proyecto, Municipales, Titulación, Imprevistos, Amortización, Intereses, Pago a Cuenta del Impuesto a la Renta, etc.) constituyeron el 20.69\%. Ver tabla 7.3 y anexo 80.

\section{Tabla 7.3}

Flujo de Caja al 31 de Diciembre de 2008

\begin{tabular}{|lr|}
\hline Ingresos - Egresos & Total \\
\hline Ingresos: & \\
Contado & $2,538,000$ \\
\hline \hline Total Ingresos & $2,538,000$ \\
\hline \hline Egresos: \\
Comerciales: \\
\hline (I) Marketing \\
\hline (I) Administración y Ventas \\
\hline (I) Bancarios & 174,912 \\
\hline Operativos: & 27,370 \\
(D) Terreno & 321,372 \\
(I) Proyecto & 10,000 \\
(D) Construcción & $1,820,340$ \\
(I) Municipales & 21,380 \\
(I) Titulación & 18,226 \\
(I) Imprevistos & 17,850 \\
Otros egresos: & 220,000 \\
(I) Amortización & 16,309 \\
(I) Intereses & 46,608 \\
(I) Pago a Cuenta IR & $2,700,436$ \\
\hline \hline Total Egresos & $-162,436$ \\
\hline Ingresos menos Egresos & \\
\hline
\end{tabular}

\begin{tabular}{|lr|}
\hline Flujo de Caja & Total \\
\hline Saldo Inicial & 4,000 \\
Excedente / Déficit & $-162,436$ \\
Préstamo Accionistas / Banco & 764,000 \\
Saldo Final & 605,564 \\
\hline
\end{tabular}

Elaboración: Propia. 


\section{CAPÍTULO VIII: EVALUACIÓN DE FACTIBILIDAD DEL PROYECTO}

En el presente capítulo calculamos la factibilidad del proyecto determinando y evaluando los flujos económico y financiero, planteados en un horizonte de tiempo de cinco años. Así mismo, realizamos un análisis del punto de equilibrio y presentamos una simulación y el respectivo análisis de sensibilidad del proyecto en dos posibles escenarios, optimista y conservador.

\subsection{Determinación del costo de inversión de los accionistas}

El costo de inversión de los accionistas o también denominado el Costo de Oportunidad del Capital, lo establecimos basándonos en el estudio del mercado inmobiliario realizado por el BBVA Banco Continental en el 2007, en el que determinaron que los ratios de rentabilidad sobre el patrimonio fueron superiores a $20 \%$. Sin embargo, para evaluar nuestro proyecto utilizamos como tasa de descuento el Costo Promedio Ponderado del Capital o Weighted Average Cost of Capital (WACC) para un horizonte de tiempo de 5 años, que fue de $7.20 \%$.

Para determinar la tasa de descuento WACC, empleamos la siguiente fórmula: $\mathrm{WACC}=\% \mathrm{E} \times \mathrm{Ke}+\% \mathrm{D}^{\prime} \times \mathrm{Kd}^{\prime} \times(1-\mathrm{IMP})$, donde:

- \%E representa el porcentaje de Aporte Propio, igual a 22.8\%;

- Ke representa el Costo de Oportunidad de Capital, igual a 20\%;

- \%D' representa el porcentaje de Capital de Terceros, igual a 77.2\%; conformado por la sumatoria de los porcentajes del financiamiento bancario (\%D) de $9.2 \%$, de los desembolsos por créditos hipotecarios $(\% \mathrm{H})$ de $46.9 \%$ y de los desembolsos de las cuotas iniciales de los clientes (\% I) de $21.1 \%$;

- Kd' representa el Costo de la deuda, igual a 4.9\%; que es el promedio ponderado de los costos del financiamiento bancario (Kd) de $41.31 \%$ (TEA otorgada por el Banco Financiero) y los costos de los desembolsos por créditos hipotecarios $(\mathrm{Kh})$ y cuotas iniciales $(\mathrm{Ki})$ que fueron iguales a $0 \%$, ya que no tienen costo financiero;

- IMP representa el Impuesto a la Renta del 2008, igual a 30\%; 


\subsection{Determinación de las variables estimadas para el proyecto}

Para elaborar y proyectar los flujos económico y financiero del proyecto en un horizonte de tiempo de cinco años consideramos que tanto nuestros ingresos como nuestras inversiones se incrementarían anualmente.

Para determinar la variación porcentual anual de los ingresos, analizamos el comportamiento de los indicadores del mercado inmobiliario del 2003 al 2007 y nos permitieron concluir que tanto la demanda efectiva de hogares como el precio promedio de los departamentos en Lima Metropolitana mostraban una tendencia creciente. En el caso de la demanda efectiva de hogares, establecimos que la variación porcentual anual promedio fue de $7 \%$ y en el caso específico del precio promedio de los departamentos, determinamos que la variación porcentual anual promedio fue del $9 \%$, por lo que establecimos que dicho porcentaje representaría la variación porcentual anual de nuestros ingresos. Ver anexo 81.

Para establecer la variación porcentual anual de las inversiones, analizamos la evolución del precio de los terrenos y de los materiales, del monto de la Unidad Impositiva Tributaria (UIT), de la Remuneración Mínima Vital (RMV) y de la Remuneración Promedio de los Empleados en el Sector Construcción (RPESC) del 2003 al 2007. La evolución del precio de los terrenos nos llevó a determinar que la variación porcentual anual promedio fue de $11 \%$, por lo que establecimos que dicho porcentaje representaría la variación porcentual anual de nuestra inversión en terrenos. Por otro lado, la evolución porcentual anual del precio de los materiales fue en promedio de $6 \%$, por lo que determinamos que dicho porcentaje representaría la variación porcentual anual de nuestra inversión en construcción. Para determinar la variación porcentual anual de los costos indirectos, tomamos en cuenta las variaciones porcentuales anuales promedio de la UIT (2\%), de la RMV (5\%) y de la RPESC (5\%), estableciendo el valor más alto para la variación porcentual anual de nuestra inversión en costos indirectos, es decir, $5 \%$. Ver anexo 82.

En resumen, las variaciones porcentuales anuales establecidas para evaluar el proyecto son: WACC de $7.20 \%$; el préstamo representaría el $9.20 \%$ del total de la inversión anual en el proyecto; los ingresos se incrementarían en 9\% anualmente; la inversión en terrenos aumentaría en 11\%, la inversión en construcción en $6 \%$ y la inversión en costos indirectos en $5 \%$, anualmente. 


\subsection{Flujo económico del proyecto estimado}

Tomando en cuenta las variables mencionadas y los incrementos porcentuales supuestos, determinamos el flujo económico, tal como se muestra a continuación.

Tabla 8.1

Flujo económico del proyecto estimado

\begin{tabular}{|lrrrrrr|}
\hline & Año 0 & Año 1 & Año 2 & Año 3 & Año 4 & Año 5 \\
\hline Ingresos & & $2,538,000$ & $2,769,517$ & $3,022,153$ & $3,297,835$ & $3,598,664$ \\
Inversión & & & & & \\
Terreno & & $-321,372$ & $-356,385$ & $-395,212$ & $-438,269$ & $-486,018$ \\
Construcción & & $-1,820,340$ & $-1,932,109$ & $-2,050,740$ & $-2,176,656$ & $-2,310,302$ \\
Costos Indirectos & & $-262,397$ & $-276,386$ & $-291,120$ & $-306,641$ & $-322,988$ \\
Inversión Inicial & $-548,000$ & & & & & \\
\hline Flujo Económico & $-548,000$ & 133,891 & 204,638 & 285,080 & 376,269 & 479,356 \\
\hline
\end{tabular}

Elaboración: Propia.

\subsection{Evaluación económica del proyecto estimado (VAN y TIR Económicos)}

Para realizar la evaluación económica, utilizamos dos parámetros fundamentales, el Valor Actual Neto Económico (VANE) y la Tasa Interna de Retorno Económica (TIRE), obteniendo los siguientes resultados: VANE de S/. 609,719 y TIRE de 35\%.

\subsection{Flujo financiero del proyecto estimado}

Para elaborar y proyectar el flujo financiero del proyecto en un horizonte de tiempo de cinco años consideramos que el préstamo representaría un $9.20 \%$ del total de nuestras inversiones., tal como se muestra a continuación.

Tabla 8.2

Flujo financiero del proyecto estimado

\begin{tabular}{|lrrrrrr|}
\hline \multicolumn{1}{|l}{} & Año 0 & Año 1 & Año 2 & Año 3 & Año 4 & Año 5 \\
\hline Financiamiento & & & & & & \\
Amortización & & $-220,000$ & $-234,712$ & $-250,470$ & $-267,352$ & $-285,448$ \\
Interés & & $-16,302$ & $-17,392$ & $-18,560$ & $-19,811$ & $-21,152$ \\
Préstamo & 220,000 & 234,712 & 250,470 & 267,352 & 285,448 & \\
\hline \hline FCD & 220,000 & $-1,590$ & $-1,635$ & $-1,677$ & $-1,715$ & $-306,600$ \\
\hline & & & & & & \\
\hline Flujo Financiero & $-328,000$ & 132,301 & 203,003 & 283,404 & 374,554 & 172,757 \\
\hline Elaboración: Propia. & & & & & \\
\hline
\end{tabular}




\subsection{Evaluación financiera del proyecto estimado (VAN y TIR Financieros)}

Para complementar la evaluación de la factibilidad del proyecto realizamos una evaluación financiera, utilizando dos parámetros, el Valor Actual Neto Financiero (VANF) y la Tasa Interna de Retorno Financiera (TIRF), obteniendo los siguientes resultados: VANF de S/. 607,632 y TIRF de 55\%.

\subsection{Análisis del punto de equilibrio}

Para determinar el punto de equilibrio nos basamos en el supuesto de que nuestras inversiones se incrementarían anualmente, tal como lo establecimos inicialmente (terreno en $11 \%$, construcción en $6 \%$ y costos indirectos en 5\%), que el WACC sería de $7.20 \%$ y que nuestros ingresos solo aumentarían en $6 \%$, es decir, se reducirían en $30 \%$ respecto a nuestro hipotético escenario inicial. Tomando en cuenta dichas variables y los incrementos porcentuales supuestos, determinamos el flujo económico, tal como se muestra en la siguiente tabla.

Tabla 8.3

Flujo económico del proyecto en punto de equilibrio

\begin{tabular}{|lrrrrrr|}
\hline & Año 0 & Año 1 & Año 2 & Año 3 & Año 4 & Año 5 \\
\hline Ingresos & & $2,538,000$ & $2,700,164$ & $2,872,690$ & $3,056,239$ & $3,251,516$ \\
Inversión & & & & & & \\
Terreno & & $-321,372$ & $-356,385$ & $-395,212$ & $-438,269$ & $-486,018$ \\
Construcción & & $-1,820,340$ & $-1,932,109$ & $-2,050,740$ & $-2,176,656$ & $-2,310,302$ \\
Costos Indirectos & & $-262,397$ & $-276,386$ & $-291,120$ & $-306,641$ & $-322,988$ \\
Inversión Inicial & $-548,000$ & & & & & \\
\hline \hline F. Económico PE & $-548,000$ & 133,891 & 135,285 & 135,617 & 134,673 & 132,208 \\
\hline
\end{tabular}

Elaboración: Propia.

Utilizando los parámetros Valor Actual Neto Económico en Punto de Equilibrio (VANE PE) y la Tasa Interna de Retorno Económica en Punto de Equilibrio (TIRE PE), obtuvimos los siguientes resultados: VANE PE igual a Cero y una TIRE PE de $7.20 \%$, equivalente al WACC establecido.

\subsection{Simulación bajo un escenario optimista}

Para realizar una simulación de nuestro proyecto bajo un escenario optimista nos basamos en el supuesto de que nuestras inversiones se incrementarían anualmente, tal 
como lo establecimos originalmente (terreno en $11 \%$, construcción en $6 \%$ y costos indirectos en 5\%), que nuestros ingresos aumentarían en $14 \%$ anualmente, es decir, se incrementarían en $50 \%$ respecto a nuestro hipotético escenario inicial, el préstamo representaría un $10 \%$ de la inversión total y que la tasa de descuento WACC sería de $6.89 \%$, es decir, se reduciría en $4 \%$ respecto al escenario original. Tomando en cuenta dichas variables y los incrementos porcentuales supuestos, determinamos el flujo económico, tal como se muestra a continuación.

Tabla 8.4

Flujo económico del proyecto bajo un escenario optimista

\begin{tabular}{|lrrrrrr||}
\hline & Año 0 & Año 1 & Año 2 & Año 3 & Año 4 & Año 5 \\
\hline Ingresos & & $2,538,000$ & $2,885,276$ & $3,280,069$ & $3,728,882$ & $4,239,107$ \\
Inversión & & & & & & \\
Terreno & & $-321,372$ & $-356,385$ & $-395,212$ & $-438,269$ & $-486,018$ \\
Construcción & & $-1,820,340$ & $-1,932,109$ & $-2,050,740$ & $-2,176,656$ & $-2,310,302$ \\
Costos Indirectos & & $-262,397$ & $-276,386$ & $-291,120$ & $-306,641$ & $-322,988$ \\
Inversión Inicial & $-548,000$ & & & & & \\
\hline \hline F. Económico EO & $-548,000$ & 133,891 & 320,396 & 542,996 & 807,317 & $1,119,799$ \\
\hline
\end{tabular}

Elaboración: Propia.

Utilizando los parámetros Valor Actual Neto Económico bajo un Escenario Optimista (VANE Eo) y la Tasa Interna de Retorno Económica bajo un Escenario Optimista (TIRE EO), obtuvimos los siguientes resultados: VANE EO de S/. 1,723, 146 y una TIRE EO de $62 \%$.

De igual modo, determinamos el flujo financiero del proyecto bajo un escenario optimista, tal como se muestra a continuación.

Tabla 8.5

Flujo financiero del proyecto bajo un escenario optimista

\begin{tabular}{|lrrrrrr||}
\hline & Año 0 & Año 1 & Año 2 & Año 3 & Año 4 & Año 5 \\
\hline Financiamiento & & & & & & \\
Amortización & & $-220,000$ & $-256,488$ & $-273,707$ & $-292,157$ & $-311,931$ \\
Interés & & $-16,302$ & $-19,006$ & $-20,282$ & $-21,649$ & $-23,114$ \\
Préstamo & 220,000 & 256,488 & 273,707 & 292,157 & 311,931 & \\
\hline FCD & 220,000 & 20,186 & $-1,786$ & $-1,832$ & $-1,875$ & $-335,045$ \\
\hline
\end{tabular}

Elaboración: Propia. 
Utilizando los parámetros Valor Actual Neto Financiero bajo un Escenario Optimista (VANF EO) y la Tasa Interna de Retorno Financiera bajo un Escenario Optimista (TIRF EO), obtuvimos los siguientes resultados: VANF EO de S/. 1,717,432 y TIRF EO de $93 \%$.

En conclusión, podemos afirmar que tanto los parámetros económicos como los financieros nos indican que el proyecto es factible bajo el escenario optimista.

\subsection{Simulación bajo un escenario conservador}

Para realizar una simulación de nuestro proyecto bajo un escenario conservador nos basamos en el supuesto de que nuestros ingresos se incrementarían en $14 \%$ anualmente, nuestras inversiones aumentarían $16 \%$ en terreno, $9 \%$ en construcción y $8 \%$ en costos indirectos, es decir, se incrementarían en $50 \%$ respecto a nuestro hipotético escenario inicial. El préstamo representaría el 35\% de la inversión total del proyecto y el WACC ascendería a $14.12 \%$, es decir, $96 \%$ por encima de la tasa de descuento original. Tomando en cuenta dichas variables y los incrementos porcentuales supuestos, determinamos el flujo económico, tal como se muestra en la siguiente tabla.

Tabla 8.6

Flujo económico del proyecto bajo un escenario conservador

\begin{tabular}{|lrrrrrr||}
\hline & Año 0 & Año 1 & Año 2 & Año 3 & Año 4 & Año 5 \\
\hline Ingresos & & $2,538,000$ & $2,885,276$ & $3,280,069$ & $3,728,882$ & $4,239,107$ \\
Inversión & & & & & & \\
Terreno & & $-321,372$ & $-373,891$ & $-434,993$ & $-506,080$ & $-588,784$ \\
Construcción & & $-1,820,340$ & $-1,987,993$ & $-2,171,087$ & $-2,371,045$ & $-2,589,418$ \\
Costos Indirectos & & $-262,397$ & $-283,380$ & $-306,041$ & $-330,515$ & $-356,946$ \\
Inversión Inicial & $-548,000$ & & & & & \\
\hline F. Económico EC & $-548,000$ & 133,891 & 240,011 & 367,947 & 521,243 & 703,960 \\
\hline
\end{tabular}

Elaboración: Propia.

Utilizando los parámetros Valor Actual Neto Económico bajo un Escenario Conservador (VANE EC) y la Tasa Interna de Retorno Económica bajo un Escenario Conservador (TIRE EC), obtuvimos los siguientes resultados: VANE EC de S/. 672,216 y una TIRE EC $_{\text {de }} 46 \%$.

De igual modo, determinamos el flujo financiero del proyecto bajo un escenario conservador, tal como se muestra en la siguiente tabla. 
Tabla 8.7

Flujo financiero del proyecto bajo un escenario conservador

\begin{tabular}{|lrrrrrr||}
\hline & Año 0 & Año 1 & Año 2 & Año 3 & Año 4 & Año 5 \\
\hline Financiamiento & & & & & & \\
Amortización & & $-220,000$ & $-925,843$ & $-1,019,243$ & $-1,122,674$ & $-1,237,302$ \\
Interés & & $-16,302$ & $-68,605$ & $-75,526$ & $-83,190$ & $-91,684$ \\
Préstamo & 220,000 & 925,843 & $1,019,243$ & $1,122,674$ & $1,237,302$ & \\
\hline FCD & 220,000 & 689,541 & 24,795 & 27,905 & 31,438 & $-1,328,986$ \\
\hline & & & & & & \\
\hline F. Financiero & & & & & & \\
\hline
\end{tabular}

Elaboración: Propia.

Utilizando los parámetros Valor Actual Neto Financiero bajo un Escenario Conservador (VANF EC) y la Tasa Interna de Retorno Financiera bajo un Escenario Conservador (TIRF EC), obtuvimos los siguientes resultados: VANF EC de S/. 866,172 y una TIRF EC de $196 \%$.

En conclusión, podemos afirmar que tanto los parámetros económicos como los financieros nos indican que el proyecto también es factible bajo el escenario conservador. 


\section{CONCLUSIONES}

- Desde mediados del 2003 hasta inicios del 2008, los principales indicadores económicos, demográficos, sociales, políticos y jurídicos mostraban una situación propicia para emprender un negocio. Los favorables indicadores del sector construcción confirmaban tal situación. Sin embargo, fueron tres los factores decisivos para ingresar al mercado inmobiliario: la gran demanda insatisfecha de hogares en Lima determinada en el 2007 (283,019 hogares), la baja participación de mercado de las empresas constructoras (ninguna de las más de 400 empresas dedicadas a la construcción de proyectos inmobiliarios representaba más del $10 \%$ de las ventas) y las altas rentabilidades obtenidas (más de 20\% de rentabilidad sobre sus patrimonios, durante el 2006 y 2007).

- Para poder determinar las principales necesidades y preferencias de los clientes, realizamos un estudio de mercado, basado en encuestas y en la observación y análisis de los proyectos ejecutados por las empresas competidoras en la zona de influencia del proyecto. Esto nos llevó a diseñar un proyecto que se diferenció de la competencia, ofreciendo departamentos con mayor área y menor precio por metro cuadrado, cumpliendo con las expectativas de los clientes.

- La alta rivalidad entre las empresas competidoras, el alto poder de negociación de los proveedores y la creciente entrada de nuevos competidores, generaron una alta intensidad de la competencia entre las empresas de la industria, por lo que decidimos seguir una estrategia intensiva de penetración en el mercado a nivel corporativo y una estrategia genérica de diferenciación, enfocada en un segmento del mercado a nivel de negocio. Ambas estrategias se complementaron al encontrar la oportunidad de cubrir parte de la demanda insatisfecha y poder obtener una participación del mercado mínima de $10 \%$.

- En ese sentido, decidimos contar con una estructura organizativa reducida y horizontal, conformada por una Gerencia General y tres jefaturas. La Jefatura Comercial se encargaría de las actividades de marketing, ventas, servicios de venta y post venta. La Jefatura de Operaciones se responsabilizaría de las actividades de operaciones, logística interna y externa. La Jefatura de Administración respondería por las actividades de soporte, infraestructura de la empresa, gestión de recursos humanos, desarrollo tecnológico y abastecimiento. 
- Nuestro proyecto consistió en la construcción de un edificio multifamiliar denominado "Torre Barrón", compuesto por un bloque de siete pisos de altura, con un total de 12 departamentos, distribuidos a razón de dos departamentos por piso, a partir del segundo nivel, con áreas que oscilaban entre los 90 y $127 \mathrm{~m} 2$ y 12 estacionamientos en el primer nivel. Se edificó sobre un terreno de $330 \mathrm{~m} 2$, en la Urbanización de Santa Beatriz, del Distrito de Cercado de Lima. Los departamentos fueron del tipo flat y estaban compuestos de sala-comedor, 3 dormitorios, 2 baños y cocina-lavandería, baño de servicio y cuarto de servicio. Los precios oscilaron entre los S/. 187 mil y S/. 223 mil (S/. 2 mil por m2).

- Nuestra estrategia de publicidad buscaba informar y persuadir a nuestro público objetivo. Para ello empleamos diferentes medios de comunicación, tales como la distribución de volantes dípticos, la instalación de carteles de obra, publicaciones en los principales diarios impresos, envío de correos electrónicos, creación de una cuenta de Facebook, entre otros. Adicionalmente, ofrecimos un descuento de hasta el $5 \%$ por la compra futura del inmueble, si se realizaba en la etapa de pre venta o se adquiría al contado.

- Para determinar la localización óptima del proyecto, desarrollamos un estudio técnico a nivel de macro localización para acordar la región del país donde nos estableceríamos y otro a nivel de micro localización para convenir la ubicación exacta del proyecto en la región escogida (Urbanización de Santa Beatriz).

- La obra se ejecutó a lo largo de siete meses, siendo las principales partidas constructivas: las estructuras, la arquitectura, las instalaciones eléctricas, sanitarias, electromecánicas y de gas. Sin embargo, el proyecto se desarrolló en diez meses, desde la constitución de la empresa (marzo 2008) hasta la inscripción de independización de los departamentos en los Registros Públicos (diciembre 2008), realizando diferentes gestiones en las entidades públicas y privadas involucradas, como la Municipalidad Metropolitana de Lima, la Superintendencia Nacional de los Registros Públicos (SUNARP), el Servicio de Parques de Lima (SERPAR), Luz del Sur, Sedapal y Telefónica del Perú.

- El análisis del Estado de Resultados nos permitió precisar que obtuvimos un margen bruto de $17.88 \%$, un margen neto de $5.75 \%$ y que el costo de venta representó el $87.1 \%$ del total de los costos y gatos del proyecto. Del análisis del Estado Situacional pudimos inferir que la rentabilidad patrimonial obtenida (ROE) de $19.64 \%$ se aproximó a nuestro objetivo estratégico que era de $20 \%$, 
que la rentabilidad de los activos (ROA) llegó a $18.08 \%$ y que la rentabilidad sobre nuestro aporte fue de $24.43 \%$. Del análisis del Flujo de Caja podemos mencionar que los costos directos representaron el $79.3 \%$ del total de egresos, mientras que los indirectos constituyeron el $20.7 \%$.

- La inversión total del proyecto tuvo cuatro fuentes de financiamiento, conformadas por S/. 548,000 de aporte propio (\% de $22.8 \%$ ) a un costo de $20 \%(\mathrm{Ke})$, por S/. 220,000 de financiamiento bancario (\% D de $9.2 \%$ ) a un costo de $41.31 \%$ (Kd), por S/. 507,600 de las cuotas iniciales de los clientes (\% I de $21.1 \%$ ) y por S/. 1,128,509 de los créditos hipotecarios (\%H de 46.9\%). Estos dos últimos aportes no tuvieron costo financiero (Ki y Kh igual a 0\%).

- Para evaluar la factibilidad del proyecto en un horizonte de tiempo de cinco años, consideramos una WACC de $7.2 \%$, una variación porcentual anual de $9 \%$ en los ingresos, una variación porcentual anual en nuestras inversiones de $11 \%$ en terrenos, de $6 \%$ en construcción y de $5 \%$ en costos indirectos, y que el financiamiento representaría un $9.2 \%$ de nuestra inversiones. Del análisis realizado pudimos concluir que el proyecto era factible y rentable ya que se obtuvo un VAN económico de S/. 609,719.00, una TIR económica de 35\%, un VAN financiero de S/. 607,632.00, una TIR financiera de 55\% y un ROE que se incrementó de $19.64 \%$ a $23.84 \%$ en promedio.

- De igual modo, pudimos afirmar que si nuestros ingresos sólo se incrementarían en $6 \%$ anualmente, manteniendo las demás variables constantes, encontraríamos el punto de equilibrio del negocio, en el que el VAN económico sería igual a cero y la TIR económica igual al WACC establecido de $7.20 \%$.

- Al realizar la evaluación del proyecto bajo un escenario optimista, comprobamos que sería factible y rentable obteniendo un VAN económico de S/. 1,723,146.00, una TIR económica de 62\%, un VAN financiero de S/. 1,717,432.00, una TIR financiera de 93\% y un ROE que se incrementó de $19.64 \%$ a $33.42 \%$ en promedio. Para este escenario consideramos una WACC de $6.89 \%$, una variación anual de $14 \%$ en los ingresos y que el financiamiento bancario representaría un $10 \%$ de nuestra inversión total.

- Bajo un escenario conservador, comprobamos que el proyecto seguía siendo factible y rentable, obteniendo un VAN económico de S/. 672,216.00, una TIR económica de 46\%, un VAN financiero de S/. 866,172.00, una TIR financiera de $196 \%$ y un ROE que se incrementó de $19.64 \%$ a $27.83 \%$ en promedio. Para 
este escenario consideramos una WACC de $14.12 \%$, una variación anual de $14 \%$ en los ingresos, de $16 \%$ en terrenos, de $9 \%$ en construcción, de $8 \%$ en costos indirectos y que el financiamiento bancario representaría un $35 \%$ de nuestra inversión total.

- Finalmente podemos concluir que el éxito de un proyecto inmobiliario radica en realizar un adecuado estudio de mercado; satisfacer las necesidades y preferencias del público objetivo; organizarte funcionalmente; informar, asesorar y persuadir oportunamente a los clientes; establecer alianzas estratégicas con tus proveedores; y procurar financiar el proyecto solo con aporte de capital propio y con aporte de los clientes a través de los desembolsos de las cuotas iniciales y los créditos hipotecarios a cero costo financiero. 


\section{REFERENCIAS}

Banco Central de Reserva del Perú - BCRP (2008). Cuadros Anuales Históricos. Estadística. Recuperado de http://www.bcrp.gob.pe/estadisticas/cuadrosanuales-historicos.html

Banco Central de Reserva del Perú - BCRP (2008). Tasas de interés activas y pasivas promedio de las empresas bancarias en moneda nacional. Estadística - Cuadros Históricos de Tasa de Interés. Recuperado de http://www.bcrp.gob.pe/estadisticas/cuadros-historicos-de-tasa-de-interes.html

BBVA Banco Continental (2008). Situación Inmobiliaria Perú - Agosto 2008. Servicio de Estudios Económicos. [Versión PDF]. Recuperado de https://www.bbvaresearch.com/KETD/fbin/mult/080826_SitInmobiliariaPeru_tc $\underline{\text { m346-191187.pdf }}$

Cámara Peruana de la Construcción - CAPECO (2004). El Mercado de Edificaciones Urbanas en Lima Metropolitana y el Callao, IX Estudio. (1. a ed.). Perú: Cámara Peruana de la Construcción.

Cámara Peruana de la Construcción - CAPECO (2005). El Mercado de Edificaciones Urbanas en Lima Metropolitana y el Callao, X Estudio. (1. ${ }^{a}$ ed.). Perú: Cámara Peruana de la Construcción.

Cámara Peruana de la Construcción - CAPECO (2006). El Mercado de Edificaciones Urbanas en Lima Metropolitana y el Callao, XI Estudio. (1. ${ }^{a}$ ed.). Perú: Cámara Peruana de la Construcción.

Cámara Peruana de la Construcción - CAPECO (2007). El Mercado de Edificaciones Urbanas en Lima Metropolitana y el Callao, XII Estudio. (1. a ed.). Perú: Cámara Peruana de la Construcción.

Cámara Peruana de la Construcción - CAPECO (2008). El Mercado de Edificaciones Urbanas en Lima Metropolitana y el Callao, XIII Estudio. (1. ${ }^{\text {a }}$ ed.). Perú: Cámara Peruana de la Construcción.

Diario Oficial El Peruano (1999). Decreto Supremo No 055-1999-EF “Ley de Impuesto general a las Ventas e Impuesto Selectivo al Consumo". Recuperado de http://diariooficial.elperuano.pe/Normas

Diario Oficial El Peruano (1999). Ley $N^{o} 27157$ "Ley de Regularización de Edificaciones, del Procedimiento para la Declaratoria de Fábrica y del Régimen de Unidades Inmobiliarias de Propiedad Exclusiva y de Propiedad Común”. Recuperado de http://diariooficial.elperuano.pe/Normas

Diario El Peruano (2001). Decreto Supremo $N^{o}$ 064-2001-EF “Modificación al D.S. $N^{o}$ 29-1994-EF en lo referido a la aplicación del IGV en la primera venta de inmuebles realizada por el constructor". Recuperado de http://diariooficial.elperuano.pe/Normas 
Diario Oficial El Peruano (2005). Resolución No 079-2005-SUNARP/SN "Texto Único Ordenado del Reglamento General de los Registros Públicos”. Recuperado de http://diariooficial.elperuano.pe/Normas

Diario Oficial El Peruano (2006). Decreto Supremo $N^{o}$ 011-2006-VIVIENDA "Reglamento Nacional de Edificaciones". Recuperado de http://diariooficial.elperuano.pe/Normas

Diario Oficial El Peruano (2007). Decreto Supremo No 005-2007-EF “Texto Único de Procedimientos Administrativos de la Superintendencia Nacional de Administración Tributaria”. Recuperado de http://diariooficial.elperuano.pe/Normas

Diario Oficial El Peruano (2008). Decreto Supremo $N^{o}$ 024-2008-VIVIENDA "Reglamento de Licencias de Habilitación Urbana y Licencias de Edificación". Recuperado de http://diariooficial.elperuano.pe/Normas

Diario Oficial El Peruano (2009). Ordenanza $N^{\circ} 1334$ "Texto Único de Procedimientos Administrativos de la Municipalidad Metropolitana de Lima". Recuperado de http://diariooficial.elperuano.pe/Normas

Instituto Nacional de Estadística e Informática - INEI (2001). Boletín de Análisis Perú: Estimaciones y Proyecciones de Población 1950 - 2050. [Versión PDF]. Recuperado de https://www.inei.gob.pe/media/MenuRecursivo/publicaciones_digitales/Est/Lib 0466/Libro.pdf

Instituto Nacional de Estadística e Informática - INEI (2007). Créditos totales del Fondo Mi Vivienda, según departamento. Estadística. Índice Temático. Economía. Estadísticas Sectoriales. Construcción. Recuperado de https://www.inei.gob.pe/estadisticas/indice-tematico/economia/

Instituto Nacional de Estadística e Informática - INEI (2007). Cuentas Nacionales Anuales. Estadística. Índice Temático. Economía. Cuentas Nacionales. Recuperado de https://www.inei.gob.pe/estadisticas/indice-tematico/economia/

Instituto Nacional de Estadística e Informática - INEI (2007). Índice de Precios de Materiales de Construcción de Lima Metropolitana (Base $1994=100$ ), y variación porcentual mensual y acumulada. Estadística. Índice Temático. Economía. Índice de Trecios. Recuperado de https://www.inei.gob.pe/estadisticas/indice-tematico/economia/

Instituto Nacional de Estadística e Informática - INEI (2007). Licencias para la construcción otorgadas por la municipalidad, por tipo, según departamento. Estadística. Índice Temático. Economía. Estadísticas Sectoriales. Construcción. Recuperado de https://www.inei.gob.pe/estadisticas/indice-tematico/economia/

Instituto Nacional de Estadística e Informática - INEI (2007). Principales indicadores del sector construcción. Estadística. Índice Temático. Economía. Estadísticas Sectoriales. Construcción. Recuperado de https://www.inei.gob.pe/estadisticas/indice-tematico/economia/ 
Instituto Nacional de Estadística e Informática - INEI (2007). Producción y venta de barras de construcción. Estadística. Índice Temático. Economía. Estadísticas Sectoriales. Construcción. Recuperado de https://www.inei.gob.pe/estadisticas/indice-tematico/economia/

Instituto Nacional de Estadística e Informática - INEI (2007). Producto Bruto Interno por Departamentos. Estadística. Índice Temático. Economía. Cuentas Nacionales. Recuperado de https://www.inei.gob.pe/estadisticas/indicetematico/economia/

Instituto Nacional de Estadística e Informática - INEI (2007). Sistema de Consulta de Resultados Censales: Cuadros Estadísticos. Censos Nacionales 2007: XI de Población y VI de Vivienda. Recuperado de https://www.inei.gob.pe/estadisticas/censos/

Instituto Nacional de Estadística e Informática - INEI (2007). Venta local de cemento por empresa, según departamento. Estadística. Índice Temático. Economía. Estadísticas Sectoriales. Construcción. Recuperado de https://www.inei.gob.pe/estadisticas/indice-tematico/economia/

Instituto Metropolitano de Planificación - IMP (2008). Cuadros Normativos de Zonificación Residencial, Área de Tratamiento II. Recuperado de http://www.imp.gob.pe/index.php/reajuste-integral-del-plano-de-zonificacionde-lima-metropolitana

Maximixe Consult S.A. (2005). CASER: Riesgos Macro - Agosto 2005. (1. a ed.). Perú: Grupo Maximixe (Lima). Inteligencia Económica.

Maximixe Consult S.A. (2006). CASER: Riesgos Macro - Mayo 2006. (1. a ed.). Perú: Grupo Maximixe (Lima). Inteligencia Económica.

Maximixe Consult S.A. (2006). CASER: Perú Ejecutivo - Proyecciones Económicas 2006-2011. (1. a ed.). Perú: Grupo Maximixe (Lima). Inteligencia Económica.

Maximixe Consult S.A. (2007). CASER: Perú Ejecutivo - Proyecciones Económicas 2007-2012. (1. a ed.). Perú: Grupo Maximixe (Lima). Inteligencia Económica.

Ministerio de Economía y Finanzas - MEF (2001). Marco Macroeconómico Multianual 2002 - 2004. (1. ed.). Perú: Ministerio de Economía y Finanzas.

Ministerio de Economía y Finanzas - MEF (2002). Marco Macroeconómico Multianual 2003 - 2005. (1. ed.). Perú: Ministerio de Economía y Finanzas.

Ministerio de Economía y Finanzas - MEF (2003). Marco Macroeconómico Multianual 2004 - 2006. (1. ${ }^{\mathrm{a}}$ ed.). Perú: Ministerio de Economía y Finanzas.

Ministerio de Economía y Finanzas - MEF (2004). Marco Macroeconómico Multianual 2005 - 2007. (1. ${ }^{\mathrm{a}}$ ed.). Perú: Ministerio de Economía y Finanzas.

Ministerio de Economía y Finanzas - MEF (2005). Marco Macroeconómico Multianual 2006 - 2008. (1. ${ }^{\mathrm{a}}$ ed.). Perú: Ministerio de Economía y Finanzas. 
Ministerio de Trabajo y Promoción del Empleo (2008). Evolución de la Remuneración Mínima Vital Nominal a Feb 2013. Estadísticas Laborales. Recuperado de http://www2.trabajo.gob.pe/promocion-del-empleo-y-autoempleo/informaciondel-mercado-de-trabajo/estadisticas-de-empleo/

Ministerio de Trabajo y Promoción del Empleo (2008). Remuneración Promedio de Empleados en el Sector Construcción. Estadísticas Laborales. Recuperado de http://www2.trabajo.gob.pe/promocion-del-empleo-y-autoempleo/informaciondel-mercado-de-trabajo/estadisticas-de-empleo/

Ministerio de Vivienda, Construcción y Saneamiento (2008). Boletín Estadístico. Productos Estadísticos. Recuperado de http://www3.vivienda.gob.pe/destacados/producto.aspx

Ministerio de Vivienda, Construcción y Saneamiento (2008). Indicadores del Sector. Recuperado de http://www3.vivienda.gob.pe/destacados/indicadores.aspx

Ministerio de Vivienda, Construcción y Saneamiento (2008). Información Estadística. Recuperado de http://www3.vivienda.gob.pe/Destacados/estadistica.aspx

Ministerio de Vivienda, Construcción y Saneamiento (2008). Producto Bruto Interno. Recuperado de http://www3.vivienda.gob.pe/destacados/indicador_coyuntural.aspx

Municipalidad de Chiclayo (2007). El Diagnóstico Urbano. Proyecto: Modernización de la Gestión del Desarrollo Urbano de la Provincia de Chiclayo - Componente $N^{\circ}$ 1: Plan de Desarrollo Urbano Ambiental. [Versión PDF] Recuperado de http://www.munichiclayo.gob.pe/Documentos/PDF_PDUA/PDUA_CAP_III_P1 . $\mathrm{pdf}$

Superintendencia de Banca, Seguros y AFP (2008). Ranking de Créditos Directos por Tipo. Información Estadística de Banca Múltiple. Alcance y Participación de Mercado. Recuperado de http://www.sbs.gob.pe/app/stats_net/stats/EstadisticaBoletinEstadistico.aspx?p= $\underline{1 \#}$

Superintendencia Nacional de Administración Tributaria (2008). Unidad Impositiva Tributaria. Índices y $\quad$ Tasas. Recuperado de http://www.sunat.gob.pe/indicestasas/uit.html

Webb, R. y Fernandez, G. (2006). Perú en Números 2006: Anuario Estadístico. (1. a ed.). Perú: Instituto Cuánto.

Webb, R. y Fernandez, G. (2007). Perú en Números 2007: Anuario Estadístico. (1. a ed.). Perú: Instituto Cuánto. 


\section{BIBLIOGRAFÍA}

David, F. (1997). Conceptos de Administración Estratégica (5. a ed.). México: Prentice Hall Hispanoamericana, S.A.

Gallagher, T. y Andrew, J. (2001). Administración Financiera Teoría y Práctica (2. ${ }^{a}$ ed.). Colombia: Pearson Educación de Colombia Ltda.

Hellriegel, D. y Slocum, J. (1998). Administración (7. a ed.). México: International Thomson Editores, S.A. de C.V.

Horngren, C., Sundem, G. y Elliott, J. (2000). Introducción a la Contabilidad Financiera (7. ${ }^{\mathrm{a}}$ ed.). México: Pearson Educación de México, S.A. de C.V.

Kafka, F. (2001). Evaluación Estratégica de Proyectos de Inversión (2. ${ }^{a}$ ed.). Perú: Universidad del Pacífico.

Kotler, P. y Armstrong, G. (1998). Fundamentos de Mercadotecnia (4. ${ }^{\mathrm{a}}$ ed.). México: Prentice Hall Hispanoamericana, S.A.

Mintzberg, H., Quinn, J. y Voyer, J. (1997). El Proceso Estratégico Conceptos,

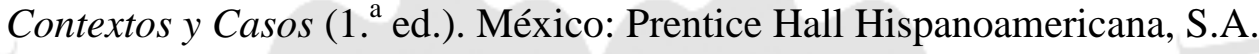

Porter, M. (1996). Ventaja Competitiva Creación y Sostenimiento de un Desempeño Superior (12 ${ }^{\mathrm{a}}$ ed.). México: Compañía Editorial Continental, S.A 


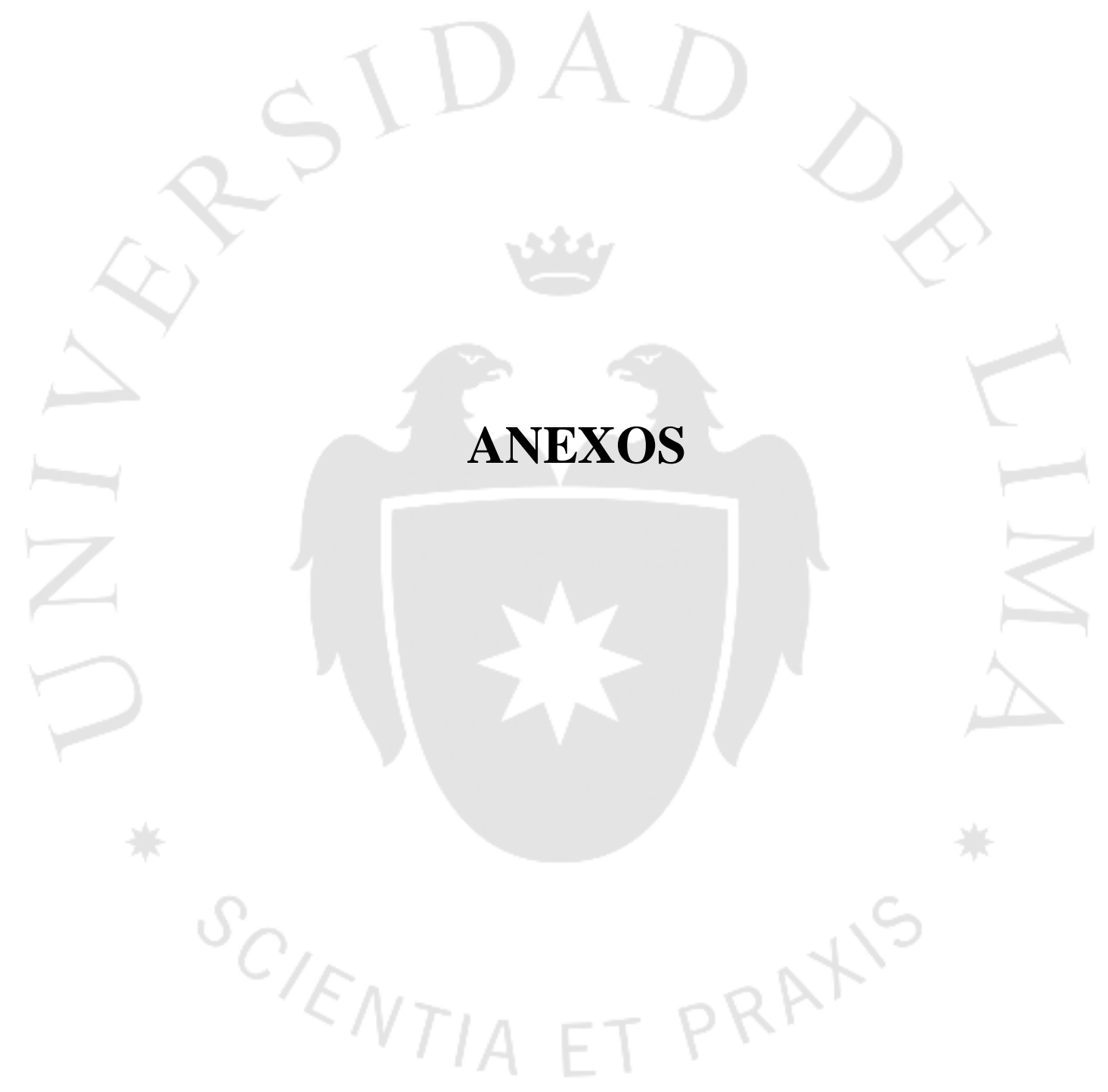




\section{ANEXO 1: Edad de las personas encuestadas}

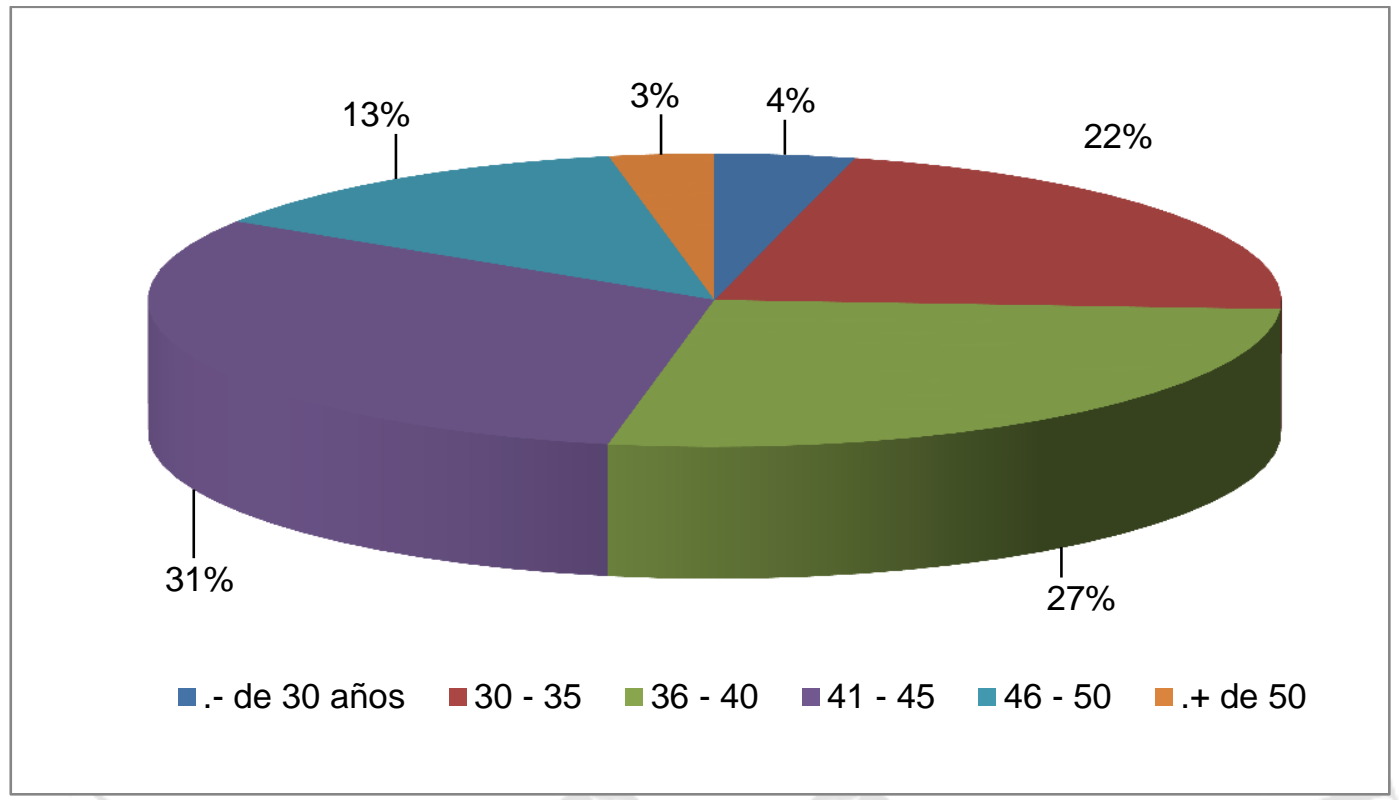

Nota: Total de personas encuestadas (100).

Fuente: Encuestas realizadas por nuestra empresa en Marzo 2008.

Elaboración: Propia. 


\section{ANEXO 2: Género de las personas encuestadas}

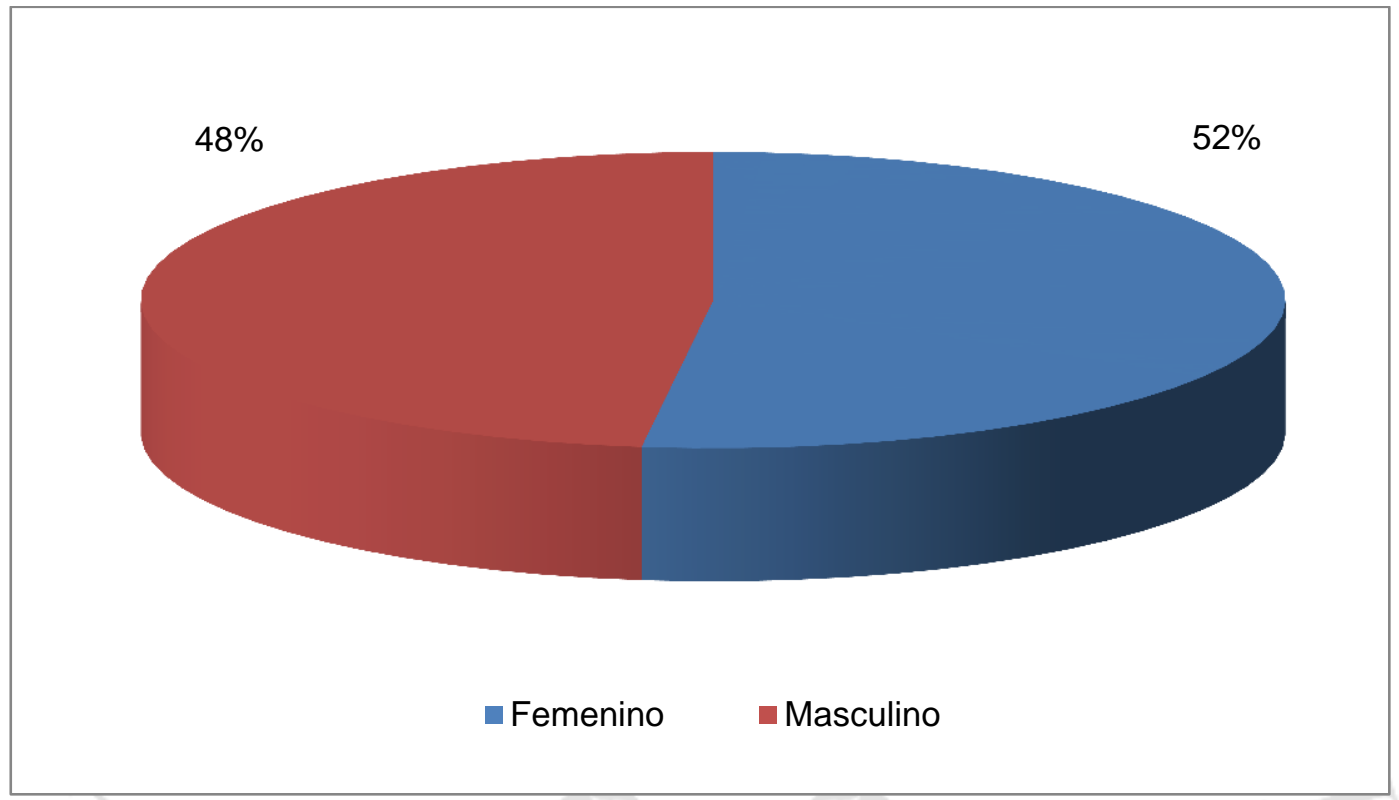

Nota: Total de personas encuestadas (100).

Fuente: Encuestas realizadas por nuestra empresa en Marzo 2008.

Elaboración: Propia. 
ANEXO 3: Estado civil de los encuestados

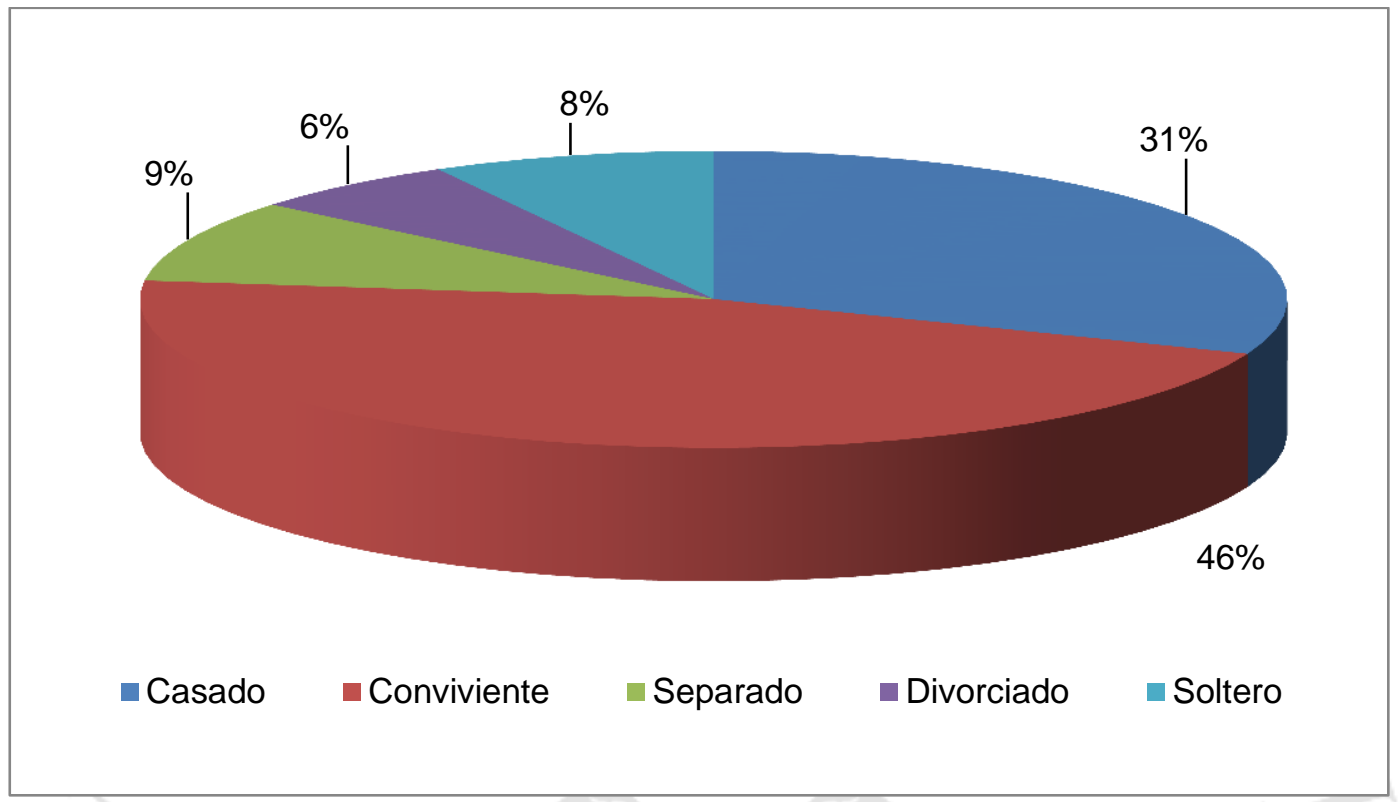

Nota: Total de personas encuestadas (100).

Fuente: Encuestas realizadas por nuestra empresa en Marzo 2008.

Elaboración: Propia. 
ANEXO 4: Dependientes de los encuestados

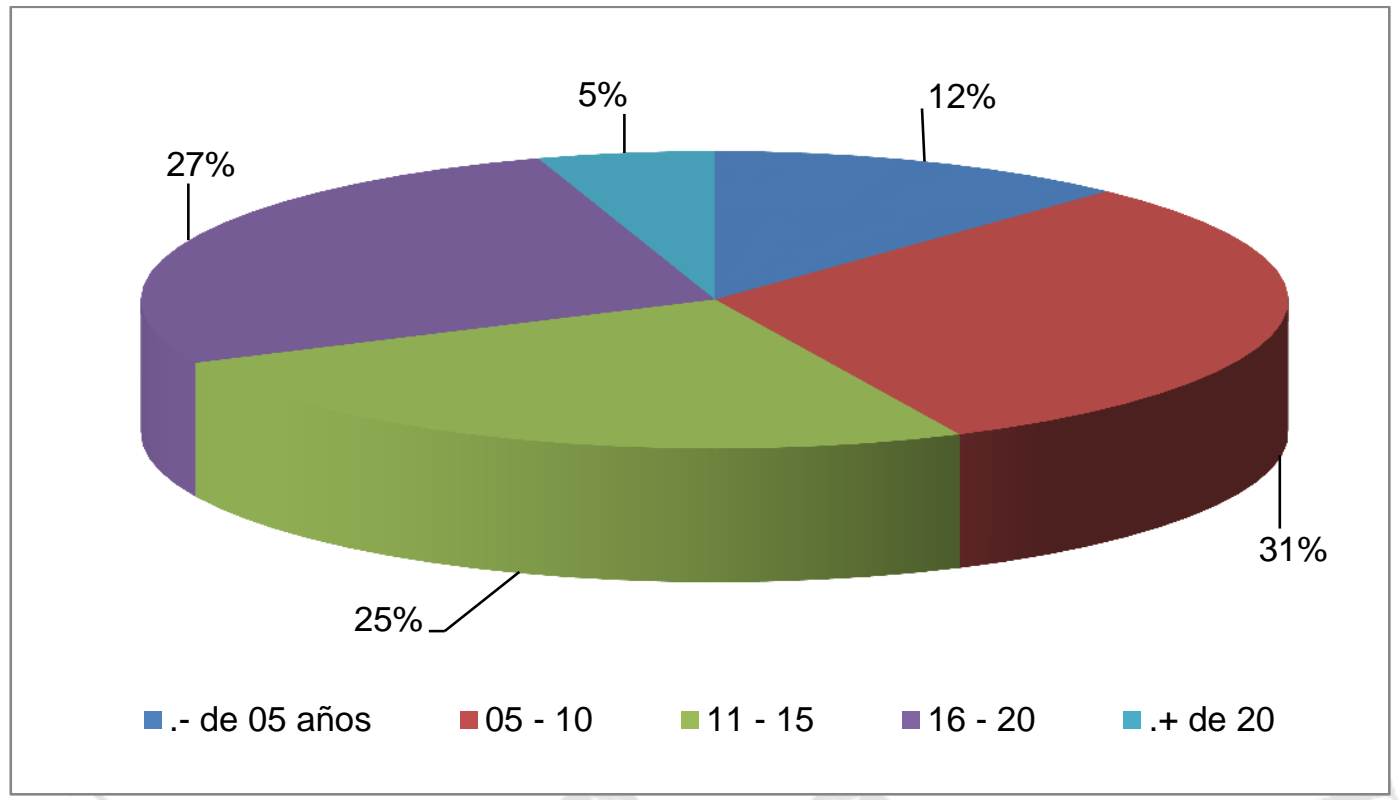

Nota: Total de personas encuestadas (100).

Fuente: Encuestas realizadas por nuestra empresa en Marzo 2008.

Elaboración: Propia. 
ANEXO 5: Segmentación de los encuestados

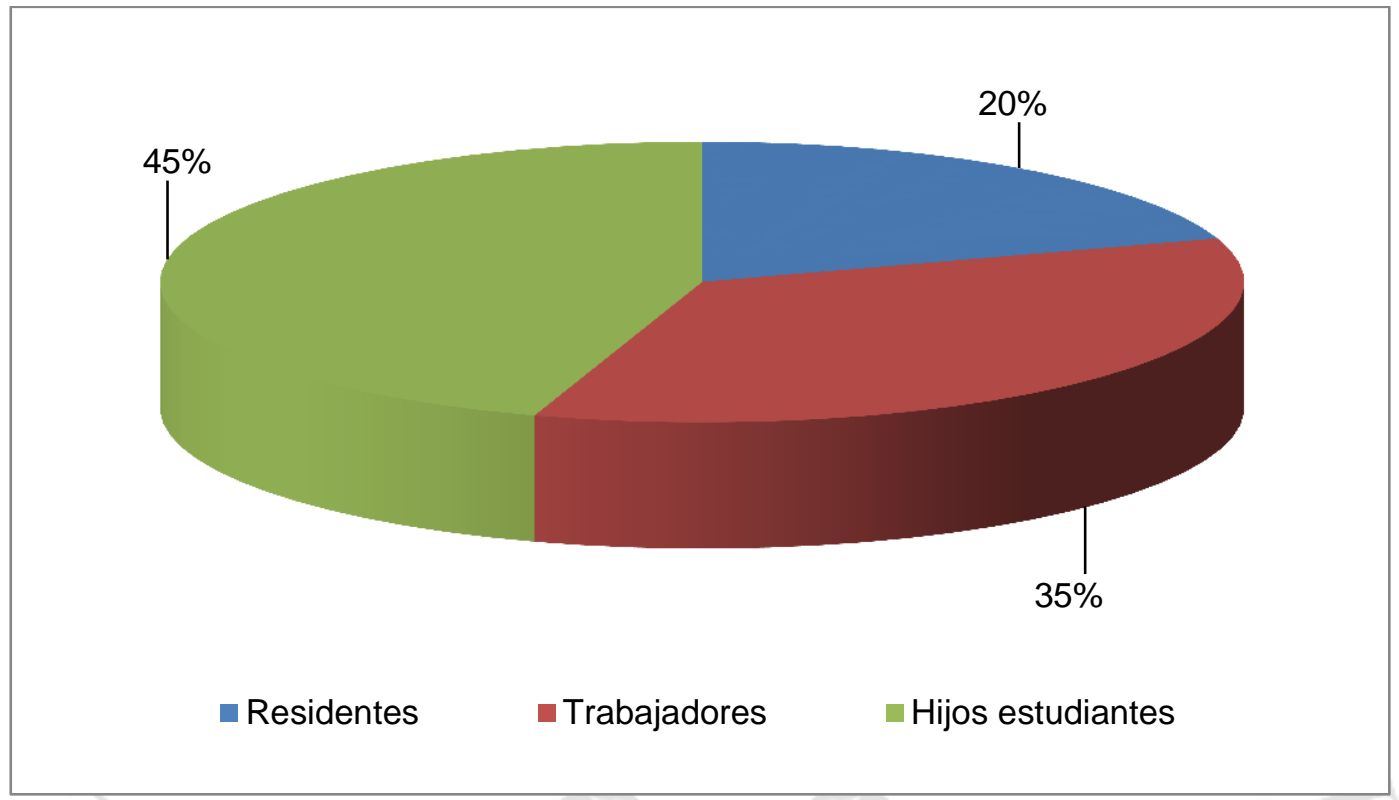

Nota: Total de personas encuestadas (100).

Fuente: Encuestas realizadas por nuestra empresa en Marzo 2008.

Elaboración: Propia. 


\section{ANEXO 6: Tipo de trabajo de los encuestados}

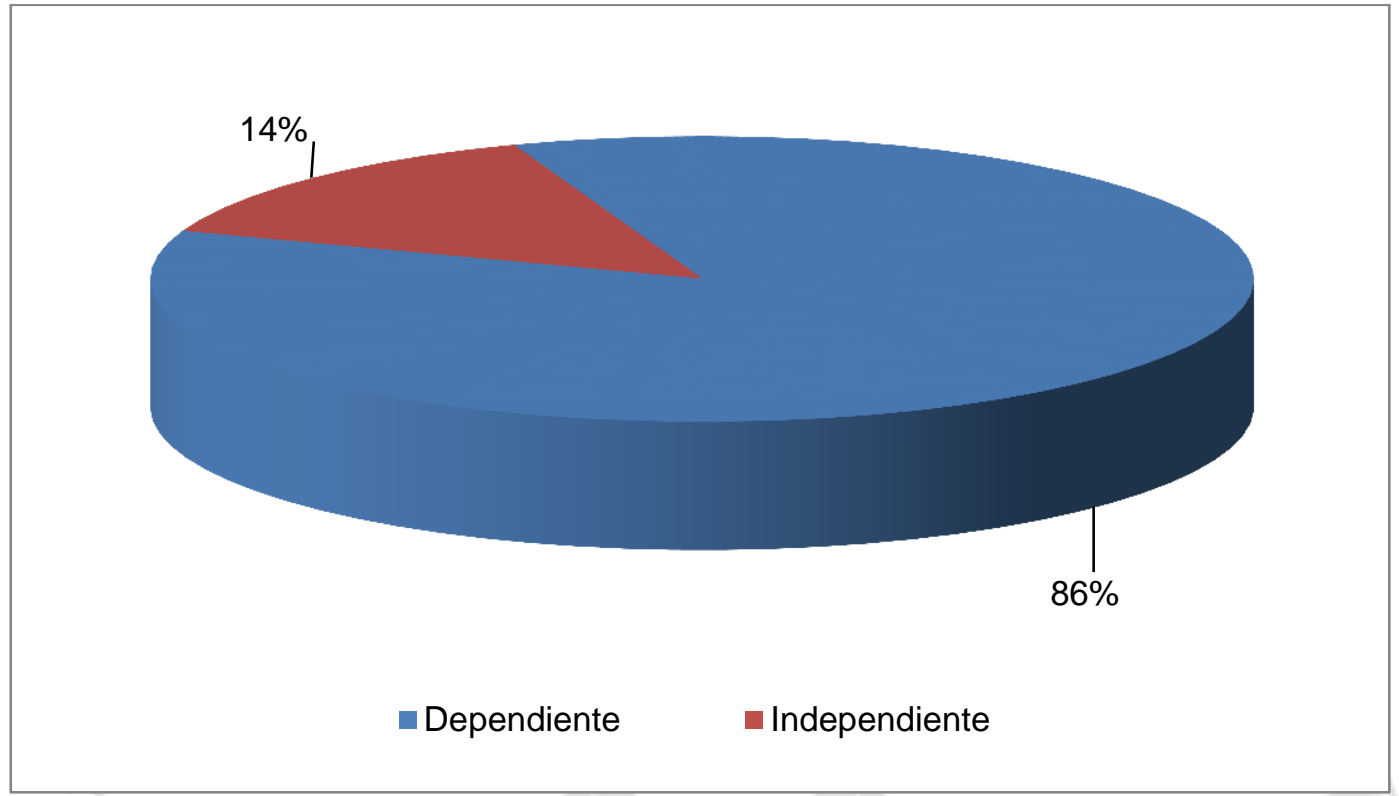

Nota: Total de personas encuestadas (100).

Fuente: Encuestas realizadas por nuestra empresa en Marzo 2008.

Elaboración: Propia. 


\section{ANEXO 7: Nivel de ingresos de los encuestados}

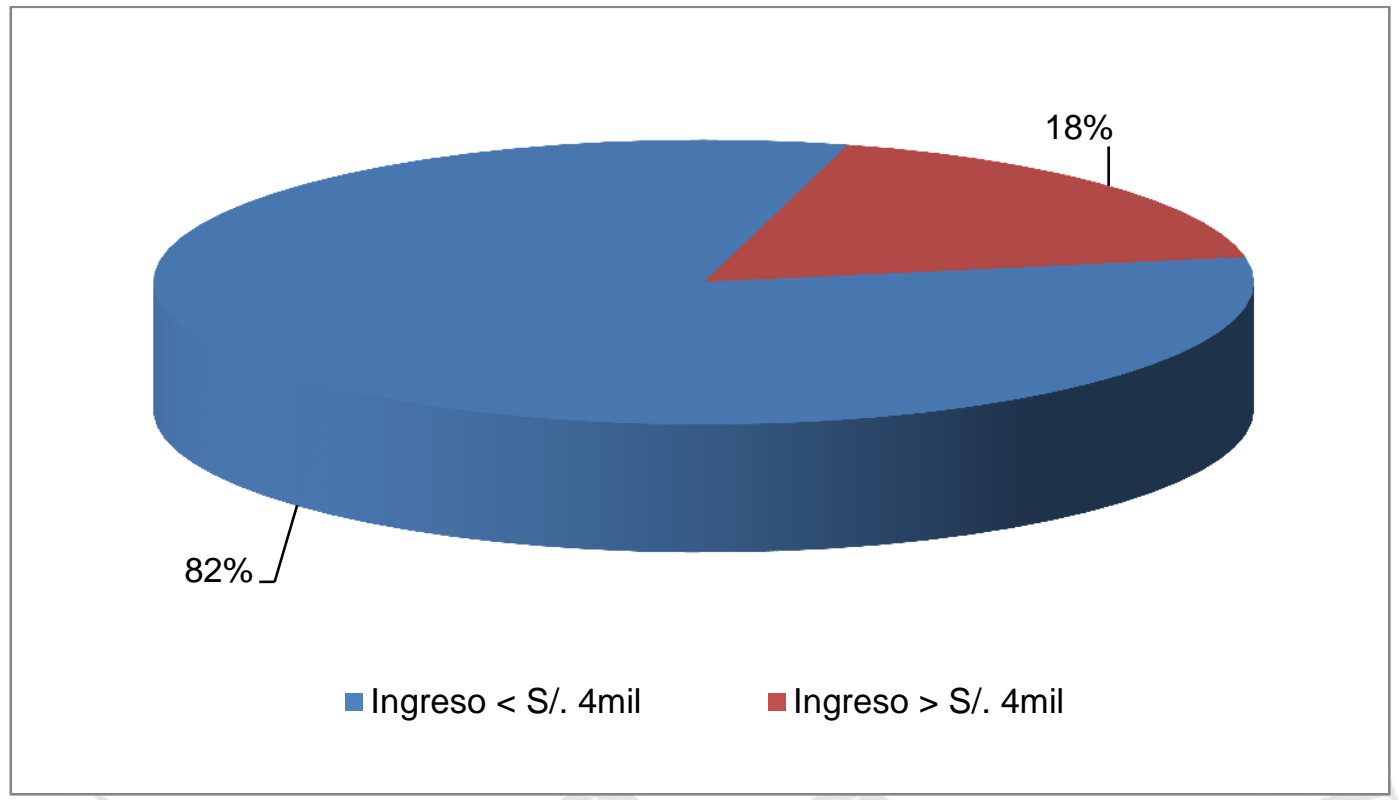

Nota: Total de personas encuestadas (100).

Fuente: Encuestas realizadas por nuestra empresa en Marzo 2008.

Elaboración: Propia. 


\section{ANEXO 8: Recordación de constructoras}

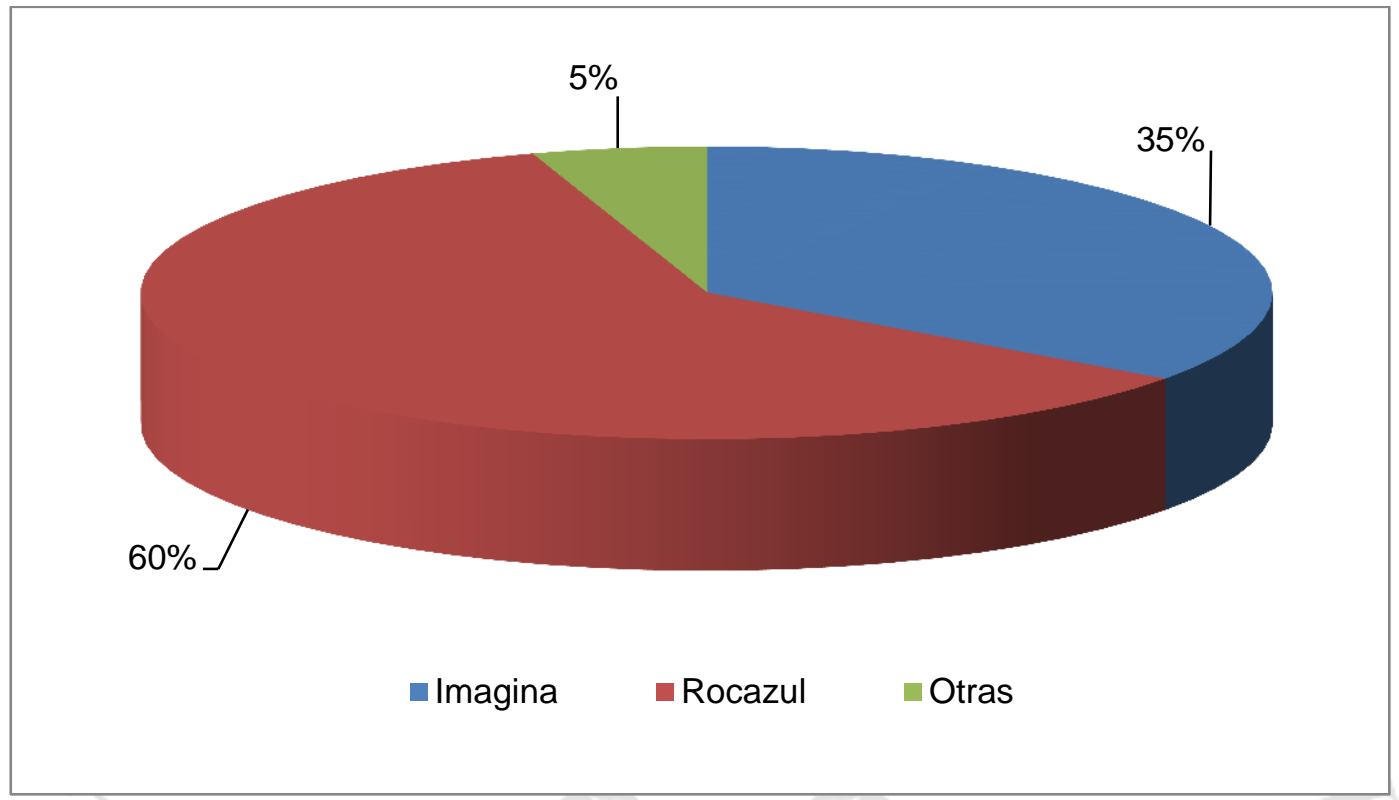

Nota: Total de personas encuestadas (100).

Fuente: Encuestas realizadas por nuestra empresa en Marzo 2008.

Elaboración: Propia. 
ANEXO 9: Nivel de cumplimiento de expectativas

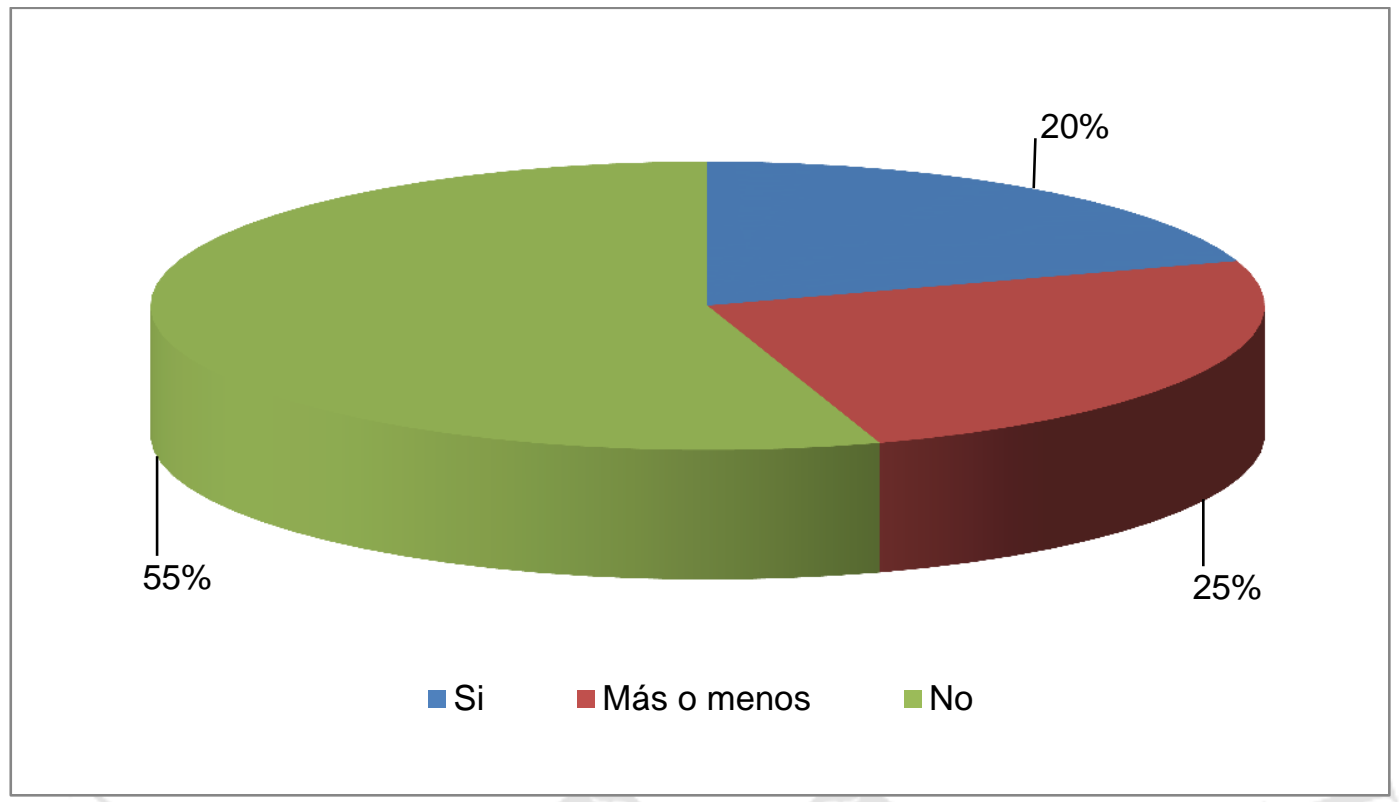

Nota: Total de personas encuestadas (100).

Fuente: Encuestas realizadas por nuestra empresa en Marzo 2008.

Elaboración: Propia. 


\section{ANEXO 10: Ventajas de los actuales proyectos}

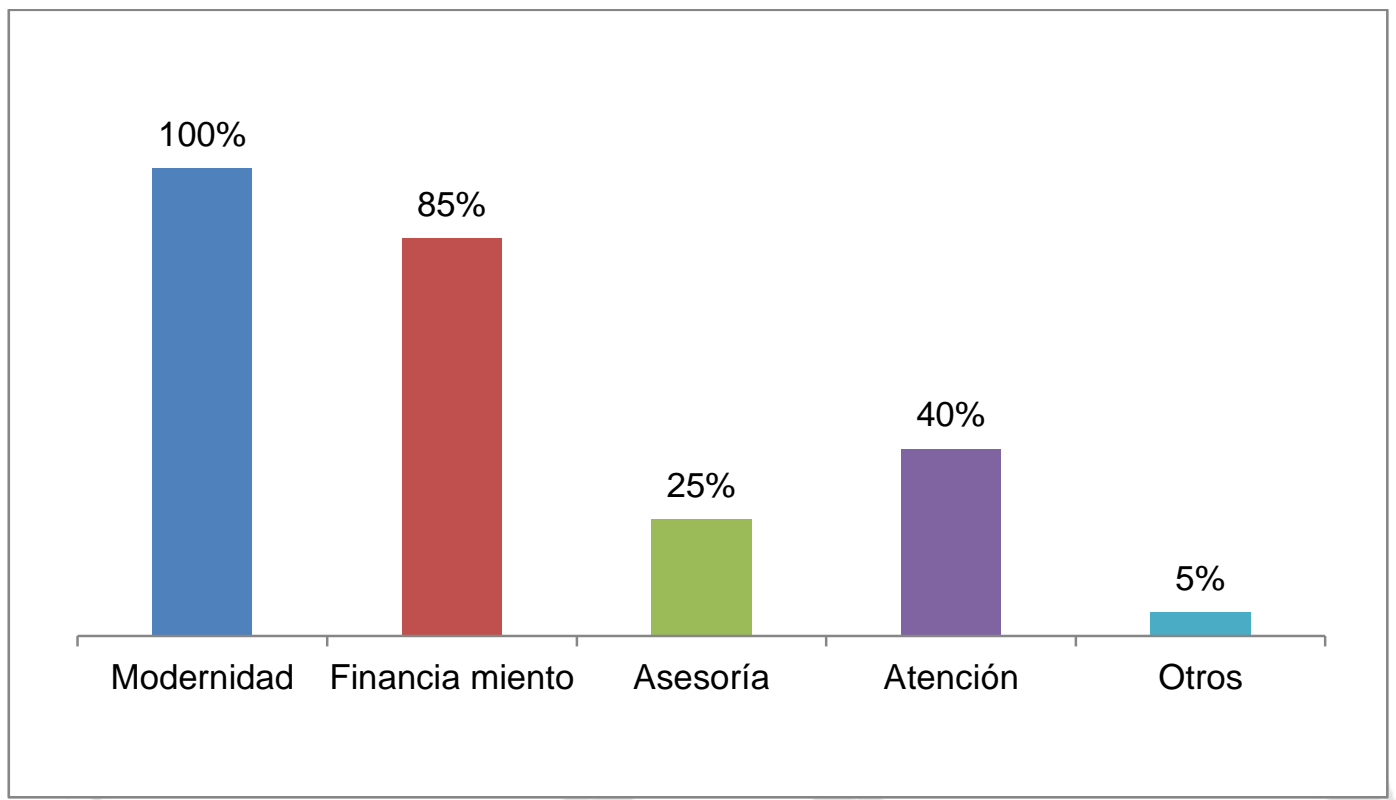

Nota: Total de personas encuestadas (100).

Fuente: Encuestas realizadas por nuestra empresa en Marzo 2008.

Elaboración: Propia. 


\section{ANEXO 11: Desventajas de los proyectos}

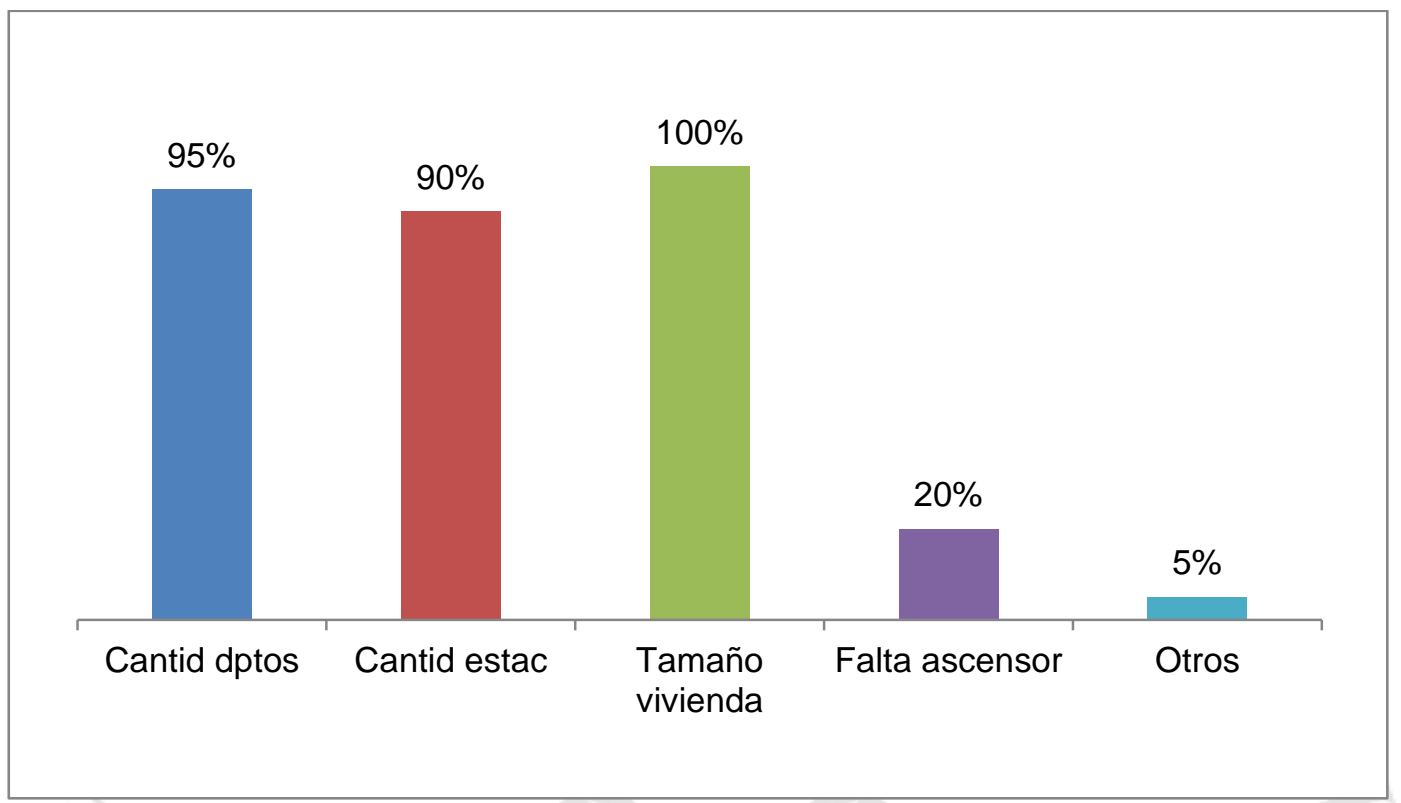

Nota: Total de personas encuestadas (100).

Fuente: Encuestas realizadas por nuestra empresa en Marzo 2008.

Elaboración: Propia. 


\section{ANEXO 12: Apreciación de información ofrecida}

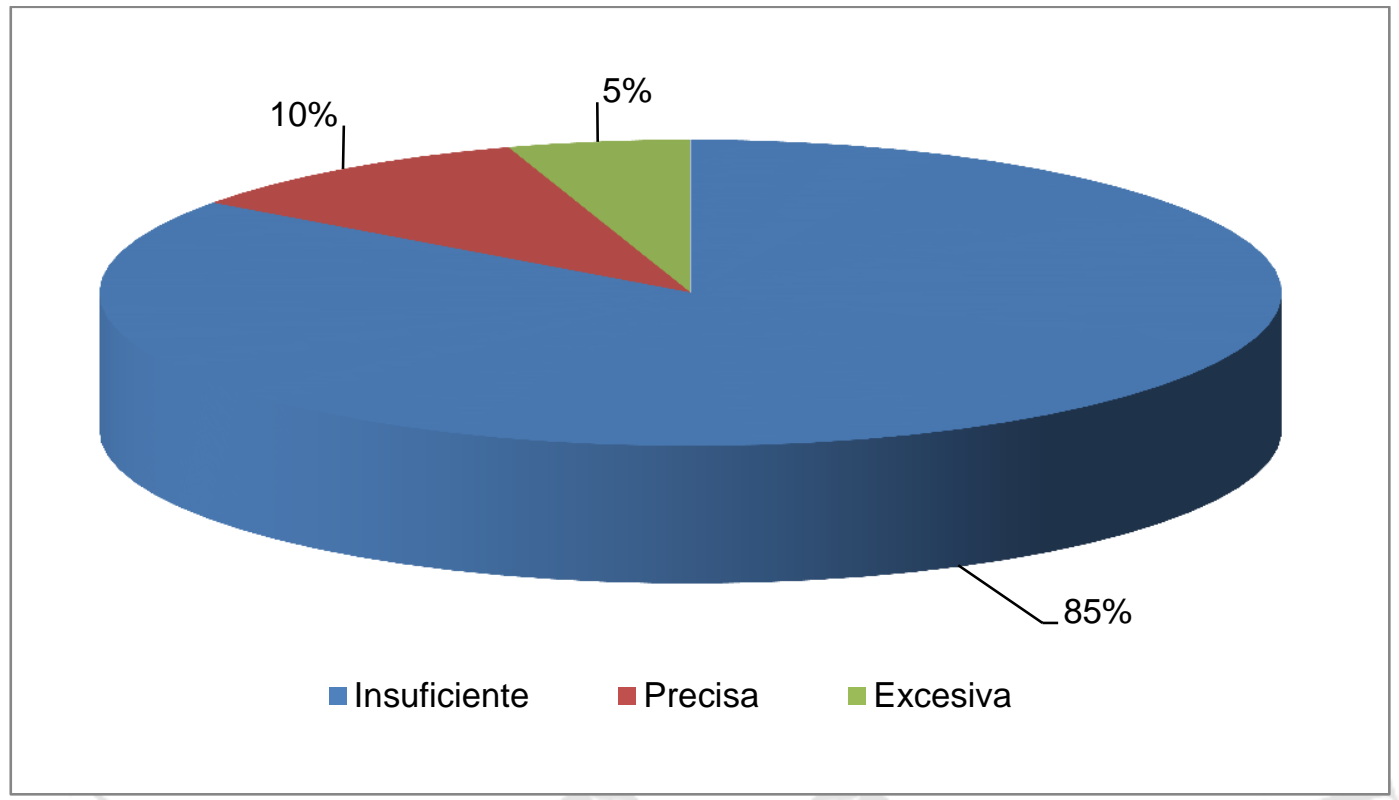

Nota: Total de personas encuestadas (100).

Fuente: Encuestas realizadas por nuestra empresa en Marzo 2008.

Elaboración: Propia. 


\section{ANEXO 13: Información necesaria para la toma de decisiones}

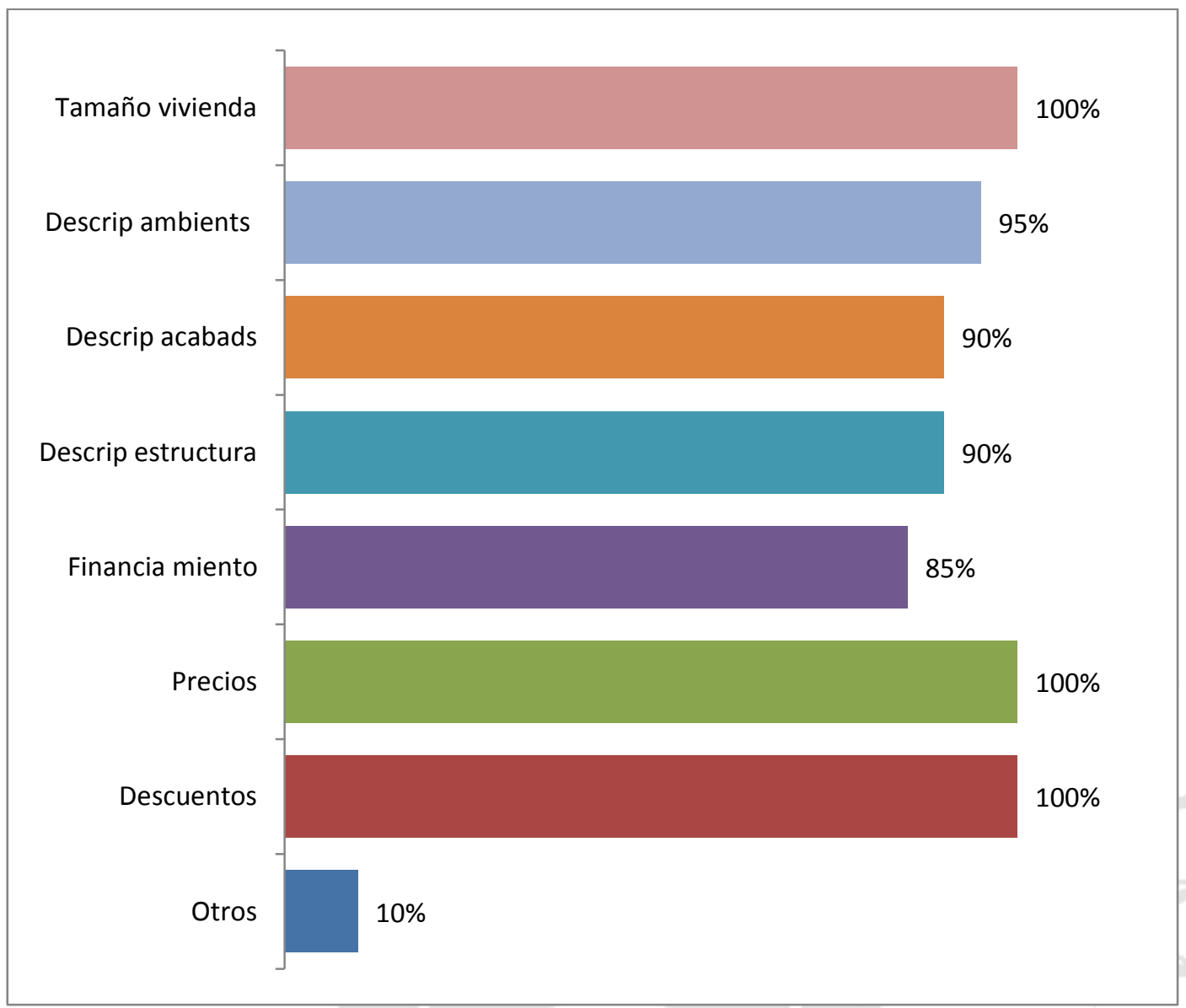

Nota: Total de personas encuestadas (100).

Fuente: Encuestas realizadas por nuestra empresa en Marzo 2008.

Elaboración: Propia. 


\section{ANEXO 14: Cantidad de departamentos que debería tener un edificio}

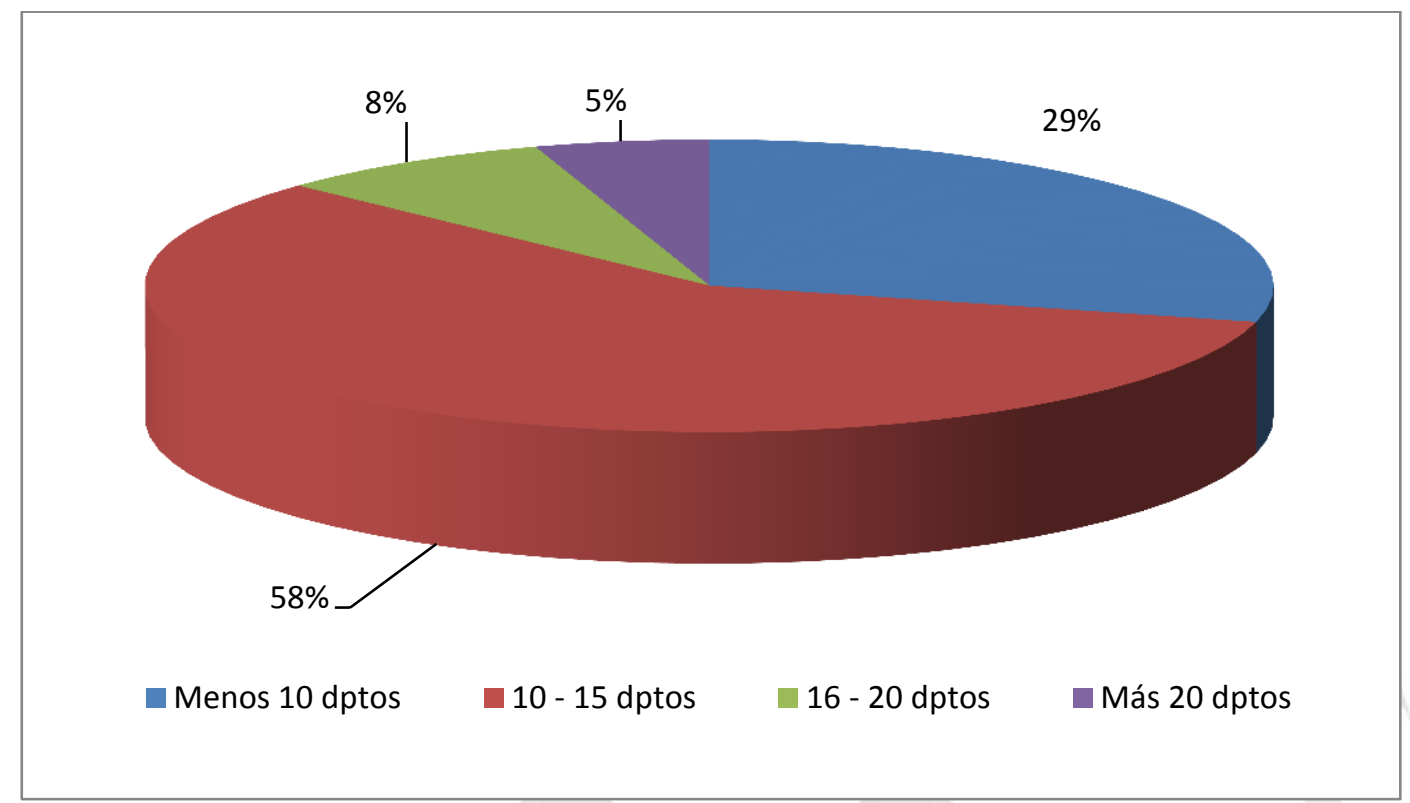

Nota: Total de personas encuestadas (100).

Fuente: Encuestas realizadas por nuestra empresa en Marzo 2008. Elaboración: Propia. 


\section{ANEXO 15: Cantidad de pisos que debería tener un edificio}

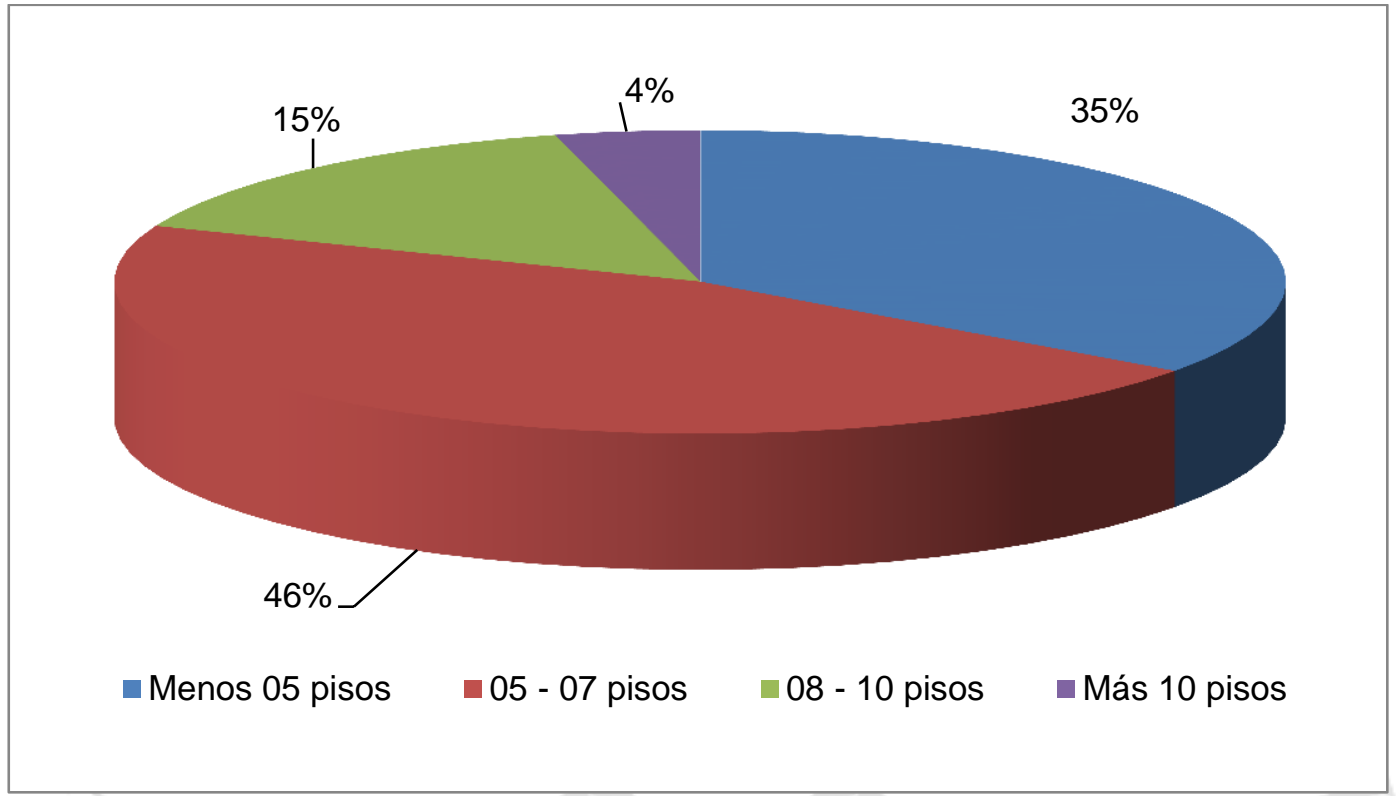

Nota: Total de personas encuestadas (100).

Fuente: Encuestas realizadas por nuestra empresa en Marzo 2008.

Elaboración: Propia. 


\section{ANEXO 16: Frontis ideal de un departamento}

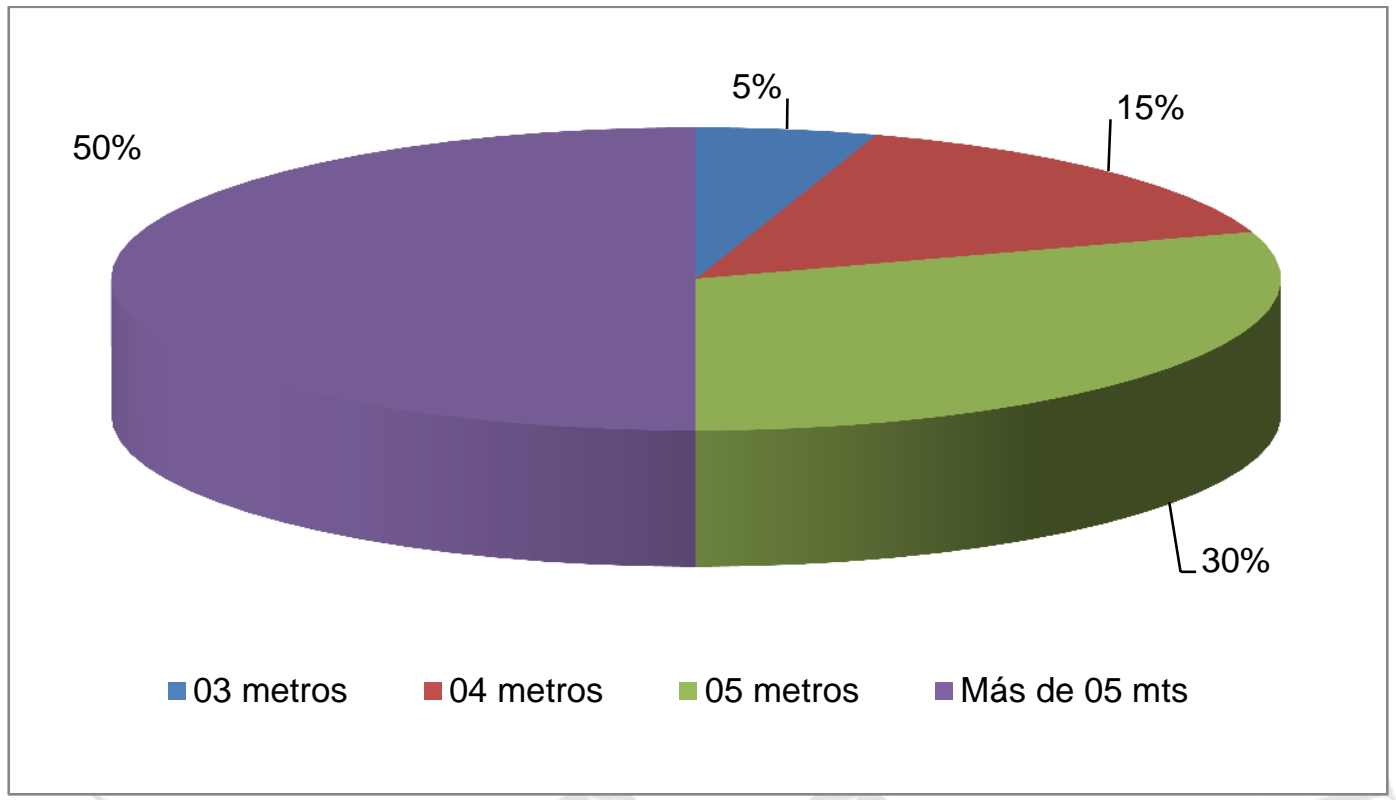

Nota: Total de personas encuestadas (100).

Fuente: Encuestas realizadas por nuestra empresa en Marzo 2008.

Elaboración: Propia. 


\section{ANEXO 17: Altura idónea de un departamento}

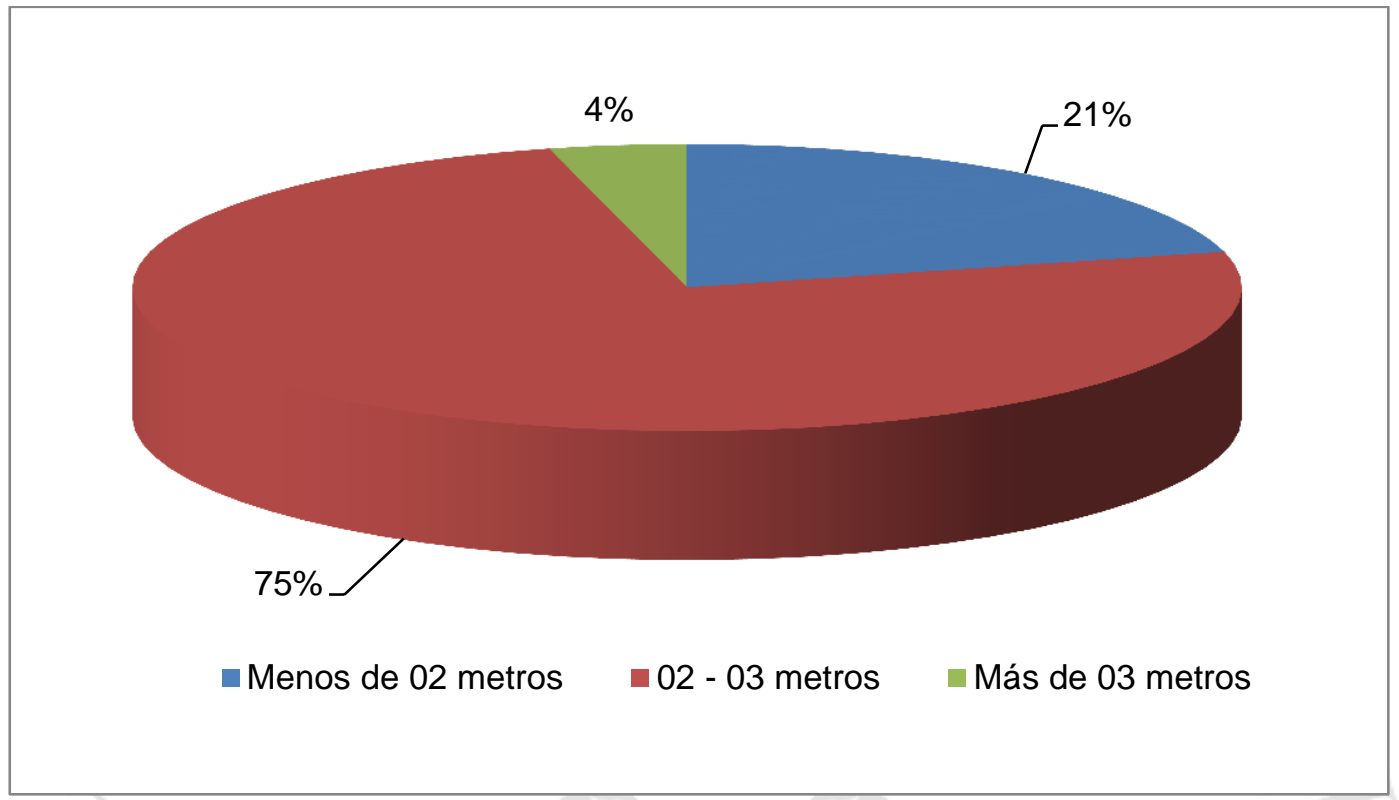

Nota: Total de personas encuestadas (100).

Fuente: Encuestas realizadas por nuestra empresa en Marzo 2008.

Elaboración: Propia. 


\section{ANEXO 18: Ambientes que deberían tener vista hacia la calle}

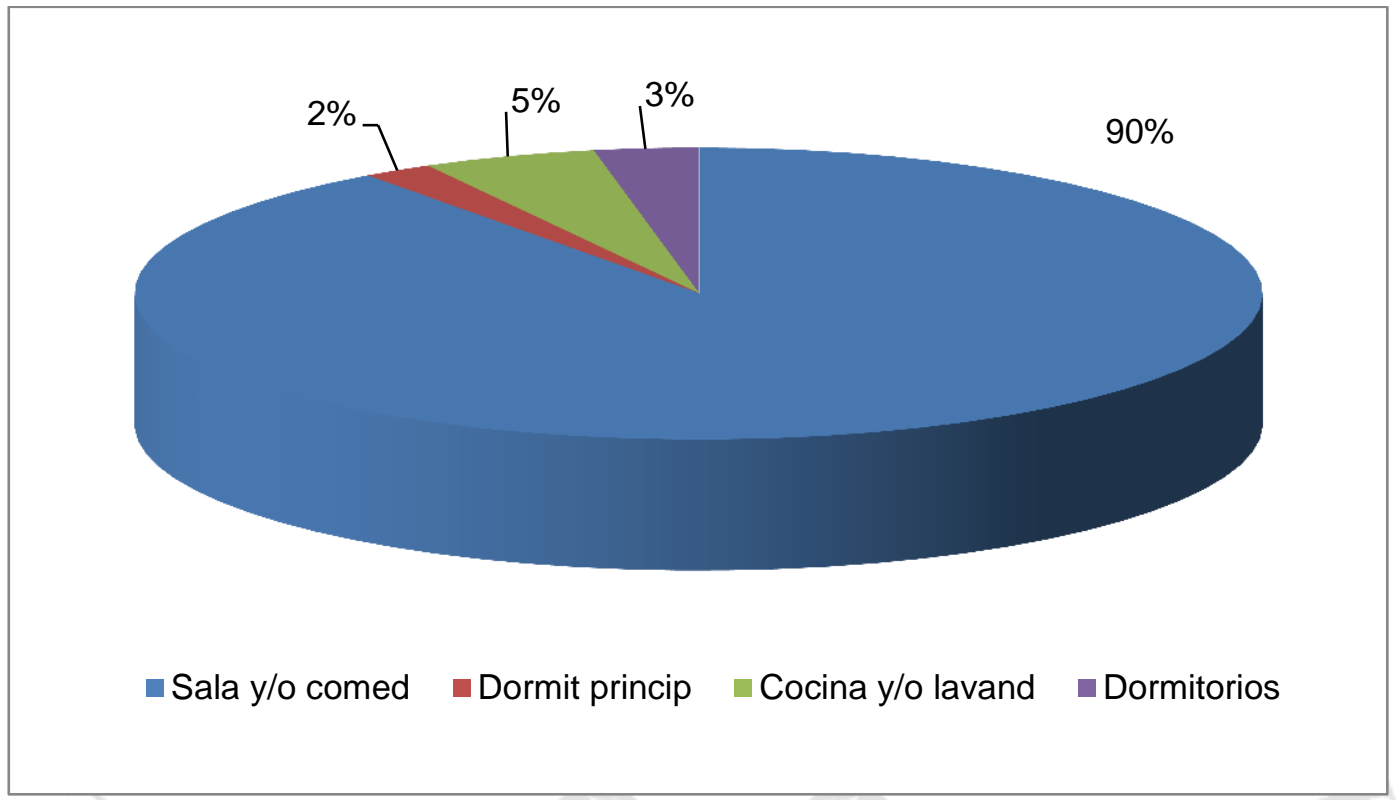

Nota: Total de personas encuestadas (100).

Fuente: Encuestas realizadas por nuestra empresa en Marzo 2008.

Elaboración: Propia. 
ANEXO 19: Cantidad mínima de muebles en ambiente de sala

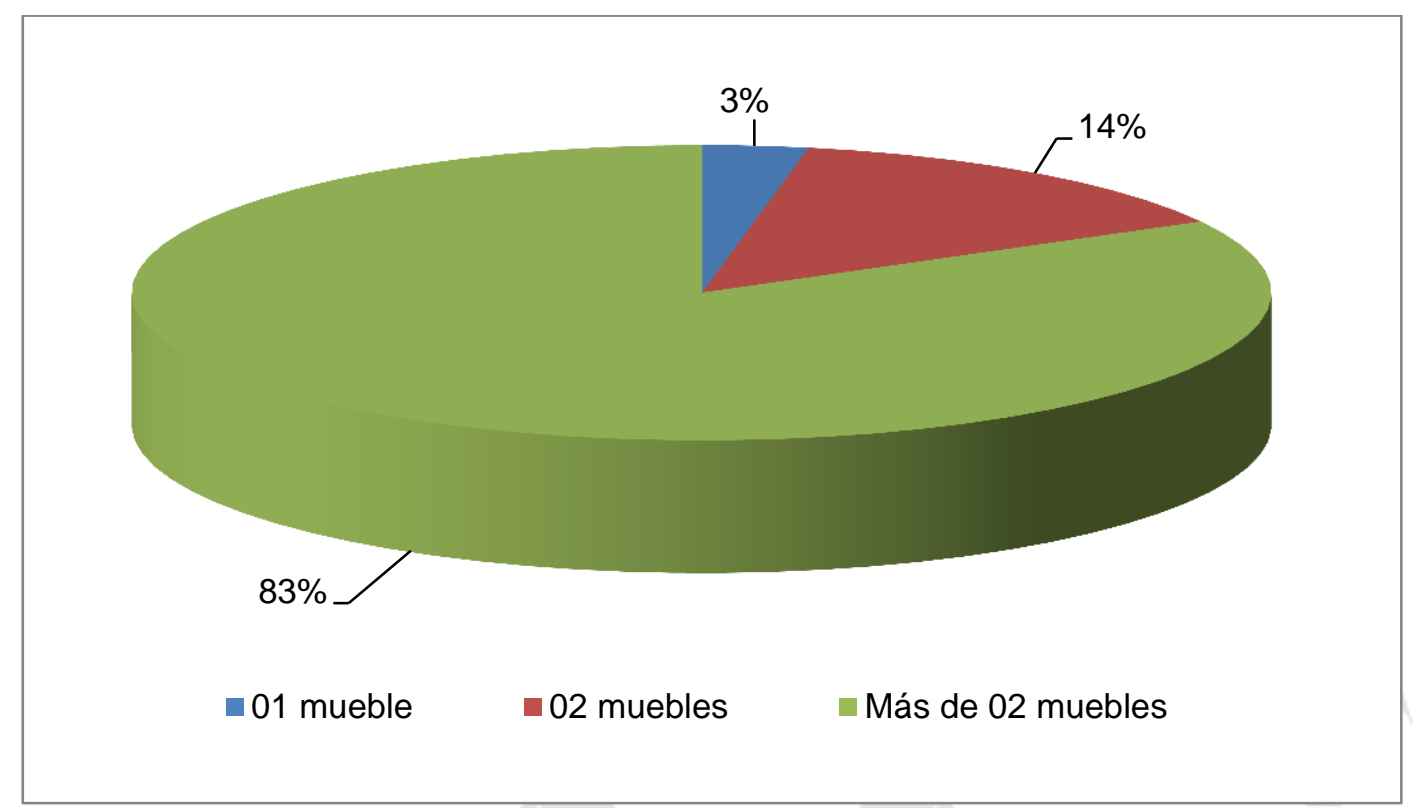

Nota: Total de personas encuestadas (100).

Fuente: Encuestas realizadas por nuestra empresa en Marzo 2008. Elaboración: Propia. 


\section{ANEXO 20: Cantidad mínima de personas en ambiente de}

comedor

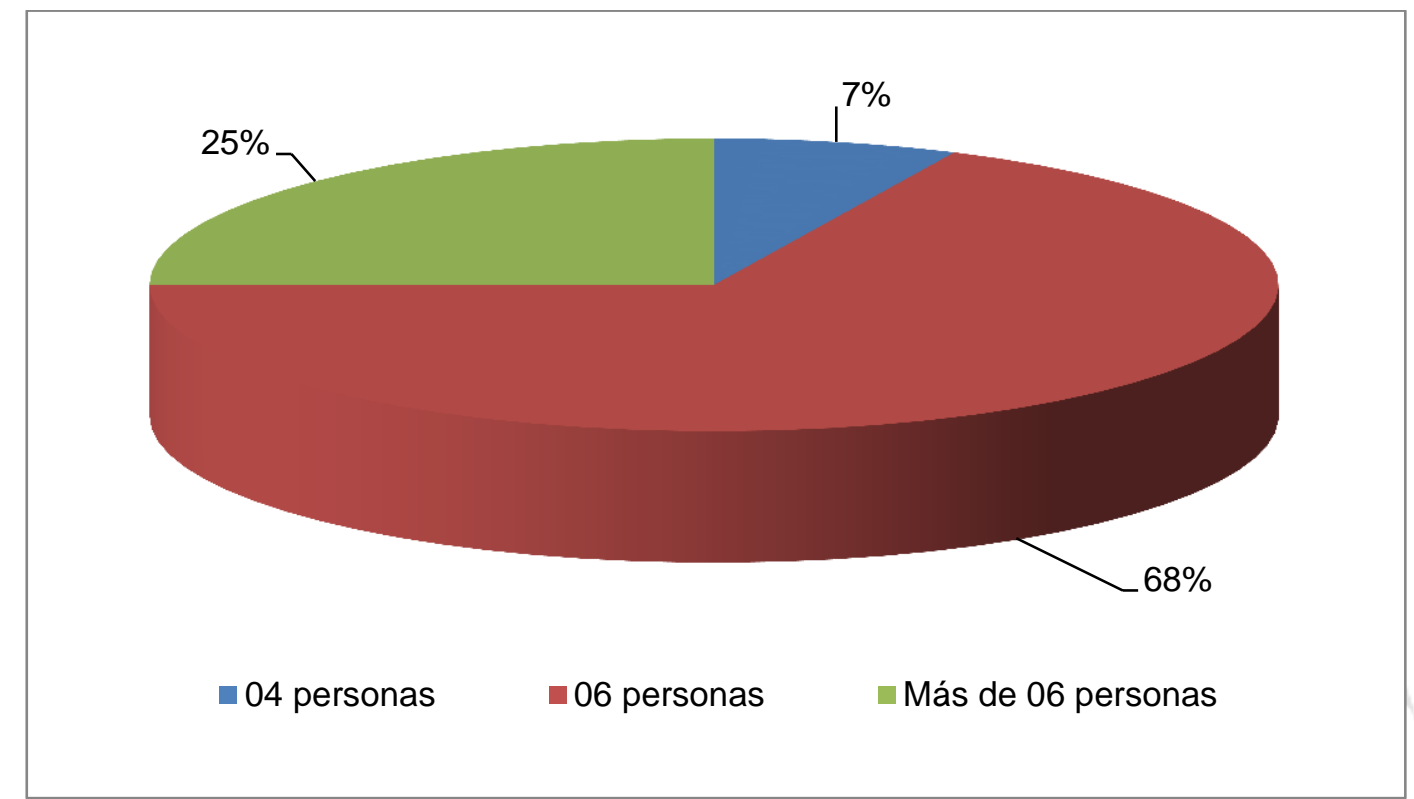

Nota: Total de personas encuestadas (100).

Fuente: Encuestas realizadas por nuestra empresa en Marzo 2008. Elaboración: Propia. 


\section{ANEXO 21: Ubicación del ambiente de lavandería}

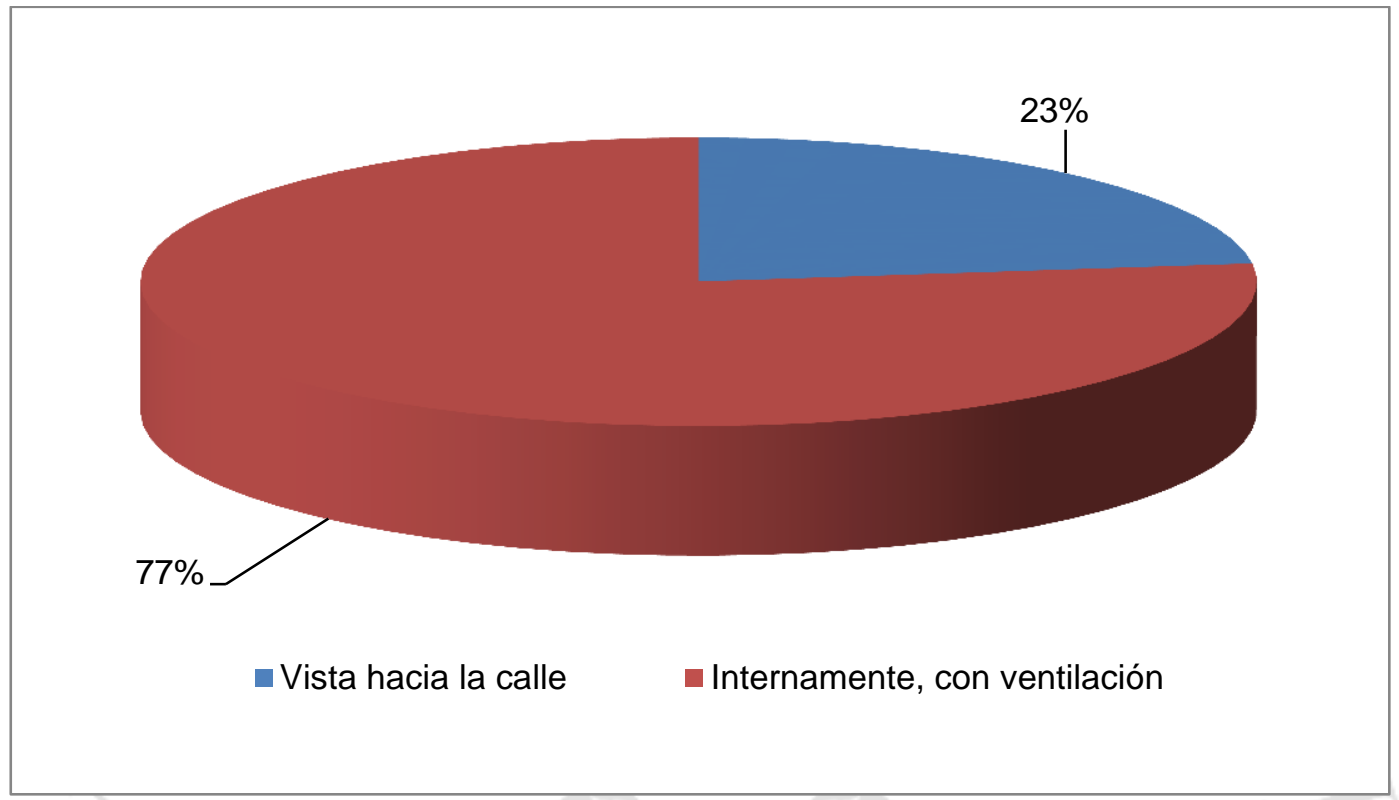

Nota: Total de personas encuestadas (100).

Fuente: Encuestas realizadas por nuestra empresa en Marzo 2008.

Elaboración: Propia. 


\section{ANEXO 22: Cantidad apropiada de dormitorios}

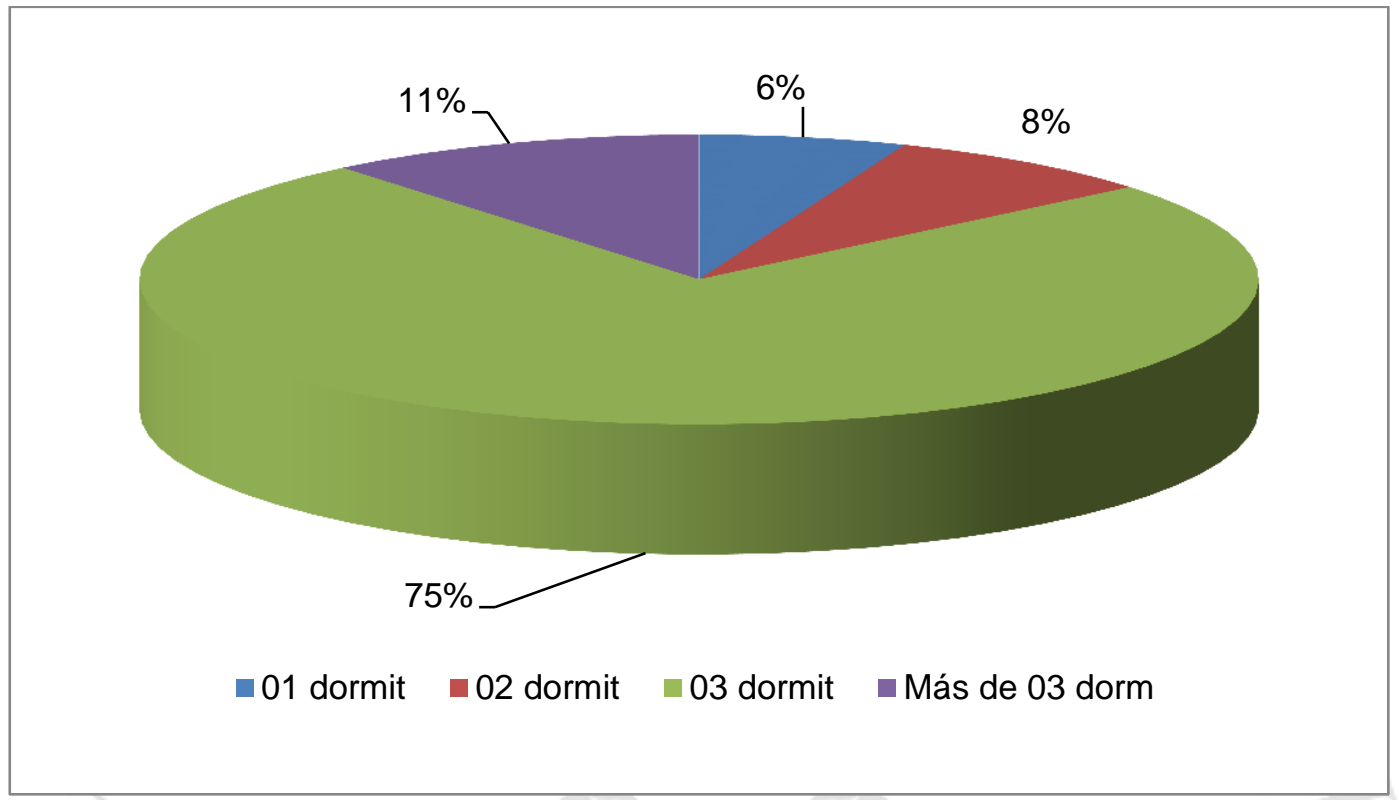

Nota: Total de personas encuestadas (100).

Fuente: Encuestas realizadas por nuestra empresa en Marzo 2008.

Elaboración: Propia. 


\section{ANEXO 23: Tamaño de camas en los dormitorios}

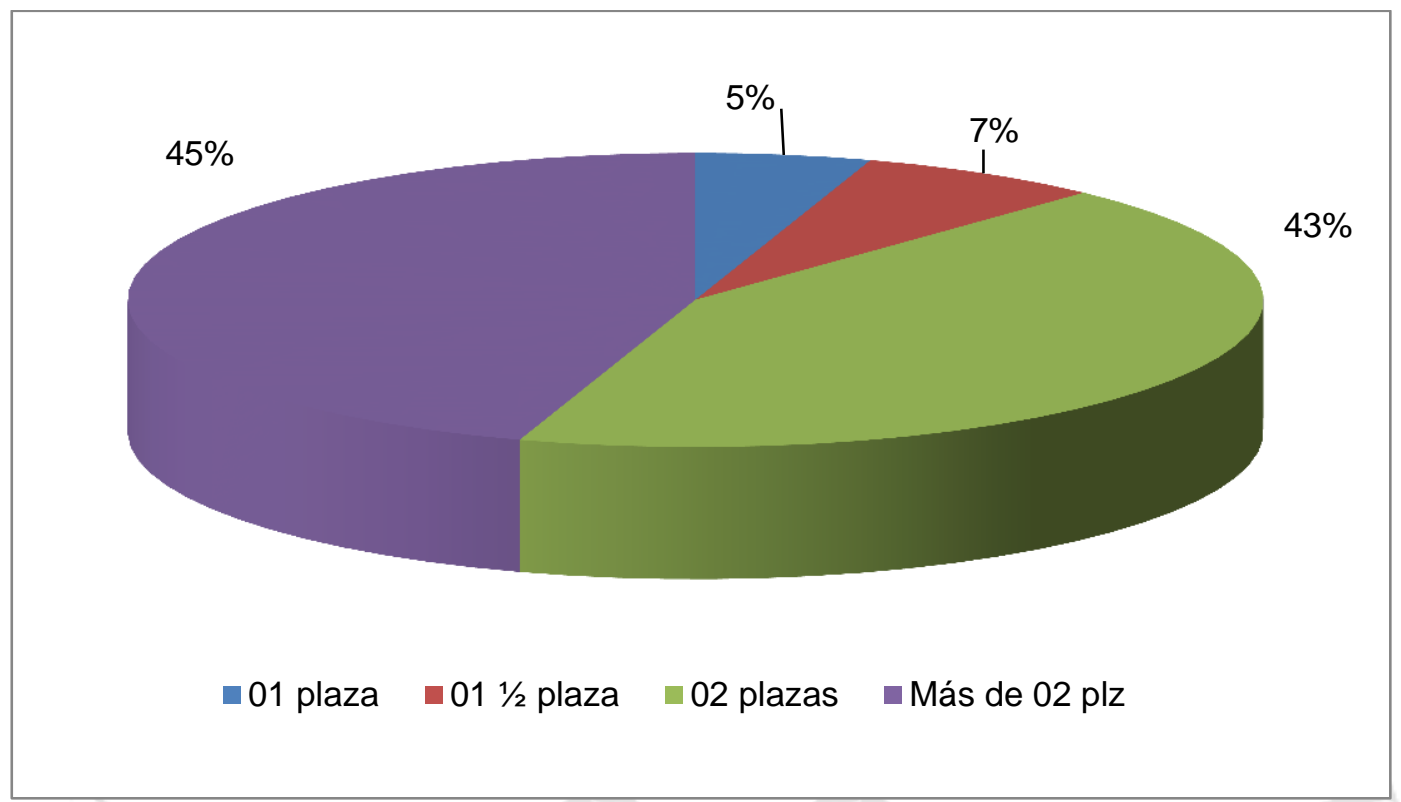

Nota: Total de personas encuestadas (100).

Fuente: Encuestas realizadas por nuestra empresa en Marzo 2008.

Elaboración: Propia. 


\section{ANEXO 24: Cantidad de baños necesarios}

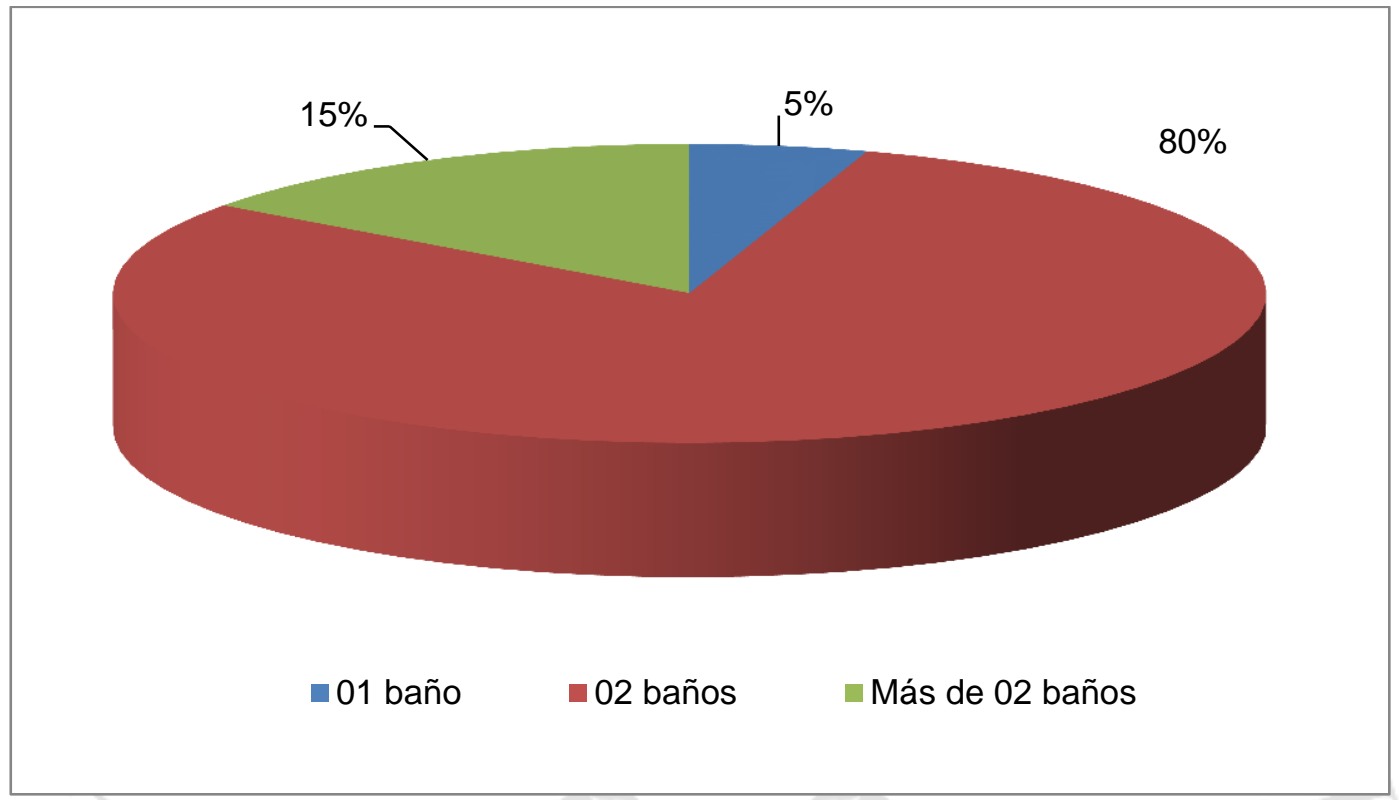

Nota: Total de personas encuestadas (100).

Fuente: Encuestas realizadas por nuestra empresa en Marzo 2008.

Elaboración: Propia. 


\section{ANEXO 25: Demanda insatisfecha de hogares en Lima Metropolitana y el Callao 2007}

\begin{tabular}{|ccccc|}
\hline Año & $\begin{array}{c}\text { Demanda } \\
\text { Efectiva } \\
\text { Hogares }\end{array}$ & $\begin{array}{c}\text { Oferta } \\
\text { Inmediata } \\
\text { Viviendas }\end{array}$ & $\begin{array}{c}\text { Demanda } \\
\text { Insatisfecha } \\
\text { Hogares }\end{array}$ & Variación \% \\
\hline 2004 & 219.977 & 13.948 & 206.029 & - \\
2005 & 242.131 & 11.413 & 230.718 & 0,12 \\
2006 & 280.648 & 13.364 & 267.284 & 0,16 \\
2007 & 296.921 & 13.902 & 283.019 & 0,06 \\
2008 & 303.283 & 12.782 & 290.501 & 0,03 \\
2009 & 330.578 & 13.932 & 316.646 & 0,09 \\
\hline 2010 & 360.331 & 15.186 & 345.144 & 0,09 \\
\hline 2011 & 392.760 & 16.553 & 376.207 & 0,09 \\
\hline
\end{tabular}

Nota: Los años 2009, 2010 y 2011 son proyectados.

Fuente: CAMARA PERUANA DE LA CONSTRUCCIÓN (CAPECO) - El Mercado de Edificaciones Urbanas en Lima Metropolitana y el Callao, IX Estudio Año 2004, X Estudio Año 2005, XI Estudio Año 2006, XII Estudio Año 2007, XIII Estudio Año 2008.

Elaboración: Propia. 


\section{ANEXO 26: Demanda insatisfecha de departamentos en Lima Metropolitana y el Callao 2007}

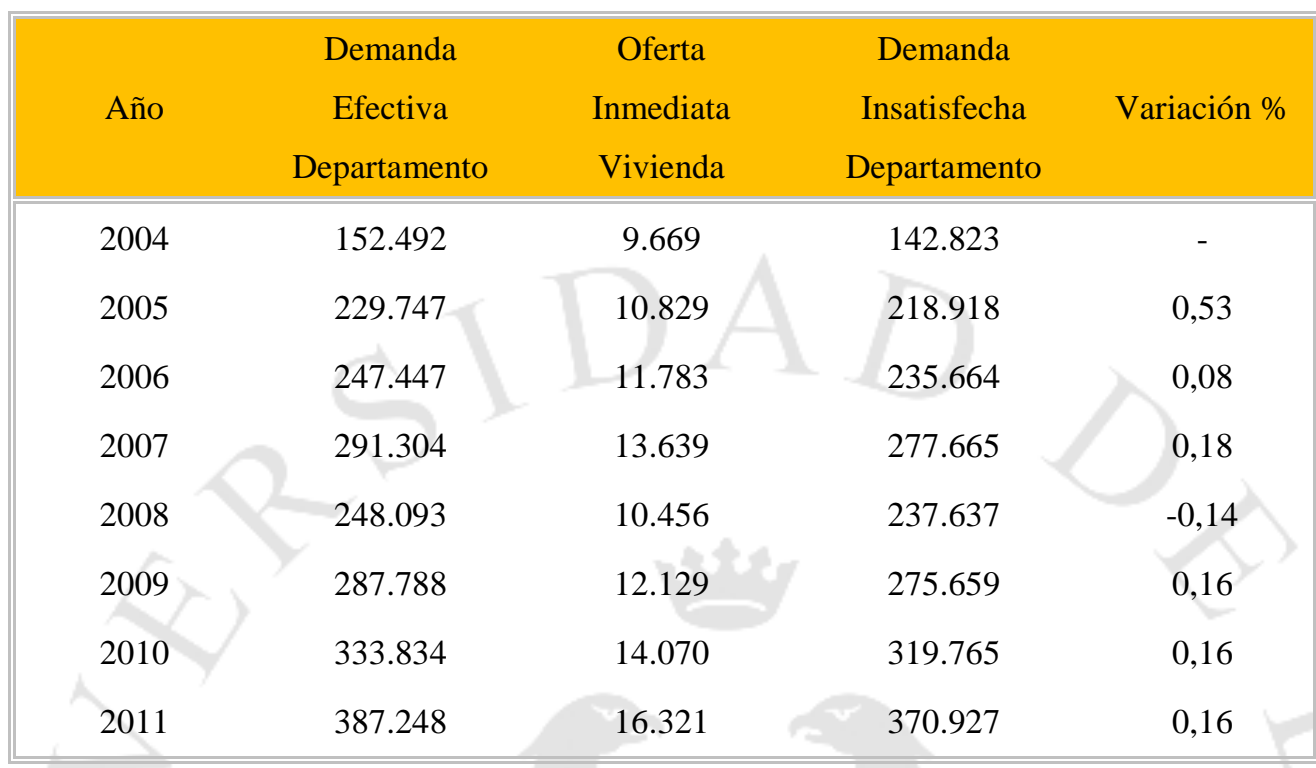

Nota: Los años 2009, 2010 y 2011 son proyectados.

Fuente: CÁMARA PERUANA DE LA CONSTRUCCIÓN (CAPECO) - El Mercado de Edificaciones Urbanas en Lima Metropolitana y el Callao, IX Estudio Año 2004, X Estudio Año 2005, XI Estudio Año 2006, XII Estudio Año 2007, XIII Estudio Año 2008.

Elaboración: Propia. 


\section{ANEXO 27: Indicadores económicos 2000 - 2007}

\begin{tabular}{|lrrrrrrrr|}
\hline \multicolumn{1}{|c}{ Indicadores } & 2000 & 2001 & 2002 & 2003 & 2004 & 2005 & 2006 & 2007 \\
\hline Población (Miles habitantes) & 25.9 & 26.3 & 26.7 & 27.1 & 27.2 & 27.5 & 27.7 & 27.9 \\
PBI Miles de millones S/. & 186.8 & 189.5 & 200.0 & 210.7 & 234.3 & 261.6 & 304.5 & 341.2 \\
PBI Variación \% real & 3.1 & 0.2 & 5.4 & 3.8 & 4.8 & 6.4 & 7.6 & 9.0 \\
PBI Per Cápita S/. & 7212 & 7205 & 7491 & 7775 & 8614 & 9513 & 10993 & 12229 \\
PBI Construcción Variación \% & -4.3 & -6.0 & 8.3 & 4.2 & 4.7 & 8.4 & 14.8 & 16.5 \\
Tipo de Cambio (N/S x US\$) & 3.49 & 3.51 & 3.52 & 3.48 & 3.41 & 3.30 & 3.27 & 3.13 \\
Depreciación (Variación \%) & 3.3 & 0.6 & 0.3 & -1.1 & -1.9 & -3.4 & -0.7 & -4.5 \\
Inflación promedio (Variación \%) & 3.8 & 2.0 & 0.2 & 2.3 & 3.7 & 1.6 & 2.0 & 1.8 \\
Tasa Interbancaria Nominal S/. & 11.4 & 3.15 & 3.8 & 2.51 & 3 & 3.3 & 3.42 & $\mathrm{n} / \mathrm{d}$ \\
Tasa Interbancaria Nominal US\$ & 8.4 & 2.07 & 2.2 & 1.09 & 2.19 & 4.2 & 4.12 & $\mathrm{n} / \mathrm{d}$ \\
TAMN promedio S/. & 32.5 & 24.98 & 20.77 & 21.02 & 24.67 & 23.6 & 25.15 & 19.7 \\
TAMEX promedio US\$ & 13.8 & 12.16 & 10.04 & 9.66 & 9.07 & 10.4 & 12.23 & 10.7 \\
\hline
\end{tabular}

Fuentes: MINISTERIO DE ECONOMÍA Y FINANZAS (MEF) - "Marco Macroeconómico Multianual 2002 - 2004, 2003 - 2005, 2004 - 2006, 2005 - 2007 y 2006-2008”. BANCO CENTRAL DE RESERVA DEL PERÚ (BCRP) www.bcrp.gob.pe "Estadísticas - Cuadros Anuales". INSTITUTO CUANTO cuanto.org “Anuario Estadístico: Perú en Números 2006 y 2007”. INSTITUTO PERUANO DE ECONOMÍA (IPE) www.ipe.org.pe. MAXIMIXE CONSULT S.A. “CASER Riesgo Macro Agosto 2005 y Mayo 2006.

Elaboración: Propia 


\section{ANEXO 28: Crecimiento de los grupos de edad (1995 - 2010)}

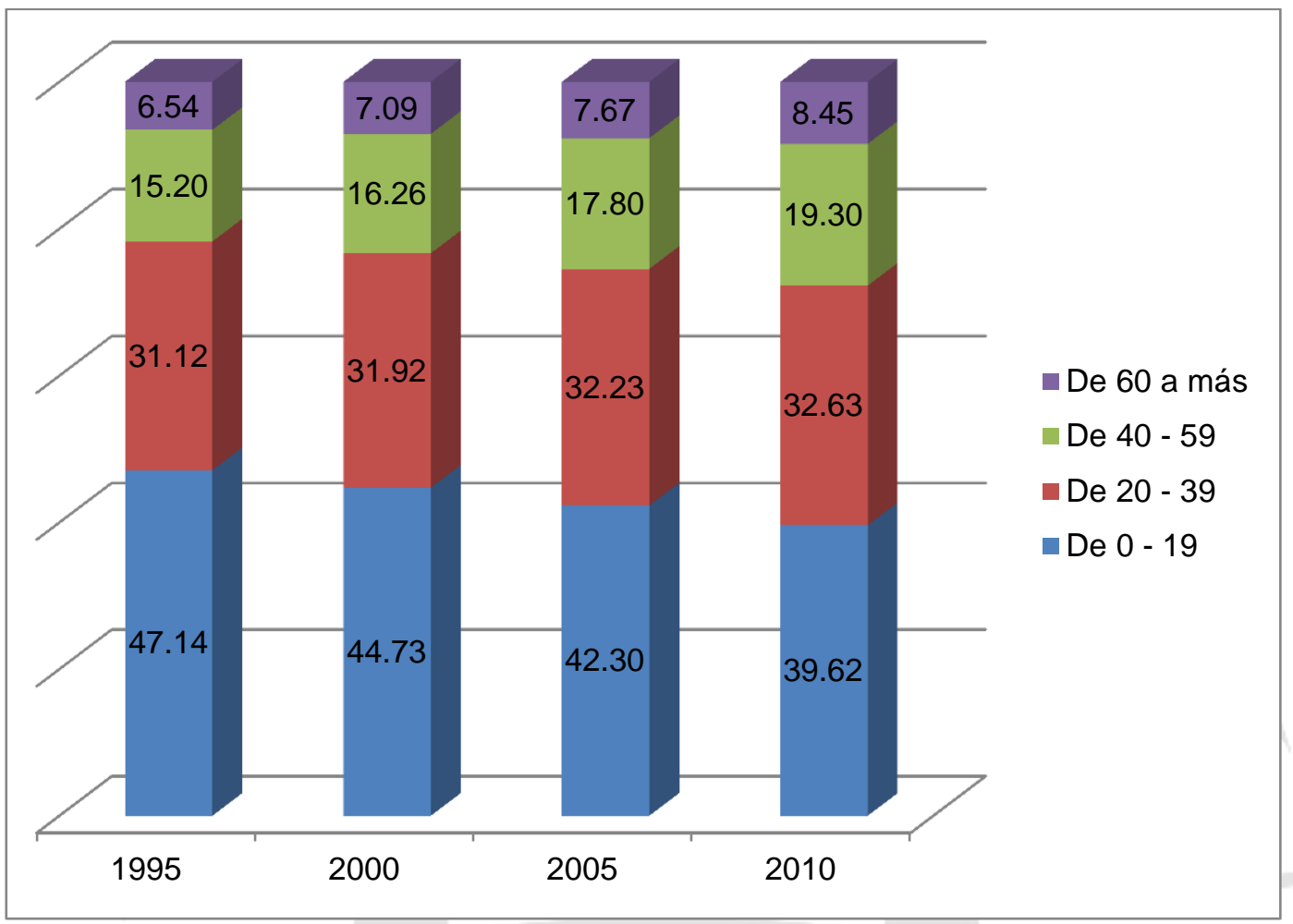

Fuente: INSTITUTO NACIONAL DE ESTADÍSTICA E INFORMÁTICA (INEI) Boletín "Perú: Estimaciones y Proyecciones de Población 1950 - 2050". Elaboración: Propia. 


\section{ANEXO 29: Población total estimada por sexo y tasa de crecimiento, 2003 - 2010 (miles)}

\begin{tabular}{|ccccccc|}
\hline \multirow{2}{*}{ Año } & Total & \multicolumn{2}{c}{ Hombre } & \multicolumn{2}{c|}{ Mujer } & Tasa anual \\
& Población & Cantidad & $\%$ & Cantidad & $\%$ & \% \\
\hline 2003 & 27,148 & 13,654 & $50.29 \%$ & 13,494 & $49.71 \%$ & 1.49 \\
2004 & 27,547 & 13,852 & $50.29 \%$ & 13,694 & $49.71 \%$ & 1.47 \\
2005 & 27,947 & 14,051 & $50.28 \%$ & 13,895 & $49.72 \%$ & 1.45 \\
2006 & 28,349 & 14,254 & $50.28 \%$ & 14,095 & $49.72 \%$ & 1.44 \\
2007 & 28,751 & 14,451 & $50.26 \%$ & 14,300 & $49.74 \%$ & 1.42 \\
2008 & 29,153 & 14,650 & $50.25 \%$ & 14,503 & $49.75 \%$ & 1.40 \\
2009 & 29,555 & 14,850 & $50.24 \%$ & 14,705 & $49.76 \%$ & 1.38 \\
2010 & 29,958 & 15,049 & $50.23 \%$ & 14,909 & $49.77 \%$ & 1.36 \\
\hline
\end{tabular}

Fuente: INSTITUTO NACIONAL DE ESTADÍSTICA E INFORMÁTICA (INEI)

Boletín "Perú: Estimaciones y Proyecciones de Población 1950 - 2050".

Elaboración: Propia. 


\section{ANEXO 30: Créditos hipotecarios para vivienda (miles de NS/.) 2005-2008}

\begin{tabular}{|lrrrr||}
\hline & 2005 & 2006 & 2007 & Jun.2008 \\
\hline B. de Crédito del Perú & 27.013 .882 & 30.583 .359 & 36.300 .981 & 20.442 .353 \\
B. Continental & 18.283 .679 & 22.508 .420 & 27.526 .097 & 14.352 .507 \\
Scotiabank Perú & 0 & 7.541 .774 & 11.641 .020 & 6.162 .705 \\
B. Wiese Sudameris & 6.861 .584 & 2.677 .712 & 0 & 0 \\
Interbank & 5.169 .880 & 6.345 .154 & 7.942 .039 & 5.307 .442 \\
B. Interamericano Finanzas & 3.444 .882 & 4.075 .741 & 4.549 .274 & 2.335 .896 \\
B. Sudamericano & 3.150 .744 & 1.103 .484 & 0 & 0 \\
B. Financiero & 2.042 .779 & 2.697 .885 & 2.839 .284 & 1.405 .098 \\
Mibanco & 282.066 & 403.567 & 511.557 & 274.209 \\
B. Falabella Perú & 0 & 0 & 192.156 & 162.298 \\
HSBC Bank Perú & 0 & 0 & 38.881 & 127.117 \\
Citibank & 133.969 & 132.805 & 135.128 & 59.956 \\
B. de Comercio & 51.870 & 62.573 & 62.509 & 33.617 \\
B. del Trabajo & 1.872 .922 & 2.323 .421 & 1.499 .518 & 16.459 \\
BankBoston & 310 & 0 & 0 & 0 \\
B. Standard Chartered & 185 & 0 & 0 & 0 \\
\hline Total & 68.308 .752 & 80.455 .895 & 93.238 .444 & 50.679 .657 \\
\hline Variación \% & $0 \%$ & $17,8 \%$ & $15,9 \%$ & \\
\hline Fute: Superis & & 0 & 0 & 0 \\
\hline
\end{tabular}

Fuente: Superintendencia de Banca, Seguros y AFP - Boletín Estadístico de Banca Múltiple Alcance y Participación de Mercado: Ranking de Créditos Directos por Tipo.

Elaboración: Propia. 


\section{ANEXO 31: Demanda insatisfecha según precio de la vivienda (julio 2007)}

\begin{tabular}{|c|c|c|c|c|c|}
\hline \multirow{2}{*}{\multicolumn{2}{|c|}{$\begin{array}{l}\text { Precios de las } \\
\text { Viviendas en US\$ }\end{array}$}} & \multirow{3}{*}{$\begin{array}{l}\text { Demanda } \\
\text { Efectiva } \\
\text { Hogares }\end{array}$} & \multirow{3}{*}{$\begin{array}{c}\text { Oferta } \\
\text { Inmediata } \\
\text { Vivienda }\end{array}$} & \multirow{3}{*}{$\begin{array}{c}\text { Demanda } \\
\text { Insatisfecha } \\
\text { Hogares }\end{array}$} & \multirow{3}{*}{$\begin{array}{c}\text { Participación } \\
\text { por Rango } \\
\%\end{array}$} \\
\hline & & & & & \\
\hline & & & & & \\
\hline Hasta & 4,000 & 28.787 & 0 & 28.787 & 10,17 \\
\hline 4,001 & 8,000 & 64.084 & 0 & 64.084 & 22,64 \\
\hline 8,001 & 10,000 & 40.252 & 100 & 40.152 & 14,19 \\
\hline 10,001 & 15,000 & 56.234 & 5 & 56.229 & 19,87 \\
\hline 15,001 & 20,000 & 39.324 & 1.181 & 38.143 & 13,48 \\
\hline 20,001 & 25,000 & 33.077 & 1.188 & 31.889 & 11,27 \\
\hline 25,001 & 30,000 & 10.516 & 1.582 & 8.934 & 3,16 \\
\hline 30,001 & 40,000 & 9.343 & 3.221 & 6.122 & 2,16 \\
\hline 40,001 & 50,000 & 3.585 & 1.521 & 2.064 & 0,73 \\
\hline 50,001 & 60,000 & 3.084 & 1.186 & 1.898 & 0,67 \\
\hline 60,001 & 70,000 & 1.893 & 1.148 & 745 & 0,26 \\
\hline 70,001 & 80,000 & 2.086 & 663 & 1.423 & 0,50 \\
\hline 80,001 & 100,000 & 3.471 & 798 & 2.673 & 0,94 \\
\hline 100,001 & 120,000 & 334 & 394 & -60 & $-0,02$ \\
\hline 120,001 & 150,000 & 508 & 367 & 141 & 0,05 \\
\hline 150,001 & 200,000 & 343 & 274 & 69 & 0,02 \\
\hline 200,001 & 250,000 & 0 & 162 & -162 & $-0,06$ \\
\hline 250,001 & 300,000 & 0 & 57 & -57 & $-0,02$ \\
\hline 300,001 & 500,000 & 0 & 48 & -48 & $-0,02$ \\
\hline Más de & 500,000 & 0 & & -7 & 0,00 \\
\hline Total & & 296.921 & 13.902 & 283.019 & 100,00 \\
\hline
\end{tabular}

Fuente: XII Estudio Año 2007 El Mercado de Edificaciones Urbanas en Lima Metropolitana y el Callao - Cámara Peruana de la Construcción (CAPECO) Elaboración: Propia 


\section{ANEXO 32: Oferta total de vivienda según precios de venta (julio 2007)}

\begin{tabular}{|c|c|c|c|c|c|c|c|}
\hline \multirow{3}{*}{\multicolumn{2}{|c|}{$\begin{array}{l}\text { Precios de las } \\
\text { Viviendas en US\$ }\end{array}$}} & \multicolumn{4}{|c|}{ Oferta Total } & \multirow{2}{*}{\multicolumn{2}{|c|}{ Total }} \\
\hline & & \multicolumn{2}{|c|}{ Casas } & \multicolumn{2}{|c|}{ Departamentos } & & \\
\hline & & Unids & $\mathrm{m} 2$ & Unids & $\mathrm{m} 2$ & Unids & $\mathrm{m} 2$ \\
\hline Hasta & 4,000 & 0 & 0 & 0 & 0 & 0 & 0 \\
\hline 4,001 & 8,000 & 0 & 0 & 0 & 0 & 0 & 0 \\
\hline 8,001 & 10,000 & 0 & 0 & 100 & 5.900 & 100 & 5.900 \\
\hline 10,001 & 15,000 & 0 & 0 & 5 & 305 & 5 & 305 \\
\hline 15,001 & 20,000 & 1 & & 1.187 & 73.524 & 1.188 & 73.604 \\
\hline 20,001 & 25,000 & 0 & & 1.196 & 78.004 & 1.196 & 78.004 \\
\hline 25,001 & 30,000 & 0 & 0 & 1.653 & 118.664 & 1.653 & 118.664 \\
\hline 30,001 & 40,000 & 104 & 14.955 & 3.285 & 260.647 & 3.389 & 275.602 \\
\hline 40,001 & 50,000 & 0 & 0 & 1.557 & 139.687 & 1.557 & 139.687 \\
\hline 50,001 & 60,000 & 9 & 918 & 1.264 & 122.401 & 1.273 & 123.319 \\
\hline 60,001 & 70,000 & 40 & 4.444 & 1.128 & 114.860 & 1.168 & 119.304 \\
\hline 70,001 & 80,000 & 0 & 0 & 671 & 74.722 & 671 & 74.722 \\
\hline 80,001 & 100,000 & 0 & 0 & 801 & 98.436 & 801 & 98.436 \\
\hline 100,001 & 120,000 & 2 & 540 & 402 & 55.992 & 404 & 56.532 \\
\hline 120,001 & 150,000 & 16 & 3.080 & 373 & 58.557 & 389 & 61.637 \\
\hline 150,001 & 200,000 & 45 & 9.975 & 261 & 45.927 & 306 & 55.902 \\
\hline 200,001 & 250,000 & 17 & 4.696 & 179 & 37.228 & 196 & 41.924 \\
\hline 250,001 & 300,000 & 16 & 4.540 & 41 & 9.631 & 57 & 14.171 \\
\hline 300,001 & 500,000 & 18 & 5.859 & 30 & 10.657 & 48 & 16.516 \\
\hline Más de & 500,000 & 0 & 0 & -7 & 3.997 & 7 & 3.997 \\
\hline Total & & 268 & 49.087 & 14.140 & 1.309 .139 & 14.408 & 1.358 .226 \\
\hline
\end{tabular}

Fuente: XII Estudio Año 2007 El Mercado de Edificaciones Urbanas en Lima Metropolitana y el Callao - Cámara Peruana de la Construcción (CAPECO) Elaboración: Propia. 


\section{ANEXO 33: Oferta total de viviendas vendidas según precios de venta (julio 2007)}

\begin{tabular}{|c|c|c|c|c|c|c|c|}
\hline \multirow{3}{*}{\multicolumn{2}{|c|}{$\begin{array}{l}\text { Precios de las } \\
\text { Viviendas en US\$ }\end{array}$}} & \multicolumn{4}{|c|}{ Vendidos } & \multirow{2}{*}{\multicolumn{2}{|c|}{ Total }} \\
\hline & & \multicolumn{2}{|c|}{ Casas } & \multicolumn{2}{|c|}{ Departamentos } & & \\
\hline & & Unids & $\mathrm{m} 2$ & Unids & $\mathrm{m} 2$ & Unids & $\mathrm{m} 2$ \\
\hline Hasta & 4,000 & 0 & 0 & 0 & 0 & 0 & 0 \\
\hline 4,001 & 8,000 & 430 & 14.620 & 328 & 15.088 & 758 & 29.708 \\
\hline 8,001 & 10,000 & 0 & 0 & 0 & 0 & 0 & 0 \\
\hline 10,001 & 15,000 & 0 & 0 & 55 & 3.355 & 55 & 3.355 \\
\hline 15,001 & 20,000 & 0 & 0 & 350 & 22.554 & 350 & 22.554 \\
\hline 20,001 & 25,000 & 0 & 0 & 405 & 26.062 & 405 & 26.062 \\
\hline 25,001 & 30,000 & 0 & 0 & 1.086 & 74.428 & 1.086 & 74.428 \\
\hline 30,001 & 40,000 & 8 & 1.176 & 2.079 & 161.247 & 2.087 & 162.423 \\
\hline 40,001 & 50,000 & 5 & 900 & 1.117 & 97.356 & 1.122 & 98.256 \\
\hline 50,001 & 60,000 & 7 & 714 & 947 & 87.658 & 954 & 88.372 \\
\hline 60,001 & 70,000 & 16 & 1.762 & 919 & 92.877 & 935 & 94.639 \\
\hline 70,001 & 80,000 & 0 & 0 & 528 & 58.518 & 528 & 58.518 \\
\hline 80,001 & 100,000 & 0 & 0 & 837 & 101.939 & 837 & 101.939 \\
\hline 100,001 & 120,000 & 0 & 0 & 247 & 34.859 & 247 & 34.859 \\
\hline 120,001 & 150,000 & 26 & 5.521 & 334 & 51.248 & 360 & 56.769 \\
\hline 150,001 & 200,000 & 25 & 5.475 & 300 & 54.725 & 325 & 60.200 \\
\hline 200,001 & 250,000 & 1 & 212 & 280 & 57.234 & 281 & 57.446 \\
\hline 250,001 & 300,000 & 5 & 1.435 & 84 & 20.218 & 89 & 21.653 \\
\hline 300,001 & 500,000 & 5 & 1.705 & 112 & 36.221 & 117 & 37.926 \\
\hline Más de & 500,000 & 0 & & 35 & 17.932 & 35 & 17.932 \\
\hline Total & & 528 & 33.520 & 10.043 & 1.013 .519 & 10.571 & 1.047 .039 \\
\hline
\end{tabular}

Fuente: XII Estudio Año 2007 El Mercado de Edificaciones Urbanas en Lima Metropolitana y el Callao - Cámara Peruana de la Construcción (CAPECO) Elaboración: Propia. 


\section{ANEXO 34: Oferta total de departamentos según precios de venta (julio 2007)}

\begin{tabular}{|c|c|c|c|c|c|c|c|c|}
\hline \multirow{2}{*}{\multicolumn{2}{|c|}{$\begin{array}{c}\text { Precios de los } \\
\text { Departamentos en US\$\$ }\end{array}$}} & \multicolumn{2}{|c|}{ Oferta Inmediata } & \multicolumn{2}{|c|}{ Oferta Futura } & \multicolumn{3}{|c|}{ Oferta Total } \\
\hline & & Unids & $\mathrm{m} 2$ & Unids & $\mathrm{m} 2$ & Unids & $\%$ & $\mathrm{~m} 2$ \\
\hline Hasta & 4,000 & 0 & 0 & 0 & 0 & 0 & 0,0 & \\
\hline 4,001 & 8,000 & 0 & 0 & 0 & 0 & 0 & 0,0 & 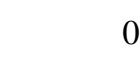 \\
\hline 8,001 & 10,000 & 100 & 5.900 & 0 & 0 & 100 & 0,7 & 5.900 \\
\hline 10,001 & 15,000 & 5 & 305 & 0 & 0 & & 0,0 & 305 \\
\hline 15,001 & 20,000 & 1.181 & 73.014 & 6 & 510 & 1.187 & 8,4 & 73.524 \\
\hline 20,001 & 25,000 & 1.188 & 77.284 & 8 & 720 & 1.196 & 8,5 & 78.004 \\
\hline 25,001 & 30,000 & 1.582 & 113.458 & 71 & 5.206 & 1.653 & 11,7 & 118.664 \\
\hline 30,001 & 40,000 & 3.117 & 247.712 & 168 & 12.935 & 3.285 & 23,2 & 260.647 \\
\hline 40,001 & 50,000 & 1.521 & 136.332 & 36 & 3.355 & 1.557 & 11,0 & 139.687 \\
\hline 50,001 & 60,000 & 1.177 & 113.249 & 87 & 9.152 & 1.264 & 8,9 & 122.401 \\
\hline 60,001 & 70,000 & 1.108 & 112.795 & 20 & 2.065 & 1.128 & 8,0 & 114.860 \\
\hline 70,001 & 80,000 & 663 & 73.962 & 8 & 760 & 671 & 4,7 & 74.722 \\
\hline 80,001 & 100,000 & 798 & 98.106 & 3 & 330 & 801 & 5,7 & 98.436 \\
\hline 100,001 & 120,000 & 392 & 54.652 & 10 & 1.340 & 402 & 2,8 & 55.992 \\
\hline 120,001 & 150,000 & 351 & 54.917 & 22 & 3.640 & 373 & 2,6 & 58.557 \\
\hline 150,001 & 200,000 & 233 & 40.947 & 28 & 4.980 & 261 & 1,8 & 45.927 \\
\hline 200,001 & 250,000 & 145 & 30.088 & 34 & 7.140 & 179 & 1,3 & 37.228 \\
\hline 250,001 & 300,000 & 41 & 9.631 & 0 & 0 & 41 & 0,3 & 9.631 \\
\hline 300,001 & 500,000 & 30 & 10.657 & 0 & 0 & 30 & 0,2 & 10.657 \\
\hline Más de & 500,000 & 7 & 3.997 & 0 & & & 0,0 & 3.997 \\
\hline $\mathrm{Tc}$ & tal & 13.639 & 1.257 .006 & 501 & 52.133 & 14.140 & 100,0 & 1.309 .139 \\
\hline
\end{tabular}

Fuente: XII Estudio Año 2007 El Mercado de Edificaciones Urbanas en Lima Metropolitana y el Callao - Cámara Peruana de la Construcción (CAPECO) Elaboración: Propia. 


\section{ANEXO 35: Oferta total de departamentos según sector urbano y precio (julio 2007)}

\begin{tabular}{|c|c|c|c|c|}
\hline \multirow{2}{*}{ Sector Urbano } & \multicolumn{4}{|c|}{ Estructura de la Oferta } \\
\hline & Unids & $\begin{array}{l}\text { Precio } \\
\text { Medio US\$ }\end{array}$ & $\begin{array}{c}\text { Área } \\
\text { Prom } \mathrm{m} 2\end{array}$ & $\begin{array}{l}\text { Precio por } \\
\text { m2 US\$ }\end{array}$ \\
\hline 1. Miraflores & 1.696 & 89.365 & 112,1 & 770 \\
\hline 2. San Isidro & 670 & 128.777 & 141,6 & 884 \\
\hline 3. La Molina & 385 & 52.723 & 104,8 & 503 \\
\hline 4. Santiago de Surco, San Borja & 3.044 & 66.754 & 106,1 & 589 \\
\hline $\begin{array}{l}\text { 5. Jesús María, Lince, Magdalena del Mar, Pueblo } \\
\text { Libre, San Miguel }\end{array}$ & 3.912 & 42.196 & 85,4 & 493 \\
\hline 6. Barranco, Chorrillos, Surquillo & 1.140 & 44.366 & 82,8 & 467 \\
\hline $\begin{array}{l}\text { 7. Ate, Cieneguilla, Chaclacayo, Lurigancho, Santa } \\
\text { Anita }\end{array}$ & 530 & 27.483 & 72,6 & 381 \\
\hline $\begin{array}{l}\text { 8. Cercado de Lima, Breña, La Victoria, Rímac, San } \\
\text { Luis }\end{array}$ & 724 & 28.279 & 74,0 & 382 \\
\hline $\begin{array}{l}\text { 9. Carabayllo, Comas, Independencia, Los Olivos, } \\
\text { Pte. Piedra, S.M.P }\end{array}$ & 148 & 25.322 & 86,2 & 301 \\
\hline 10. El Agustino, San Juan de Lurigancho & 1.377 & 18.589 & 62,1 & 300 \\
\hline 11. Ancón, Santa Rosa & 0 & 0 & 0,0 & 0 \\
\hline $\begin{array}{l}\text { 12. Lurín, Pachacamac, S.J.M., Villa El Salvador, } \\
\text { Villa María del Triunfo }\end{array}$ & 0 & 0 & 0,0 & 0 \\
\hline $\begin{array}{l}\text { 13. Pucusana, Pta. Hermosa, Pta. Negra, S. Bartolo, } \\
\text { Sta. María del Mar }\end{array}$ & 75 & 58.693 & 111,3 & 516 \\
\hline $\begin{array}{l}\text { 14. Bellavista, Callao, Carmen de la Legua, La } \\
\text { Perla, La Punta }\end{array}$ & 439 & 28.565 & 76,9 & 374 \\
\hline 15. Ventanilla & 0 & 0 & 0,0 & 0 \\
\hline Total & 14.140 & 53.629 & 92,6 & 529 \\
\hline
\end{tabular}

Fuente: XII Estudio Año 2007 El Mercado de Edificaciones Urbanas en Lima Metropolitana y el Callao - Cámara Peruana de la Construcción (CAPECO) Elaboración: Propia 


\section{ANEXO 36: Oferta total de departamentos según distrito y grupo (julio 2007)}

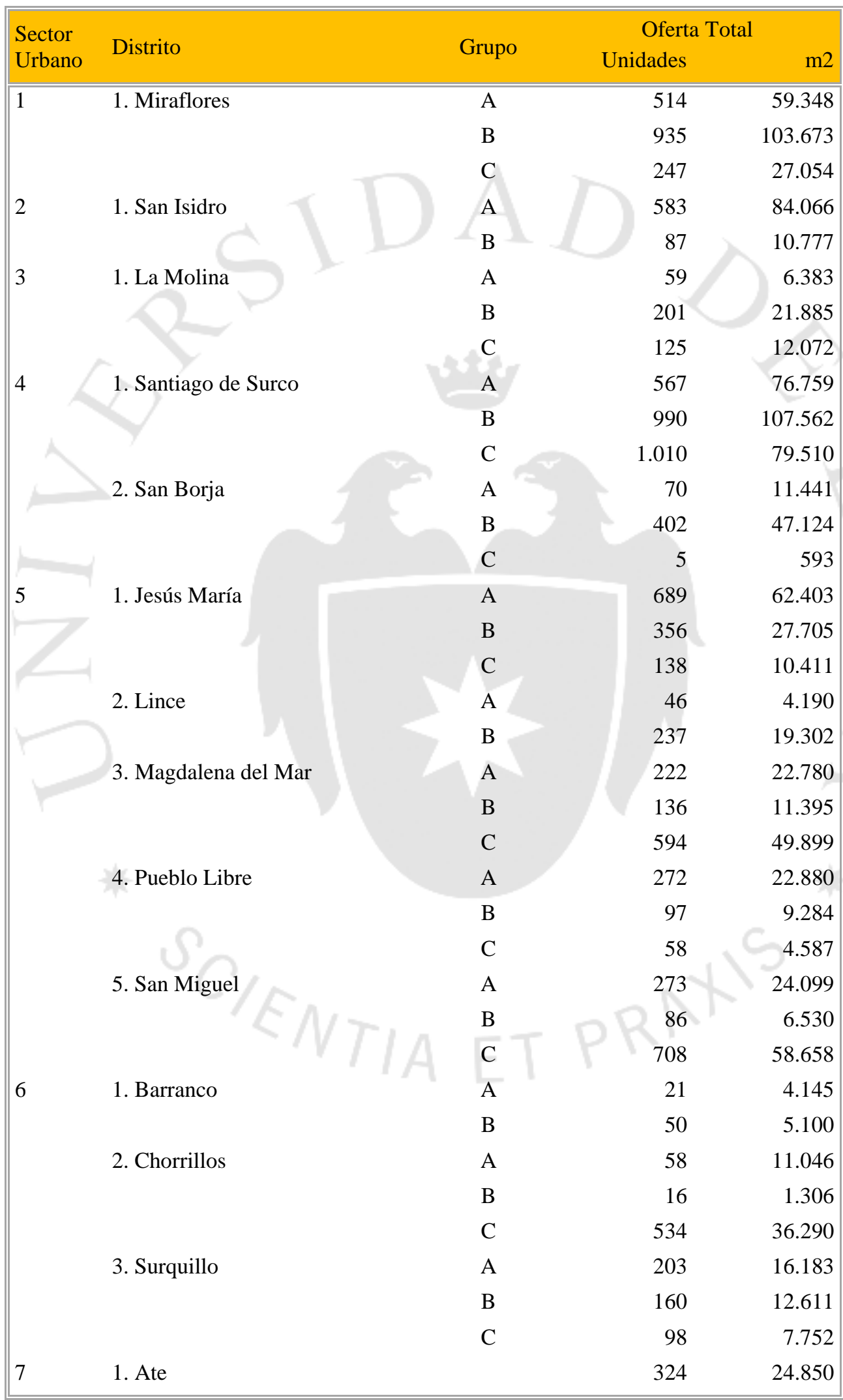




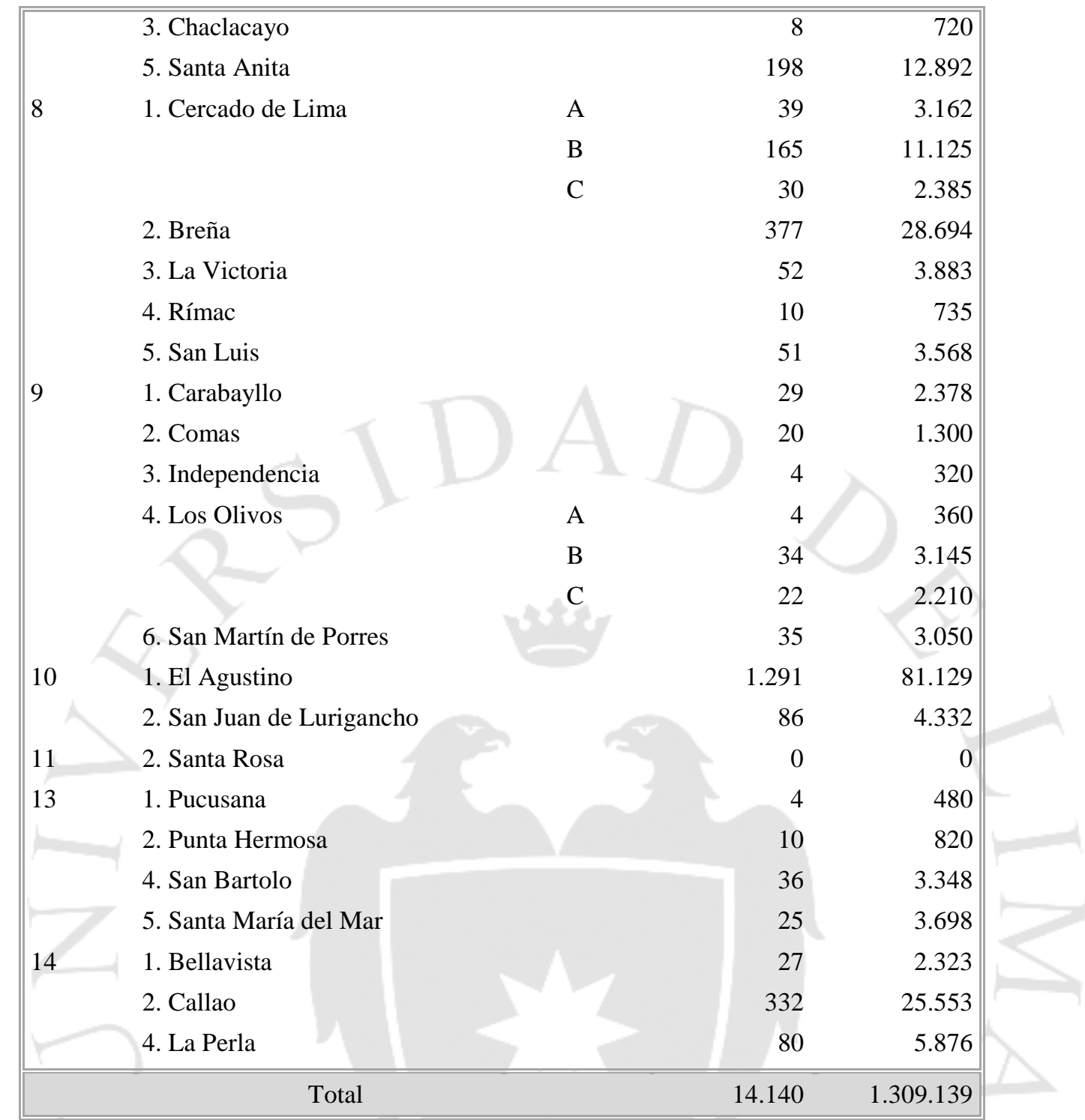

Fuente: XII Estudio Año 2007 El Mercado de Edificaciones Urbanas en Lima Metropolitana y el Callao - Cámara Peruana de la Construcción (CAPECO) Elaboración: Propia. 


\section{ANEXO 37: Precios promedio anuales de los materiales de construcción, 2003 - 2007}

\begin{tabular}{|c|c|c|c|c|c|c|}
\hline Materiales de construcción & Unid & 2003 & 2004 & 2005 & 2006 & 2007 \\
\hline \multicolumn{7}{|l|}{ Ladrillos } \\
\hline King Kong & Millar & 287.61 & 282.82 & 317.02 & 354.76 & 495.98 \\
\hline Pandereta & Millar & 236.44 & 227.82 & 253.62 & 276.60 & 397.11 \\
\hline Techo Hueco 15 & Millar & 885.92 & 850.95 & 922.45 & 1005.5 & 1417.2 \\
\hline Corriente & Millar & 488.56 & 518.27 & 532.29 & 580.24 & 593.63 \\
\hline Mayólica & $\mathrm{M} 2$ & 19.85 & 19.24 & 18.13 & 18.10 & 19.21 \\
\hline \multicolumn{7}{|l|}{ Aglomerantes } \\
\hline Cemento bls $45.5 \mathrm{~kg}$ & Unid & 17.11 & 17.28 & 17.24 & 17.39 & 17.28 \\
\hline Yeso bls $25 \mathrm{~kg}$ & Unid & 5.64 & 5.82 & 5.93 & 5.94 & 5.40 \\
\hline Cal bls $25 \mathrm{~kg}$ & Unid & 13.70 & 14.88 & 16.72 & 16.72 & 16.72 \\
\hline \multicolumn{7}{|l|}{ Agregados } \\
\hline Piedra chancada 1/2" & M3 & 34.91 & 37.83 & 40.19 & 43.03 & 44.79 \\
\hline Arena gruesa & M3 & 17.68 & 21.16 & 23.24 & 25.95 & 28.12 \\
\hline Hormigón & M3 & 11.13 & 19.07 & 24.65 & 27.95 & 30.70 \\
\hline \multicolumn{7}{|l|}{ Metálicos } \\
\hline Fierro constr $9 \mathrm{mtsx} 1 / 2 "$ & Varilla & 14.73 & 22.83 & 22.97 & 23.71 & 24.56 \\
\hline Fierro constr $9 \mathrm{mts} \times 3 / 8 "$ & Varilla & 8.30 & 12.73 & 12.78 & 13.26 & 13.72 \\
\hline Fierro constr $9 \mathrm{mts} \times 5 / 8 "$ & Varilla & 23.14 & 35.47 & 35.71 & 36.94 & 38.26 \\
\hline Alambre negro & $\mathrm{Kg}$ & 2.38 & 3.65 & 3.32 & 3.37 & 3.45 \\
\hline Clavos 2" a 4" & $\mathrm{Kg}$ & 2.36 & 3.70 & 3.46 & 3.60 & 3.72 \\
\hline \multicolumn{7}{|l|}{ Accesorios plásticos } \\
\hline Alambre TW & Unid & 0.65 & 0.94 & 1.01 & 1.39 & 1.40 \\
\hline Cable WP & Unid & 2.85 & 3.80 & 3.93 & 5.43 & 5.13 \\
\hline Alambre telefónico & Unid & 0.45 & 0.58 & 0.82 & 1.08 & 1.10 \\
\hline \multicolumn{7}{|l|}{ Maderas } \\
\hline Tornillo & Unid & 3.06 & 3.06 & 3.20 & 3.56 & 3.82 \\
\hline Cedro & Unid & 6.27 & 6.64 & 6.91 & 8.51 & 9.21 \\
\hline Caoba & Unid & 11.42 & 11.99 & 13.61 & 14.57 & 15.23 \\
\hline Tripley & Unid & 19.41 & 22.62 & 23.64 & 24.31 & 27.12 \\
\hline
\end{tabular}

Fuente: Precios de Materiales de Construcción, Sistema de Precios Promedios, Información Económica, Instituto Nacional de Estadística e Informática (INEI). Elaboración: Propia. 


\section{ANEXO 38: Variación porcentual anual de los precios de los materiales de construcción, 2003 - 2007}

\begin{tabular}{|c|c|c|c|c|c|c|}
\hline Materiales de construcción & Unidad & 2003 & 2004 & 2005 & 2006 & 2007 \\
\hline \multicolumn{7}{|l|}{ Ladrillos } \\
\hline King Kong & Millar & $-1.0 \%$ & $-1.7 \%$ & $12.1 \%$ & $11.9 \%$ & $39.8 \%$ \\
\hline Pandereta & Millar & $-1.8 \%$ & $-3.6 \%$ & $11.3 \%$ & $9.1 \%$ & $43.6 \%$ \\
\hline Techo Hueco 15 & Millar & $-1.8 \%$ & $-3.9 \%$ & $8.4 \%$ & $9.0 \%$ & $40.9 \%$ \\
\hline Corriente & Millar & $0.3 \%$ & $6.1 \%$ & $2.7 \%$ & $9.0 \%$ & $2.3 \%$ \\
\hline Mayólica & M2 & $-3.1 \%$ & $-3.0 \%$ & $-5.8 \%$ & $-0.2 \%$ & $6.1 \%$ \\
\hline \multicolumn{7}{|l|}{ Aglomerantes } \\
\hline Cemento bls $45.5 \mathrm{~kg}$ & Unid & $0.8 \%$ & $1.0 \%$ & $-0.2 \%$ & $0.8 \%$ & $-0.6 \%$ \\
\hline Yeso bls $25 \mathrm{~kg}$ & Unid & $1.2 \%$ & $3.1 \%$ & $1.8 \%$ & $0.3 \%$ & $-9.2 \%$ \\
\hline Cal bls $25 \mathrm{~kg}$ & Unid & $-12.2 \%$ & $8.6 \%$ & $12.3 \%$ & $0.0 \%$ & $0.0 \%$ \\
\hline \multicolumn{7}{|l|}{ Agregados } \\
\hline Piedra chancada 1/2" & M3 & $19.5 \%$ & $8.4 \%$ & $6.2 \%$ & $7.1 \%$ & $4.1 \%$ \\
\hline Arena gruesa & M3 & $40.6 \%$ & $19.7 \%$ & $9.8 \%$ & $11.7 \%$ & $8.4 \%$ \\
\hline Hormigón & M3 & $21.1 \%$ & $71.4 \%$ & $29.3 \%$ & $13.4 \%$ & $9.8 \%$ \\
\hline \multicolumn{7}{|l|}{ Metálicos } \\
\hline Fierro constr 9mtsx 1/2" & Varilla & $6.1 \%$ & $55.1 \%$ & $0.6 \%$ & $3.2 \%$ & $3.6 \%$ \\
\hline Fierro constr 9mtsx3/8" & Varilla & $7.1 \%$ & $53.3 \%$ & $0.4 \%$ & $3.8 \%$ & $3.5 \%$ \\
\hline Fierro constr 9mtsx5/8" & Varilla & $7.1 \%$ & $53.3 \%$ & $0.7 \%$ & $3.5 \%$ & $3.6 \%$ \\
\hline Alambre negro & $\mathrm{Kg}$ & $7.8 \%$ & $53.6 \%$ & $-9.2 \%$ & $1.6 \%$ & $2.4 \%$ \\
\hline Clavos 2" a 4" & $\mathrm{Kg}$ & $4.6 \%$ & $56.7 \%$ & $-6.4 \%$ & $4.1 \%$ & $3.2 \%$ \\
\hline \multicolumn{7}{|l|}{ Accesorios plásticos } \\
\hline Alambre TW & Unid & $-9.5 \%$ & $45.8 \%$ & $6.9 \%$ & $38.2 \%$ & $0.3 \%$ \\
\hline Cable WP & Unid & $-7.6 \%$ & $33.2 \%$ & $3.5 \%$ & $38.1 \%$ & $-5.6 \%$ \\
\hline Alambre telefónico & Unid & $-8.5 \%$ & $30.5 \%$ & $40.5 \%$ & $31.3 \%$ & $2.1 \%$ \\
\hline \multicolumn{7}{|l|}{ Maderas } \\
\hline Tornillo & Unid & $5.0 \%$ & $0.0 \%$ & $4.5 \%$ & $11.4 \%$ & $7.3 \%$ \\
\hline Cedro & Unid & $7.7 \%$ & $5.8 \%$ & $4.2 \%$ & $23.0 \%$ & $8.3 \%$ \\
\hline Caoba & Unid & $13.8 \%$ & $4.9 \%$ & $13.6 \%$ & $7.0 \%$ & $4.6 \%$ \\
\hline Tripley & Unid & $5.1 \%$ & $16.5 \%$ & $4.5 \%$ & $2.8 \%$ & $11.6 \%$ \\
\hline
\end{tabular}

Fuente: Precios de Materiales de Construcción, Sistema de Precios Promedios, Información Económica, Instituto Nacional de Estadística e Informática (INEI). Elaboración: Propia. 


\section{ANEXO 39: Comparativo entre preferencias de los clientes y características reales del edificio}

\begin{tabular}{|c|c|c|}
\hline Descripción de la preferencia & $\begin{array}{r}\text { Preferencias } \\
\text { según encuesta }\end{array}$ & $\begin{array}{l}\text { Características } \\
\text { reales del edifico }\end{array}$ \\
\hline \multicolumn{3}{|l|}{ Características de diseño de los departamentos } \\
\hline La cantidad de departamentos, máximo 15 & $87 \%$ & 12 dptos \\
\hline La cantidad de pisos o niveles, máximo 7 & $81 \%$ & 7 pisos \\
\hline El frontis debe ser mayor a $5 \mathrm{mts}$ & $50 \%$ & $6 \mathrm{mts}$ \\
\hline La altura del departamento de 2 a $3 \mathrm{mts}$ & $75 \%$ & $2.40 \mathrm{mts}$ \\
\hline El diseño debe considerar vista a la calle & $98 \%$ & $\mathrm{Si}$ \\
\hline La sala y el comedor con vista a la calle & $90 \%$ & $\mathrm{Si}$ \\
\hline En la sala deben entrar más de 2 muebles & $83 \%$ & $\mathrm{Si}$ \\
\hline El comedor debe tener un aforo de 6 personas & $68 \%$ & $\mathrm{Si}$ \\
\hline La cocina y la lavandería deben estar separadas & $82 \%$ & $\mathrm{Si}$ \\
\hline La cocina debe tener muebles reposteros & $98 \%$ & $\mathrm{Si}$ \\
\hline La lavandería debe ser al interior y ventilada & $77 \%$ & $\mathrm{Si}$ \\
\hline El diseño debe incluir cuarto y baño de servicio & $92 \%$ & $\mathrm{Si}$ \\
\hline El diseño debe considerar 3 dormitorios & $75 \%$ & $\mathrm{Si}$ \\
\hline En el dormitorio debe entrar una cama de $2 \mathrm{plz}$ & $88 \%$ & $\mathrm{Si}$ \\
\hline El diseño debe considerar 2 baños completos & $80 \%$ & $\mathrm{Si}$ \\
\hline El diseño debe contar con iluminación natural & $100 \%$ & $\mathrm{Si}$ \\
\hline El diseño debe contar suficiente ventilación & $100 \%$ & $\mathrm{Si}$ \\
\hline \multicolumn{3}{|l|}{ Acabados de los departamentos } \\
\hline Las ventanas deben ser de aluminio & $46 \%$ & $\mathrm{Si}$ \\
\hline Los pisos deben ser laminados en sala y comedor & $88 \%$ & $\mathrm{Si}$ \\
\hline Los pisos deben ser laminados en dormitorios & $90 \%$ & $\mathrm{Si}$ \\
\hline Los pisos deben ser cerámicos en cocina & $97 \%$ & $\mathrm{Si}$ \\
\hline Los pisos deben ser cerámicos en lavandería & $100 \%$ & $\mathrm{Si}$ \\
\hline Los pisos deben ser cerámicos en baños & $100 \%$ & $\mathrm{Si}$ \\
\hline La grifería y sanitarios deben ser marca "Trebol" & $85 \%$ & $\mathrm{Si}$ \\
\hline Los dormitorios deben incluir closets & $100 \%$ & $\mathrm{Si}$ \\
\hline Se debe considerar agua fria y caliente en baños & $100 \%$ & $\mathrm{Si}$ \\
\hline Se debe considerar agua fría y caliente en cocina & $82 \%$ & $\mathrm{Si}$ \\
\hline Se debe considerar agua fría y caliente lavandería & $65 \%$ & $\mathrm{Si}$ \\
\hline El cliente debe elegir el color de pintura del dpto.. & $95 \%$ & $\mathrm{Si}$ \\
\hline \multicolumn{3}{|l|}{ Instalaciones y servicios de los departamentos } \\
\hline Puntos de TV cable en sala y comedor & $85 \%$ & $\mathrm{Si}$ \\
\hline Puntos de TV cable en dormitorios & $100 \%$ & $\mathrm{Si}$ \\
\hline
\end{tabular}


Puntos de Internet en dormitorios

$100 \%$

$\mathrm{Si}$

Puntos de telefonía fija en sala y comedor

$89 \%$

$\mathrm{Si}$

Puntos de telefonía fija en dormitorios

$100 \%$

$\mathrm{Si}$

Puntos de telefonía fija en cocina

$56 \%$

$\mathrm{Si}$

Más de 2 tomacorrientes en sala y comedor

$85 \%$

3 puntos

Más de 2 tomacorrientes en dormitorios

$80 \%$

3 puntos

Más de 2 tomacorrientes en cocina

$90 \%$

3 puntos

Suficiente 2 tomacorrientes en baños

$75 \%$

2 puntos

Suficiente 2 tomacorrientes en lavandería

$57 \%$

2 puntos

Medidor independiente de agua

Medidor independiente de energía eléctrica

$100 \%$

$\mathrm{Si}$

Intercomunicador

$100 \%$

$100 \%$

Características de las áreas comunes

Contar con ascensor con capacidad de 6 personas

$80 \%$

6 personas

Piso de estacionamiento con piso pulido

$86 \%$

$\mathrm{Si}$

Elaboración: Propia. 


\section{ANEXO 40: Imágenes del volante díptico del proyecto}

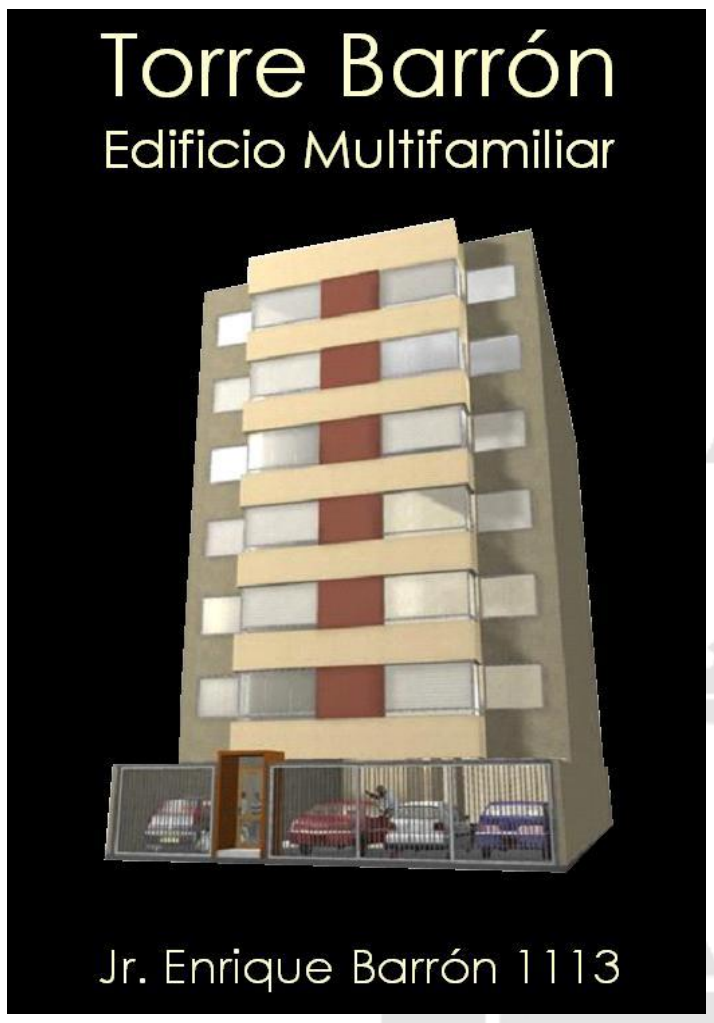

Torre Barrón Edificio Multifamiliar

$>$ Edificio multifamiliar de 07 pisos

$>12$ exclusivos departamentos (02 por piso)

$>12$ estacionamientos ( 1 er piso)

> Departamentos de $90 \mathrm{~m}^{2}$ a $127 \mathrm{~m}^{2}$ aprox.

> Sala y comedor amplios, con vista a la calle

$>$ Cocina y lavandería

$>03$ dormitorios

$>02$ baños completos

$>$ Dormitorio principal con baño incorporado

$>$ Baño y cuarto de servicio

$>$ Terraza y patio interior

$>$ Ascensor de lujo y hall de ingreso

$>$ Sistema contra incendios

$>$ Instalaciones de Teléfono, Cable e Internet

$>$ Instalación de Gas

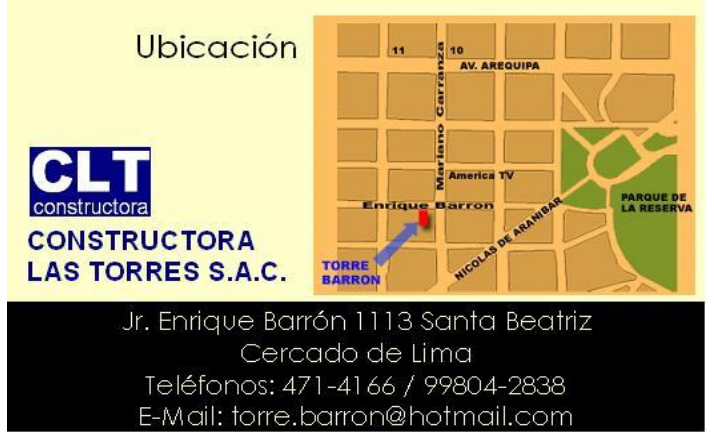

Elaboración: Propia.

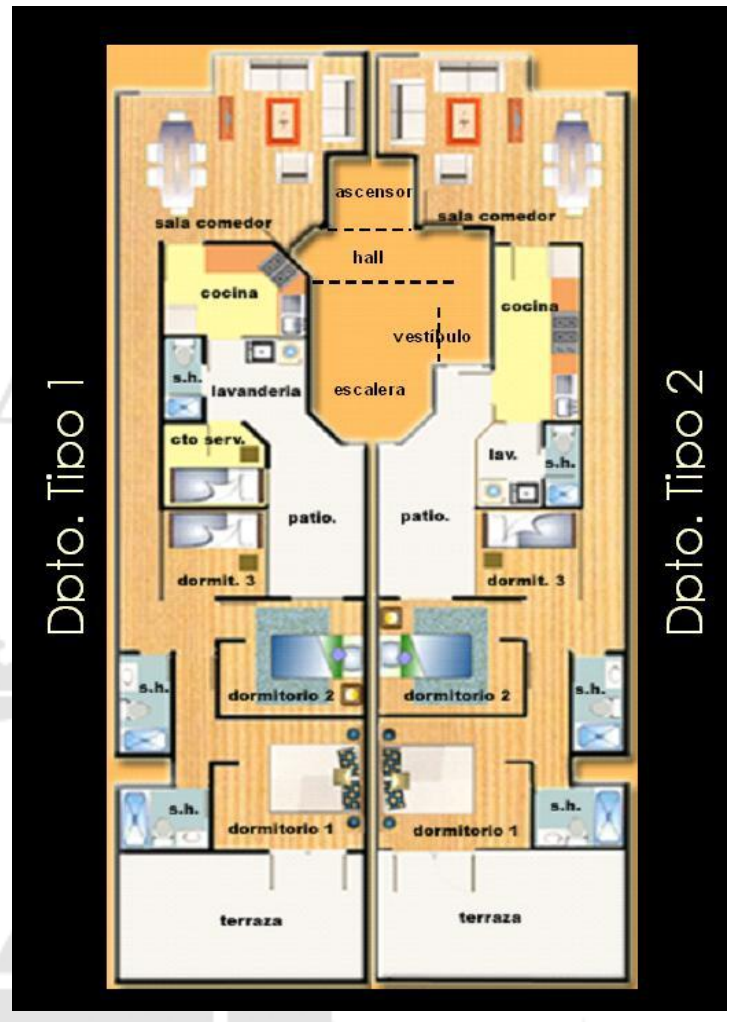

REQUISTOS PARA EL FINANCIAMIENTO BANCARIO:

1. Copia del DNI de titular(es)

. Copia del último recibo de luz agua y teléfono fijo

. Copia de tarieta de propie dad vehicular, de ser el caso

. Copia del ulimo estado do cuenta de tarjela de consumo y/o crédito

SI ES TRABAJAD OR DE EMPRESA (DEP ENDIENTE - 5 ta CATEGORÍA)

5. Copia de las 3 últimas boletas de pago ( 6 últimas en caso de recibir

copia del certificado de retención de 5 ta cate goría emitido por la empresa 7. Copia del estado de cuenta corriente AFP

SI EMITE RECIBOS POR HONORARIOS (IND EP ENDIENTE - 4ta CATEGORÍA)

5. Copia de recibos por honorarios emitidos en los últimos 6 meses

Copia de las declaraciones mensuales a SUNAT de los últimos 6 meses, adjuntando constancia de pago

Copia de las declaraciones juradas anuales de los 2 últimos años,

adjuntando constancia de pago (Ejercicio Gravable)

8. Copia del certificado de retención de 4ta categoría de la empresa en que

Copia del RU

cia de trabajo

SI CUENTA CON NEGOCIO PROP IO (INDEPENDIENTE - 3ra C ATEGORIA)

5. Copia de 6 últimos pagos de IGV

6 Copia de las declaraciones mensuales a SUNAT de los últimos 6 meses, adjuntando constancia de pago (PDT mensual)

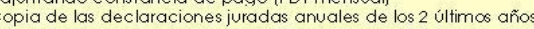
ravable o PDT anua

. copia deluc

.

SI ALQUILA UN INMUEBLE (RENTISTA - 1 ra CATEGORIA)

5. Copia del contrato de Alquiler de los 3 últimos años

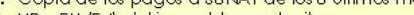

\section{SI RECIBE REMES AS DEL EXTERIOR}

5. Cuota inicial mínima del $40 \%$ 6. Copia de las remesas de los 6 últimos meses

Nota: Deberá presentar 02 juegos de todos los documentos en copia fotostática. 


\section{ANEXO 41: Distribución de volantes dípticos}

\begin{tabular}{|c|c|c|c|}
\hline \multicolumn{2}{|r|}{ Entidad } & \multirow{2}{*}{$\begin{array}{l}\text { Entregado a: } \\
\text { Gerente de Recursos Humanos } \\
\text { Carlos A. Beteta Godoy }\end{array}$} & \multirow{2}{*}{$\begin{array}{c}\text { Cantidad } \\
400 \text { dípticos }\end{array}$} \\
\hline 01 & $\begin{array}{l}\text { Compañía Peruana de Radiodifusión } \\
\text { S.A. (Canal 4) }\end{array}$ & & \\
\hline 02 & $\begin{array}{l}\text { Panamericana Contenidos S.A.A. } \\
\text { (Canal 5) }\end{array}$ & $\begin{array}{l}\text { Gerente de Recursos Humanos } \\
\text { Miguel Merino Silva }\end{array}$ & 300 dípticos \\
\hline 03 & $\begin{array}{l}\text { Instituto Nacional de Radio y } \\
\text { Televisión - IRTP (Canal 7) }\end{array}$ & Asistencia Social - Sara Soria & 300 dípticos \\
\hline 04 & Banco Financiero Agencia Risso & $\begin{array}{l}\text { Ejecutivo de Banca Personal Ana } \\
\text { María Casafranca }\end{array}$ & 1,000 dípticos \\
\hline 05 & $\begin{array}{l}\text { Bancos de Cercado de Lima, Jesús } \\
\text { María y Lince }\end{array}$ & Ejecutivos de banca personal & 1,200 dípticos \\
\hline 06 & Colegio Dante Alighieri & Secretaría / Padres de familia & 500 dípticos \\
\hline 07 & Colegio Trilce - Santa Beatriz & Secretaría / Padres de familia & 300 dípticos \\
\hline & $\begin{array}{l}\text { Centro Preuniversitario San Marcos - } \\
\text { Santa Beatriz }\end{array}$ & Secretaría / Estudiantes & 300 dípticos \\
\hline 09 & Academia Pamer I - Santa Beatriz & Secretaría / Estudiantes & 300 dípticos \\
\hline 10 & Academia Pamer II - Santa Beatriz & Secretaría / Estudiantes & 300 dípticos \\
\hline 11 & Instituto Sise & Secretaría / Estudiantes & 500 dípticos \\
\hline 12 & Instituto Idat & Secretaría / Estudiantes & 500 dípticos \\
\hline 13 & Instituto Interglobal - Idiomas & Secretaría / Estudiantes & 100 dípticos \\
\hline 14 & Academia Trilce & Secretaría / Estudiantes & 500 dípticos \\
\hline 15 & Telefónica del Perú & A trabajadores & 500 dípticos \\
\hline 16 & $\begin{array}{l}\text { Bodegas y estaciones de servicio } \\
\text { (grifos) de la zona }\end{array}$ & A los propietarios & 1,000 dípticos \\
\hline 17 & $\begin{array}{l}\text { Transporte público en principales } \\
\text { avenidas }\end{array}$ & $\begin{array}{l}\text { Pasajeros de las diferentes líneas de } \\
\text { transporte }\end{array}$ & 1,000 dípticos \\
\hline 18 & Vecinos y visitantes del proyecto & Entrevista personal en obra & 1,000 dípticos \\
\hline Tot: & & & 10,000 dípticos \\
\hline
\end{tabular}

Elaboración: Propia. 


\section{ANEXO 42: Entidades próximas al proyecto}

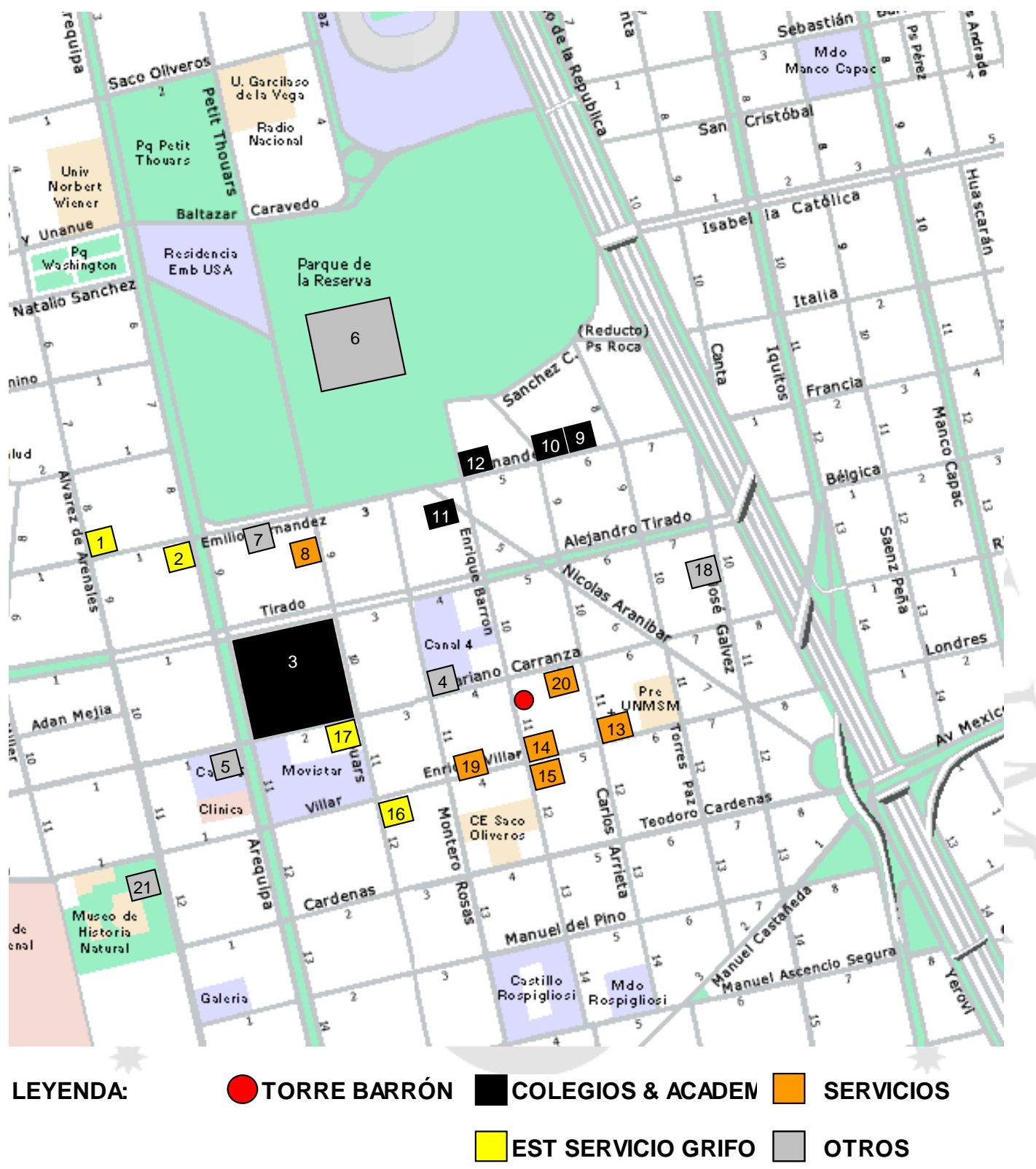

1. Estación de Servicio Repsol

2. Estación de Servicio Repsol \& KFC 10. Colegio Pamer

3. Colegio Dante Alighieri 11. Academia Pamer I

18. Canal 7

19. Librería

13. Iglesia Cristo Rey

20. Internet

5. Canal 5

14. Panadería

21. Museo Historia Natural

7. Ofic Normalización Previsional ONPE 15. Botica
8. Sauna Villa Roma
16. Estación de servicio $A B C$
9. Colegio Trilce
17. Estación de servicio ABA SINGER

Elaboración: Propia. 
ANEXO 43: Cartel de obra $\mathbf{N}^{\circ} 1$

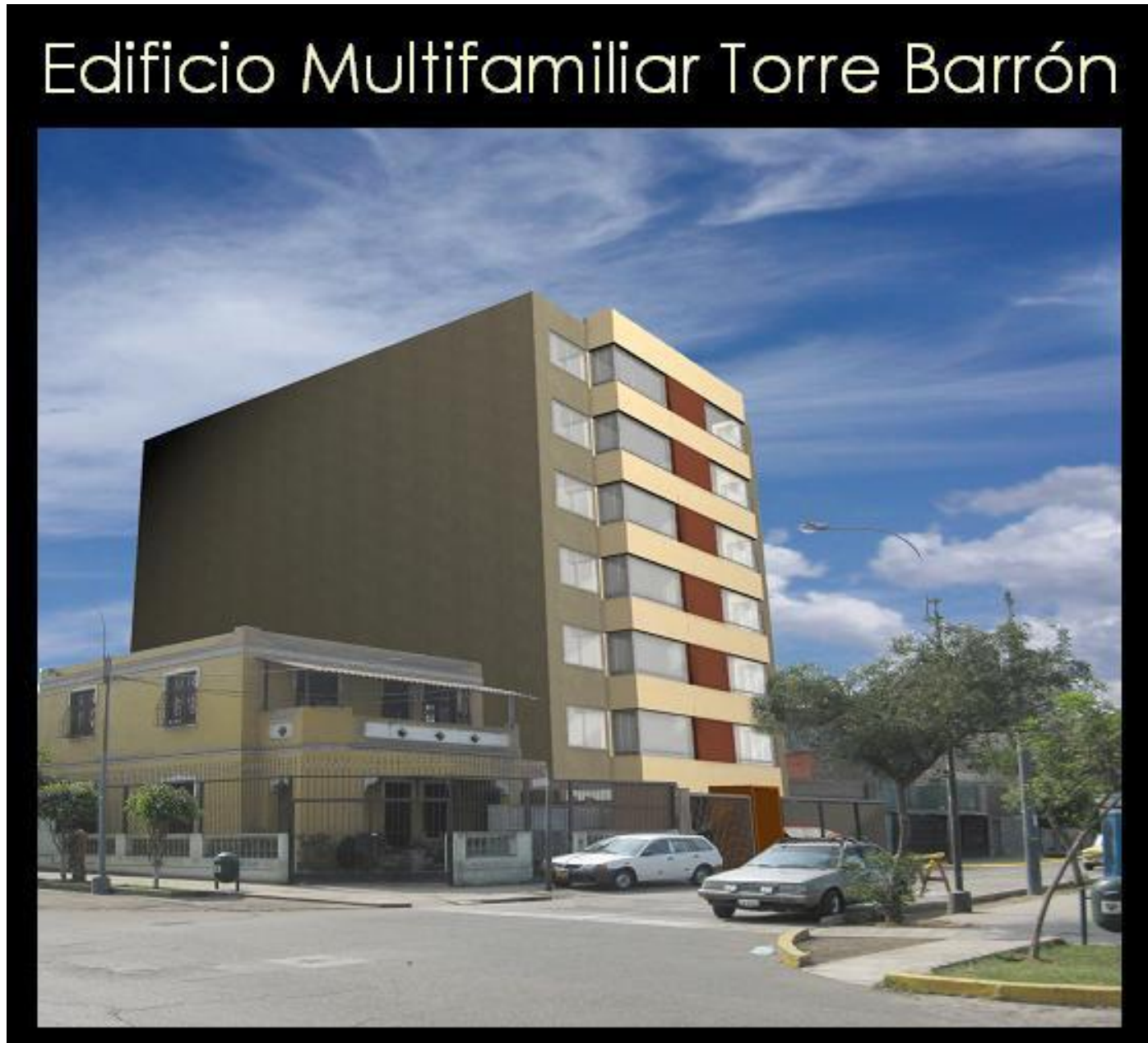

Elaboración: Propia. 
ANEXO 44: Cartel de obra $\mathbf{N}^{\circ} 2$

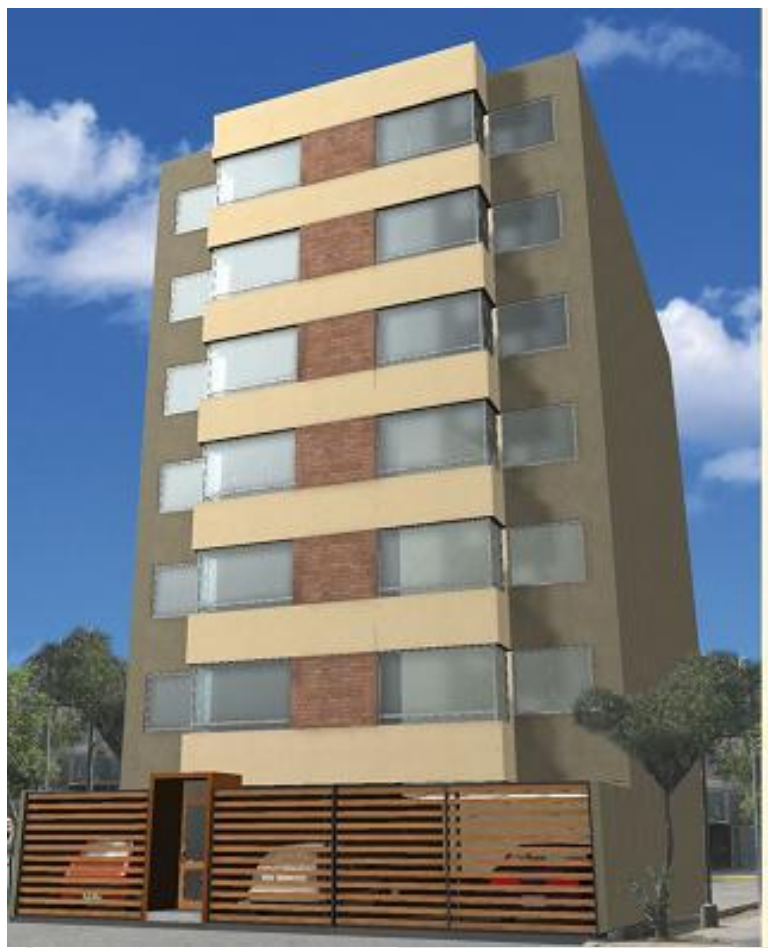

\section{Torre Barrón Edificio Multifamiliar}

12 exclusivos departamentos ( 02 por piso)

12 amplios estacionamientos (1er piso)

Departamentos de $90 \mathrm{~m} 2$ a $127 \mathrm{~m} 2$

Sala y comedor con vista a la calle Amplia cocina y lavandería

03 Dormitorios y 02 Baños

Cuarto y baño de servicio

Patio interno y terraza

Ascensor de lujo

Hall de ingreso

Escalera de emergencia

Sistema contra incendios

Instalación de Teléfono, Internet, Cable y Gas

Jr. Enrique Barrón № 1113 Urb. Santa Beatriz Dist. Cercado de Lima

(511) 4714166 / (511) 998042838

torre.barron@hotmail.com

Elaboración: Propia. 
ANEXO 45: Cartel de obra $\mathbf{N}^{\circ} 3$

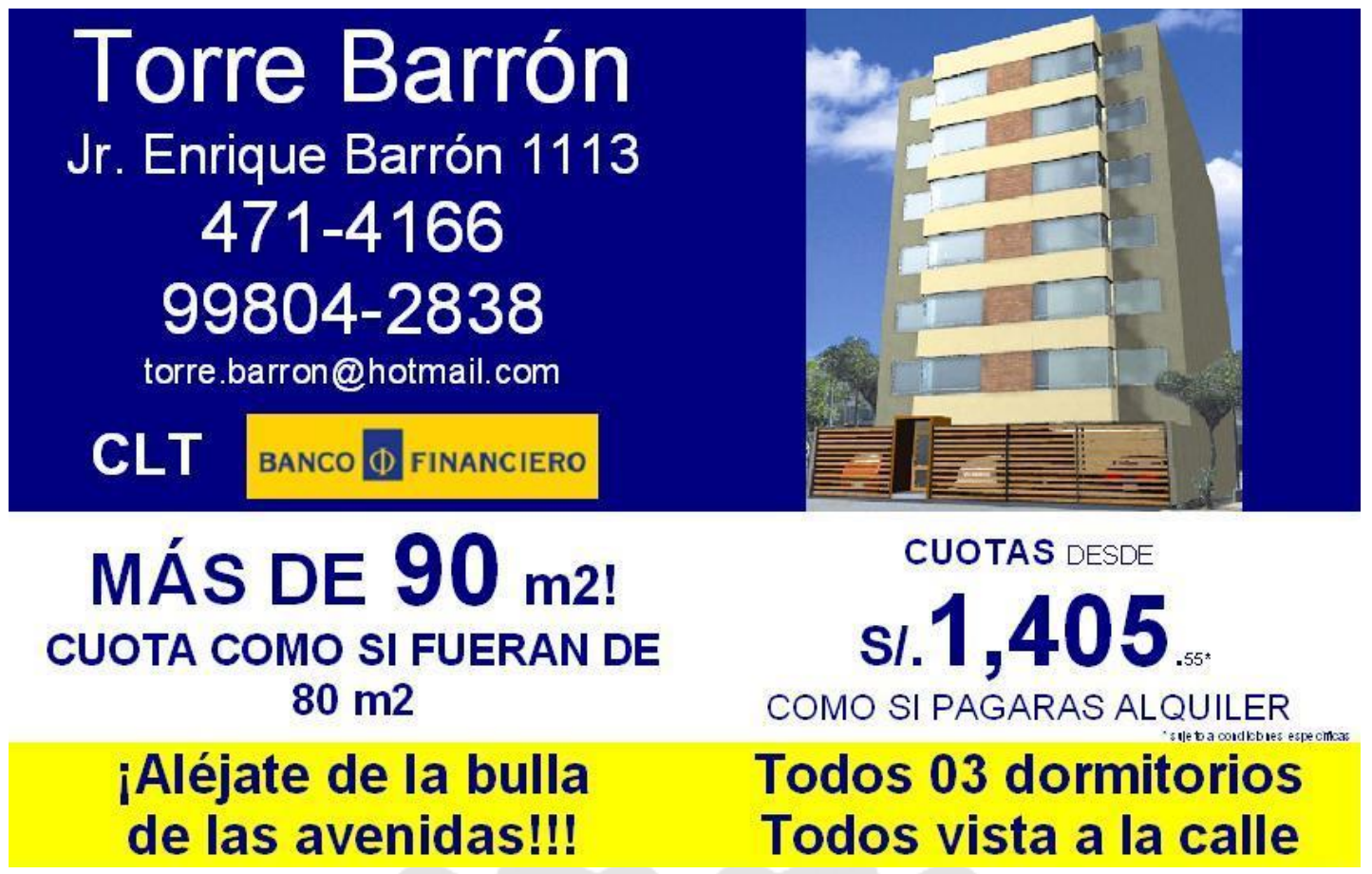

Elaboración: Propia. 
ANEXO 46: Cartel de obra $\mathbf{N}^{\circ} 4$

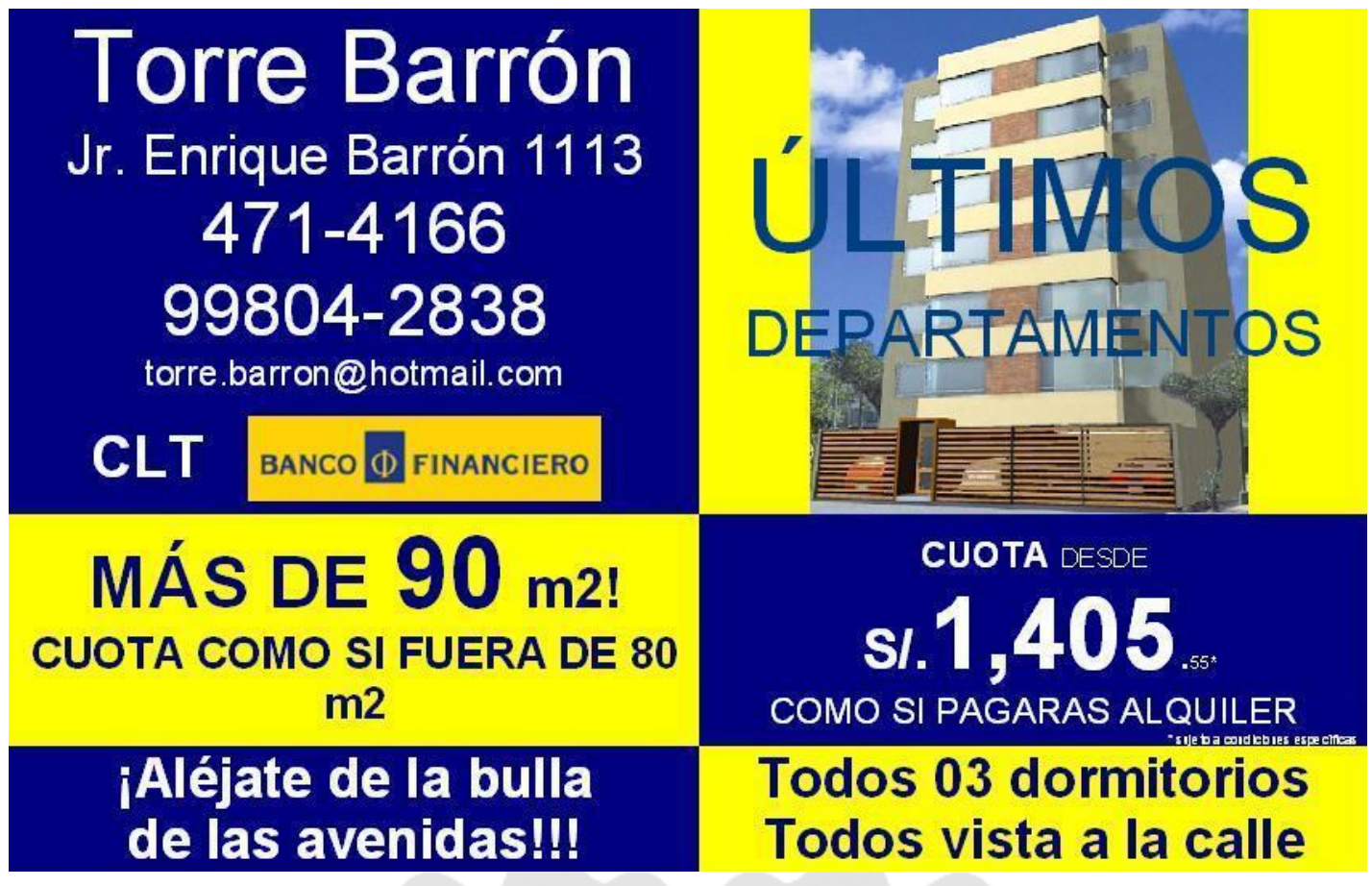

Elaboración: Propia. 


\section{ANEXO 47: Participación del mercado proyectada del año cero al año 5}

\begin{tabular}{|c|c|c|c|c|c|c|c|c|}
\hline Año & Empresas & $\begin{array}{l}\text { Const. } \\
\text { Roca } \\
\text { Azul }\end{array}$ & $\begin{array}{l}\text { Const. } \\
\text { Imagina }\end{array}$ & $\begin{array}{c}\text { Lima } \\
\text { Kensetsu }\end{array}$ & $\begin{array}{c}\text { Yufra } \\
\text { Construct }\end{array}$ & Otros & $\begin{array}{l}\text { Const. } \\
\text { Las } \\
\text { Torres }\end{array}$ & Total \\
\hline \multirow{2}{*}{0} & Cant. Edificios & 12 & 4 & 1 & 1 & 2 & 0 & 20 \\
\hline & Participación \% & $60 \%$ & $20 \%$ & $5 \%$ & $5 \%$ & $10 \%$ & $0 \%$ & $100 \%$ \\
\hline \multirow{2}{*}{1} & Cant. Edificios & 12 & 4 & 1 & 1 & 4 & 1 & 23 \\
\hline & Participación \% & $52 \%$ & $17 \%$ & $4 \%$ & $4 \%$ & $17 \%$ & $4 \%$ & $100 \%$ \\
\hline \multirow{2}{*}{2} & Cant. Edificios & 12 & 5 & 1 & 1 & 7 & 2 & 28 \\
\hline & Participación \% & $43 \%$ & $18 \%$ & $4 \%$ & $4 \%$ & $25 \%$ & $7 \%$ & $100 \%$ \\
\hline \multirow{2}{*}{3} & Cant. Edificios & 12 & 6 & 01 & 1 & 11 & 3 & 34 \\
\hline & Participación \% & $35 \%$ & $18 \%$ & $3 \%$ & $3 \%$ & $32 \%$ & $9 \%$ & $100 \%$ \\
\hline \multirow{2}{*}{4} & Cant. Edificios & 12 & 7 & 1 & 1 & 16 & 4 & 41 \\
\hline & Participación \% & $29 \%$ & $17 \%$ & $2 \%$ & $2 \%$ & $39 \%$ & $10 \%$ & $100 \%$ \\
\hline & Cant. Edificios & 12 & 8 & 1 & 1 & 22 & 5 & 49 \\
\hline & Participación \% & $24 \%$ & $16 \%$ & $2 \%$ & $2 \%$ & $45 \%$ & $10 \%$ & $100 \%$ \\
\hline
\end{tabular}

Elaboración: Propia. 


\section{ANEXO 48: Relación de los acabados instalados en los departamentos}

\begin{tabular}{|c|c|c|}
\hline Ambiente & & Descripción \\
\hline \multirow{6}{*}{$\begin{array}{l}\text { Dormitorio } \\
\text { principal }\end{array}$} & Piso & Listones laminados color madera \\
\hline & Contrazócalo & De madera de 3" x 1⁄2" (sin rodón) \\
\hline & Muros & Empastado y pintado con látex lavable \\
\hline & Cielo raso & Empastado y pintado con látex lavable \\
\hline & Puerta & De MDF \\
\hline & Ventanas & Sistema NOVA \\
\hline \multirow{6}{*}{$\begin{array}{l}\text { Dormitorio } \\
\underline{\text { secundario }}\end{array}$} & Piso & Listones laminados color madera \\
\hline & Contrazócalo & De madera de $3 "$ x 1/2" (sin rodón) \\
\hline & Muros & Empastado y pintado con látex lavable \\
\hline & Cielo raso & Empastado y pintado con látex lavable \\
\hline & Puerta & De MDF \\
\hline & Ventanas & Sistema NOVA \\
\hline \multirow[t]{4}{*}{$\underline{\text { Pasadizo }}$} & Piso & Listones laminados color madera \\
\hline & Contrazócalo & De madera de $3 "$ x 1/2" (sin rodón) \\
\hline & Muros & Empastado y pintado con látex lavable \\
\hline & Cielo raso & Empastado y pintado con látex lavable \\
\hline \multirow[t]{9}{*}{ Baño principal } & Piso & Cerámico CELIMA de 30 x 30, modelo Duna o similar \\
\hline & Pared & $\begin{array}{l}\text { Cerámico CELIMA de } 30 \text { x } 30 \text {, modelo Duna o similar, } \\
\text { altura } 1.20 \mathrm{~m} \text { en baño y } 1.80 \mathrm{~m} \text { en ducha }\end{array}$ \\
\hline & Muros & Empastado y pintado con látex lavable \\
\hline & Cielo raso & Empastado y pintado con látex lavable \\
\hline & Puerta & De MDF \\
\hline & Ventanas & Sistema NOVA \\
\hline & Grifería & $\begin{array}{l}\text { Griferia TREBOL modelo iris cromada, con desagüe } \\
\text { cromado simple. Mezcladora para ducha marca TREBOL } \\
\text { o similar. }\end{array}$ \\
\hline & Inodoro & Marca TREBOL, modelo Top Piece, color blanco \\
\hline & Lavatorio & Marca TREBOL, color blanco \\
\hline \multirow[t]{9}{*}{$\underline{B a n ̃ o ~ s e c u n d a r i o ~}$} & Piso & Cerámico CELIMA de 30 x 30, modelo Duna o similar \\
\hline & Pared & $\begin{array}{l}\text { Cerámico CELIMA de } 30 \text { x } 30 \text {, modelo Duna o similar, } \\
\text { altura } 1.20 \mathrm{~m} \text { en baño y } 1.80 \mathrm{~m} \text { en ducha }\end{array}$ \\
\hline & Muros & Empastado y pintado con látex lavable \\
\hline & Cielo raso & Empastado y pintado con látex lavable \\
\hline & Puerta & De MDF \\
\hline & Ventanas & Sistema NOVA \\
\hline & Grifería & $\begin{array}{l}\text { Griferia TREBOL modelo iris cromada, con desaguie } \\
\text { cromado simple. Mezcladora para ducha marca TREBOL. }\end{array}$ \\
\hline & Inodoro & Marca TREBOL o similar, color blanco \\
\hline & Lavatorio & Marca TREBOL, color blanco \\
\hline
\end{tabular}




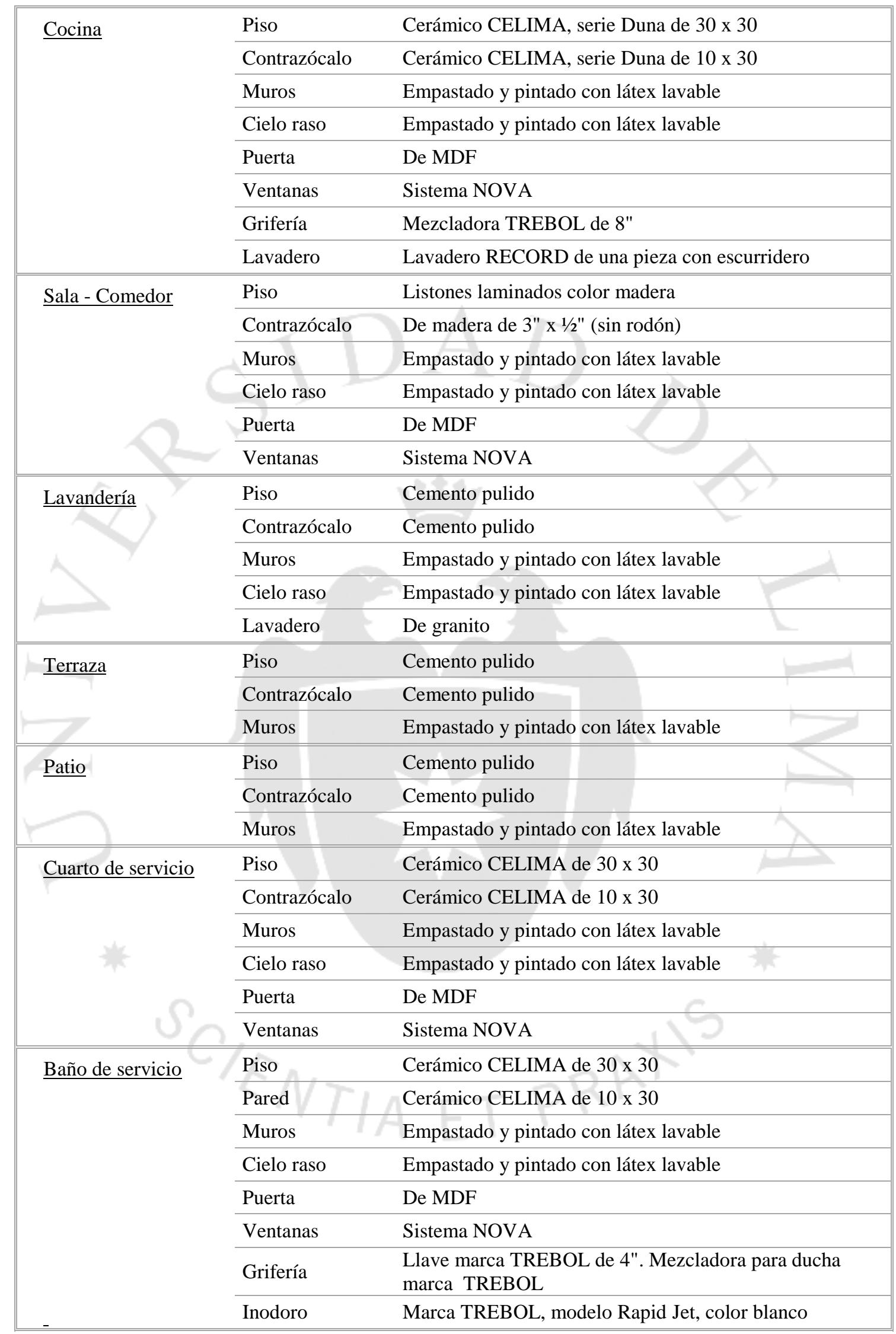

Elaboración: Propia. 


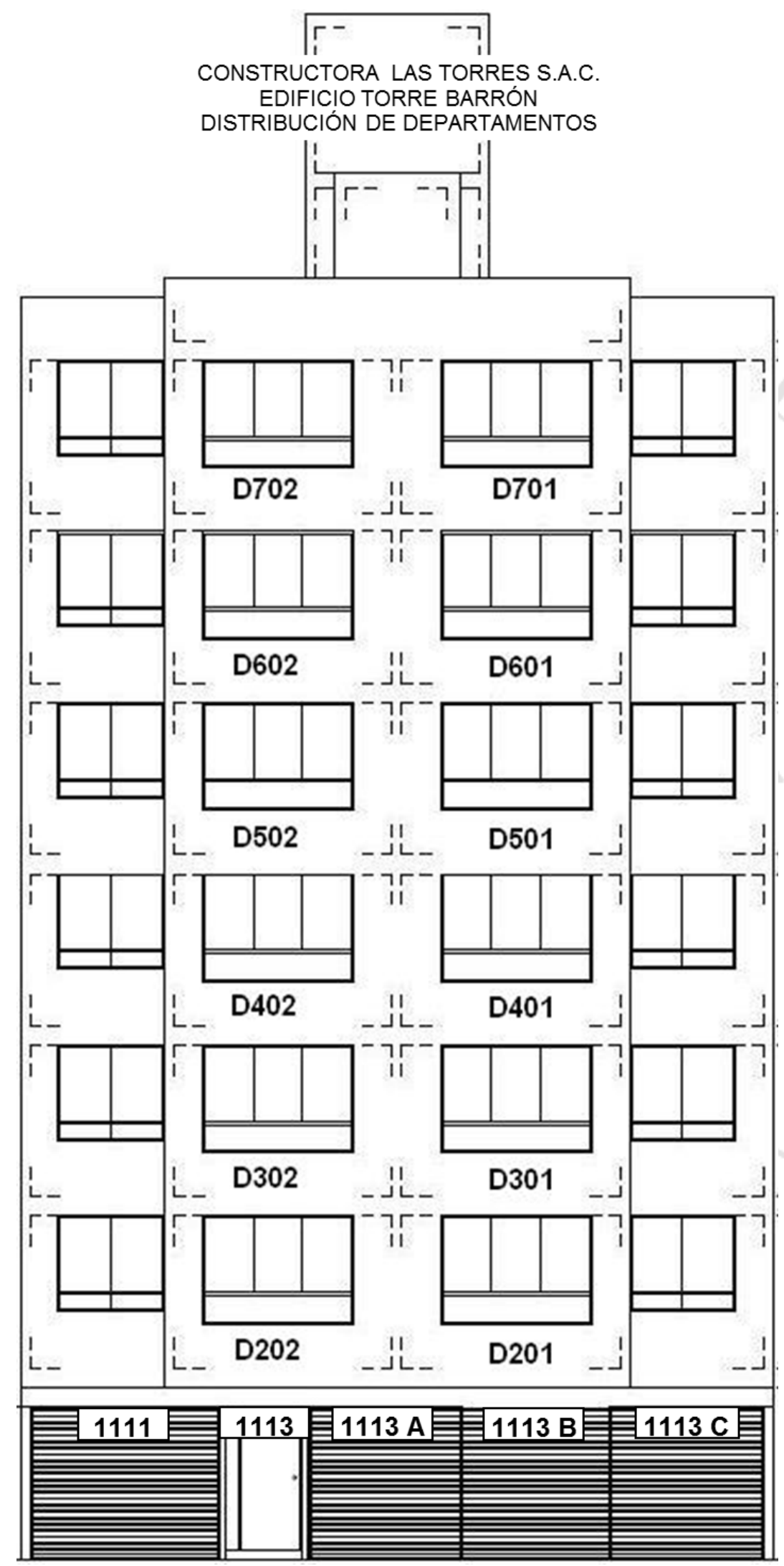

Elaboración: Propia. 


\section{ANEXO 50: Plano de planta del primer piso}

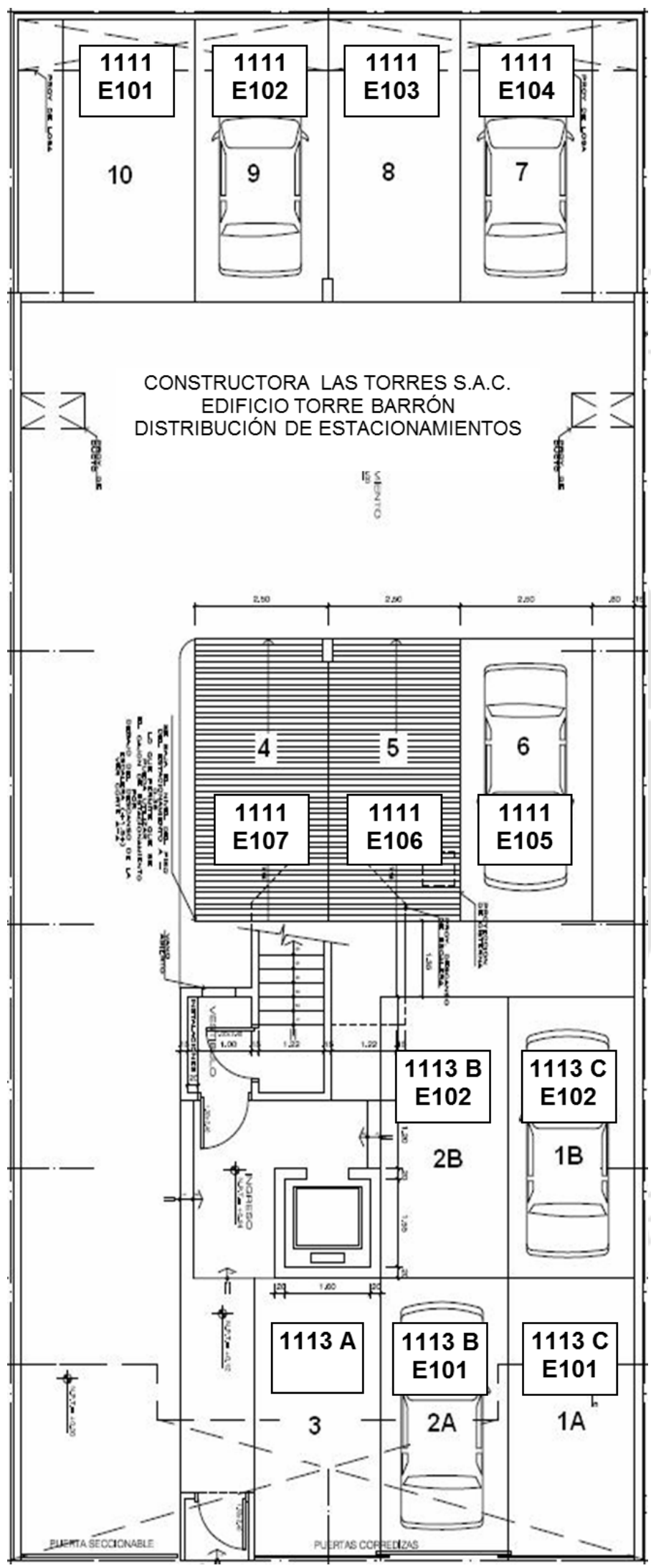

Elaboración: Propia. 


\section{ANEXO 51: Plano de planta segundo piso}

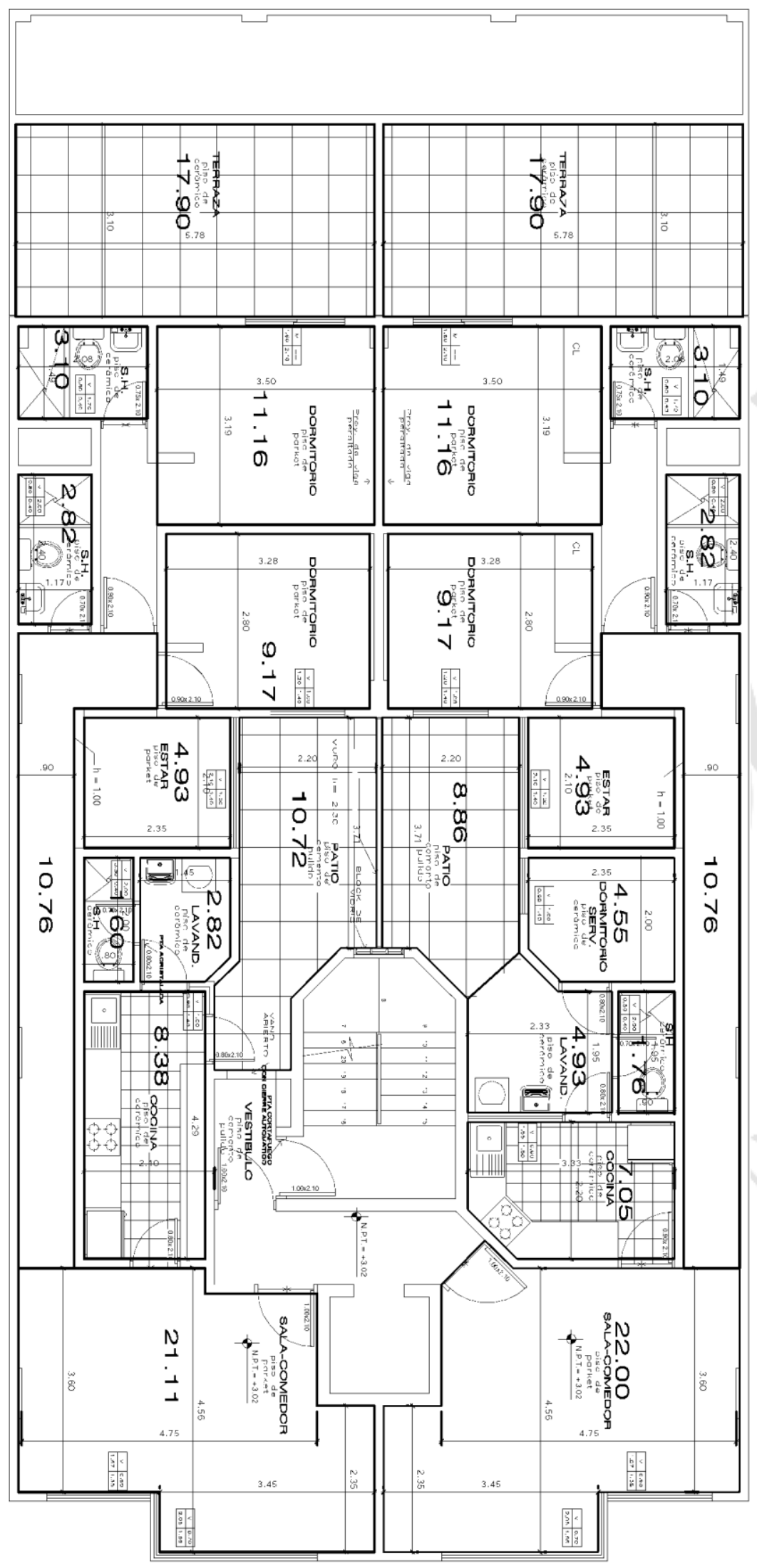

Elaboración: Propia. 
ANEXO 52: Plano de planta típica 3er al 6to piso

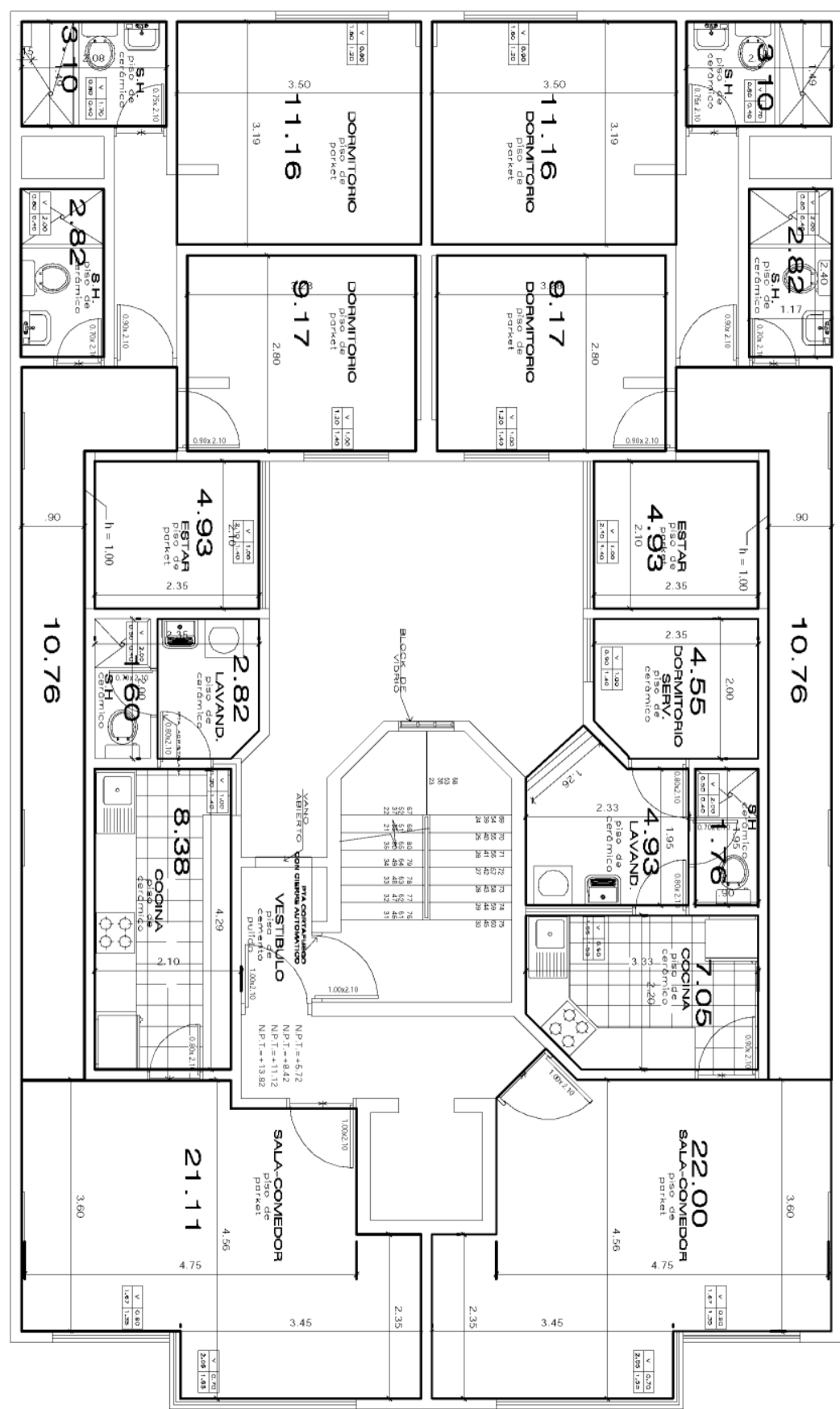

Elaboración: Propia. 
ANEXO 53: Plano de planta sétimo piso

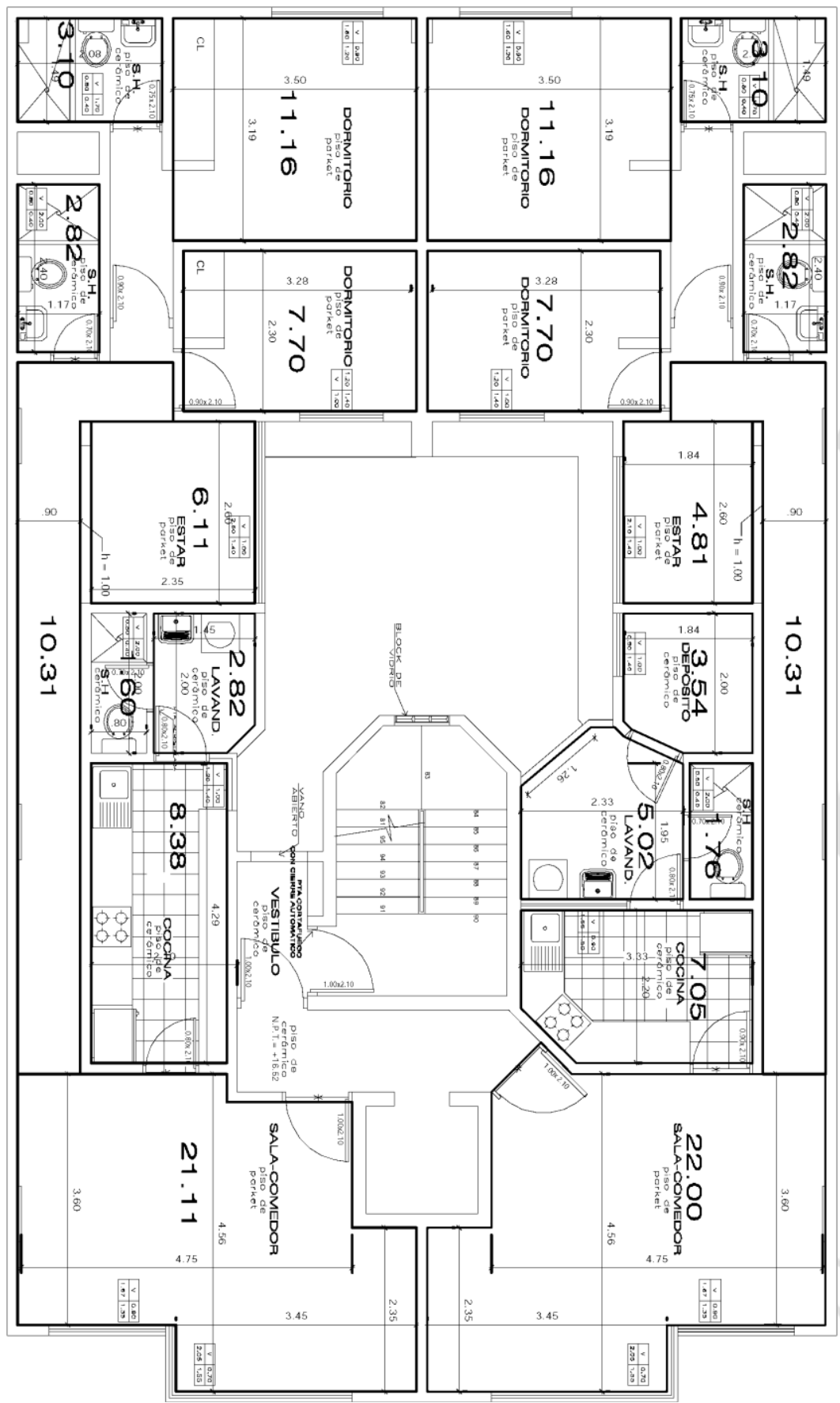

Elaboración: Propia. 
ANEXO 54: Licencia de Obra para Edificación Nueva

\section{MUNICIPALIDAD METROPOLITANA DE LIMA}

(EXHIBIR EN LUGAR VISIBLE)

\section{3-2008-MML}

LICENCIA N $N^{\circ}$ GDU-SAU-DE-LO Expediente No 77239.08

fechade expebicion $09 / 09 / 08$ fechade caducidad $09 / 09 / 2011$

PROPIETARIO CONSTRUCTORA

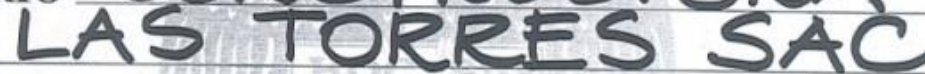

OBRA OBRA UUEVA AREA $1,449.48 \mathrm{~m}^{2}$ UBICACION JR. COMANDANTE ENRIQUE BARRON N 1113 . URB. SANTA BEATRIZ PROFESIONALRESPONSABLE ING: ANTONIO MORENO ESPINOZA CIP: 3231
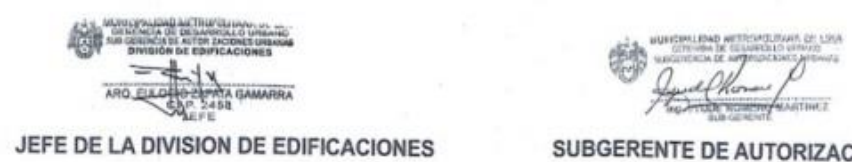

SUBGERENTE DE AUTORIZACIONES URBANAS

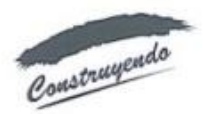

Elaboración: Propia. 


\section{ANEXO 55: Relación de Unidades Inmobiliarias, Numeración Municipal y Propietarios}

\begin{tabular}{|c|c|c|c|c|}
\hline $\begin{array}{l}\text { Unidad } \\
\text { Inmob. }\end{array}$ & Nivel & Numeración Municipal & Propietario & DNI \\
\hline D_201 & 2do piso & Jr. Enrique Barrón No 1113 - D201 & $\begin{array}{l}\text { David Eduardo Márquez } \\
\text { Atahui }\end{array}$ & 09393900 \\
\hline D_202 & 2do piso & Jr. Enrique Barrón No 1113 - D202 & Marisa Celia Luna Vela & 10082403 \\
\hline D_301 & 3er piso & Jr. Enrique Barrón No 1113 - D301 & Hugo Aurelio León Cheng & 06389923 \\
\hline D_302 & 3er piso & Jr. Enrique Barrón No 1113 - D302 & Nicolai Vásquez Yap Sam & 16718381 \\
\hline D_401 & 4to piso & Jr. Enrique Barrón Nº 1113 - D401 & Julio Fernández Beltrán & 06025589 \\
\hline D_402 & 4 to piso & Jr. Enrique Barrón No 1113 - D402 & Ana Carola Burga Yncio & 16637192 \\
\hline D_501 & 5to piso & Jr. Enrique Barrón No 1113 - D501 & Fausto Edwin Torrecilla Pérez & 10196895 \\
\hline D_502 & 5to piso & Jr. Enrique Barrón No 1113 - D502 & Hugo Aurelio León Cheng & 06389923 \\
\hline D_601 & 6to piso & Jr. Enrique Barrón No 1113 - D601 & $\begin{array}{l}\text { Norma Bertha Aguilar } \\
\text { Damaso }\end{array}$ & 20403258 \\
\hline D_602 & 6to piso & Jr. Enrique Barrón No 1113 - D602 & Germaín Sánchez Hinojosa & 01335062 \\
\hline D_701 & $7 \mathrm{mo}$ piso & Jr. Enrique Barrón Nº 1113 - D701 & $\begin{array}{l}\text { Jesús Hildebrando Poma } \\
\text { Viscaya }\end{array}$ & 04000523 \\
\hline D_702 & $7 \mathrm{mo}$ piso & Jr. Enrique Barrón No 1113 - D702 & Margarita Estrada Linares & 04081235 \\
\hline E_1A & 1er piso & Jr. Enrique Barrón No 1113 - C - E101 & Nicolai Vásquez Yap Sam & 16718381 \\
\hline E_1B & 1er piso & Jr. Enrique Barrón Nº 1113 - C - E102 & Nicolai Vásquez Yap Sam & 16718381 \\
\hline E_2A & 1er piso & Jr. Enrique Barrón Nº 1113 - B - E101 & $\begin{array}{l}\text { David Eduardo Márquez } \\
\text { Atahui }\end{array}$ & 09393900 \\
\hline E_2B & 1er piso & Jr. Enrique Barrón No 1113 - B - E102 & $\begin{array}{l}\text { David Eduardo Márquez } \\
\text { Atahui }\end{array}$ & 09393900 \\
\hline E_3 & 1er piso & Jr. Enrique Barrón No 1113 - A & Hugo Aurelio León Cheng & 06389923 \\
\hline E_4 & 1er piso & Jr. Enrique Barrón Nº 1111 - E107 & $\begin{array}{l}\text { Miguel Angel Paniagua } \\
\text { García }\end{array}$ & 06102456 \\
\hline E_5 & 1er piso & Jr. Enrique Barrón No 1111 - E106 & $\begin{array}{l}\text { Miguel Angel Paniagua } \\
\text { García }\end{array}$ & 06102456 \\
\hline E_6 & 1er piso & Jr. Enrique Barrón No 1111 - E105 & $\begin{array}{l}\text { Miguel Angel Paniagua } \\
\text { García }\end{array}$ & 06102456 \\
\hline E_7 & 1er piso & Jr. Enrique Barrón Nº 1111 - E104 & $\begin{array}{l}\text { Miguel Angel Paniagua } \\
\text { García }\end{array}$ & 06102456 \\
\hline E_8 & 1er piso & Jr. Enrique Barrón Nº 1111 - E103 & $\begin{array}{l}\text { Miguel Angel Paniagua } \\
\text { García }\end{array}$ & 06102456 \\
\hline E_9 & 1er piso & Jr. Enrique Barrón No 1111 - E102 & Hugo Aurelio León Cheng & 06389923 \\
\hline E_10 & 1er piso & Jr. Enrique Barrón Noo 1111 - E101 & $\begin{array}{l}\text { Miguel Angel Paniagua } \\
\text { García }\end{array}$ & 06102456 \\
\hline
\end{tabular}

Elaboración: Propia. 


\section{ANEXO 56: Cronograma General de Implementación Detallado}

\begin{tabular}{|c|c|c|c|c|c|c|c|c|c|c|}
\hline Presupuestos & $\begin{array}{cc}\text { Tipo } & \text { mar } \\
\text { Gasto } & 08\end{array}$ & $\begin{array}{l}a b r \\
08\end{array}$ & $\begin{array}{c}\text { may } \\
08\end{array}$ & $\begin{array}{l}\text { jun } \\
08\end{array}$ & $\begin{array}{l}\text { jul } \\
08\end{array}$ & $\begin{array}{c}\text { ago } \\
08\end{array}$ & $\begin{array}{r}\text { sep } \\
08\end{array}$ & $\begin{array}{l}\text { oct } \\
08\end{array}$ & $\begin{array}{c}\text { nov } \\
08\end{array}$ & $\begin{array}{l}\text { dic } \\
08\end{array}$ \\
\hline P. de Ventas Netas & - & & & & & & & & & \\
\hline P. de Gastos Marketing & Ind. & & & & & & & & & \\
\hline Material de venta & Ind. & & & & & & & & & \\
\hline Publicaciones en diarios & Ind. & $\Delta$ & & & & & & & & \\
\hline Letreros & Ind. & & & & & & & & & \\
\hline Oficina de ventas & Ind. & & & & & & & & & \\
\hline Estudio de mercado & Ind. & & & & & & & & & \\
\hline P. de Gastos Admin. y Ventas & Ind. & & & & & & & & & \\
\hline Gastos Personal & Ind. & & & & & & & & & \\
\hline Gastos Contabilidad & Ind. & & & & & & & & & \\
\hline Gastos Legales & Ind. & & & & & & & & & \\
\hline Constitución Empresa & Ind. & & & & & & & & & \\
\hline Legalización libros & Ind. & & & & & & & & & \\
\hline Vigencia de poder & Ind. & & & & & & & & 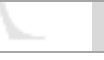 & \\
\hline Contrato Construcción & Ind. & & & & & & & & & \\
\hline Contrato Comp/Venta & Ind. & & & & & & & & & \\
\hline Útiles de oficina & Ind. & & & & & & & & & \\
\hline Copias e impresiones & Ind. & & & & & 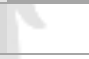 & & & & \\
\hline Servicios Públicos & Ind. & V & & & & & & & 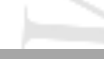 & \\
\hline Luz del Sur (Luz) & Ind. & & & & & & & & & \\
\hline Sedapal (Agua) & Ind. & & & & & & & & & \\
\hline Internet y Telefonía & Ind. & & & & & & & & & \\
\hline Representación & Ind. & & & & & & & & & \\
\hline Combustible & Ind. & & & & & & & & & \\
\hline Equipos & Ind. & & 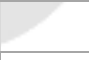 & & & & & $\frac{1}{4}$ & & \\
\hline Herramientas & Ind. & & & & & & & & & \\
\hline Transporte & Ind. & & & & & & & & & \\
\hline Gastos Municipales & Ind. & & & & & $\sqrt{2}$ & 8 & & & \\
\hline Arbitrios & Ind. & & & & & & & & & \\
\hline Predial & Ind. & L & & & & & & & & \\
\hline P. de Gastos Bancarios & Ind. & - & $t$ & & & & & & & \\
\hline Estudio Técnico & Ind. & & & & & & & & & \\
\hline Valorización & Ind. & & & & & & & & & \\
\hline Póliza CAR & Ind. & & & & & & & & & \\
\hline Cartas fianzas & Ind. & & & & & & & & & \\
\hline P. de Gastos Adq. del Terreno & Dir. & & & & & & & & & \\
\hline Adquisic terreno & Dir. & & & & & & & & & \\
\hline Adquisic imp alcabala & Dir. & & & & & & & & & \\
\hline Adquisic notariales & Dir. & & & & & & & & & \\
\hline Adquisic registrales & Dir. & & & & & & & & & \\
\hline
\end{tabular}




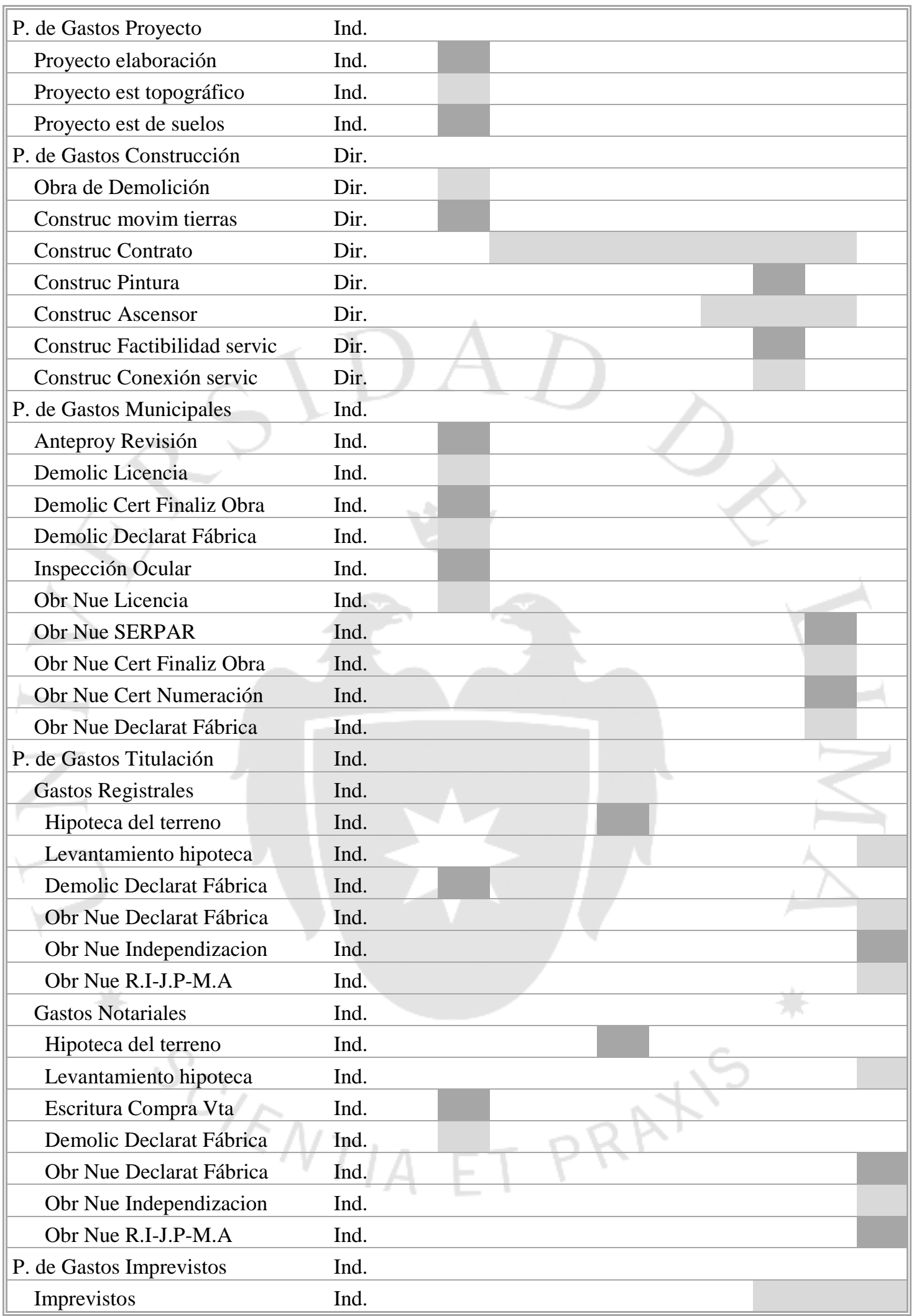

Elaboración: Propia. 
ANEXO 57: Presupuesto de Ventas Netas

\begin{tabular}{|c|c|c|c|c|c|c|c|c|c|c|c|c|}
\hline Unidades Inmobiliarias & IGV & mar 08 & abr 08 & may 08 & jun 08 & jul 08 & ago 08 & sep 08 & oct 08 & nov 08 & $\operatorname{dic} 08$ & Total \\
\hline Departamento 201 & c/igv & & & 203,653 & & & & & & & & 203,653 \\
\hline Departamento 202 & c/igv & & & 193,607 & & & & & & & & 193,607 \\
\hline Departamento 301 & c/igv & & & & 185,388 & & & & & & & 185,388 \\
\hline Departamento 302 & c/igv & & & & 174,429 & & & & & & & 174,429 \\
\hline Departamento 401 & c/igv & & & & & 185,388 & & & & & & 185,388 \\
\hline Departamento 402 & c/igv & & & & & 174,429 & & & & & & 174,429 \\
\hline Departamento 501 & c/igv & & & & & & 185,388 & & & & & 185,388 \\
\hline Departamento 502 & c/igv & & & & & & 174,429 & & & & & 174,429 \\
\hline Departamento 601 & c/igv & & & & & & & 185,388 & & & & 185,388 \\
\hline Departamento 602 & c/igv & $=$ & & & & & & 174,429 & & & & 174,429 \\
\hline Departamento 701 & c/igv & & & & & & & & 178,082 & & & 178,082 \\
\hline Departamento 702 & c/igv & 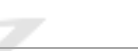 & & & & & & & 170,776 & & & 170,776 \\
\hline Sub Total Departamentos & & 0 & & 397,260 & 359,817 & 359,817 & 359,817 & 359,817 & 348,858 & 0 & 0 & $2,185,388$ \\
\hline Estacionamiento 1A & s/igv & & & 10,000 & & & & & $\begin{array}{l} \\
\end{array}$ & & & 10,000 \\
\hline Estacionamiento 1B & s/igv & & & 15,000 & & & & & & & & 15,000 \\
\hline Estacionamiento $2 \mathrm{~A}$ & s/igv & & & & 10,000 & & & & & & & 10,000 \\
\hline Estacionamiento 2B & s/igv & & & & 15,000 & & & & & & & 15,000 \\
\hline Estacionamiento 3 & s/igv & & & & & 10,000 & & & & & & 10,000 \\
\hline Estacionamiento 4 & s/igv & & & & & 10,000 & & & & & & 10,000 \\
\hline Estacionamiento 5 & s/igv & & & & & & 10,000 & & & & & 10,000 \\
\hline Estacionamiento 6 & s/igv & 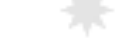 & & & & & 15,000 & & & & & 15,000 \\
\hline Estacionamiento 7 & s/igv & & & & & & & 15,000 & & & & 15,000 \\
\hline Estacionamiento 8 & s/igv & & & & & & & 10,000 & & & & 10,000 \\
\hline Estacionamiento 9 & s/igv & & & & & & & & 10,000 & & & 10,000 \\
\hline Estacionamiento 10 & s/igv & & & & & & & & 15,000 & & & 15,000 \\
\hline Sub Total Estacionamientos & & 0 & & 25,000 & 25,000 & 20,000 & 25,000 & 25,000 & 25,000 & 0 & 0 & 145,000 \\
\hline Ventas Totales & & 0 & & 422,260 & 384,817 & 379,817 & 384,817 & 384,817 & 373,858 & 0 & 0 & $2,330,388$ \\
\hline
\end{tabular}




\section{ANEXO 58: Presupuesto de Cobranza por Ventas}

\begin{tabular}{|c|c|c|c|c|c|c|c|c|c|c|c|c|}
\hline Unidades Inmobiliarias & IGV & $\operatorname{mar} 08$ & abr 08 & may 08 & jun 08 & jul 08 & ago 08 & sep 08 & oct 08 & nov 08 & $\operatorname{dic} 08$ & Total \\
\hline Departamento 201 & c/igv & & & 44,600 & - & 178,400 & - & - & & - & - & 223,000 \\
\hline Departamento 202 & c/igv & & & 42,400 & - & 169,600 & - & - & & - & - & 212,000 \\
\hline Departamento 301 & c/igv & & & - & 40,600 & 162,400 & - & - & & - & - & 203,000 \\
\hline Departamento 302 & c/igv & & & - & 38,200 & 152,800 & - & - & & - & - & 191,000 \\
\hline Departamento 401 & c/igv & & & - & - & 203,000 & - & - & & - & - & 203,000 \\
\hline Departamento 402 & c/igv & & & - & - & 191,000 & - & - & & - & - & 191,000 \\
\hline Departamento 501 & c/igv & & & - & - & $r=-$ & 203,000 & - & & - & - & 203,000 \\
\hline Departamento 502 & c/igv & & & - & - & - & 191,000 & - & & - & - & 191,000 \\
\hline Departamento 601 & c/igv & & & - & - & - & - & 203,000 & & - & - & 203,000 \\
\hline Departamento 602 & c/igv & 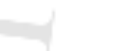 & & - & - & - & - & 191,000 & & (1) & - & 191,000 \\
\hline Departamento 701 & c/igv & & & - & - & - & - & - & 195,00 & - & - & 195,000 \\
\hline Departamento 702 & c/igv & Z & & - & - & - & - & - & 187,00 & 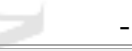 & - & 187,000 \\
\hline Sub Total Departamentos & & & & 87,000 & 78,800 & $1,057,200$ & 394,000 & 394,000 & 382,00 & - & - & $2,393,000$ \\
\hline Estacionamiento 1A & s/igv & & & 10,000 & - & - & - & - & & $\mathrm{m}$ & - & 10,000 \\
\hline Estacionamiento 1B & s/igv & & & 15,000 & - & - & - & - & & - & - & 15,000 \\
\hline Estacionamiento 2A & s/igv & & & - & 10,000 & - & - & - & & - & - & 10,000 \\
\hline Estacionamiento 2B & s/igv & & & - & 15,000 & - & - & - & & - & - & 15,000 \\
\hline Estacionamiento 3 & s/igv & & & - & - & 10,000 & - & - & & - & - & 10,000 \\
\hline Estacionamiento 4 & s/igv & & & - & - & 10,000 & - & - & & - & - & 10,000 \\
\hline Estacionamiento 5 & s/igv & & & - & - & - & 10,000 & - & & - & - & 10,000 \\
\hline Estacionamiento 6 & s/igv & & & - & - & - & 15,000 & - & & - & - & 15,000 \\
\hline Estacionamiento 7 & s/igv & & & - & - & - & - & 15,000 & & - & - & 15,000 \\
\hline Estacionamiento 8 & s/igv & & & - & - & - & - & 10,000 & & - & - & 10,000 \\
\hline Estacionamiento 9 & s/igv & & & - & - & - & - & - & 10,00 & - & - & 10,000 \\
\hline Estacionamiento 10 & s/igv & & & - & - & - & $m$ & - & 15,000 & - & - & 15,000 \\
\hline Sub Total Estacionamient & & & & 25,000 & 25,000 & 20,000 & 25,000 & 25,000 & 25,00 & - & - & 145,000 \\
\hline Ventas Totales & & & & 112,000 & 103,800 & $1,077,200$ & 419,000 & 419,000 & 407,00 & - & - & $2,538,000$ \\
\hline
\end{tabular}




\section{ANEXO 59: Presupuesto de Gastos de Marketing}

\begin{tabular}{|c|c|c|c|c|c|c|c|c|c|c|c|c|}
\hline Partidas & IGV & $\operatorname{mar} 08$ & abr 08 & may 08 & jun 08 & jul 08 & ago 08 & sep 08 & oct 08 & nov 08 & $\operatorname{dic} 08$ & Total \\
\hline Material de venta & c/igv & & & 300 & & 300 & & 300 & & & & 900 \\
\hline Publicaciones en diarios & c/igv & & & 300 & 300 & 300 & 300 & 300 & 300 & & & 1,800 \\
\hline Letreros & c/igv & & 100 & & & 100 & & & & & & 200 \\
\hline Oficina de ventas & c/igv & & 2,000 & & & & & & & & & 2,000 \\
\hline Estudio de mercado & c/igv & & 200 & & & & & & & & & 200 \\
\hline Total & & & 2,300 & 600 & 300 & 700 & 300 & 600 & 300 & 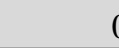 & 0 & 5,100 \\
\hline
\end{tabular}




\section{ANEXO 60: Presupuesto de Desembolso de Gastos de Marketing}

\begin{tabular}{|c|c|c|c|c|c|c|c|c|c|c|c|c|}
\hline Partidas & IGV & $\operatorname{mar} 08$ & abr 08 & may 08 & jun 08 & jul 08 & ago 08 & sep 08 & oct 08 & nov 08 & $\operatorname{dic} 08$ & Total \\
\hline Material de venta & c/igv & & - & 357 & - & 357 & - & 357 & - & - & - & 1,071 \\
\hline Publicaciones en diarios & c/igv & & - & 357 & 357 & 357 & 357 & 357 & 357 & - & - & 2,142 \\
\hline Letreros & c/igv & & 119 & - & - & 119 & - & - & - & - & - & 238 \\
\hline Oficina de ventas & c/igv & & 2,380 & - & - & - & - & - & - & - & - & 2,380 \\
\hline Estudio de mercado & c/igv & & 238 & - & - & - & - & - & - & - & - & 238 \\
\hline Total & & & 2,737 & 714 & 357 & 833 & 357 & 714 & 357 & - & - & 6,069 \\
\hline
\end{tabular}


ANEXO 61: Presupuesto de Gastos de Administración y Ventas

\begin{tabular}{|c|c|c|c|c|c|c|c|c|c|c|c|c|}
\hline Partidas & IGV & mar 08 & abr 08 & may 08 & jun 08 & jul 08 & ago 08 & sep 08 & oct 08 & nov 08 & $\operatorname{dic} 08$ & Total \\
\hline Sueldo Total & $100 \%$ & & 11,500 & 11,500 & 11,500 & 11,500 & 11,500 & 11,500 & 11,500 & 11,500 & 11,500 & 103,500 \\
\hline Gratificaciones & $17 \%$ & & 1,917 & 1,917 & 1,917 & 1,917 & 1,917 & 1,917 & 1,917 & 1,917 & 1,917 & 17,250 \\
\hline Remuneración & $117 \%$ & & 13,417 & 13,417 & 13,417 & 13,417 & 13,417 & 13,417 & 13,417 & 13,417 & 13,417 & 120,750 \\
\hline CTS & $10 \%$ & & 1,118 & 1,118 & 1,118 & 1,118 & 1,118 & 1,118 & 1,118 & 1,118 & 1,118 & 10,063 \\
\hline ESSALUD & $11 \%$ & & 1,208 & 1,208 & 1,208 & 1,208 & 1,208 & 1,208 & 1,208 & 1,208 & 1,208 & 10,868 \\
\hline Gastos Personal & $137 \%$ & & 15,742 & 15,742 & 15,742 & 15,742 & 15,742 & 15,742 & 15,742 & 15,742 & 15,742 & 141,680 \\
\hline Gastos Contabilidad & s/igv & & 350 & & $=350$ & $r=4$ & 350 & & 350 & & 350 & 1,750 \\
\hline \multicolumn{13}{|l|}{ Gastos Legales } \\
\hline Constitución Empresa & s/igv & 4,000 & & & & & & & & & & 4,000 \\
\hline Legalización libros & c/igv & a & 1,500 & & & & & & $p=$ & & & 1,500 \\
\hline Vigencia de poder & s/igv & & & 200 & & & & & & & 200 & 400 \\
\hline Contrato Construcción & s/igv & & & 800 & & & & & & & & 800 \\
\hline Contrato Comp/Venta & s/igv & & & 600 & 600 & 600 & 600 & 600 & 600 & & & 3,600 \\
\hline Útiles de oficina & c/igv & & 1,000 & & 1,000 & & 1,000 & & 1,000 & & & 4,000 \\
\hline Copias e impresiones & c/igv & & 100 & 100 & & 100 & & 100 & & 200 & & 600 \\
\hline \multicolumn{13}{|l|}{ Servicios Públicos } \\
\hline Luz del Sur (Luz) & c/igv & & 100 & 100 & 100 & 100 & 100 & 100 & 100 & 100 & 100 & 900 \\
\hline Sedapal (Agua) & c/igv & & 200 & 200 & 200 & 200 & 200 & 200 & 200 & 200 & 200 & 1,800 \\
\hline Internet y Telefonía & c/igv & & 300 & 300 & 300 & 300 & 300 & 300 & 300 & 300 & 300 & 2,700 \\
\hline Representación & c/igv & & 300 & 300 & 300 & 300 & 300 & 300 & 300 & & & 2,100 \\
\hline Combustible & c/igv & $3 x$ & 100 & 100 & 100 & 100 & 100 & 100 & 100 & 100 & 100 & 900 \\
\hline Equipos & c/igv & & 500 & & & & & & & & & 500 \\
\hline Herramientas & c/igv & & 500 & & & & & & & & & 500 \\
\hline Transporte & s/igv & & 300 & 300 & 300 & 300 & 300 & 300 & 300 & 300 & 300 & 2,700 \\
\hline \multicolumn{13}{|l|}{ Gastos Municipales } \\
\hline Arbitrios & s/igv & & & & & & & & & 4,500 & & 4,500 \\
\hline Predial & s/igv & & & & & & & & & 6,000 & & 6,000 \\
\hline Total & & 4,000 & 20,992 & 18,742 & 18,992 & 17,742 & 18,992 & 17,742 & 18,992 & 27,442 & 17,292 & 180,930 \\
\hline
\end{tabular}


ANEXO 62: Presupuesto de Desembolso de Gastos de Administración y Ventas

\begin{tabular}{|c|c|c|c|c|c|c|c|c|c|c|c|c|}
\hline Partidas & IGV & $\operatorname{mar} 08$ & abr 08 & may 08 & jun 08 & jul 08 & ago 08 & sep 08 & oct 08 & nov 08 & dic 08 & Total \\
\hline Sueldo Total & & 0 & 11,500 & 11,500 & 11,500 & 11,500 & 11,500 & 11,500 & 11,500 & 11,500 & 11,500 & 103,500 \\
\hline (-) AFP & & 0 & $-1,475$ & $-1,475$ & $-1,475$ & $-1,475$ & $-1,475$ & $-1,475$ & $-1,475$ & $-1,475$ & $-1,475$ & $-13,279$ \\
\hline (-) IR 5TA & & & $-1,706$ & $-1,706$ & $-1,706$ & $-1,706$ & $-1,706$ & $-1,706$ & $-1,706$ & $-1,706$ & $-1,706$ & $-15,356$ \\
\hline Sueldo Neto & & 0 & 8,318 & 8,318 & 8,318 & 8,318 & 8,318 & 8,318 & 8,318 & 8,318 & 8,318 & 74,865 \\
\hline Gratificación & & & & & & 5,750 & & & & & 11,500 & 17,250 \\
\hline (-) AFP & & & & & & -738 & & & & & $-1,475$ & $-2,213$ \\
\hline Gratificación líquida & & & & & & 5,012 & & & & & 10,025 & 15,037 \\
\hline CTS & & & & 1,118 & & & & & & 6,708 & & 7,826 \\
\hline ESSALUD & & & 0 & 1,035 & 1,035 & 1,035 & 1,553 & 1,035 & 1,035 & 1,035 & 1,035 & 8,798 \\
\hline AFP & & & 0 & 1,475 & 1,475 & 1,475 & 2,213 & 1,475 & 1,475 & 1,475 & 1,475 & 12,541 \\
\hline IR 5TA & be & & 0 & 1,706 & 1,706 & 1,706 & 1,706 & 1,706 & 1,706 & 1,706 & 1,706 & 13,650 \\
\hline Pago Remunerac & & & 8,318 & 13,653 & 12,535 & 17,547 & 13,790 & 12,535 & 12,535 & 19,243 & 22,560 & 132,717 \\
\hline Gastos Contabilidad & s/igv & 0 & 350 & 0 & 350 & 0 & 350 & 0 & 350 & 0 & 350 & 1,750 \\
\hline Constitución Empresa & s/igv & 4,000 & 0 & 0 & 0 & 0 & 0 & 0 & 0 & 0 & 0 & 4,000 \\
\hline Legalización libros & c/igv & 0 & 1,785 & 0 & 0 & 0 & 0 & 0 & 0 & 0 & 0 & 1,785 \\
\hline Vigencia de poder & s/igv & 0 & 0 & 200 & 0 & 0 & 0 & 0 & 0 & 0 & 200 & 400 \\
\hline Contrat Construcción & s/igv & 0 & 0 & 800 & 0 & 0 & 0 & 0 & 0 & 0 & 0 & 800 \\
\hline Contrat Comp/Venta & s/igv & 0 & 0 & 600 & 600 & 600 & 600 & 600 & 600 & 0 & 0 & 3,600 \\
\hline Útiles de oficina & c/igv & 0 & 1,190 & 0 & 1,190 & 0 & 1,190 & 0 & 1,190 & 0 & 0 & 4,760 \\
\hline Copias e impresiones & c/igv & 0 & 119 & 119 & 0 & 119 & 0 & 119 & 0 & 238 & 0 & 714 \\
\hline Luz del Sur (Luz) & c/igv & 0 & 119 & 119 & 119 & 119 & 119 & 119 & 119 & 119 & 119 & 1,071 \\
\hline Sedapal (Agua) & c/igv & 0 & 238 & 238 & 238 & 238 & 238 & 238 & 238 & 238 & 238 & 2,142 \\
\hline Internet y Telefonía & c/igv & 0 & 357 & 357 & 357 & 357 & 357 & 357 & 357 & 357 & 357 & 3,213 \\
\hline Representación & c/igv & 0 & 357 & 357 & 357 & 357 & 357 & 357 & 357 & 0 & 0 & 2,499 \\
\hline Combustible & c/igv & 0 & 119 & 119 & 119 & 119 & 119 & 119 & 119 & 119 & 119 & 1,071 \\
\hline Equipos & c/igv & 0 & 595 & 0 & 0 & 0 & 0 & 0 & 0 & 0 & 0 & 595 \\
\hline Herramientas & c/igv & 0 & 595 & 0 & 0 & 0 & 0 & 0 & 0 & 0 & 0 & 595 \\
\hline Transporte & s/igv & 0 & 300 & 300 & 300 & 300 & 300 & 300 & 300 & 300 & 300 & 2,700 \\
\hline Arbitrios & s/igv & 0 & 0 & 0 & 0 & 0 & 0 & 0 & 0 & 4,500 & 0 & 4,500 \\
\hline Predial & s/igv & 0 & 0 & 0 & 0 & 0 & 0 & 0 & 0 & 6,000 & 0 & 6,000 \\
\hline Total & & 4,000 & 14,442 & 16,862 & 16,165 & 19,756 & 17,420 & 14,744 & 16,165 & 31,114 & 24,243 & 174,912 \\
\hline
\end{tabular}


ANEXO 63: Presupuesto de Gastos Bancarios

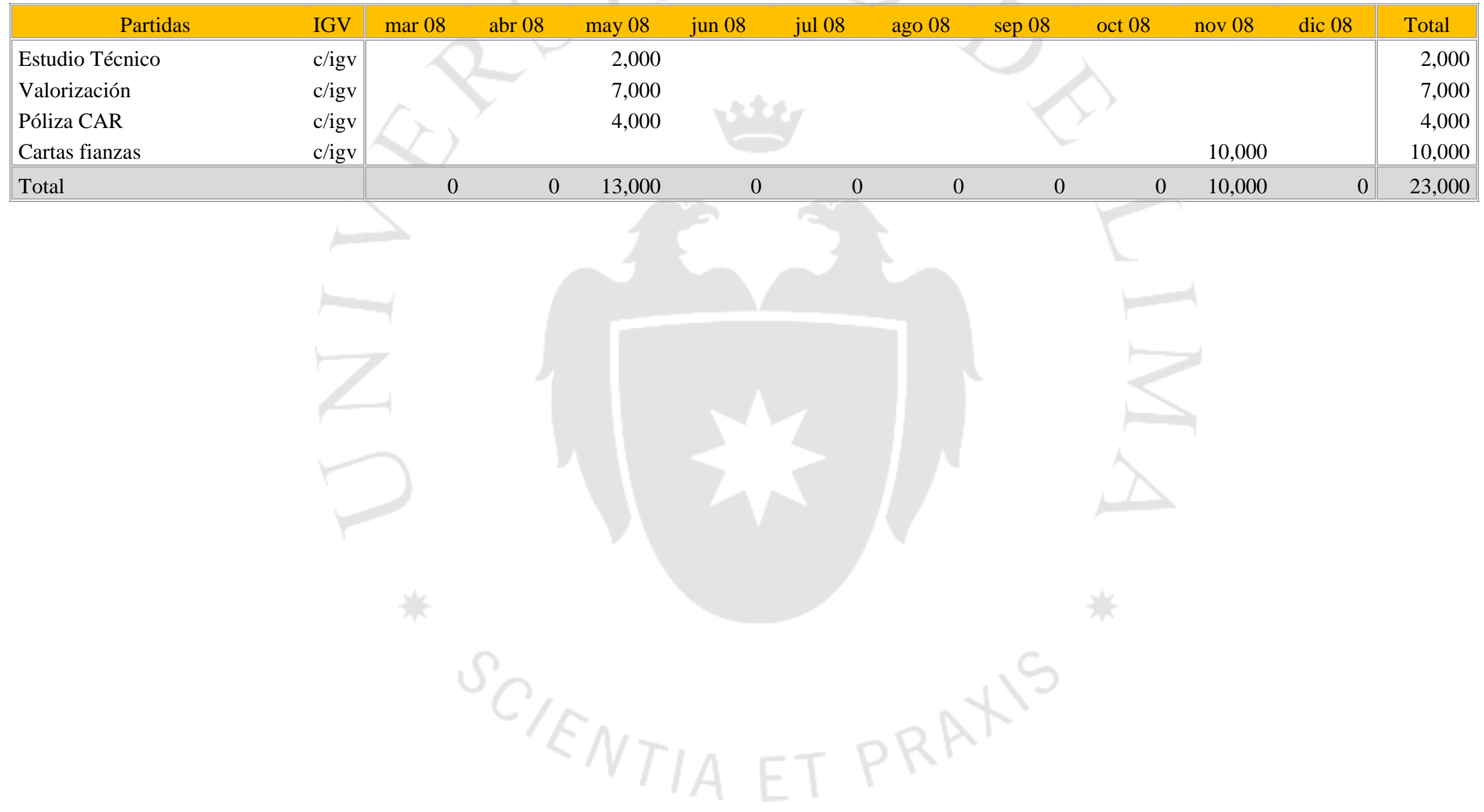


ANEXO 64: Presupuesto de Desembolso de Gastos Bancarios

\begin{tabular}{|c|c|c|c|c|c|c|c|c|c|c|c|c|}
\hline Partidas & IGV & mar 08 & abr 08 & may 08 & jun 08 & jul 08 & ago 08 & sep 08 & oct 08 & nov 08 & $\operatorname{dic} 08$ & Total \\
\hline Estudio Técnico & c/igv & & $\nabla$ & 2,380 & & & & & & - & - & 2,380 \\
\hline Valorización & c/igv & & & 8,330 & & & & & & - & - & 8,330 \\
\hline Póliza CAR & c/igv & . & & 4,760 & & & & & & - & - & 4,760 \\
\hline Cartas fianzas & c/igv & . & & - & 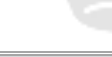 & & & & & 11,900 & - & 11,900 \\
\hline Total & & . & & 15,470 & & & & & & 11,900 & - & 27,370 \\
\hline
\end{tabular}


ANEXO 65: Presupuesto de Gastos por Adquisición de Terreno

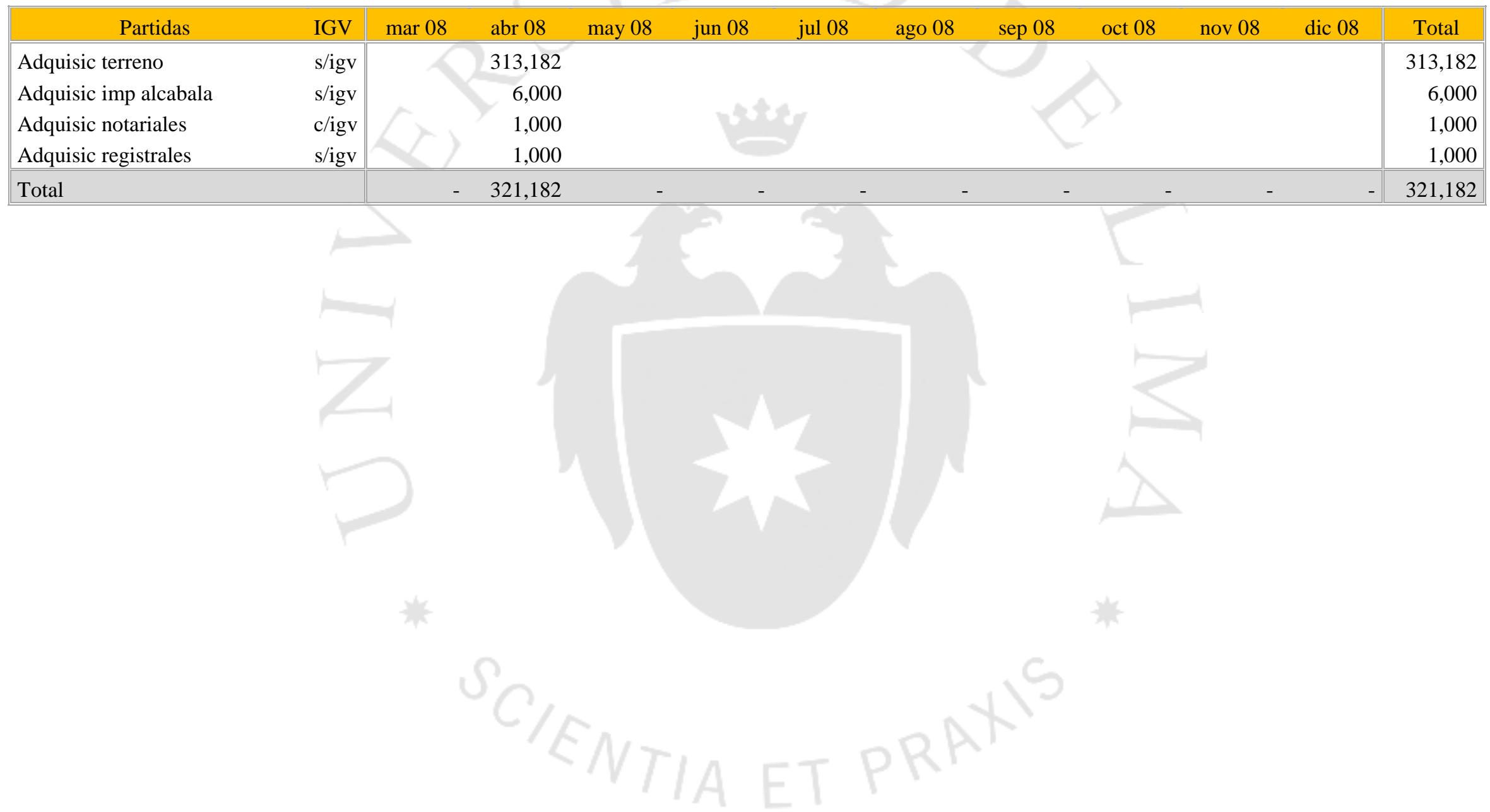


ANEXO 66: Presupuesto de Desembolso de Gastos por Adquisición de Terreno

\begin{tabular}{|c|c|c|c|c|c|c|c|c|c|c|c|c|}
\hline Partidas & IGV & mar 08 & abr 08 & may 08 & jun 08 & jul 08 & ago 08 & sep 08 & oct 08 & nov 08 & $\operatorname{dic} 08$ & Total \\
\hline Adquisic terreno & s/igv & 2 & 313,182 & - & & & & & & - & - & 313,182 \\
\hline Adquisic imp alcabala & s/igv & & 6,000 & - & & & & & & - & - & 6,000 \\
\hline Adquisic notariales & c/igv & . & 1,190 & - & & & & & & - & - & 1,190 \\
\hline Adquisic registrales & s/igv & . & 1,000 & - & & & & 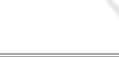 & & - & - & 1,000 \\
\hline Total & & 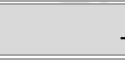 & 321,372 & - & & & & 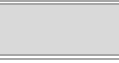 & & - & - & 321,372 \\
\hline
\end{tabular}




\section{ANEXO 67: Presupuesto de Gastos de Proyecto}

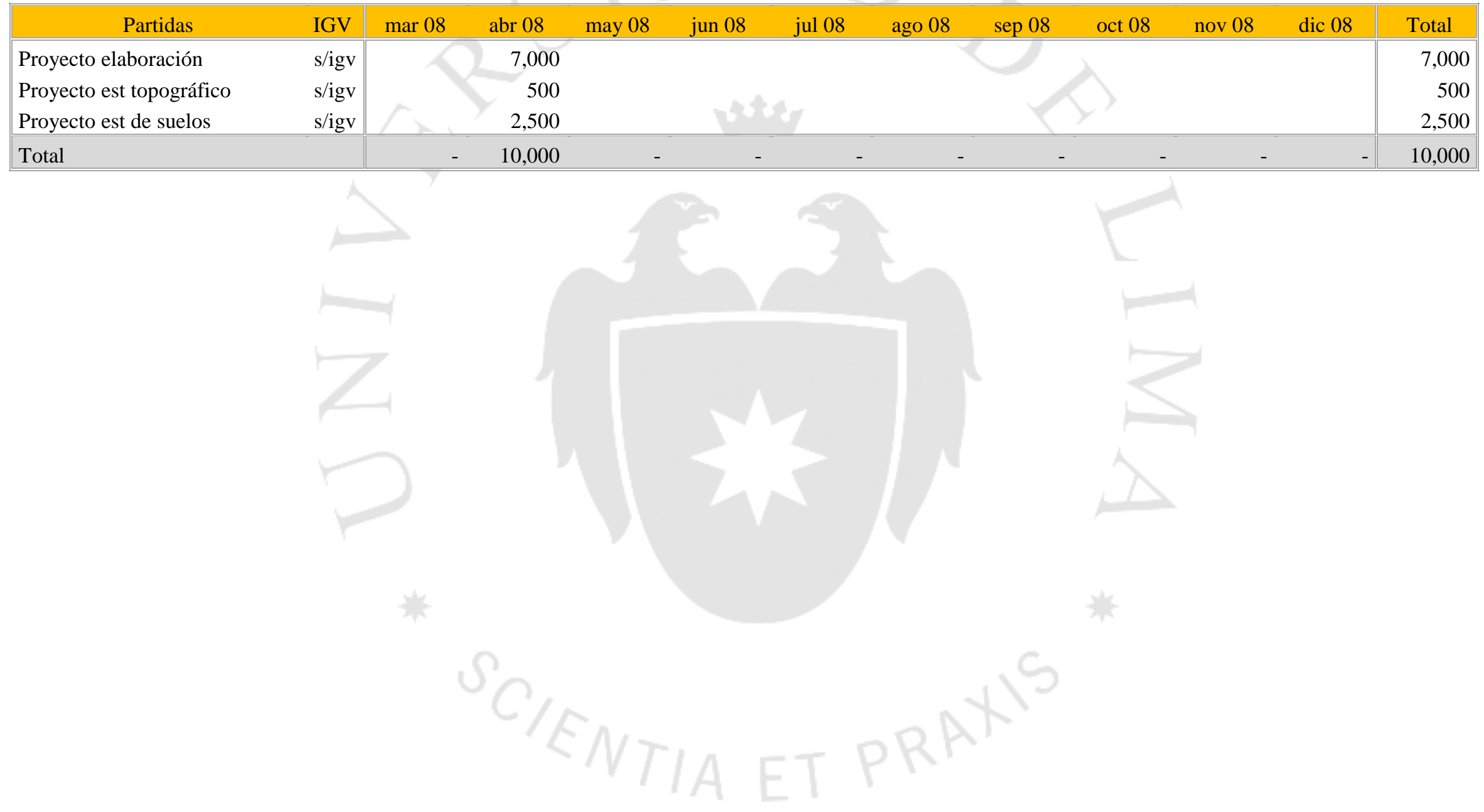




\section{ANEXO 68: Presupuesto de Desembolso de Gastos de Proyecto}

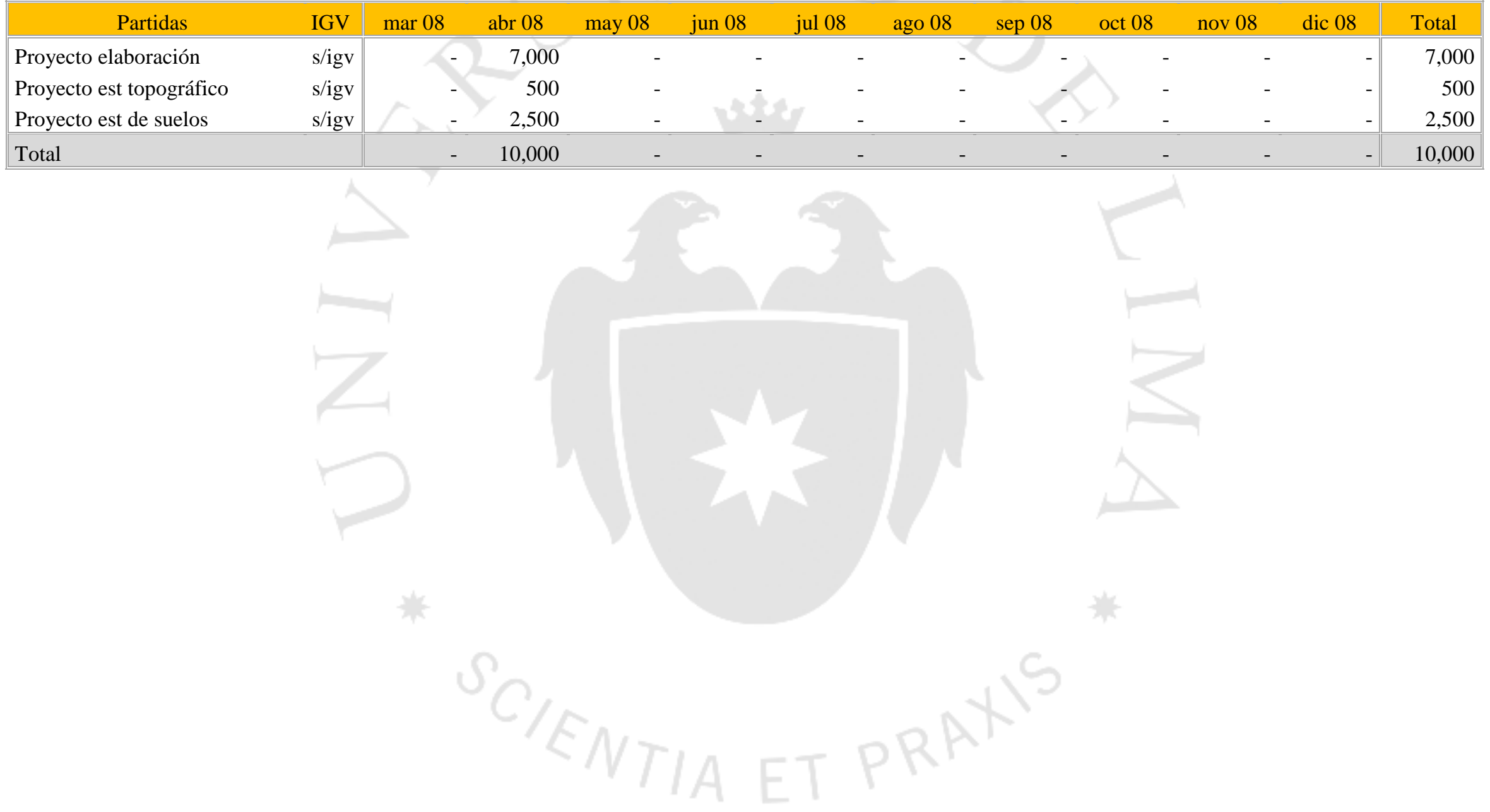




\section{ANEXO 69: Presupuesto de Gastos de Construcción}

\begin{tabular}{|c|c|c|c|c|c|c|c|c|c|c|c|c|}
\hline Partidas & IGV & mar 08 & abr 08 & may 08 & jun 08 & jul 08 & ago 08 & sep 08 & oct 08 & nov 08 & $\operatorname{dic} 08$ & Total \\
\hline Obra de Demolición & s/igv & & 10,000 & & & & & & & & & 10,000 \\
\hline Construc movim tierras & c/igv & & 10,000 & & & & & & & & & 10,000 \\
\hline Construc Contrato & c/igv & & & 151,269 & 205,903 & 207,386 & 213,087 & 214,349 & 204,936 & 191,870 & & $1,388,800$ \\
\hline Construc Pintura & c/igv & & & & & & & & 30,000 & & & 30,000 \\
\hline Construc Ascensor & c/igv & & & 8,529 & & 42,647 & & 25,588 & & 8,529 & & 85,294 \\
\hline Construc Factibilidad servic & c/igv & & & & & & & & 200 & & & 200 \\
\hline Construc Conexión servic & c/igv & & & & & & & & 7,000 & & & 7,000 \\
\hline Total & & & 20,000 & 159,799 & 205,903 & 250,033 & 213,087 & 239,938 & 242,136 & 200,399 & & $1,531,294$ \\
\hline
\end{tabular}




\section{ANEXO 70: Presupuesto de Desembolso de Gastos de Construcción}

\begin{tabular}{|c|c|c|c|c|c|c|c|c|c|c|c|c|}
\hline Partidas & IGV & $\operatorname{mar} 08$ & abr 08 & may 08 & jun 08 & jul 08 & ago 08 & sep 08 & oct 08 & nov 08 & $\operatorname{dic} 08$ & Total \\
\hline Obra de Demolición & s/igv & & 10,000 & - & - & - & & & - & - & - & 10,000 \\
\hline Construc movim tierras & c/igv & & 11,900 & - & - & - & - & & - & - & - & 11,900 \\
\hline Construc Contrato & c/igv & & - & 180,010 & 245,024 & 246,789 & 253,574 & 255,076 & 243,874 & 228,325 & - & $1,652,672$ \\
\hline Construc Pintura & c/igv & & - & - & - & - & - & - & 35,700 & - & - & 35,700 \\
\hline Construc Ascensor & c/igv & & - & 10,150 & - & 50,750 & - & 30,450 & - & 10,150 & - & 101,500 \\
\hline Construc Factibilidad servic & c/igv & & - & - & - & $f=-$ & - & - & 238 & - & - & 238 \\
\hline Construc Conexión servic & c/igv & & - & - & - & - & - & - & 8,330 & - & - & 8,330 \\
\hline Total & & & 21,900 & 190,160 & 245,024 & 297,539 & 253,574 & 285,526 & 288,142 & 238,475 & - & $1,820,340$ \\
\hline
\end{tabular}




\section{ANEXO 71: Presupuesto de Gastos Municipales}

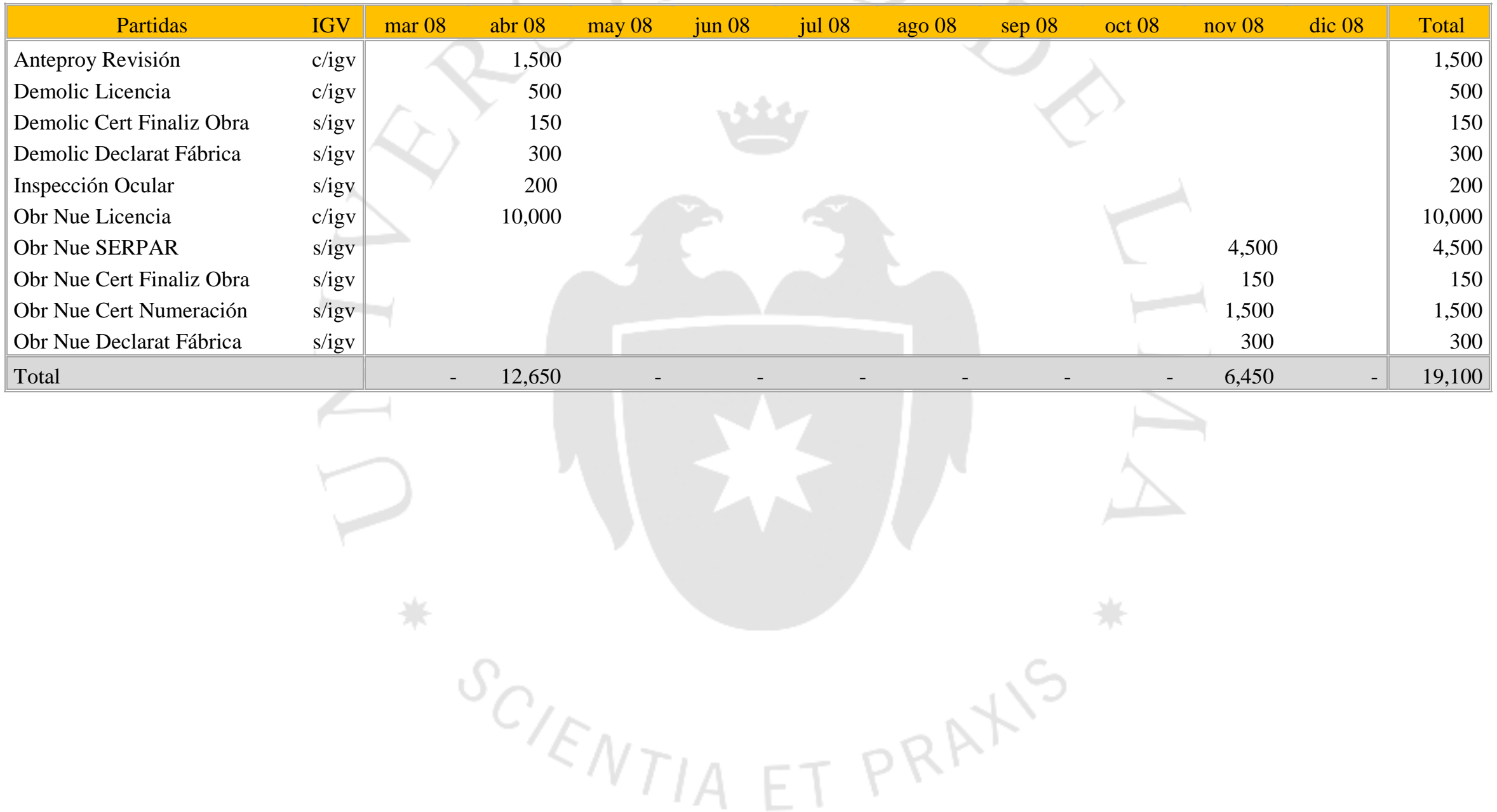




\section{ANEXO 72: Presupuesto de Desembolso de Gastos Municipales}

\begin{tabular}{|c|c|c|c|c|c|c|c|c|c|c|c|c|}
\hline Partidas & IGV & mar 08 & abr 08 & may 08 & jun 08 & jul 08 & ago 08 & sep 08 & oct 08 & nov 08 & dic 08 & Total \\
\hline Anteproy Revisión & c/igv & 4 & 1,785 & - & - & - & & & & - & - & 1,785 \\
\hline Demolic Licencia & c/igv & - & 595 & - & - & - & & & & - & - & 595 \\
\hline Demolic Cert Finaliz Obra & s/igv & - & 150 & - & - & - & & & & - & - & 150 \\
\hline Demolic Declarat Fábrica & s/igv & - & 300 & - & - & - & & & & - & - & 300 \\
\hline Inspección Ocular & s/igv & - & 200 & - & - & - & & & & - & - & 200 \\
\hline Obr Nue Licencia & c/igv & - & 11,900 & - & - & - & & & & - & - & 11,900 \\
\hline Obr Nue SERPAR & s/igv & - & - & - & - & - & & & & 4,500 & - & 4,500 \\
\hline Obr Nue Cert Finaliz Obra & s/igv & - & & - & - & - & & & & 150 & - & 150 \\
\hline Obr Nue Cert Numeración & s/igv & 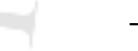 & - & - & - & - & & & & 1,500 & - & 1,500 \\
\hline Obr Nue Declarat Fábrica & s/igv & - & - & - & - & - & & & & 300 & - & 300 \\
\hline Total & & - & 14,930 & - & - & - & . & & & 6,450 & - & 21,380 \\
\hline
\end{tabular}




\section{ANEXO 73: Presupuesto de Gastos de Titulación}

\begin{tabular}{|c|c|c|c|c|c|c|c|c|c|c|c|}
\hline Partidas & IGV & $\operatorname{mar} 08$ & abr 08 & may 08 & jun 08 & jul 08 & ago 08 sep 08 & oct 08 & nov 08 & dic 08 & Total \\
\hline Gastos Registrales & & & & & & & & & & & - \\
\hline Hipoteca del terreno & s/igv & & & & & 800 & & & & & 800 \\
\hline Levantamiento hipoteca & s/igv & & & & & & & & & 800 & 800 \\
\hline Demolic Declarat Fábrica & s/igv & & 200 & & & & & & & & 200 \\
\hline Obr Nue Declarat Fábrica & s/igv & & & & & & & & & 4,500 & 4,500 \\
\hline Obr Nue Independizacion & s/igv & & & & & & & & & 3,500 & 3,500 \\
\hline Obr Nue R.I-J.P-M.A & s/igv & & & & & & & & & 2,000 & 2,000 \\
\hline Gastos Notariales & & & & & & & & & & & - \\
\hline Hipoteca del terreno & c/igv & z & & & & 700 & & & & & 700 \\
\hline Levantamiento hipoteca & c/igv & & & & & & & & & 700 & 700 \\
\hline Escritura Compra Vta & c/igv & & 500 & & & & & & & & 500 \\
\hline Demolic Declarat Fábrica & c/igv & & 500 & & & & & & & & 500 \\
\hline Obr Nue Declarat Fábrica & c/igv & & & & & & & & & 500 & 500 \\
\hline Obr Nue Independizacion & c/igv & & & & & & & & & 2,000 & 2,000 \\
\hline Obr Nue R.I-J.P-M.A & c/igv & & & & & & & & & 500 & 500 \\
\hline Total & & & 1,200 & & & 1,500 & - & & & 14,500 & 17,200 \\
\hline
\end{tabular}


ANEXO 74: Presupuesto de Desembolso de Gastos de Titulación

\begin{tabular}{|c|c|c|c|c|c|c|c|c|c|c|c|c|}
\hline Partidas & IGV & mar 08 & abr 08 & may 08 & jun 08 & jul 08 & ago 08 & sep 08 & oct 08 & nov 08 & $\operatorname{dic} 08$ & Total \\
\hline Gastos Registrales & & & - & - & & - & & & & & - & - \\
\hline Hipoteca del terreno & s/igv & & - & - & & 800 & - & & & & - & 800 \\
\hline Levantamiento hipoteca & s/igv & & - & - & & - & - & & & & 800 & 800 \\
\hline Demolic Declarat Fábrica & s/igv & & 200 & - & & - & - & & & & - & 200 \\
\hline Obr Nue Declarat Fábrica & s/igv & & - & - & & - & - & & & & 4,500 & 4,500 \\
\hline Obr Nue Independización & s/igv & & - & - & & - & - & & & & 3,500 & 3,500 \\
\hline Obr Nue R.I-J.P-M.A & s/igv & & - & - & & - & - & & & & 2,000 & 2,000 \\
\hline \multicolumn{13}{|l|}{ Gastos Notariales } \\
\hline Hipoteca del terreno & c/igv & 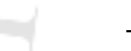 & - & - & & 833 & - & & & . & - & 833 \\
\hline Levantamiento hipoteca & c/igv & . & - & - & & - & - & & & & 833 & 833 \\
\hline Escritura Compra Vta & c/igv & 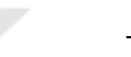 & 595 & - & & - & - & & & $y$ & - & 595 \\
\hline Demolic Declarat Fábrica & c/igv & -1 & 595 & - & & - & - & & & . & - & 595 \\
\hline Obr Nue Declarat Fábrica & c/igv & & - & - & & - & - & & & . & 595 & 595 \\
\hline Obr Nue Independización & c/igv & & - & - & & - & - & & & & 2,380 & 2,380 \\
\hline Obr Nue R.I-J.P-M.A & c/igv & & - & - & & - & - & & & . & 595 & 595 \\
\hline Total & & & 1,390 & - & & 1,633 & - & & & s. & 15,203 & 18,226 \\
\hline
\end{tabular}




\section{ANEXO 75: Presupuesto de Gastos Imprevistos}

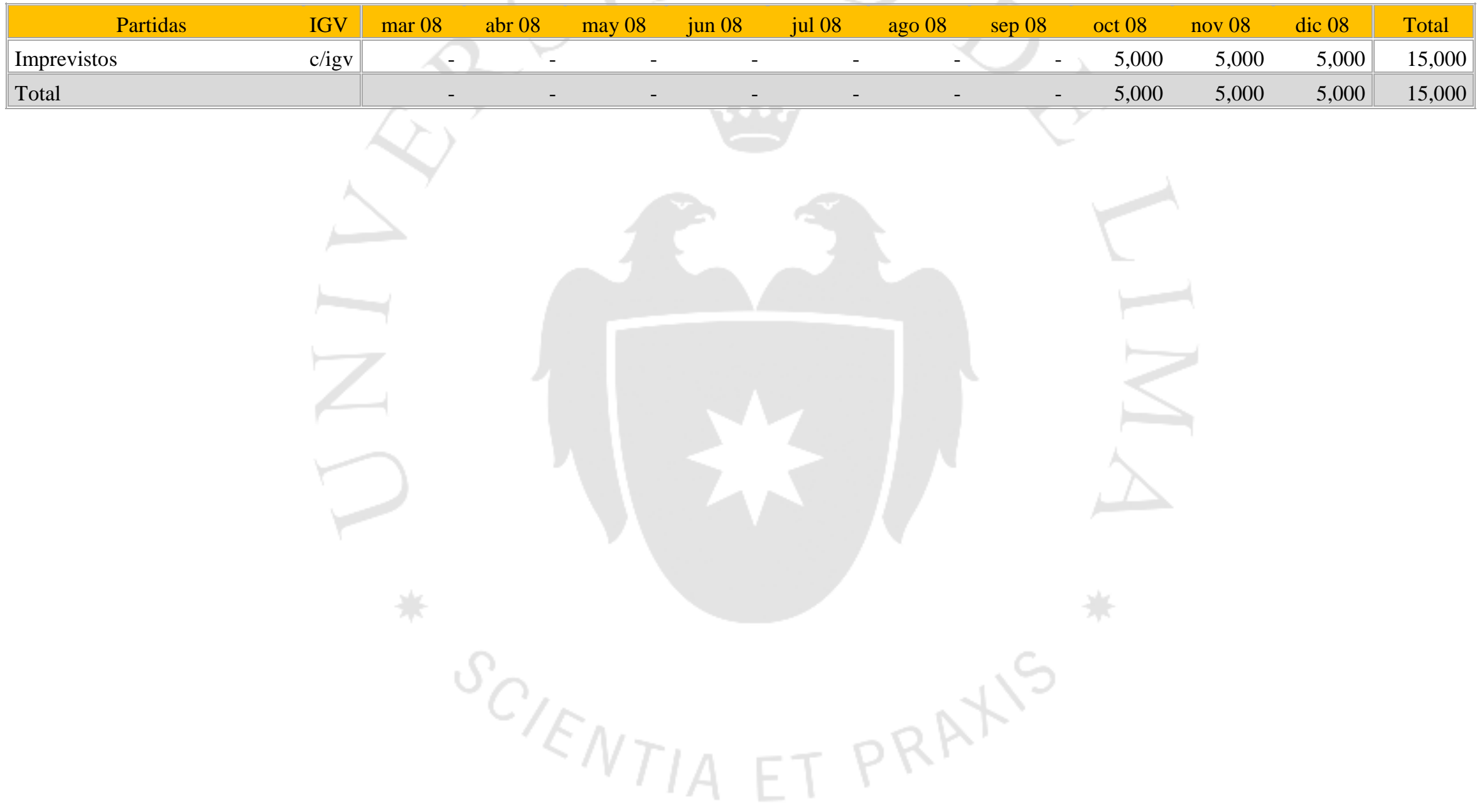


ANEXO 76: Presupuesto de Desembolso de Gastos Imprevistos

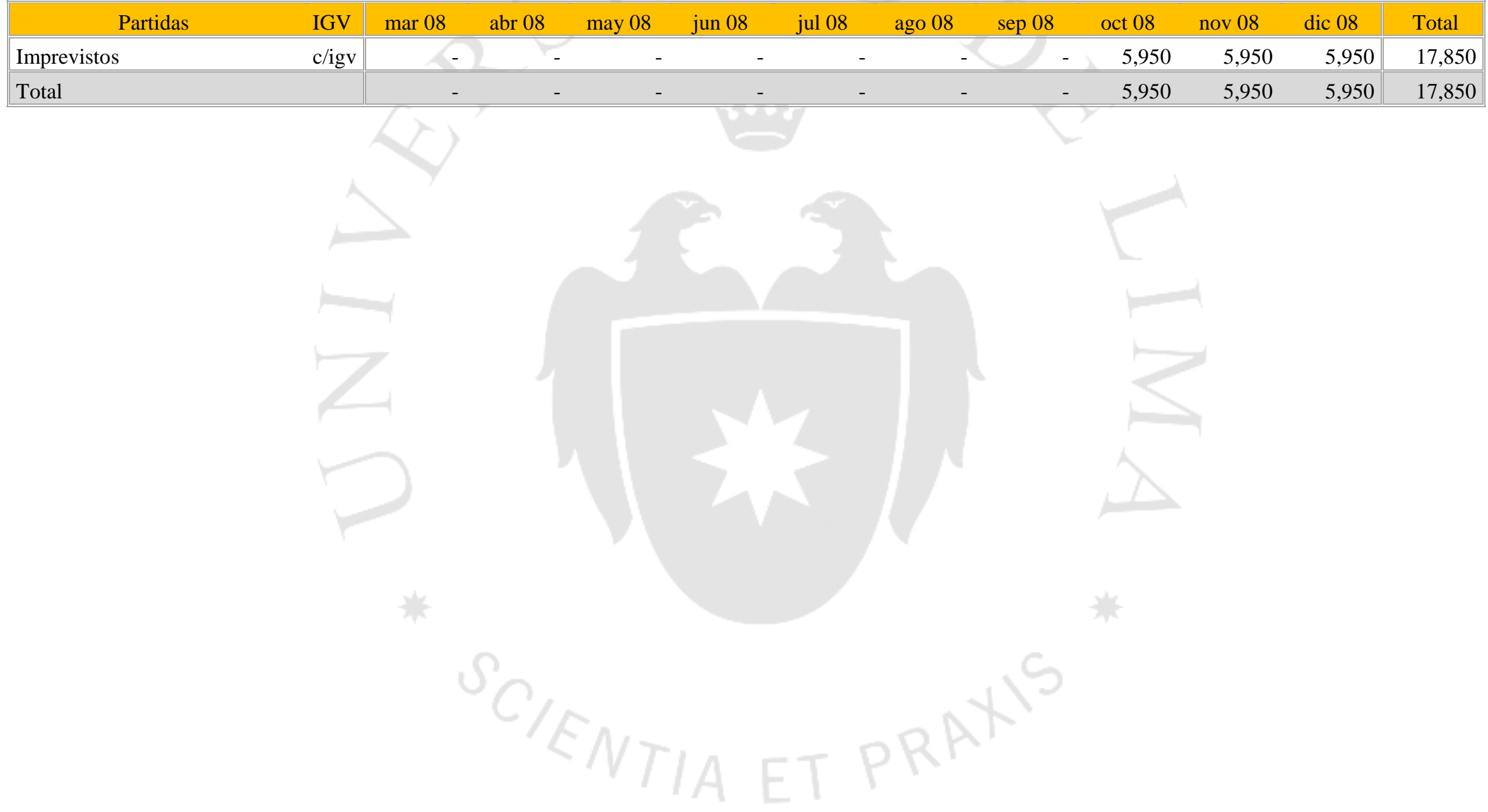




\section{ANEXO 77: Presupuesto de Gastos Financieros}

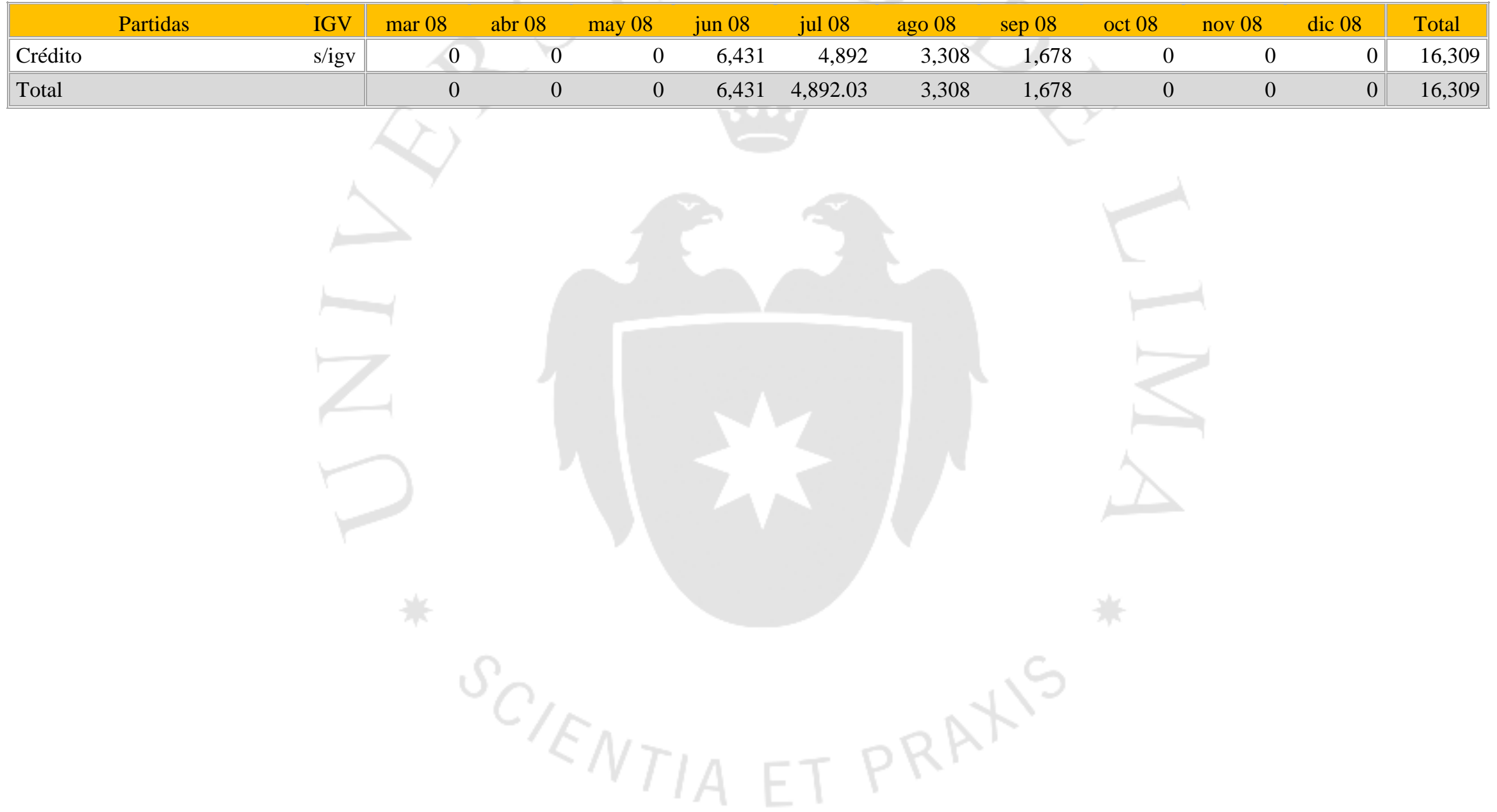


ANEXO 78: Presupuesto de Pago de Deuda

\begin{tabular}{|c|c|c|c|c|c|c|c|c|c|c|c|c|}
\hline Partidas & IGV & mar 08 & abr 08 & may 08 & jun 08 & jul 08 & ago 08 & sep 08 & oct 08 & nov 08 & dic 08 & Total \\
\hline Amortización & s/igv & 0 & 0 & 0 & 52,646 & 54,185 & 55,769 & 57,399 & 0 & 0 & 0 & 220,000 \\
\hline Interés & s/igv & 0 & 0 & 0 & 6,431 & 4,892 & 3,308 & 1,678 & 0 & 0 & 0 & 16,309 \\
\hline Total & & 0 & 0 & 0 & 59,077 & 59,077 & 59,077 & 59,077 & 0 & 0 & 0 & 236,309 \\
\hline
\end{tabular}




\section{ANEXO 79: Estado de Resultados Mensual del 1 de Marzo al 31 de Diciembre de 2008}

\begin{tabular}{|c|c|c|c|c|c|c|c|c|c|c|c|}
\hline Partidas Contables & mar 08 & abr 08 & may 08 & jun 08 & jul 08 & ago 08 & sep 08 & oct 08 & nov 08 & $\operatorname{dic} 08$ & Total en NS/. \\
\hline Ventas Netas & 0 & 0 & 422,260 & 384,817 & 379,817 & 384,817 & 384,817 & 373,858 & 0 & 0 & $2,330,388$ \\
\hline (-) Costo de Ventas & 0 & $-365,032$ & $-159,799$ & $-205,903$ & $-251,533$ & $-213,087$ & $-239,938$ & $-247,136$ & $-211,849$ & $-19,500$ & $-1,913,776$ \\
\hline Utilidad Bruta & 0 & $-365,032$ & 262,462 & 178,914 & 128,284 & 171,730 & 144,880 & 126,722 & $-211,849$ & $-19,500$ & 416,612 \\
\hline (-) Gastos Operativos & $-4,000$ & $-23,292$ & $-32,342$ & $-19,292$ & $-18,442$ & $-19,292$ & $-18,342$ & $-19,292$ & $-37,442$ & $-17,292$ & $-209,030$ \\
\hline Utilidad Operativa & $-4,000$ & $-388,325$ & 230,120 & 159,622 & 109,842 & 152,438 & 126,538 & 107,430 & $-249,291$ & $-36,792$ & 207,582 \\
\hline (-) Gastos Financieros & 0 & 0 & 0 & $-6,431$ & $-4,892$ & $-3,308$ & $-1,678$ & 0 & 0 & 0 & $-16,309$ \\
\hline Utilidad Antes de Impuestos & $-4,000$ & $-388,325$ & 230,120 & 153,191 & 104,950 & 149,130 & 124,860 & 107,430 & $-249,291$ & $-36,792$ & 191,273 \\
\hline (-) Impuesto a la Renta & 1,200 & 116,497 & $-69,036$ & $-45,957$ & $-31,485$ & $-44,739$ & $-37,458$ & $-32,229$ & 74,787 & 11,038 & $-57,382$ \\
\hline Utilidad Neta & $-2,800$ & $-271,827$ & 161,084 & 107,234 & 73,465 & 104,391 & 87,402 & 75,201 & $-174,504$ & $-25,755$ & 133,891 \\
\hline
\end{tabular}




\section{ANEXO 80: Flujo de Caja Mensual al 31 de Diciembre de 2008}

\begin{tabular}{|c|c|c|c|c|c|c|c|c|c|c|c|}
\hline Ingresos - Egresos & mar 08 & abr 08 & may 08 & jun 08 & jul 08 & ago 08 & sep 08 & oct 08 & nov 08 & $\operatorname{dic} 08$ & Total \\
\hline Ingresos: & & & rar & & & & & & & & \\
\hline Contado & - & - & 112,000 & 103,800 & $1,077,200$ & 419,000 & 419,000 & 407,000 & - & - & $2,538,000$ \\
\hline Total Ingresos & - & - & 112,000 & 103,800 & $1,077,200$ & 419,000 & 419,000 & 407,000 & - & - & $2,538,000$ \\
\hline Egresos: & & & & & 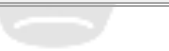 & & & 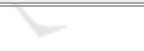 & & & \\
\hline Comerciales: & & & & & & & & & & & \\
\hline Marketing & 0 & 2,737 & 714 & 357 & 833 & 357 & 714 & 357 & 0 & 0 & 6,069 \\
\hline Administración y Ventas & 4,000 & 14,442 & 16,862 & 16,165 & 19,756 & 17,420 & 14,744 & 16,165 & 31,114 & 24,243 & 174,912 \\
\hline Bancarios & 0 & 0 & 15,470 & 0 & 0 & 0 & 0 & 0 & 11,900 & 0 & 27,370 \\
\hline Operativos: & & & & & & & & & & & - \\
\hline Terreno & 0 & 321,372 & 0 & 0 & 0 & 0 & 0 & 0 & 0 & 0 & 321,372 \\
\hline Proyecto & 0 & 10,000 & 0 & 0 & 0 & 0 & 0 & 0 & 0 & 0 & 10,000 \\
\hline Construcción & 0 & 21,900 & 190,160 & 245,024 & 297,539 & 253,574 & 285,526 & 288,142 & 238,475 & 0 & $1,820,340$ \\
\hline Municipales & 0 & 14,930 & 0 & 0 & 0 & 0 & 0 & 0 & 6,450 & 0 & 21,380 \\
\hline Titulación & 0 & 1,390 & 0 & 0 & 1,633 & 0 & 0 & 0 & 0 & 15,203 & 18,226 \\
\hline Imprevistos & 0 & 0 & 0 & 0 & 0 & 0 & 0 & 5,950 & 5,950 & 5,950 & 17,850 \\
\hline Otros egresos: & & & & & & & & & & & \\
\hline Amortización & 0 & 0 & 0 & 52,646 & 54,185 & 55,769 & 57,399 & 0 & 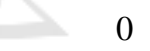 & 0 & 220,000 \\
\hline Intereses & 0 & 0 & 0 & 6,431 & 4,892 & 3,308 & 1,678 & 0 & 0 & 0 & 16,309 \\
\hline Pago a Cuenta IR & - & - & - & 8,445 & 7,696 & 7,596 & 7,696 & 7,696 & 7,477 & - & 46,608 \\
\hline Total Egresos & 4,000 & 386,772 & 223,206 & 329,069 & 386,535 & 338,025 & 367,757 & 318,310 & 301,366 & 45,396 & $2,700,436$ \\
\hline Ingresos menos Egresos & $-4,000$ & $-386,772$ & $-111,206$ & $-225,269$ & 690,665 & 80,975 & 51,243 & 88,690 & $-301,366$ & $-45,396$ & $-162,436$ \\
\hline Flujo de Caja & mar 08 & abr 08 & may 08 & jun 08 & jul 08 & ago 08 & sep 08 & oct 08 & nov 08 & $\operatorname{dic} 08$ & Total \\
\hline Saldo Inicial & 4,000 & 544,000 & 157,228 & 46,022 & 40,753 & 731,418 & 812,393 & 863,636 & 952,326 & 650,960 & 4,000 \\
\hline Excedente / Déficit & $-4,000$ & $-386,772$ & $-111,206$ & $-225,269$ & 690,665 & 80,975 & 51,243 & 88,690 & $-301,366$ & $-45,396$ & $-162,436$ \\
\hline Préstamo Accionistas / Banco & 544000 & & +1 & 220,000 & $-T$ & D. & & & & & 764,000 \\
\hline Saldo Final & 544,000 & 157,228 & 46,022 & 40,753 & 731,418 & 812,393 & 863,636 & 952,326 & 650,960 & 605,564 & 605,564 \\
\hline
\end{tabular}




\section{ANEXO 81: Evolución de la Demanda Efectiva de Hogares y Precio Promedio de los Departamentos, 2003 - 2007}

\begin{tabular}{|lrrrrrr|}
\hline Variables & 2003 & 2004 & 2005 & 2006 & 2007 & Prom \\
\hline DEH (miles) & 239 & 220 & 242 & 281 & 297 & \\
Var \% DEH & $13 \%$ & $-8 \%$ & $10 \%$ & $16 \%$ & $6 \%$ & $7 \%$ \\
$P P D(\$ x m 2)$ & 426 & 431 & 480 & 526 & 629 & \\
Var \% PPD & $4 \%$ & $1 \%$ & $11 \%$ & $10 \%$ & $20 \%$ & $\mathbf{9 \%}$ \\
\hline
\end{tabular}

Notas: a. $\mathrm{DEH}=$ Demanda Efectiva de Hogares; $\mathrm{b} . \mathrm{PPD}=$ Precio Promedio de los Departamentos Fuente: El Mercado de Edificaciones Urbanas en Lima Metropolitana y el Callao - CAPECO Elaboración: Propia. 


\section{ANEXO 82: Evolución del Precio de los Terrenos, de los}

Materiales, de la UIT, RMV y PRESC, 2003 - 2007

\begin{tabular}{|lrrrrrr|}
\hline Variables & 2003 & 2004 & 2005 & 2006 & 2007 & Prom \\
\hline PTERR $(\$ \times m 2)$ & 210 & 228 & 252 & 286 & 325 & \\
Var \% PTERR & $8 \%$ & $9 \%$ & $11 \%$ & $13 \%$ & $14 \%$ & $\mathbf{1 1 \%}$ \\
Var \% PMAT & $1 \%$ & $13 \%$ & $7 \%$ & $3 \%$ & $8 \%$ & $\mathbf{6 \%}$ \\
UIT (NS/.) & 3100 & 3200 & 3300 & 3400 & 3450 & \\
Var \% UIT & $0 \%$ & $3 \%$ & $3 \%$ & $3 \%$ & $1 \%$ & $2 \%$ \\
RMV (NS/.) & 460 & 460 & 500 & 500 & 530 & \\
Var \% RMV & $12 \%$ & $0 \%$ & $9 \%$ & $0 \%$ & $6 \%$ & $5 \%$ \\
RPESC (NS/.) & 1777 & 1708 & 1869 & 1882 & 2240 & \\
Var \% RPESC & $1 \%$ & $-4 \%$ & $9 \%$ & $1 \%$ & $19 \%$ & $\mathbf{5 \%}$ \\
\hline
\end{tabular}

Notas: a. PTERR = Precio de los Terrenos en Cercado de Lima; b. PMAT = Precio Promedio de los Materiales; $c$. UIT = Unidad Impositiva Tributaria; d. RMV = Remuneración Mínima Vital; e. RPESC = Remuneración Promedio de Empleados en el Sector Construcción

Fuentes: El Mercado de Edificaciones Urbanas en Lima Metropolitana y el Callao - CAPECO; PERU EJECUTIVO Proyecciones Económicas 2006-2011 y 2007-2012 MAXIMIXE CASER;

Superintendencia Nacional de Administración Tributaria - Índices y Tasas - Unidad Impositiva Tributaria, recuperado de http://www.sunat.gob.pe/indicestasas/uit.html; Ministerio de Trabajo y Promoción del Empleo - Estadísticas Laborales - Evolución de la Remuneración Mínima Vital Nominal a Feb 2013, recuperado de http://www2.trabajo.gob.pe/promocion-del-empleo-y-autoempleo/informaciondel-mercado-de-trabajo/estadisticas-de-empleo/; Ministerio de Trabajo y Promoción del Empleo Estadísticas Laborales - Prom Remunerac. Empleados en el Sector Construcción, recuperado de http://www2.trabajo.gob.pe/promocion-del-empleo-y-autoempleo/informacion-del-mercado-detrabajo/estadisticas-de-empleo/ Elaboración: Propia. 